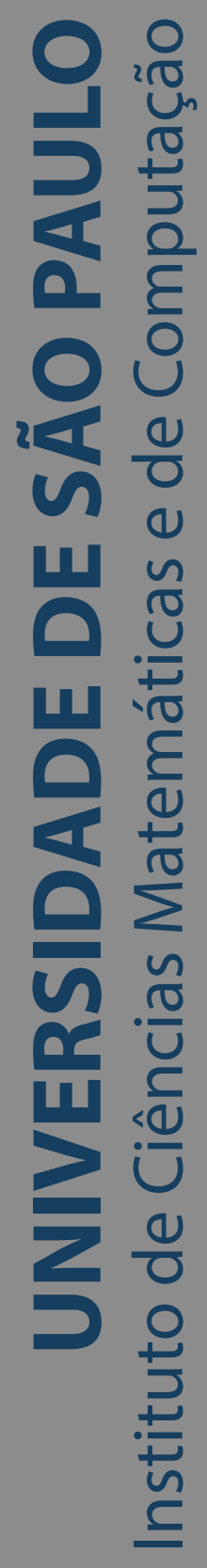

\title{
SIRA - reversão anaglífica utilizando técnicas de análise de
} séries temporais

\section{Lucas Felipe Kunze}

Dissertação de Mestrado do Programa de Pós-Graduação em Ciências de Computação e Matemática Computacional (PPG-CCMC) 

SERVIÇO DE PÓS-GRADUAÇÃO DO ICMC-USP

Data de Depósito:

Assinatura:

\section{Lucas Felipe Kunze}

\section{SIRA - reversão anaglífica utilizando técnicas de análise de séries temporais}

Dissertação apresentada ao Instituto de Ciências Matemáticas e de Computação - ICMC-USP, como parte dos requisitos para obtenção do título de Mestre em Ciências - Ciências de Computação e Matemática Computacional. VERSÃO REVISADA

Área de Concentração: Ciências de Computação e Matemática Computacional

Orientadora: Profa. Dra. Elaine Parros Machado de Sousa

Coorientador: Prof. Dr. Rudinei Goularte 
Ficha catalográfica elaborada pela Biblioteca Prof. Achille Bassi e Seção Técnica de Informática, ICMC/USP, com os dados inseridos pelo(a) autor(a)

Kunze, Lucas Felipe SIRA - reversão anaglífica utilizando técnicas de análise de séries temporais / Lucas Felipe Kunze; orientadora Elaine Parros Machado de Sousa; coorientador Rudinei Goularte. -- São Carlos, 2019. $136 \mathrm{p}$.

Dissertação (Mestrado - Programa de Pós-Graduação em Ciências de Computação e Matemática Computacional) -- Instituto de Ciências Matemáticas e de Computação, Universidade de São Paulo, 2019.

1. Reversão Anaglífica. 2. Séries Temporais. 3. Imagens Estéreo. 4. Processamento de Sinais. 5. Superpixels. I. Sousa, Elaine Parros Machado de, orient. II. Goularte, Rudinei, coorient. III. Título. 


\title{
Lucas Felipe Kunze
}

\section{SIRA - anaglyph reversion using time series analysis techniques}

\begin{abstract}
Master dissertation submitted to the Institute of Mathematics and Computer Sciences - ICMC-USP, in partial fulfillment of the requirements for the degree of the Master Program in Computer Science and Computational Mathematics. FINAL VERSION

Concentration Area: Computer Science and Computational Mathematics

Advisor: Profa. Dra. Elaine Parros Machado de Sousa Co-advisor: Prof. Dr. Rudinei Goularte
\end{abstract}



Dedico esta dissertação aos meus pais, por todo apoio, amor e incentivos constantes. 

Agradeço aos meus pais Marli e Wilson por me apoiarem nos momentos mais difíceis e me incentivarem a enfrentar os obstáculos.

À minha orientadora Profa. Dra. Elaine Parros Machado de Sousa e meu co-orientador Prof. Dr. Rudinei Goularte, por me guiarem na execução deste mestrado, pelo tempo e esforço investidos, sempre muito atenciosos, pacientes e justos, com excelentes sugestões para aperfeiçoamento e melhoria do trabalho.

Aos amigos do GBDI, em especial à Thábata Amaral, Altamir Bispo e Jadson José por todas as conversas, amizade e sugestões para execução deste trabalho.

À Universidade de São Paulo por toda estrutura física e de conhecimento fornecida.

Aos funcionários do ICMC-USP que direta ou indiretamente contribuíram para a execução deste mestrado.

Ao CNPQ (Conselho Nacional de Desenvolvimento Científico e Tecnológico) e CAPES (Coordenação de Aperfeiçoamento de Pessoal de Nível Superior) pelo apoio financeiro à realização deste trabalho. 

If we knew what it was we were doing, it would not be called research, would it? 



\section{RESUMO}

KUNZE, L. F. SIRA - reversão anaglífica utilizando técnicas de análise de séries temporais. 2019. 136 p. Dissertação (Mestrado em Ciências - Ciências de Computação e Matemática Computacional) - Instituto de Ciências Matemáticas e de Computação, Universidade de São Paulo, São Carlos - SP, 2019.

Nos últimos anos, a visualização das chamadas imagens tridimensionais (3D) voltou a ter destaque, em especial as imagens estereoscópicas. Tal destaque é devido à geração de conteúdos e dispositivos com suporte para tal tecnologia e grande aceitação por parte do público, utilizando uma vasta gama de modos de visualização. Para mimificar a percepção tridimensional, existem as chamadas imagens estéreoscópicas, que são formadas por um par de imagens ligeiramente deslocadas no espaço uma em relação à outra, sendo uma delas enviada para o olho direito e a outra para o olho esquerdo. Um dos métodos mais simples de visualização estereoscópica é obtido por meio da geração do anáglifo, que baseia-se na separação das componentes de cores (RGB), permitindo qualquer permutação entre elas, sem repetição, com uma componente de cor enviada para um dos olhos e duas componentes para o outro olho. O método anaglífico é interessante por duas razões principais, sendo elas o baixo custo de processamento e visualização, já que pode ser visualizado por meio de simples óculos com filtros de cor, e por utilizar metade do volume de dados em relação a outros métodos de visualização. Assim, aplicações e sistemas podem se beneficiar ao utilizar imagens anaglíficas para fins de armazenamento e transmissão. Contudo, como os métodos de visualização existentes são incompatíveis entre si, tais imagens não podem ser visualizadas por métodos mais robustos de visualização. Neste contexto, este trabalho de mestrado propõe uma técnica automática de reversão anaglífica SIRA (Stereo Images Retrieving from Anaglyphs), que utiliza técnicas empregadas na análise de séries temporais. Reverter implica em produzir aproximações das informações descartadas na geração das imagens anaglíficas, obtendo uma aproximação do par estéreo original, a qual pode ser utilizada para fins de visualização por qualquer método. Resultados objetivos e subjetivos apresentados na avaliação experimental indicam que a técnica proposta apresenta qualidade comparável aos trabalhos considerados estado-da-arte, mas com custo computacional significativamente inferior.

Palavras-chave: Reversão Anaglífica, Séries Temporais, Imagens Estéreo, Processamento de Sinais, Superpixels. 



\section{ABSTRACT}

KUNZE, L. F. SIRA - anaglyph reversion using time series analysis techniques. 2019. 136 p. Dissertação (Mestrado em Ciências - Ciências de Computação e Matemática Computacional) - Instituto de Ciências Matemáticas e de Computação, Universidade de São Paulo, São Carlos SP, 2019.

In the last years, the visualization of the so-called three-dimensional (3D) images is highlighted again, especially stereoscopic images. Such a highlight is due to the generation of content and devices that support such technology and wide acceptance by the public using a variaty of viewing modes. To mimic three-dimensional perception, there are so-called stereoscopic images, which are formed by a pair of images slightly shifted in space relative to each other, one being sent to the right eye and the other to the left eye. One of the simplest stereoscopic visualization methods is obtained by generating an anaglyph, which is based on the separation of color components (RGB), allowing any permutation between them without repetition, such that a color component is sent to one eye and two components to the other eye. The anaglyphic method is interesting for two main reasons, namely the low processing and visualization cost, since it can be viewed through simple glasses with color filters, and the use of half the data volume compared to other visualization methods. Thus, applications and systems can benefited from using anaglyphic images for storage and transmission purposes. However, as existing viewing methods are incompatible with each other, such images cannot be viewed by more robust viewing methods. In this context, this master's work proposes an automatic anaglyphic reversal technique SIRA (Stereo Images Retrieving from Anaglyphs), which uses techniques employed in time series analysis. Reverting implies producing approximations of the information discarded for anaglyph generation, thus obtaining an approximation of the original stereo pair, wich is compatible with any viasualization method. Objective and subjective results achieved in the experimental evaluation indicate that the proposed technique presents quality comparable to considered state-of-the-art works, but with significantly lower computational cost.

Keywords: Anaglyph Reversion, Time Series, Stereo Images, Signal Processing, Superpixels. 



\section{LISTA DE ILUSTRAÇÕES}

Figura 1 - Câmera utilizada para captura de conteúdos estereoscópicos. Em simultâneo, uma das lentes captura a imagem do lado esquerdo, e a outra do lado direito. 26

Figura 2 - Anáglifo gerado a partir de par estéreo e óculos utilizados para visualização. 27

Figura 3 - Disparidade existente entre os pontos correspondentes da imagem. . . . . . 32

Figura 4 - Sugestões psicológicas de profundidade, que podem ser notadas utilizando apenas a visão monocular. . . . . . . . . . . . . . . . . 33

Figura 5 - Sugestões fisiológicas para a percepção de profundidade, que só podem ser visualizadas por meio da visão binocular (2 olhos). . . . . . . . . . . . . . . 34

Figura 6 - Verificando a existência de disparidade ao focar nos objetos. . . . . . . . . 34

Figura 7 - Diferentes tipos de paralaxes. . . . . . . . . . . 35

Figura 8 - Imagens do par estéreo e mapa de profundidade para a visão esquerda do par. 36

Figura 9 - Métodos para a visualização estereoscópica. . . . . . . . . . . . . 37

Figura 10 - Processo de geração de imagem anaglífica. Par estéreo é apresentado à esquerda. Componentes separadas para a geração do anáglifo ao centro. Anáglifo no formato vermelho-ciano gerado à direita. . . . . . . . . . . 39

Figura 11 - Processo para a visualização do anáglifo. Anáglifo é apresentado ao fundo e filtros de cor à frente. . . . . . . . . . . . . . . . . . . . 39

Figura 12 - Funcionamento da multiplexação por polarização. . . . . . . . . . . . . . . 40

Figura 13 - Funcionamento da multiplexação temporal. . . . . . . . . . . . . . . . . 41

Figura 14 - Um dos modelos de HMD existentes. . . . . . . . . . . . . . . . . . 42

Figura 15 - Autoestereoscopia por folhas lenticulares à esquerda e barreira de paralaxe à direita. . . . . . . . . . . . . . . . . . . 44 43

Figura 16 - Funcionamento geral da geração do par estéreo a partir do anáglifo. . . . . . 45

Figura 17 - Imagem anaglífica que representa a disparidade entre os pixels correspondentes. 46

Figura 18 - Algoritmo RevGliph e extensão HaaRGliph. . . . . . . . . . . . . . . . . 48

Figura 19 - Captura de anáglifos, utilizando três filtros de cor em câmeras convencionais, proposta por Bando, Chen e Nishita (2008). . . . . . . . . . . . . . . 49

Figura 20 - Distribuição dos pontos, para cada uma das disparidades. . . . . . . . . . 50

Figura 21 - Captura de anáglifos, utilizando dois filtros de cor em câmeras convencionais, proposta por Dietz (2012) . . . . . . . . . . . . . . . 5 51

Figura 22 - Descritor de característica utilizando algoritmo SIFT, com bloco quadrado de

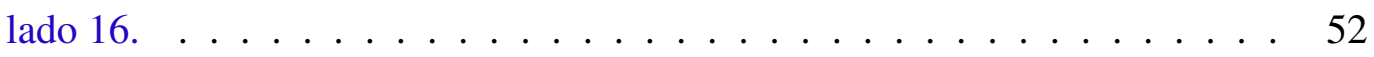


Figura 23 - Funcionamento do cálculo de custo para $D_{p}^{R I D}\left(f_{p}\right)$. Originalmente os patches possuem tamanho $19 \times 19$, mas foram ampliados para melhor compreensão.

Figura 24 - Estrutura de grafos gerada pelo algoritmo de otimização de Boykov, Veksler e Zabih (2001) . . . . . . . . . . . . . . . . . . . . . .

Figura 25 - Colorização de imagem por meio do algoritmo proposto por Levin, Lischinski e Weiss (2004).

Figura 26 - Extração da luminância diretamente do anáglifo. . . . . . . . . . . . . . . . 60

Figura 27 - Exemplos de séries temporais. . . . . . . . . . . . . . . 62

Figura 28 - Decomposição da série temporal S nas componentes de tendência $(T e)$, sazonal $(S a)$ e estocástica $(\varepsilon) \ldots \ldots \ldots \ldots$. . . . . . . . . . . . 63

Figura 29 - Distâncias computadas entre ponto em verde e ponto em laranja para $p=1$, $p=2$ e $p=\infty$, respectivamente. . . . . . . . . . . 65

Figura 30 - Diferença entre distâncias da família Minkowsky e DTW. . . . . . . . . . . 66

Figura 31 - Cálculo da matriz de custo da DTW . . . . . . . . . . . . . . . 67

Figura 32 - Diferença entre as distâncias DTW e LCSS. . . . . . . . . . . . . 68

Figura 33 - Modos de representação das séries temporais. . . . . . . . . . . . . . 69

Figura 34 - Representação da série temporal por meio da DFT. . . . . . . . . . . . . . 70

Figura 35 - Geração das Wavelets filhas a partir da Wavelet mãe. . . . . . . . . . . . . 72

Figura 36 - Representação da série temporal por meio da DWT. . . . . . . . . . . . . 72

Figura 37 - Representação do Piecewise Aggregate Approximation . . . . . . . . . . . . 73

Figura 38 - Soma dos quadrados ou erro residual de um segmento do Piecewise Linear Approximation. . . . . . . . . . . . . . . 74

Figura 39 - Representação do Piecewise Linear Approximation. . . . . . . . . . . . . . 74

Figura 40 - Representação do Symbolic Aggregate Approximation . . . . . . . . . . . 75

Figura 41 - Etapas do processo de recuperação anaglífica proposto. . . . . . . . . . . 78

Figura 42 - Problema no processo para encontrar blocos correspondentes entre as imagens. 79

Figura 43 - Representação de características por meio de séries. Ambas as séries são geradas para pixels adjacentes de uma mesma linha. . . . . . . . . . . . . 81

Figura 44 - Representação de séries por meio da diferença entre elementos adjacentes e extração do tamanho das janelas. . . . . . . . . . . . . . . . . . . . . 82

Figura 45 - (a) Extração dos tamanhos das janelas para cada um dos ângulos; (b) Extração das 4 séries representadas para um pixel $p \ldots . . \ldots$. . . . . . . 84

Figura 46 - Séries candidatas para alinhamento do pixel $p \ldots \ldots$. . . . . . . . . . . 84

Figura 47 - Geração das matrizes de disparidade res $_{e}$ e res $_{d}$. . . . . . . . . . . . . 86

Figura 48 - Processo de validação para cada pixel, por meio da reciprocidade entre distâncias. . . . . . . . . . . . . . . . . . . . 87

Figura 49 - Propagação do alinhamento para os pixels considerados incorretos nas etapas anteriores. . . . . . . . . . . . . . . . . . 88

Figura 50 - Processo para colorir pixel inválido. . . . . . . . . . . . . . . . 90 
Figura 51 - Utilizando memoization para evitar recálculos. . . . . . . . . . . . . . 92

Figura 52 - Complexidade para a etapa de alinhamento. Um único pixel $p$ é utilizado exatamente $\theta$ vezes para o alinhamento. . . . . . . . . . . . . . . . . . 94

Figura 53 - Propriedade do algoritmo SLICO para tamanho do superpixel. . . . . . . . 95

Figura 54 - Exemplo para as bases de imagens utilizadas. . . . . . . . . . . . . . . . . 99

Figura 55 - Valor PSNR para as diversas imagens. . . . . . . . . . . . . . . . 100

Figura 56 - Funcionamento do análise subjetiva DSCQS. . . . . . . . . . . . . . . 101

Figura 57 - Cartão de avaliação subjetiva das imagens, entregue ao usuário. . . . . . . . 101

Figura 58 - Parâmetros e etapas analisadas. . . . . . . . . . . . . . . . . 102

Figura 59 - Comparação das diversas funções de distância com base no PSNR das imagens.103

Figura 60 - Comparação das diversas funções de distância com base na quantidade de alinhamentos corretos das imagens. . . . . . . . . . . . . . . . . . . . . . 104

Figura 61 - Comparação das diversas representações de séries, com base na quantidade de alinhamentos corretos das imagens. . . . . . . . . . . . . . 106

Figura 62 - Comparação detalhada das melhores representações indicadas pelo experimento anterior. . . . . . . . . . . . . . . . . . . . . 107

Figura 63 - Qualidade dos resultados obtidos para os diversos algoritmos de segmentação.109

Figura 64 - Computando melhor configuração de parâmetros para cada o algoritmo SLIC. 110

Figura 65 - Qualidade dos algoritmos de segmentação, considerando a melhor configuração de parâmetros para cada algoritmo. . . . . . . . . . . . . . . . . . . . . 111

Figura 66 - Quantidade de alinhamentos corretos para cada ângulo. . . . . . . . . . . 112

Figura 67 - Exemplos de séries geradas para ângulos distintos. . . . . . . . . . . . . . . 112

Figura 68 - Utilização de múltiplos ângulos para cada uma das imagens. . . . . . . . . . 113

Figura 69 - Relação entre tamanho da janela e threshold com medida de qualidade (PSNR) final. . . . . . . . . . . . . . . . . . . 115

Figura 70 - Soma dos resultados normalizados para as diversas combinações $\beta-\delta$. . 116

Figura 71 - Sumarização dos dados apresentados no Chart 7 por Boxplots. . . . . . . . . 118

Figura 72 - Comparação de tempo de processamento entre as técnicas de Williem, ASIFT e SIRA (proposta) . . . . . . . . . . . . . . . . . . . . . . . 119

Figura 73 - Tempo de processamento das imagens ao utilizar mais núcleos de processamento para a técnica SIRA. . . . . . . . . . . . . . . . . 120

Figura 74 - Comparações para a imagem Cones (Middlebury 2003). . . . . . . . . . . . 121

Figura 75 - Comparações para a imagem Computer (Middlebury 2005) . . . . . . . . . . 122

Figura 76 - Sumarização dos dados subjetivos para o lado esquerdo, direito e ambos. . . 125 

Quadro 1 - Comparação entre métodos de visualização estereoscópica . . . . . . . . . 43

Quadro 2 - Comparação entre métodos de reversão anaglífica. . . . . . . . . . . . 57

Quadro 3 - Composição das bases utilizadas para avaliação do método proposto. . . 98

Quadro 4 - Parâmetros utilizados para os algoritmos de segmentação. . . . . . . . . 108

Quadro 5 - Comparação dos valores de PSNR com a utilização e não utilização de propagação de alinhamento. . . . . . . . . . . . . . . . . . . 115

Quadro 6 - Parâmetros fixos definidos para a técnica SIRA, utilizados na execução dos experimentos. . . . . . . . . . . . . . . 117

Quadro 7 - Comparação de PSNR entre as técnicas SIRA (proposta), ASIFT e Williem. 118

Quadro 8 - Resultado MOS da imagem original e a gerada, para imagens utilizadas nas três técnicas de reversão analisadas. . . . . . . . . . . . . . . . . . . . 124 



\section{LISTA DE ABREVIATURAS E SIGLAS}

iSAX Indexable Symbolic Aggregate Approximation

ARIMA AutoRegressive Integrated Moving Average

ARMA AutoRegressive Moving Average

ASIFT Anaglyph Scale-Invariant Feature Transform

BMP Bitmap

DCT Discrete Cosine Transform

DFT Discrete Fourier Transform

DSCQS Double Stimulous Continuous Quality Scale

DTW Dynamic Time Warping

DWT Discrete Wavelet Transform

FFT Fast Fourier Transform

HMD Head Mounted Displays

HMM Hidden Markov Models

ICMC Instituto de Ciências Matemáticas e de Computação

IQR Interquartile Range

ITS Institute for Telecommunication Sciences

JPEG Joint Photographic Experts Group

LBP Loopy Belief Propagation

LCSS Longest Common Subsequence

MOS Mean Opinion Score

MPAA Motion Pictures Association of América

MSE Mean Squared Error

PAA Piecewise Aggregate Approximation

PLA Piecewise Linear Approximation

PNG Portable Network Graphics

PSNR Peak Signal to Noise Ratio

RLE Run-lenght Encoding

SAX Symbolic Aggregate Approximation

SIFT Scale-Invariant Feature Transform

ZPS Zero Paralax Setting 

INTRODUÇÃO . . . . . . . . . . . . . . . . . 25

1.1 Motivação e Contextualização do Problema . . . . . . . . . . . . 27

1.2 Contribuições Principais . . . . . . . . . . . . . . 28

1.3 Organização do Documento . . . . . . . . . . . . . 28

2 FUNDAMENTOS DA ESTEREOSCOPIA . . . . . . . . . . . 31

$2.1 \quad$ Percepção Humana . . . . . . . . . . . . . . . . . 31

$2.2 \quad$ Geração de Imagens Estereoscópicas . . . . . . . . . . . . . 35

2.2.1 Multiplexação Estereoscópica . . . . . . . . . . . . . . 37

2.2.1.1 Multiplexação por Cor . . . . . . . . . . . . . . 38

2.2.1.2 Multiplexação por Polarização . . . . . . . . . . . . . . . . 39

2.2.1.3 Multiplexação Temporal . . . . . . . . . . . . . . . . . 40

2.2.2 Head Mounted Display's . . . . . . . . . . . . . . . . . . 42

2.2.3 Métodos Autoestereoscópicos . . . . . . . . . . . . . 42

2.2.4 Comparação entre Métodos . . . . . . . . . . . . . . . . 43

$2.3 \quad$ Considerações Finais . . . . . . . . . . . . . . . 44

3 REVERSÃO ANAGLÍfICA . . . . . . . . . . . . . . . 45

$3.1 \quad$ RevGlyph e HaarGlyph . . . . . . . . . . . . . 47

3.2 Extracting Depth and Matte Using a Color-filtered Aperture . . . 48

$3.3 \quad$ Reprocessing Anaglyph Images . . . . . . . . . . . . . . 50

$3.4 \quad$ Recovering Stereo Pair from Anaglyphs . . . . . . . . . . . . 51

3.5 Depth Map Estimation and Colorization of Anaglyph Images Using Local Color Prior and Reverse Intensity Distribution . . . . . . . . . 54

3.6 Comparação entre Métodos . . . . . . . . . . . . . 57

$3.7 \quad$ Colorização de imagens . . . . . . . . . . . . . . . 58

$3.8 \quad$ Considerações Finais . . . . . . . . . . . . . . 60

4 SÉRIES TEMPORAIS ..................... 61

4.1 Decomposição de Séries Temporais . . . . . . . . . . . . 62

$4.2 \quad$ Medidas de Dissimilaridade . . . . . . . . . . . . . . 64

4.2.1 Distâncias Minkowski . . . . . . . . . . . . . . . . . . . . 64

4.2.2 Distância DTW . . . . . . . . . . . . . . . . 65

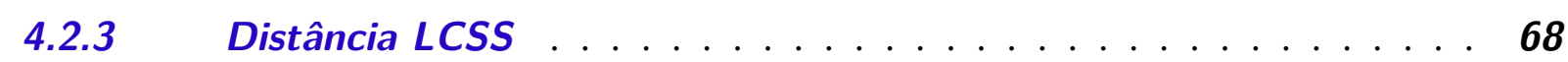


$4.3 \quad$ Representação de Séries Temporais . . . . . . . . . . . . . . . . 69

4.3.1 Transformada Discreta de Fourier . . . . . . . . . . . . . . . . . . . 70

4.3.2 Transformada Discreta de Wavelet . . . . . . . . . . . . . . . . . 71

4.3.3 Piecewise Aggregate Approximation . . . . . . . . . . . . . . 72

4.3.4 Piecewise Linear Approximation . . . . . . . . . . . . . . . . . . . 73

4.3.5 Symbolic Aggregate Approximation . . . . . . . . . . . . . 75

4.3.6 Representações Baseadas em Modelo . . . . . . . . . . . . . . . . 76

$4.4 \quad$ Considerações Finais . . . . . . . . . . . . . . . . 76

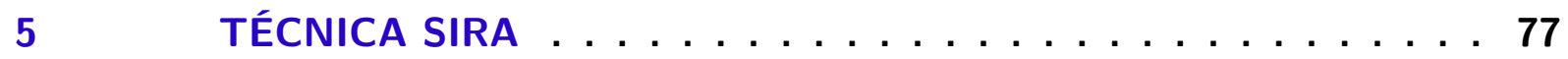

$5.1 \quad$ Etapas da técnica SIRA . . . . . . . . . . . . 77

5.1.1 Separação dos Canais e Segmentação . . . . . . . . . . . . . . . 78

5.1.2 Extração de Características . . . . . . . . . . . . . . . . . 80

5.1.3 Alinhamento de Séries . . . . . . . . . . . . . . 85

5.1.4 Validação da Reciprocidade entre Pixels . . . . . . . . . . . . 87

5.1.5 Propagação do Alinhamento. . . . . . . . . . . . . . . . 88

5.1.6 Colorir Pixels Remanescentes . . . . . . . . . . . . . . . . . . 89

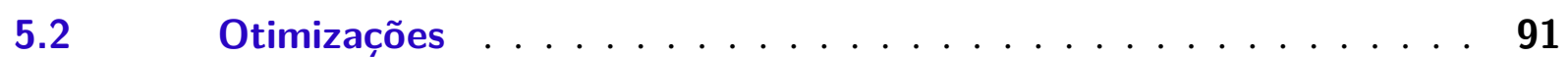

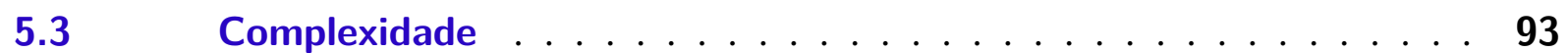

$5.4 \quad$ Considerações Finais . . . . . . . . . . . . . . . . . 96

6 AVALIAÇÃO EXPERIMENTAL . . . . . . . . . . . . . . . 97

$6.1 \quad$ Bases de Imagens Estéreos . . . . . . . . . . . . . . . 97

$6.2 \quad$ Método de Avaliação . . . . . . . . . . . . . . . . . 98

$6.3 \quad$ Análise da Técnica SIRA . . . . . . . . . . . . . . 101

6.3.1 Funções de Distância . . . . . . . . . . . . . . . . . . . 102

6.3.2 Métodos de Representação . . . . . . . . . . . . . . . . . 105

6.3.3 Algoritmos de Segmentação . . . . . . . . . . . . . . . . . 107

6.3.4 Ângulos para Extração de Características . . . . . . . . . . . . . 111

6.3.5 Propagação do Alinhamento . . . . . . . . . . . . . . . 113

$6.4 \quad$ Comparação Objetiva . . . . . . . . . . . . . . . . . . 115

6.5 Comparação Subjetiva . . . . . . . . . . . . . . . 120

$6.6 \quad$ Considerações Finais . . . . . . . . . . . . . . 125

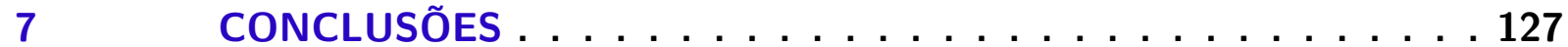

7.1 Contribuições Científicas . . . . . . . . . . . . . . . 127

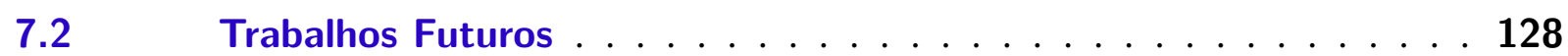

REFERÊNCIAS . . . . . . . . . . . . . . . . . . 131 


\section{INTRODUÇÃO}

A geração de imagens estereoscópicas, popularmente conhecidas como 3D, não é algo recente. Tal conceito é creditado a Wilhelm Rollman, que efetuou experimentos em 1853 com imagens tridimensionais, por meio da separação de cores (DIETZ, 2012). No final da década de 1950, com o declínio da popularidade dos cinemas, a indústria investiu em estereoscopia para atrair novamente o público. Apesar desse rápido crescimento de filmes estereoscópicos, em pouco tempo a área entrou em declínio, principalmente devido à baixa qualidade dos filmes produzidos para o formato (LIPTON, 1982).

Com o lançamento do filme Avatar em 3D, no ano de 2009, as indústrias cinematográfica e de entretenimento impulsionaram uma nova evolução e consequente amadurecimento dessa tecnologia, com a criação de novos dispositivos para visualização estéreo, tais como vídeo games, televisores e computadores. Segundo dados fornecidos pela Motion Pictures Association of América (MPAA, 2019), a indústria dos filmes estereoscópicos continua a produzir grande quantidade de conteúdo em 3D, com mais de 40 filmes lançados nesse formato somente no ano de 2018, para estúdios membros da MPAA. Essa quantidade de filmes lançados em 3D é $450 \%$ maior que para o ano de 2008. A tecnologia cresceu de tal maneira que diversos ramos de negócios a adotaram, seja para o entretenimento ou como meio de aprendizagem, como na medicina, em que é possível visualizar as juntas da anatomia humana em movimento, por meio de Head Mounted Displays (ROLLAND; FUCHS, 2000).

Imagens estereoscópicas têm como diferencial proporcionar ao espectador informação e sensação sobre distanciamento e profundidade (GOLDSTEIN, 2009). Essas informações são obtidas por meio de duas imagens levemente distintas, devido ao deslocamento espacial gerado ao serem capturadas, mimetizando a disposição dos olhos em seres humanos. A captura de imagens estereoscópicas é realizada por dispositivos semelhantes aos apresentados na Figura 1. Como é possível observar, tais dispositivos são compostos por duas lentes, gerando duas imagens. Este par de imagens, comumente chamado de par estéreo, é enviado para os olhos, sendo uma 
imagem para o olho direito e outra para o olho esquerdo. As imagens recebidas são enviadas ao cérebro, que realiza o papel de juntá-las, gerando a sensação de profundidade.

Com base nesse princípio, diversos métodos para visualização tridimensional foram desenvolvidos (UREY et al., 2011), como a multiplexação por polarização, multiplexação temporal, uso de Head Mounted Displays (HMD), e multiplexação por cor, sendo este último o foco do presente trabalho.

Figura 1 - Câmera utilizada para captura de conteúdos estereoscópicos. Em simultâneo, uma das lentes captura a imagem do lado esquerdo, e a outra do lado direito.

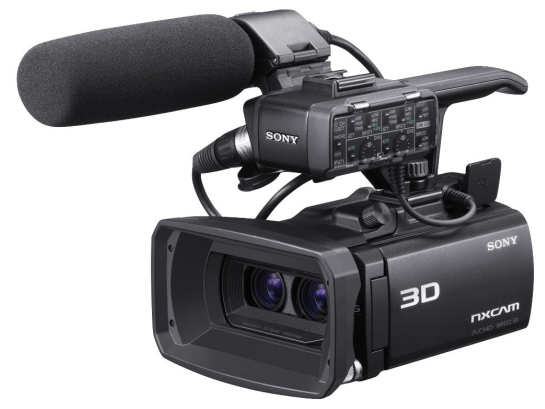

Fonte: Sony ${ }^{1}$.

A imagem gerada por meio da multiplexação por cor é comumente chamada de anáglifo (JOULIN; KANG, 2013), e funciona entrelaçando as imagens do lado direito e esquerdo, por meio da eliminação de alguns canais de cores distintos do par estéreo (Figura 2a). Os canais restantes são usados para compor uma única imagem que combina as informações de ambas as imagens do par estéreo. A multiplexação por cor é um dos métodos mais simples de visualização e não necessita de equipamentos especiais. Imagens anaglifícas podem ser visualizadas por meio de óculos com filtros de cor (Figura 2b), que realizam a tarefa de separar as imagens esquerda e direita, permitindo que cada uma seja visualizada apenas pelo olho correspondente.

Além da tecnologia de visualização barata e altamente acessível, imagens e vídeos anaglíficos possuem baixo custo computacional tanto para a geração quanto para armazenamento. Logo, são comumente encontrados em sites e repositórios na Internet ${ }^{2}$. Porém, na maioria dos casos o par estéreo original utilizado para a geração do anáglifo não é disponibilizado, impossibilitando a visualização 2D e a utilização de outras técnicas distintas para visualização estéreo. Este cenário motivou o desenvolvimento deste trabalho de mestrado, que propõe um método para reversão do anáglifo ao par estéreo.

$1<$ https://pro.sony/en_NL/products/handheld-camcorders/hxr-nx3d1e/> Acesso em: 09/05/2019.

$2<$ http://www.colorstereo.com/anaglyph.gal/ana_dir.html>

$<$ https://www.flickr.com/groups/anaglyph/pool>

$<$ https://br.pinterest.com/image3d/anaglyph-3d-pictures/> Acesso em: 09/05/2019. 
Figura 2 - Anáglifo gerado a partir de par estéreo e óculos utilizados para visualização.
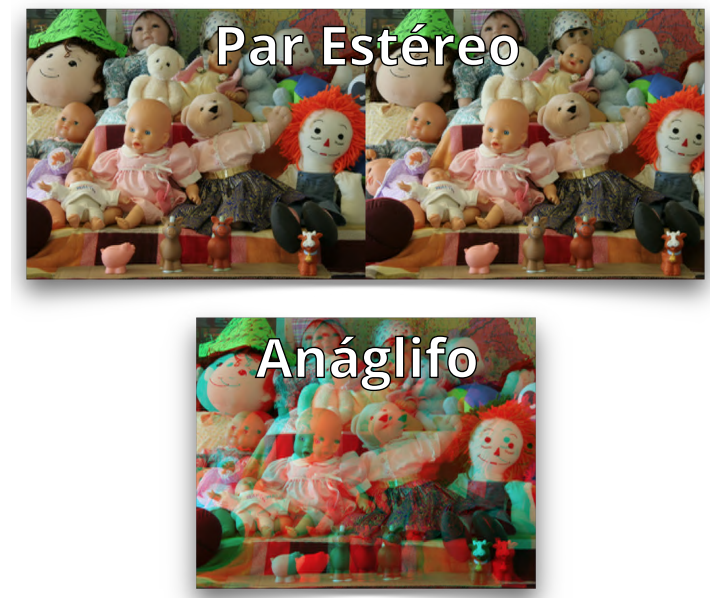

(a) Par estéreo e o anáglifo correspondente, no formato vermelho-ciano.
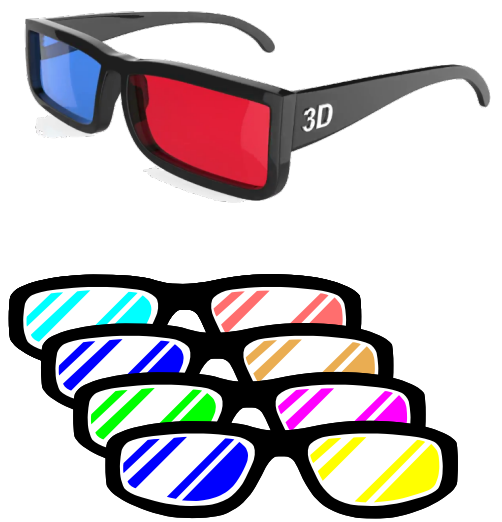

(b) Óculos com filtros de cor vermelho-ciano acima e algumas combinações abaixo.

Fonte: Elaborada pelo autor.

\subsection{Motivação e Contextualização do Problema}

No cenário atual da estereoscopia, de grande quantidade de imagens tridimensionais geradas nos mais diversos domínios de aplicação, o formato anáglifo destaca-se principalmente em imagens e vídeos encontrados na Internet.

O anáglifo é o formato de codificação estereoscópico que ocupa menos espaço de armazenamento em relação a outros métodos convencionais de visualização, pois utiliza apenas 3 canais de cores (RGB) ao invés de 6 canais ( 2 imagens RGB do par estéreo), com redução de $50 \%$ no volume de dados. O seu processo de codificação é trivial, sendo necessário apenas manipular as matrizes de pixels dos canais RGB das duas imagens que compõem o par estéreo e selecionar um canal de uma imagem e 2 canais da outra imagem. Os três canais resultantes compõem o anáglifo. Essas características beneficiam aplicações e sistemas que necessitam armazenar ou transmitir grandes quantidades de imagens estereoscópicas.

Apesar das vantagens apresentadas, o formato anaglífico fornece qualidade de visualização inferior aos demais formatos, o que acaba gerando a necessidade de apresentá-lo em formatos que exigem o par estéreo, de melhor qualidade. Muitas das vezes o par estéreo não está disponível, sendo necessário o processo de recuperação de par estéreo a partir do anáglifo, para permitir a independência entre os dispositivos de visualização, uma vez que o par estéreo é utilizado como entrada em grande parte dos demais formatos de codificação.

$\mathrm{Na}$ literatura das áreas relacionadas, como Multimídia e Processamento de Imagens, alguns trabalhos apresentam soluções para recriar os canais de cores perdidos na geração do anáglifo. Porém, como discutido no Capítulo 3, a principal abordagem existente possui tempo de processamento muito alto, inclusive para imagens de baixa resolução. Algumas soluções 
utilizam metadados para retornar o par estéreo, não sendo possível utilizar a técnica quando somente o anáglifo está disponível. Já outras técnicas funcionam apenas para anáglifos que possuem disparidades baixas ou com diferença baixa de disparidade entre os elementos/objetos da imagem, o que nem sempre ocorre em cenários reais.

Assim, diante das lacunas apresentadas, este trabalho foi realizado com o objetivo de propor um novo método de reversão anaglífica, eficiente e sem a utilização de metadados, de modo a viabilizar a independência de imagens estereoscópicas frente a diferentes mecanismos de visualização. $\mathrm{O}$ trabalho foi baseado na hipótese de que técnicas de análise de séries temporais podem ser utilizadas no processo de reversão anaglífica, em particular para identificar pixels correspondentes, provenientes de imagens distintas do par estéreo. Esta abordagem mostrouse promissora e resultou na principal contribuição deste trabalho, conforme sumarizado na Seção 1.2.

\subsection{Contribuições Principais}

A principal contribuição deste trabalho de mestrado é a técnica de reversão anaglífica denominada SIRA (Stereo Images Retrieving from Anaglyphs), desenvolvida para recuperar, a partir de um anáglifo, uma aproximação das imagens do par estéreo original. Com uma abordagem diferente das exploradas na literatura, a SIRA é baseada em técnicas de análise de séries temporais. Em linhas gerais, sequências de pixels adjacentes da imagem anaglífica são representadas por séries temporais compostas por valores de intensidade de cor; as séries são então comparadas por similaridade, com o objetivo de encontrar pixels correspondentes provenientes de imagens distintas do par estéreo. Os detalhes da abordagem proposta são apresentados no Capítulo 5.

Um outro diferencial da técnica SIRA é que apenas a informação contida na própria imagem anaglífica é utilizada para recuperação do par estéreo, ou seja, metadados não são um requisito. Além disso, o custo computacional de todo o processo de reversão é significativamente menor que o de métodos apresentados em trabalhos relacionados, gerando resultados de qualidade similar quando comparados por meio de medidas objetivas e subjetivas. A avaliação experimental é detalhada no Capítulo 6.

\subsection{Organização do Documento}

Esta dissertação está organizada da seguinte maneira. No Capítulo 2 é apresentada uma visão geral sobre estereoscopia, abordando os principais conceitos e métodos de visualização estereoscópica. O processo necessário para a reversão anaglífica e os principais trabalhos correlatos são apresentados no Capítulo 3. No Capítulo 4 são apresentados conceitos básicos relacionados a Séries Temporais. 
No Capítulo 5 é apresentada a técnica proposta SIRA, baseada na similaridade entre séries temporais criadas a partir de ambos os lados da imagem anaglífica. No Capítulo 6 são apresentados os experimentos para validação dos pontos de decisão da técnica proposta, além da comparação da técnica SIRA com trabalhos correlatos propostos na literatura. Ao final, no Capítulo 7 são apresentadas as conclusões, incluindo as principais contribuições, publicações, e propostas para trabalhos futuros, com relação a este trabalho de mestrado. 



\section{FUNDAMENTOS DA ESTEREOSCOPIA}

Este capítulo aborda os principais aspectos da visão humana relacionados com a percepção de profundidade (Seção 2.1). Também é discutida a teoria para a geração artificial de imagens estereoscópicas (Seção 2.2), incluindo os diversos métodos de separação existentes, que objetivam entregar, para cada um dos olhos, as imagens corretas.

\subsection{Percepção Humana}

A média de distância entre os olhos para um ser humano adulto é de $64 \mathrm{~mm}$. Essa distância gera a chamada disparidade na retina, que refere-se ao deslocamento existente para um mesmo objeto em relação as duas imagens recebidas pela retina de cada um dos olhos (STEREOGRAPHICS, 1997). A Figura 3 ilustra tal conceito. Supondo que a imagem menor (em vermelho) seja enviada para um olho e a imagem maior (ciano) para o outro, é possível verificar, em diversos locais da imagem, nós pretos interligados por uma aresta, os quais são exemplos da disparidade existente entre os pontos correspondentes. Vale observar que o nó mais à esquerda da imagem, rotulado como A, indica a inexistência de disparidade, já que a aresta gerada possui comprimento igual a zero.

Em Lipton (1982) são encontradas algumas propriedades interessantes relativas à percepção visual humana, em que mesmo com um olho só, ou utilizando um plano de exibição de imagens 2D, é possível ter a noção de profundidade, por meio de sugestões monoculares, ou seja, por meio da utilização de apenas um olho (GOLDSTEIN, 2009). Algumas destas sugestões são apresentadas a seguir.

1. Tamanho da Imagem na Retina. A largura projetada na retina indica se objetos são grandes ou pequenos, sendo que, quanto maior for a largura dessa projeção, mais próximo o objeto estará, aparentando ser maior. Essa propriedade é ilustrada na Figura 4a, em 
Figura 3 - Disparidade existente entre os pontos correspondentes da imagem.

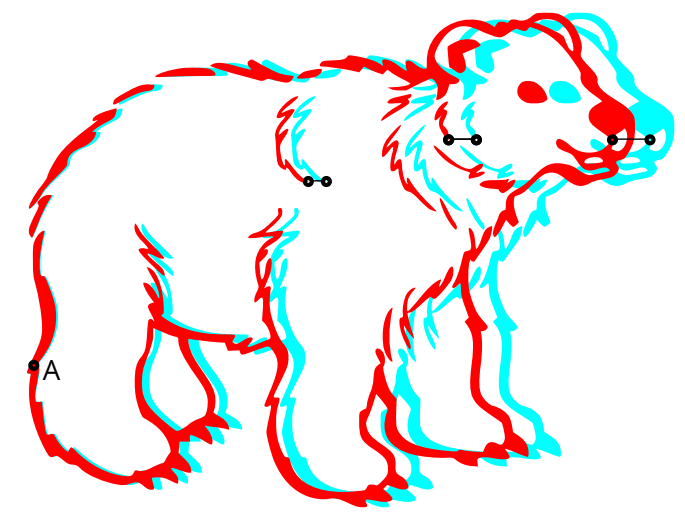

Fonte: Adaptada de Clipart World ${ }^{1}$.

que apesar dos triângulos verde e vermelho possuirem tamanhos iguais, o mais próximo (vermelho), apresenta projeção maior na retina do que o triângulo mais distante (verde).

2. Perspectiva ou Perspectiva Linear. Objetos, principalmente os construídos por seres humanos, aparentam convergir no horizonte, tal como apresentado na Figura 4b, em que a estrada aparenta estar se afunilando no horizonte, mesmo tendo sempre a mesma largura.

3. Interposição ou Sobreposição. Não é possível enxergar a parte de um objeto que está sobreposta por outro objeto, fazendo com que o objeto que está à frente aparente estar mais perto.

4. Luz e Sombra. Tais elementos permitem a percepção da profundidade ao fornecer informações relativas ao volume preenchido pelo objeto, o quão sólido o objeto é, além da relação existente entre os demais objetos.

5. Paralaxe do Movimento. Suponha que uma pessoa se encontra dentro de um carro em movimento. Ao olhar para fora e observar os objetos, consegue notar que objetos mais próximos tendem a se movimentar mais rapidamente que objetos distantes. A Figura 4c ilustra tal propriedade, em que com o movimento, a árvore, que está mais à frente, aparenta "se movimentar" mais rapidamente do que a construção que está ao fundo.

As propriedades apresentadas estão relacionadas às sugestões psicológicas geradas pelo cérebro. Apesar de ser possível perceber objetos que estão mais longe ou mais perto, por meio das propriedades citadas anteriormente, só é possível alcançar a estereopsia utilizando os dois olhos, portanto, uma informação binocular. A estereopsia proporciona ao observador uma percepção diferente de profundidade, em que a sensação de imersão é evidenciada. Algumas propriedades fisiológicas para a geração da estereopsia, que podem ser prontamente explicadas pela funções anatômicas, são apresentadas a seguir. 
Figura 4 - Sugestões psicológicas de profundidade, que podem ser notadas utilizando apenas a visão monocular.

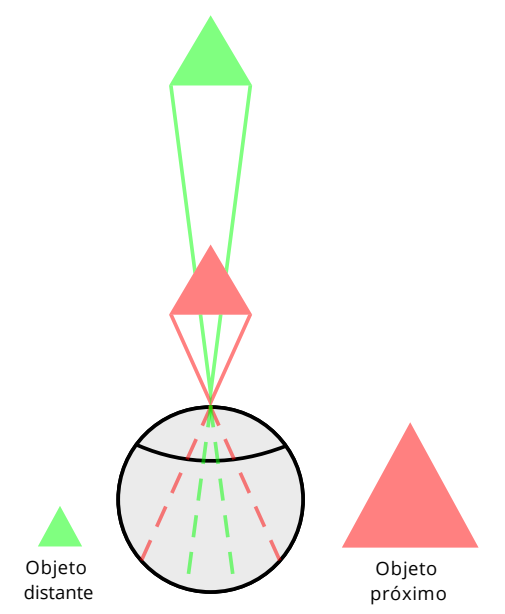

(a) Tamanho na retina. Objetos próximos aparentam ser maiores que os mais distantes.

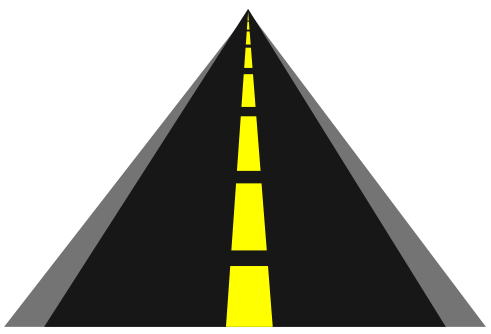

(b) Perspectiva linear. A rua aparenta convergir em um ponto no horizonte.

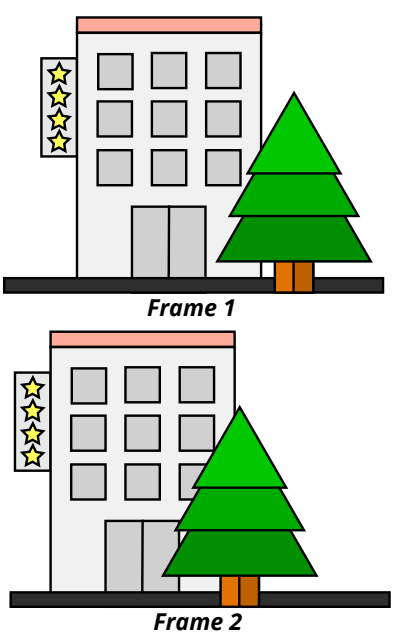

(c) Paralaxe do movimento. Objetos aparentam se deslocar em "velocidades"distintas.

Fonte: Elaborada pelo autor.

1. Acomodação. Assim como ocorre nas lentes de uma câmera, é necessário que o olho focalize em uma determinada posição. Para o olho humano é necessário um esforço muscular, e tal esforço gera feedback, principalmente relativo a profundidade.

2. Convergência. Para visualizar somente uma imagem, é necessário que os olhos estejam focados em apenas um ponto. A Figura 5a mostra os olhos convergindo em um mesmo ponto.

3. Disparidade. A disparidade, como mencionada anteriormente, é a distância dos pontos correspondentes de um determinado objeto em cada um dos olhos. Na Figura 5 b é possível verificar que o mesmo objeto encontra-se em posições diferentes em relação à imagem gerada pelo olho complementar. Vale lembrar que disparidades diferentes podem ser encontradas em um mesmo elemento visual, como apresentado na Figura 3, e também entre elementos distintos.

Um experimento pode ser feito para notar a existência da disparidade. Com um objeto ao fundo da cena, ao posicionar o dedo próximo ao rosto, entre os olhos, e focar no dedo, é possível ao visualizador notar que o objeto aparenta ficar duplicado (Figura 6a). Agora, ao invéz de focar no dedo, se o visualizador focar no objeto ao fundo, verá o dedo duplicado (Figura 6b). Tal experimento comprova que as imagens que chegam aos nossos olhos são distintas (LIPTON, 1982).

Apesar de haver sobreposição entre as imagens que chegam aos nossos olhos, não são geradas duas imagens distintas, mas apenas uma. Tal fenômeno ocorre devido a um processo 
Figura 5 - Sugestões fisiológicas para a percepção de profundidade, que só podem ser visualizadas por meio da visão binocular (2 olhos).

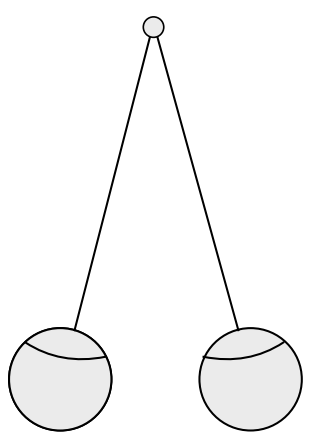

(a) Convergência dos olhos em um mesmo ponto.

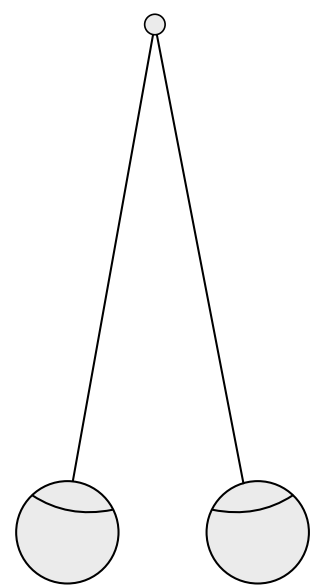

\section{(1)}

Fonte: Adaptada de Lipton (1982).

Figura 6 - Verificando a existência de disparidade ao focar nos objetos.

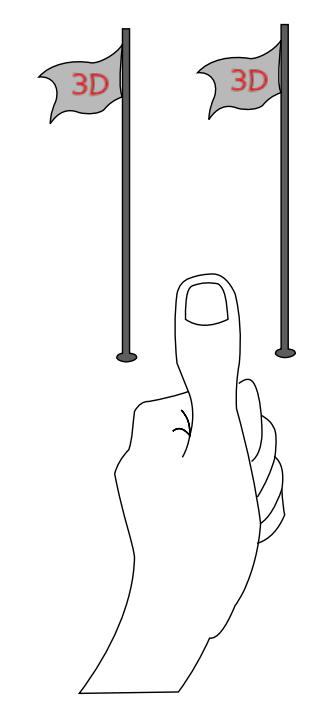

(a) Ao focar os olhos no dedo, (b) a bandeira aparenta estar du-
plicada.

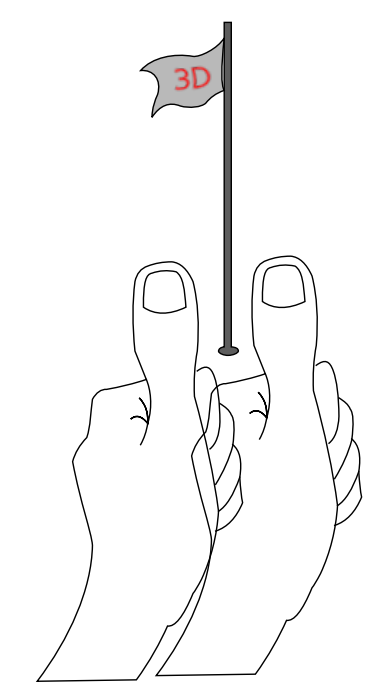

(b) Ao focar na bandeira, o dedo aparenta estar duplicado.

Fonte: Adaptada de Lipton (1982).

conhecido como fusão, que ocorre no cérebro, e tem por objetivo juntar as duas imagens geradas, gerando assim a percepção de profundidade. Por meio deste fenômeno de união das imagens, é possível recriar a sensação de profundidade de modo artifical. Tal processo é apresentado na seção a seguir. 


\subsection{Geração de Imagens Estereoscópicas}

Como mencionado no Capítulo 1, uma imagem estereoscópica é formada por duas imagens levemente deslocadas entre si, normalmente capturadas por câmeras como apresentadas na Figura 1 do Capítulo 1. Essas duas imagens bidimensionais (2D), que recebem o nome de par estéreo, são enviadas separadamente para cada um dos olhos, e devido ao seu deslocamento, geram a disparidade na retina (Seção 2.1). Por esse motivo, é possível ter a percepção real de profundidade, conhecida como estereopsia. A disparidade, quando exibida em dispositivos de visualização, é chamada de paralaxe.

A paralaxe pode existir de quatro modos distintos: Zero Paralax Setting (ZPS), paralaxe positiva, paralaxe divergente e paralaxe negativa (STEREOGRAPHICS, 1997). O presente trabalho utilizará os termos disparidade e paralaxe de maneira intercambiável, tal como utilizado em grande parte dos trabalhos existentes na literatura.

A Figura 7a ilustra a paralaxe negativa em que o observador tem a sensação de ver o objeto "saindo da tela". Assim a acomodação é realizada sobre o plano de projeção, sendo indicado pelos pontos verdes, e a convergência é representada pelo ponto mais à frente, em vermelho. A Figura 7b ilustra o Zero Paralax Setting em que a convergência e acomodação ocorrem no plano de projeção, indicado pelo ponto em amarelo. Para o ZPS, a sensação do observador é de ver o objeto no plano de projeção, assim como ocorre na visualização 2D. Na Figura 7c é ilustrada a paralaxe positiva, em que a acomodação ocorre no plano de visualização, indicado pelo ponto verde, à frente, e a convergência ao fundo do plano de visualização, indicado pelo ponto vermelho, ao fundo. A paralaxe positiva gera a sensação de ver o objeto "para dentro da tela". Por fim, na Figura 7d é apresentada a paralaxe divergente, em que a convergência não ocorre, fazendo com que o cérebro não una, ou tenha dificuldade em unir as imagens. A paralaxe divergente não representa o mundo real e portanto sua utilização deve ser evitada.

Figura 7 - Diferentes tipos de paralaxes.

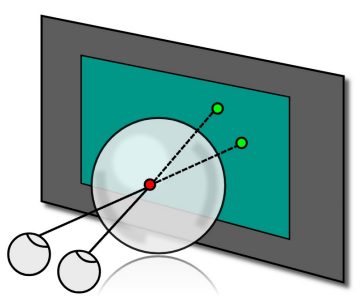

(a) Paralaxe negativa.

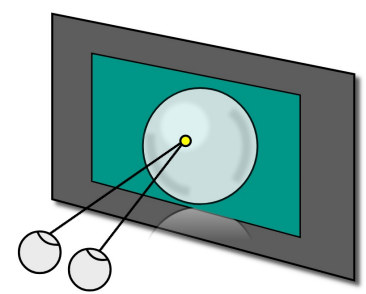

(b) Zero paralax setting.

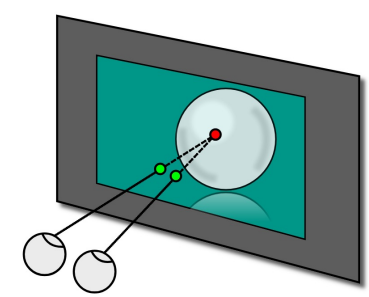

(c) Paralaxe positiva.

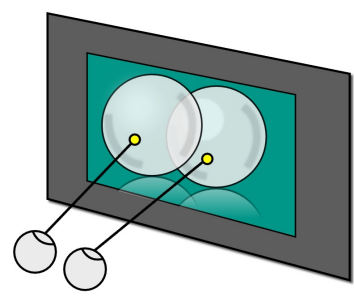

(d) Paralaxe divergente.

Fonte: Elaborada pelo autor.

Na percepção humana, normalmente a acomodação e a convergência (Seção 2.1) ocorrem em um mesmo ponto do espaço. Porém para a visualização estereoscópica ocorrem de maneira diferente, ou seja, a acomodação é feita para um ponto na tela que está exibindo o conteúdo, 
enquanto a convergência pode ocorrer em um ponto mais à frente ou mais ao fundo, em relação à tela (STEREOGRAPHICS, 1997), por meio das formas de paralaxe apresentadas (positiva ou negativa).

Uma das maneiras mais comuns de visualizar o paralaxe dos diferentes objetos de uma imagem é por meio dos mapas de profundidade, com exemplo ilustrado pela Figura 8. O mapa de profundidade é apresentado à direita, em escala de cinza, e tem por objetivo definir a profundidade em que cada objeto se encontra na cena. Quanto mais claro for um determinado pixel, maior a disparidade entre os objetos, e consequentemente mais próximo o objeto está da câmera. Observe que um mapa de profundidade é dado para uma imagem do par estéreo original (neste caso correspondente à visão esquerda).

Figura 8 - Imagens do par estéreo e mapa de profundidade para a visão esquerda do par.
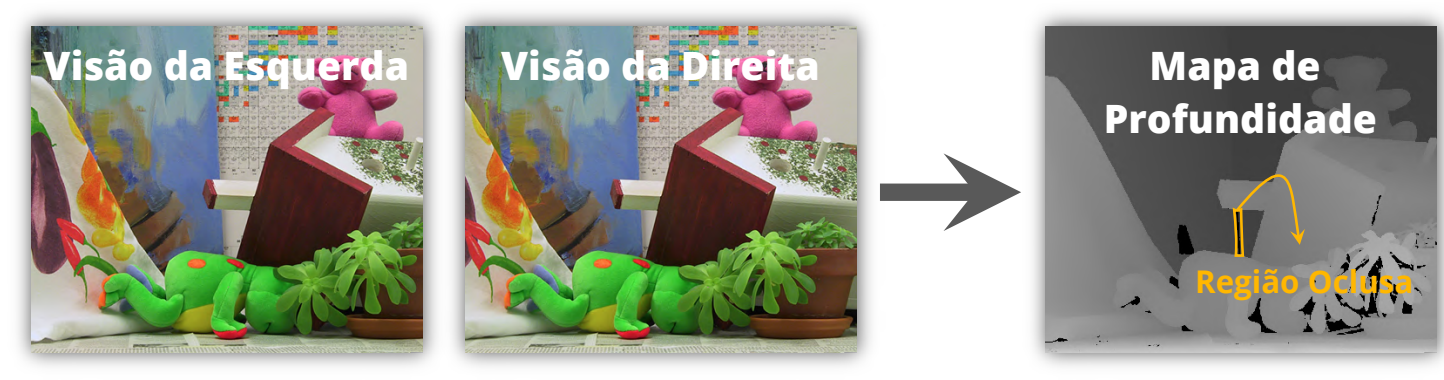

Fonte: Elaborada pelo autor.

Antes de entender como esta profundidade é interpretada, é necessário entender como as imagens estéreo são relacionadas. Como já mencionado anteriormente, as imagens estéreo são capturadas por meio de duas câmeras, tal como apresentado na Figura 1 do Capítulo 1. A disposição das lentes faz com que as imagens geradas tenham pontos correspondentes (ilustrados pelas bolinhas ligadas por arestas da Figura 3 da Seção 2.1) deslocados apenas horizontalmente, sendo possível, para cada ponto, encontrar o correspondente na mesma linha, quando este existir. Há casos em que o correspondente não existe na imagem complementar, uma vez que o ângulo de captura da imagem pode impedir uma das visões de capturá-lo. Estes pixels que não possuem correspondente recebem o nome de pixels oclusos. O deslocamento para encontrar o correspondente é medido em pixels.

Voltando ao mapa de profundidade, a codificação de deslocamento é representada pelas cores. Normalmente o mapa de profundidade possui uma escala indicando a quantidade de pixels a ser deslocada para encontrar o pixel correspondente. No caso do mapa apresentado na Figura 8, está sendo utilizado a escala 4x. Isso significa que para um pixel $p$ com cor igual a 200 (escala de cinza de 0-255) no mapa de profundidade, há uma distância de 50 pixels (200/4) entre o pixel $p$ da visão da esquerda e o correspondente na visão da direita. A única exceção é dada pelos pontos pretos, que normalmente representam as regiões oclusas. A disparidade máxima que pode existir na imagem é dada por $\mathscr{L}$, sendo comumente utilizada para algoritmos de matching 
stereo e algoritmos de reversão anaglífica, que possuem o objetivo de reconstruir mapas de profundidade, seja como um resultado intermediário ou final.

Com base na percepção visual humana, foram desenvolvidas técnicas para a visualização estereoscópica em dispositivos de visualização originalmente bidimensionais (televisores, vídeogames, dentre outros). Tais técnicas consistem no envio das imagens para cada um dos olhos de modo independente. A primeira fase é a captura das imagens (geralmente duas), então cada uma das imagens é enviada a um dos olhos (caso existam mais de duas imagens, apenas duas são selecionadas por vez), impedindo que a imagem incorreta seja visualizada pelo outro olho (efeito também conhecido como crosstalk (WOODS, 2012)).

Figura 9 - Métodos para a visualização estereoscópica.

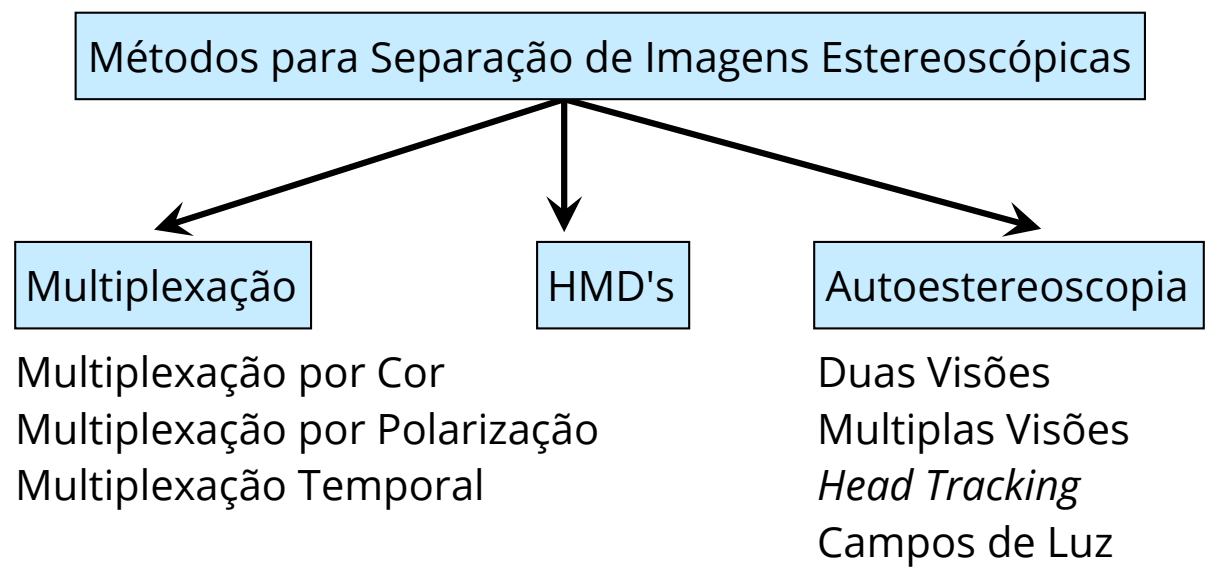

Fonte: Adaptada de Urey et al. (2011).

Como sintetizado pela Figura 9, existem três principais abordagens para os métodos criados para o envio das imagens para os olhos a fim de gerar o efeito estereoscópico. A primeira delas é baseada em multiplexação (Seção 2.2.1), que pode ser subdividida em multiplexação por cor, multiplexação por polarização e multiplexação temporal. Todos os métodos baseados em multiplexação necessitam da utilização de um óculos para visualização. A segunda abordagem considera dispositivos HMD (Seção 2.2.2), que são dispositivos completos "montados"na cabeça do visualizador. Por fim, existem os métodos autoestereoscópicos (Seção 2.2.3), para os quais não há a necessidade de dispositivos montados à cabeça ou óculos para visualização, já que o próprio dispositivo de reprodução é capaz de enviar o par estéreo, separadamente, para os olhos. Os métodos autoestereoscópicos podem ser divididos em: duas visões, multivisões, head tracking e campos de luz.

\subsubsection{Multiplexação Estereoscópica}

Segundo o Institute for Telecommunication Sciences (ITS) ${ }^{2}$, a multiplexação é a combinação de dois ou mais canais de informação, enviados por um mesmo meio de transmissão. Deste modo, os métodos de multiplexação estereoscópicos combinam as duas imagens que compôem 
o par estéreo, e transmitem essa informação pelo ar. Um demultiplexador captura a informação e separa as duas imagens, que são enviadas para os olhos de modo independente.

\subsubsection{Multiplexação por Cor}

O método de separação baseada em multiplexação por cor é uma das primeiras abordagens encontradas para a geração da estereopsia, e foi inicialmente utilizado para a exibição de filmes (ZINGARELLI; ANDRADE; GOULARTE, 2011). É um dos métodos mais simples e baratos, já que não requer equipamentos de visualização complexos (Hardwares), necessitando apenas de um óculos com filtro de cor. Uma imagem gerada por meio de multiplexação por cor pode ser visualizada inclusive em mídia impressa.

Apesar de ser um método muito atrativo, a multiplexação por cor pode resultar em perda de informação de cor, pois descarta metade das informações do par estéreo original. O método de multiplexação por cor só é possível devido a geração da imagem chamada de anáglifo, que contém parte das informações contidas nas duas imagens do par estéreo original.

O processo de geração do anáglifo é ilustrado na Figura 10, por meio da codificação de cor $R G B$. A imagem 1 contém os canais de cores $R_{1}, G_{1}$ e $B_{1}$, e a imagem 2 contém os canais $R_{2}, G_{2}$ e $B_{2}$. A partir da imagem 1 são selecionados, por meio do processo A, os canais de cores verde $\left(G_{1}\right)$ e azul $\left(B_{1}\right)$, gerando uma imagem ciano $\left(G_{1}\right.$ e $\left.B_{1}\right)$. Já o processo B seleciona o canal vermelho $\left(R_{2}\right)$ a partir da imagem 2 , gerando a imagem vermelha $\left(R_{2}\right)$. As duas imagens geradas (vermelha e ciano) são então sobrepostas, produzindo a imagem em anáglifo $\left(R_{2}, G_{1}\right.$ e $\left.B_{1}\right)$.

O modelo mais comum de anáglifo é o vermelho/ciano $(R / G B$, com $100 \%$ de suas respectivas intensidades), porém qualquer forma de permutação entre as cores é possível, assim, existe o anáglifo verde/magenta ( $G / R B$, com $100 \%$ de suas respectivas intensidades) e azul/amarelo ( $B$ / $R G$, também com $100 \%$ de suas respectivas intensidades). Além desses, que apresentam intensidades de cores iguais e máximas para os canais, existem modelos que trabalham com intensidades variáveis, como o azul/âmbar $(B / R G$, com $75 \%$ da intensidade de azul, e $100 \%$ para vermelho e verde).

Para a visualização do anáglifo, os canais de cores corretos são separados por meio de lentes com filtros de cor. A Figura 11 ilustra o funcionamento para o modelo vermelho/ciano, em que a cor vermelha da lente permite a passagem das cores verde e azul (impedindo o vermelho) e a cor ciano permite a passagem da cor vermelha (impedindo verde e azul).

O presente trabalho possui como foco o método de multiplexação por cor, objetivando a recuperação do par estereoscópico original a partir do anáglifo.

2 https://www.its.bldrdoc.gov/fs-1037/dir-001/_0066.htm\#pdf. Acesso em: 10/01/2019. 
Figura 10 - Processo de geração de imagem anaglífica. Par estéreo é apresentado à esquerda. Componentes separadas para a geração do anáglifo ao centro. Anáglifo no formato vermelho-ciano gerado à direita.

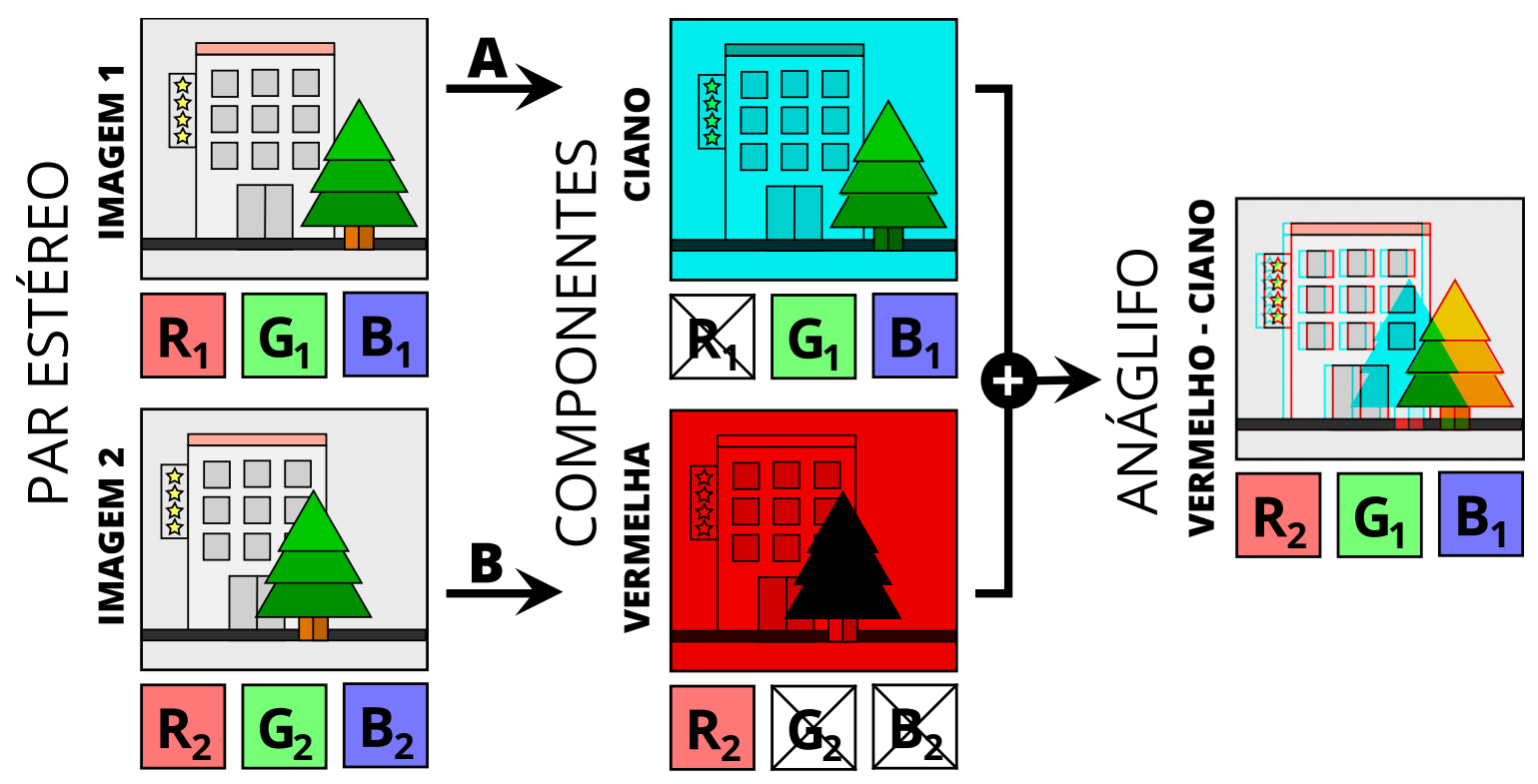

Fonte: Elaborada pelo autor.

Figura 11 - Processo para a visualização do anáglifo. Anáglifo é apresentado ao fundo e filtros de cor à frente.

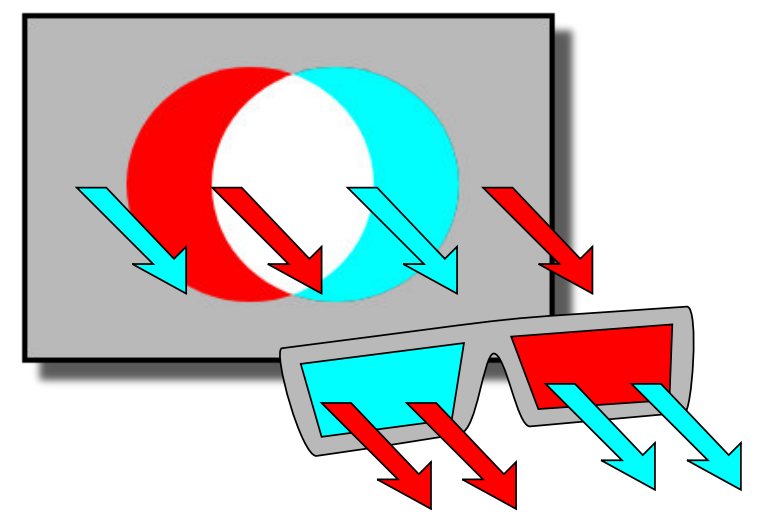

Fonte: Adaptada de Rodrigues, Yugoshi e Goularte (2016).

\subsubsection{Multiplexação por Polarização}

A multiplexação por polarização, diferentemente da multiplexação por cor, mantém todos os canais de cores, para ambas as imagens geradas, realizando a separação dos canais por meio de filtros que selecionam um determinado padrão do sinal (imagem).

A Figura 12 exemplifica o funcionamento deste método. Naturalmente, a onda de luz não possui um padrão definido, sendo emitida em todas as direções. Assim, para a multiplexação por polarização, é necessário que o dispositivo que transmite a imagem filtre sinais não interessantes, portanto somente duas direções são mantidas, uma na vertical e outra na horizontal, fazendo 
essa separação por meio de "fendas"que permitem a passagem desses padrões, funcionando como persianas. Vale observar que existem outros padrões que podem ser aplicados, tais como a geração dos padrões -45 graus e +45 graus, ou padrões circulares, em sentido horário e anti-horário (WOODS, 2012).

Apesar de filtrar apenas os sinais para os padrões definidos, o usuário continua visualizando duas imagens sobrepostas, uma vez que o olho humano não possui filtro para a detecção individual dos padrões para cada olho. Para resolver este problema é necessário a utilização de óculos, onde cada uma das lentes filtrará um dos dois padrões, de modo complementar. Este método de multiplexação possui diversas vantagens em relação aos outros, como o baixo custo para aquisição dos óculos polarizadores, a quantidade de brilho oferecido, além de possuir todos os canais de cores. Porém, possui como desvantagem a perda de resolução, já que é necessário enviar metade da informação para um olho e metade para o outro.

Atualmente os dispositivos multiplexadores apresentam baixa taxa de crosstalk, porém os principais defeitos que ainda existem ocorrem devido à baixa qualidade dos polarizadores e de sua orientação incorreta (WOODS, 2012) do multiplexador ou demultiplexador (padrões -45/+45 circulares não definidos corretamente), ou até mesmo movimentação da cabeça. Tal tecnologia é amplamente utilizada em salas de cinemas e alguns modelos de televisão.

Figura 12 - Funcionamento da multiplexação por polarização.
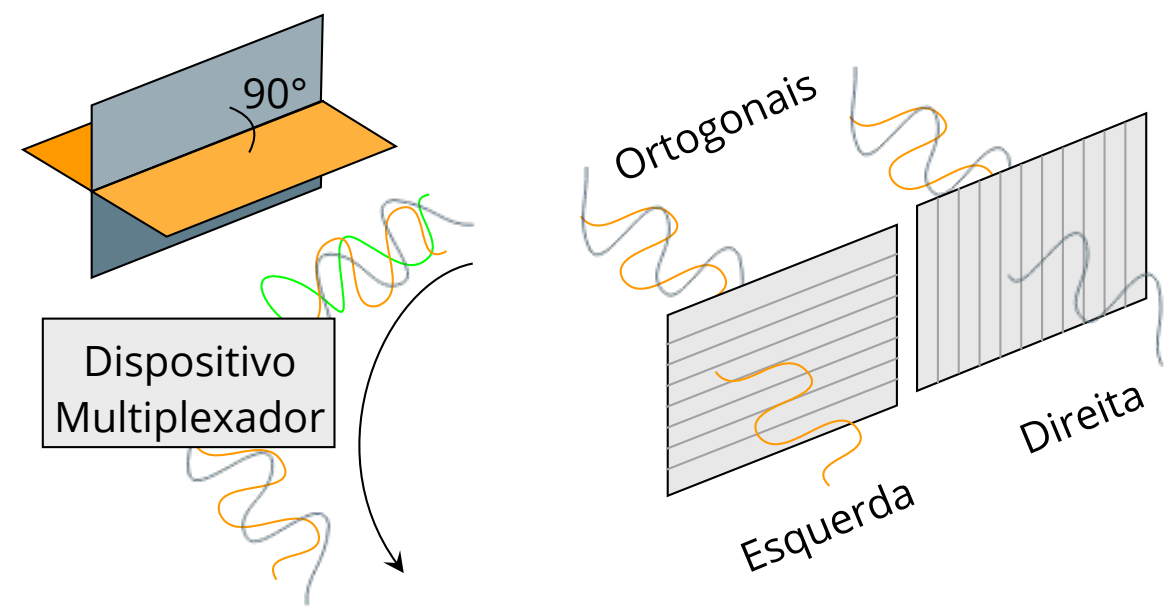

Fonte: Elaborada pelo autor.

\subsubsection{Multiplexação Temporal}

A multiplexação temporal, como o próprio nome sugere, faz uso do tempo para realizar a separação entre os canais. Assim, diferentemente da multiplexação por polarização, que é uma tecnologia passiva, a multiplexação temporal é ativa, uma vez que é necessária a sincronização entre o dispositivo emissor e os óculos.

O sistema de estereoscopia ativo necessita de um dispositivo para emitir a imagem, normalmente televisores que, em geral, rodam em frequências iguais ou superiores a $120 \mathrm{~Hz}$ 
de atualização (UREY et al., 2011), e um óculos, que necessita de pilha/bateria para funcionar. O dispositivo emissor tem por objetivo ficar alternando as imagens do par estéreo, exibindo a imagem da direita, depois a da esquerda, e assim sucessivamente, muitas vezes por segundo (60 vezes ou mais por imagem). Os óculos por sua vez possuem os chamados obturadores, que quando estão abertos para o olho direito, fecham para o olho esquerdo, e vice-versa, como ilustrado na Figura 13. A abertura dos obturadores é relacionada com a opacidade das lentes, assim o "fechado" indica que não permite a passagem da luz, enquanto "aberto" permite a passagem. A questão está justamente na sincronização existente entre os dois dispositivos, que devem se comunicar para saber quando os obturadores corretos devem se abrir e fechar, gerando assim a estereopsia.

Figura 13 - Funcionamento da multiplexação temporal.

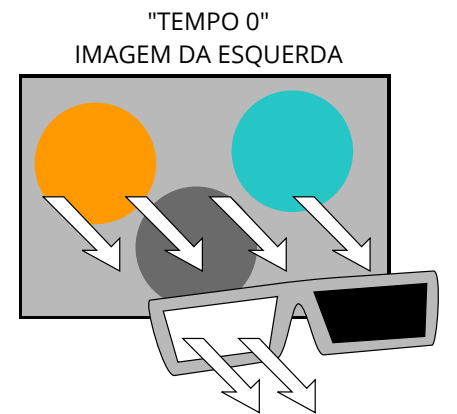

"TEMPO 2"

IMAGEM DA ESQUERDA

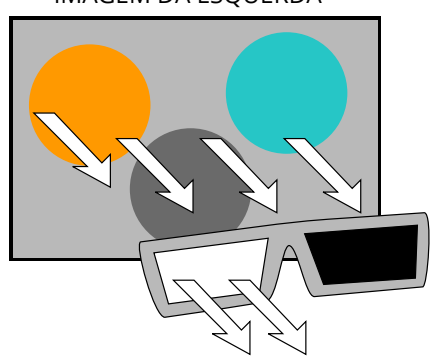

"TEMPO 1" IMAGEM DA DIREITA

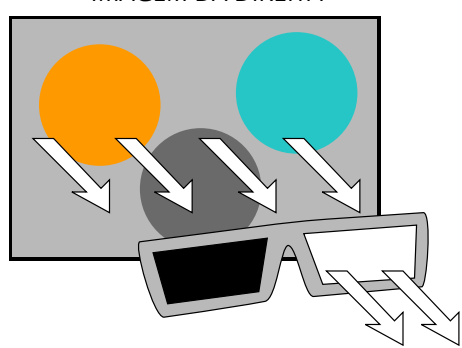

"TEMPO 3" IMAGEM DA DIREITA

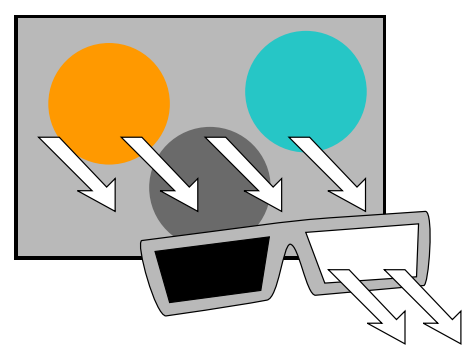

Fonte: Elaborada pelo autor.

A vantagem em relação à multiplexação por polarização é a resolução, que é duas vezes maior, uma vez que a imagem é exibida na resolução nativa. Apesar disso, é necessária uma taxa de atualização de tela duas vezes maior, além da desvantagem do brilho reduzido, que ocorre justamente porque os obturadores ficam metade do tempo fechados (escuros), e de causar maior cansaço visual.

As principais causas que podem gerar o crosstalk nesse método são a incorreta sincronização entre dispositivo emissor e óculos, velocidade de troca de cores dos pixels do dispositivo (podem deixar pixels residuais), além da performance das células de cristal líquido dos óculos (WOODS, 2012). O método de multiplexação temporal é amplamente utilizado por algumas marcas de televisores. 


\subsubsection{Head Mounted Display's}

Os HMDs são equipamentos de visualização que possuem conjuntos de lentes internas e são acoplados na cabeça do visualizador, sendo que cada um dos olhos recebe imagens distintas. Um exemplo deste dispositivo é apresentado na Figura 14. A tecnologia dos HMD tem sido utilizada para a Realidade Aumentada, juntando imagens do mundo real com informações virtuais, permitindo sua utilização para treinamentos em diversas áreas, como na medicina para simulações de cirurgias. Vale lembrar que este método de visualização ainda é considerado de alto custo (RODRIGUES; YUGOSHI; GOULARTE, 2016). Uma grande vantagem da maior parte dos dispositivos deste método é a inexistência de crosstalk, o que o torna interessante para estudar o efeito do mesmo, já que simulações eletrônicas de crosstalk, variando de $0 \%$ a 100\%, podem ser efetuadas (WOODS, 2012).

Figura 14 - Um dos modelos de HMD existentes.

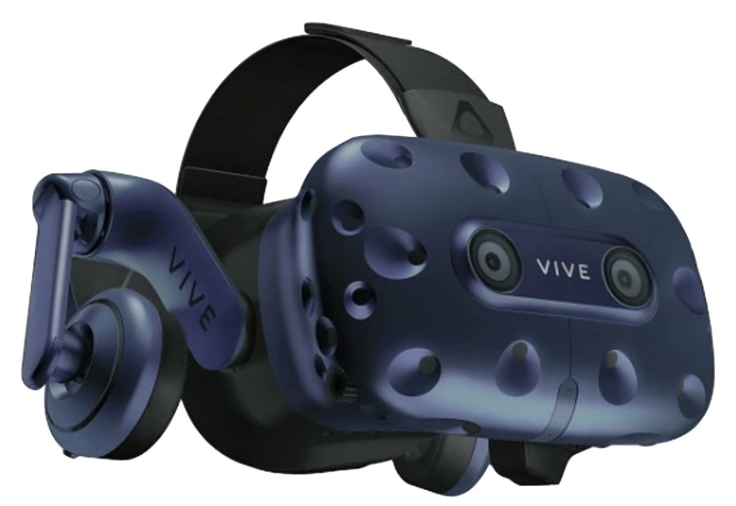

Fonte: Dell ${ }^{3}$.

\subsubsection{Métodos Autoestereoscópicos}

Os métodos autoestereoscópicos, diferentemente dos métodos por multiplexação, não necessitam de óculos ou HMD para visualização. Para tal método funcionar, é necessário que haja alguma maneira de enviar uma imagem para cada olho de modo separado. Para isso, as principais abordagens são: por meio de duas visões, head tracking e multivisões (UREY et al., 2011). Estes métodos estão fora do escopo do trabalho e são apresentados de modo sucinto. Mais detalhes podem ser encontrados em Urey et al. (2011) e Dodgson (2005).

Métodos de duas visões podem funcionar de duas maneiras: por barreira de paralaxe ou por folhas lenticulares. No lado esquerdo da Figura 15 são apresentadas as folhas lenticulares, que por meio de diversas lentes convexas, verticalmente alinhadas, fazem com que as luzes sejam direcionadas aos olhos corretos. Já na imagem da direita é exemplificado o funcionamento das barreiras de paralaxe, em que a luz do pixel indesejado para um determinado olho é bloqueada por uma barreira opaca.

3 https://www.dell.com/en-us/shop/accessories/apd/536-bbcd. Acesso em: 17/03/2019. 
Figura 15 - Autoestereoscopia por folhas lenticulares à esquerda e barreira de paralaxe à direita.
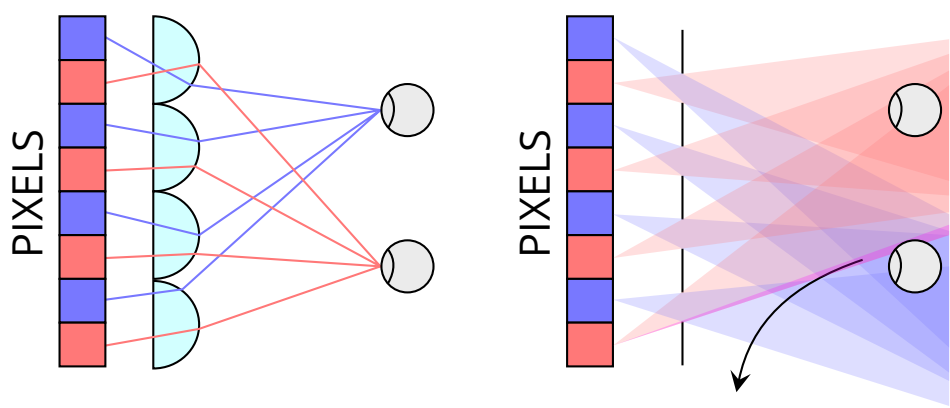

CROSSTALK

Fonte: Adaptada de Dodgson (2005).

O método de head tracking faz o rastreamento da posição em que a cabeça do visualizador está, emitindo assim a imagem correta para cada um dos olhos, possibilitando que as zonas de visualização sejam trocadas caso o visualizador mude a posição da cabeça. Problemas com esse método podem surgir quando a diferença de distância entre os olhos difere da esperada.

Os métodos multivisão fazem uso de várias imagens, logo, para cada posição em que o visualizador se encontra, são apresentadas visões distintas. Um dos maiores problemas deste método é a dificuldade de gerar e exibir tal conteúdo, uma vez que diversas imagens podem ser geradas em simultâneo, mesmo que ninguém as esteja visualizando.

\subsubsection{Comparação entre Métodos}

Os benefícios e limitações apresentados para cada um dos métodos de visualização estereoscópica permitem compará-los segundo alguns critérios básicos. O Quadro 1 resume os métodos de acordo com a qualidade visual das imagens, o custo de implementação e a quantidade de informação necessária para exibição das imagens, considerando o par estereoscópico como contendo $100 \%$ de informação, que seria equivalente à quantidade de informação recebida pelos olhos de um ser humano (duas imagens com informação completa).

Quadro 1 - Comparação entre métodos de visualização estereoscópica

\begin{tabular}{|l|l|l|l|}
\hline Método de Visualização & Qualidade Visual & Custo/Preço & Qtd. Informação \\
\hline Multiplexação por Cor & Baixa & Muito Baixo & $50 \%$ \\
\hline Multiplexação por Polarização & Alta & Baixo & $100 \%$ \\
\hline Multiplexação Temporal & Alta & Baixo & $100 \%$ \\
\hline Head Mounted Display & Muito Alta & Alto & $100 \%$ \\
\hline Autoestereoscopia & Alta & Muito Alto & $100 \%$ ou + \\
\hline
\end{tabular}

Fonte: Dados da pesquisa.

A multiplexação por cor apresenta qualidade baixa de visualização devido ao fato de cada um dos olhos receber apenas parte das informações de uma imagem, tornando a sua 
visualização incômoda para o usuário; porém, o custo de implementação é muito baixo, já que não necessita de dispositivos extras para visualização, exceto os óculos. A multiplexação por polarização e multiplexação temporal apresentam qualidade de visualização alta pois enviam todas as cores para os dois lados, porém ainda contêm crosstalk devido aos polarizadores e aos obturadores, respectivamente. Já com relação ao preço, são considerados de baixo custo, mesmo os óculos da multiplexação temporal sendo ligeiramente mais caros. Os HMDs possuem qualidade visual muito alta, uma vez que não existe a presença do crosstalk, porém seu custo ainda é considerado alto, mesmo com a existência de modelos mais acessíveis. Vale lembrar que é necessário um HMD para cada usuário. Por fim, os métodos autoestereoscópicos apresentam alta qualidade visual, porém possuem custo muito alto, e no caso dos métodos multivisão, necessitam de muitos ângulos diferentes de exibição.

\subsection{Considerações Finais}

Diversos conceitos relacionados à estereoscopia e percepção humana foram apresentados neste capítulo, além dos métodos existentes para a percepção humana de profundidade. As informações apresentadas nesse capítulo reforçam a ideia de que a recuperação dos canais de cores do anáglifo é algo interessante, pois apesar de serem considerados de qualidade baixa, os anáglifos ocupam apenas metade do volume de dados de um par estéreo. Além disso, o processo de reversão anaglífica possibilita a utilização de outros métodos de separação/visualização de imagens estéreoscópicas (exceto para multivisão) e no formato 2D convencional, utilizando toda qualidade e informação visual que o par estéreo proporciona. O próximo capítulo abordará os principais trabalhos voltados à reversão anaglífica e respectivas técnicas. 
CAPÍTULO
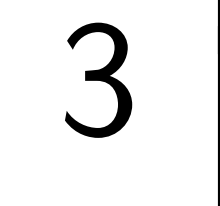

\section{REVERSÃO ANAGLÍFICA}

A reversão anaglífica pode ser definida como a reconstrução aproximada dos canais eliminados durante a geração do anáglifo, gerando assim, o par estéreo. O processo de reversão anaglífica consiste em utilizar como entrada uma única imagem, na qual dois dos canais de cores representam uma das imagens do par estéreo original e o terceiro canal representa a segunda imagem, e produzir como saída duas imagens completas, possuindo três canais de cores distintos. Esse processo é exemplificado na Figura 16, para codificação de cor RGB e modelo de anáglifo vermelho/ciano, em que o anáglifo composto pelos canais $R_{2}, G_{1}, B_{1}$ é processado, gerando as aproximações do par estéreo original. Considerando a imagem original da esquerda como $R_{1}, G_{1}, B_{1}$ e a original da direita como $R_{2}, G_{2}, B_{2}$, são geradas as imagens $R_{1}^{\prime}, G_{1}, B_{1}$ e $R_{2}, G_{2}^{\prime}, B_{2}^{\prime}$, aproximadas da esquerda e direita, respectivamente.

Figura 16 - Funcionamento geral da geração do par estéreo a partir do anáglifo.

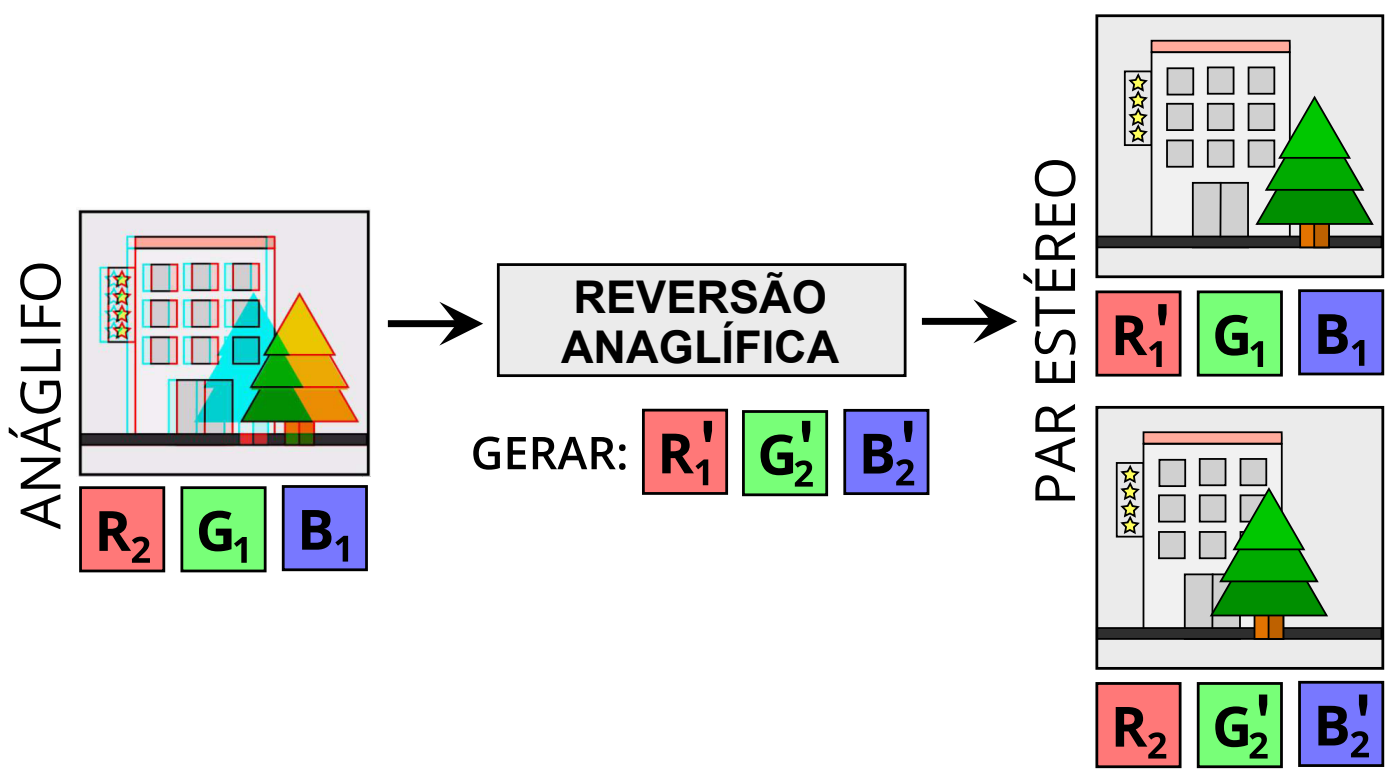

Fonte: Elaborada pelo autor. 
A reversão anaglífica não é um processo trivial. Para reconstruir cada pixel de $R_{1}^{\prime}$ é necessário navegar horizontalmente na componente $R_{2}$ procurando por uma cor adequada para $\mathrm{o}$ pixel que está sendo reconstruído. $\mathrm{O}$ mesmo processo ocorre para a reconstrução das componentes $G_{2}^{\prime}$ e $B_{2}^{\prime}$, porém navegando em $G_{1}$ e/ou $B_{2}$. Este processo de encontrar pixels correspondentes no lado complementar será chamado, ao decorrer desta dissertação, de alinhamento do pixel.

A disparidade de pixels, ilustrada na Figura 17, varia de acordo com o processo de captura do par estéreo (conforme explicado no Capítulo 2), o que dificulta o processo de alinhamento durante a reversão anaglífica. Além disso, em alguns casos, é necessária uma etapa final de colorização de regiões oclusas da imagem, ou seja, de regiões de uma imagem do par estéreo para as quais não há correspondência na imagem complementar, principalmente por um objeto aparecer na frente de outro e ocultar parte da cena para um dos lados do par estéreo. Em alguns algoritmos, metadados são armazenados, possibilitando a recuperação de tais regiões, sem a utilização de métodos de colorização.

Figura 17 - Imagem anaglífica que representa a disparidade entre os pixels correspondentes.

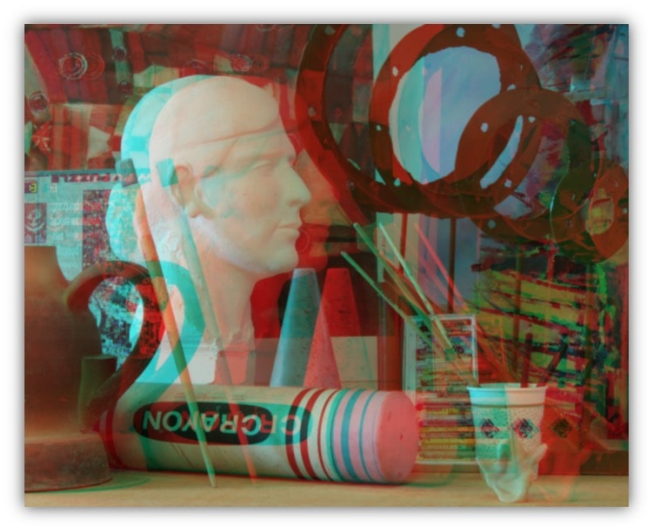

Fonte: Pal et al. (2007).

É relevante mencionar que não existe um modelo ideal para realizar a reversão anaglífica, sempre havendo perdas, e a quantidade de informação perdida é totalmente dependente da cena. Considere, por exemplo, um caso simples, em que as imagens estão em escala de cinza, ou seja, sempre o canal vermelho será igual aos canais verde e azul; assim, para recuperar as duas imagens do par estéreo, considerando o anáglifo vermelho/ciano, é necessário apenas replicar os valores do canal vermelho. Já em um cenário mais complexo, de imagens coloridas com muitas regiões oclusas, com cores distintas das existentes nas regiões não oclusas e variando muito drasticamente, é impossível recuperar tais dados, pois pode haver 256 cores para completar cada pixel do canal vermelho e $65.536\left(256^{2}\right)$ combinações para completar cada pixel do lado ciano (verde e azul).

Um outro aspecto que pode afetar a qualidade dos resultados da reversão anaglífica é o formato de codificação do anáglifo. Formatos que envolvem compressão com perdas, tais como JPEG, podem danificar a imagem pois, empiricamente, transformadas como a Discrete Cosine Transform (DCT) podem gerar o efeito de ghosting, visualizado quando os canais de cores são 
separados (DIETZ, 2012). O efeito de ghosting tende a gerar artefatos na imagem que afetam o processo de reversão anaglífica, mais especificamente o processo de alinhamento, que por sua vez tende a gerar mais correspondências incorretas. Portanto, é fortemente recomendada a utilização de formatos de codificação sem perdas, como o PNG ou o BMP, pois preservam a qualidade das imagens anaglíficas.

Além do problema com o formato das imagens, é interessante notar que apesar do embasamento conceitual de anáglifos indicar haver apenas o deslocamento longitudinal entre imagens do par estéreo original e entre componentes do anáglifo, essas imagens também podem apresentar deslocamentos verticais, principalmente imagens encontradas na Web.

O deslocamento vertical ocorre, possivelmente, em razão da maneira com que as imagens originais são capturadas. Quando a captura do par estéreo é realizada com o equipamento adequado, como a câmera ilustrada na Figura 1 do Capítulo 1, o deslocamento vertical não ocorre. Porém, quando são utilizadas duas câmeras comuns para captura do par, o desalinhamento vertical das câmeras pode gerar o deslocamento vertical nas imagens resultantes.

Em suma, o processo de reversão anaglífica tem como principais desafios o tratamento de deslocamentos horizontal e vertical, o impacto do formato de codificação das imagens, além das características de cor da imagem e a existência de regiões oclusas. Outro aspecto relevante para muitos domínios de aplicação é o tempo de processamento. Os principais trabalhos que propõem soluções para reversão anaglífica são apresentados nas seções seguintes, incluindo discussões sobre o foco de cada uma dessas soluções, bem como aspectos positivos e negativos.

\subsection{RevGlyph e HaarGlyph}

Zingarelli, Andrade e Goularte (2011) propõem uma técnica de codificação anaglífica nomeada RevGliph, como meio de obter compressão de imagens estereoscópicas e possibilitar a independência de visualização. Essa proposta, apesar de conseguir bons níveis de compressão, necessita de um processo de codificação, que faz uso das duas imagens do par estereoscópico original, gerando o anáglifo e metadados associados, que são utilizados para realizar a posterior descompressão. O processo executado para a codificação do anáglifo é exemplificado na Figura 18 (blocos cinza contínuos). O primeiro passo da técnica é gerar os anáglifos que serão chamados de principal e complementar. Considerando a primeira imagem do par estéreo contendo os canais vermelho, verde e azul $(R 1, G 1, B 1)$ e a segunda imagem $(R 2, G 2, B 2)$, são gerados os 2 anáglifos possíveis, o anáglifo principal $(R 2, G 1, B 2)$ e o anáglifo complementar $(R 1, G 2, B 1)$.

O segundo passo no processo é realizar a conversão das imagens geradas do espaço RGB para o YCbCr. O espaço de cores YCbCr contém a componente acromática Y, que representa a luminosidade, e os canais de crominância $\mathrm{Cb}$ e $\mathrm{Cr}$. A conversão do formato RGB para o $\mathrm{YCbCr}$ pode ser feito por meio de combinação linear do espaço RGB. Uma combinação linear 
Figura 18 - Algoritmo RevGliph e extensão HaaRGliph.

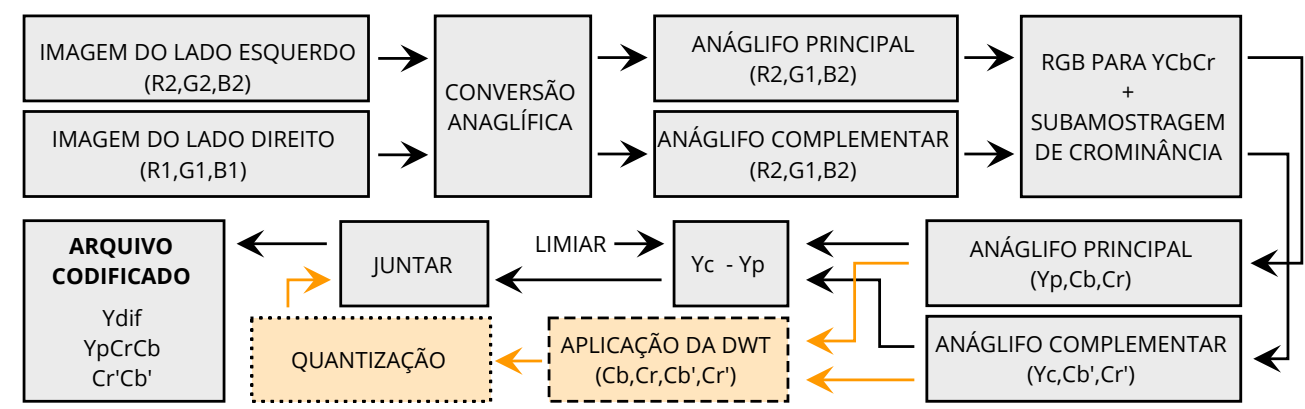

Fonte: Adaptada de Zingarelli, Andrade e Goularte (2011).

diferente é executada para retornar do YCbCr para o espaço RGB. Por meio de um processo conhecido como subamostragem de crominância, parte das informações de crominância $(\mathrm{Cb}$ e Cr) são eliminadas, em ambas as imagens (principal e complementar). Os valores restantes são armazenados como metadados.

Por fim, utilizando-se das características dos anáglifos, em que a diferença da luminosidade do anáglifo complementar e do principal são similares, é feita uma compressão agrupando elementos adjacentes que estão dentro de um determinado limiar, por meio de processo similar ao Run-lenght Encoding (RLE). Ao final, as componentes de crominância ( $\mathrm{Cr}$ e $\mathrm{Cb}$ ), de ambas as imagens (principal e complementar), a diferença de luminosidade comprimida, e a luminância original da imagem principal são armazenadas. Quando necessário recuperar o par estéreo, o processo inverso da compressão é executado.

Em um trabalho posterior, Rodrigues, Yugoshi e Goularte (2016) propuseram o HaaRGliph, que utiliza como base o trabalho de Zingarelli, Andrade e Goularte (2011) e, por meio da Discrete Wavelet Transform aplicada nos canais de crominância, consegue atingir maiores taxas de compressão, adicionando os passos indicados pelos blocos amarelos pontilhados da Figura 18. Apesar de gerarem resultados de qualidade, as técnicas não partem de um anáglifo, mas sim do par estéreo, o que permite o uso de metadados para posterior reversão do anáglifo gerado.

\subsection{Extracting Depth and Matte Using a Color-filtered Aperture}

O primeiro trabalho, de conhecimento do autor desta monografia, proposto com o intuito de realizar a reversão do anáglifo sem nenhuma imagem complementar ou metadado associado, é o de Bando, Chen e Nishita (2008). Apesar de ter como objetivo final separar o plano dos objetos que estão ao fundo dos que estão à frente, a técnica proposta gera como resultado intermediário um mapa de profundidade (Seção 2.2), que contém grande parte das informações necessárias para o processo de reversão anaglífica, já que provê informações de alinhamento dos pixels. 
A principal ideia do algoritmo é utilizar a correlação natural entre as cores para executar o alinhamento. Um outro ponto importante a destacar é que são utilizados anáglifos gerados de forma não convencional, por meio da adaptação da lente de uma câmera comum, adicionando filtros de cores RGB, permitindo que a profundidade possa ser capturada. A Figura 19 ilustra o modelo adotado para a geração dos anáglifos. Devido à posição em que os filtros estão dispostos, três imagens são geradas como saída, sendo elas $I_{r}, l_{g}$ e $l_{b}$, respectivamente para vermelho, verde e azul. Para $I_{r}$ é necessário encontrar a posição $I_{r}(x+d i s p, y)$ que melhor se adéque à posição $(x, y)$, com disp representando a disparidade para o pixel correspondente. Para $I_{g}$ é necessário encontrar a posição $I_{g}(x, y-d i s p)$, e para $l_{b}$ a posição $l_{b}(x-d i s p, y)$.

Figura 19 - Captura de anáglifos, utilizando três filtros de cor em câmeras convencionais, proposta por Bando, Chen e Nishita (2008).

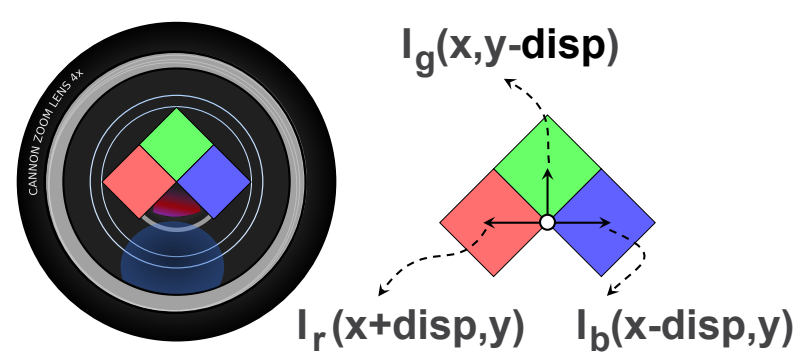

Fonte: Adaptada de Bando, Chen e Nishita (2008).

Para cada um dos pixels da imagem, a disparidade disp é variada para encontrar o pixel mais adequado, tendo $0<$ disp $<\mathscr{L}$, em que disp é a disparidade máxima permitida. O cálculo para determinar o quão adequado é a disparidade é realizado para blocos quadrados, de lado igual a 15, com centro no pixel em análise.

A medida de qualidade de alinhamento de um pixel para uma determinada posição $x, y$ em uma disparidade disp é dada pela Equação 3.1, que gera um valor único, indicando o quão adequado é esta disparidade disp para o pixel $p$. Os valores de $\delta_{0}, \delta_{1}$, e $\delta_{2}$ representam os autovalores da matriz de covariância da distribuição de cor. A matriz de covariância é mostrada pela Equação 3.3, sendo cada célula computada pela Equação 3.2, em que Color $r_{a}$ e Color $_{b}$ representam combinações para $\mathrm{R}, \mathrm{G}$ e B. Os valores $\sigma_{r}, \sigma_{g}$, e $\sigma_{b}$ são os elementos da diagonal principal da matriz de covariância, uma vez que $\sigma_{\text {Color }_{a}}^{2}=\sigma\left(\right.$ Color $_{a}$, Color $\left._{a}\right)$. Quanto menor o valor de $L(x, y ;$ dis $p)$, mais correlacionado é o espaço das cores, indicando um candidato de disparidade adequado.

$$
\begin{gathered}
L(x, y ; d)=\delta_{0} \delta_{1} \delta_{2} / \sigma_{r}^{2} \sigma_{g}^{2} \sigma_{b}^{2} \\
\sigma\left(\text { Color }_{a}, \text { Color }_{b}\right)=\frac{\sum_{i=1}^{n}\left(\text { Color }_{a_{i}}-\overline{\text { Color }_{a}}\right)\left(\text { Color }_{b_{i}}-\overline{\text { Color }_{b}}\right)}{n-1}
\end{gathered}
$$




$$
M \operatorname{Cov}=\left[\begin{array}{lll}
\sigma(r, r) & \sigma(r, g) & \sigma(r, b) \\
\sigma(g, r) & \sigma(y, g) & \sigma(g, b) \\
\sigma(b, r) & \sigma(b, g) & \sigma(z, b)
\end{array}\right]
$$

A Figura 20 ilustra a distribuição dos pontos para as disparidades (disp) iguais a 0,1,3 e 5, respectivamente. É possível observar que a disparidade disp $=0$ possui um alongamento maior do que as demais disparidades, o que é comprovado pelo valor de $L$. Assim, o melhor alinhamento para este pixel $p=(x, y)$ é igual a $d i s p=0$. Tal processo é executado para todos os pontos da imagem, gerando um mapa de profundidade.

Figura 20 - Distribuição dos pontos, para cada uma das disparidades.

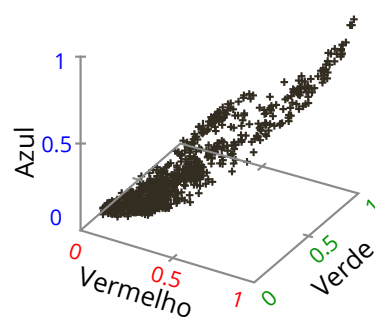

$\operatorname{disp}=0 / L=0.003$

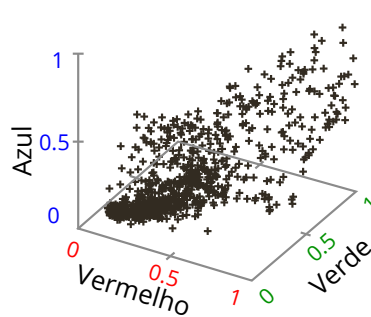

$\operatorname{disp}=1 / L=0.011$

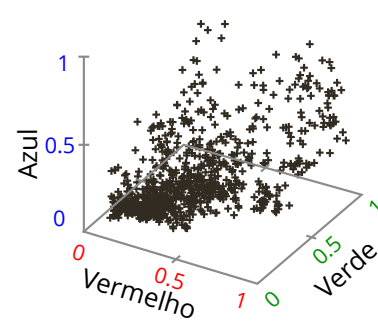

$\operatorname{disp}=3 / L=0.39$

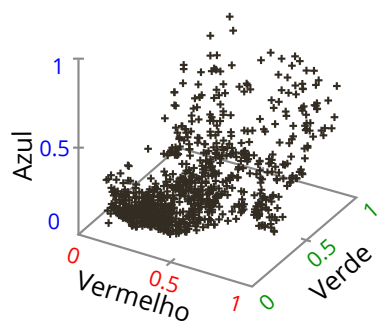

$\operatorname{disp}=5 / L=0.54$

Fonte: Adaptada de Bando, Chen e Nishita (2008).

Apesar da técnica proposta por Bando, Chen e Nishita (2008) funcionar bem para imagens geradas com uma única lente, não obtém bons resultados para disparidades maiores, capturadas a partir de duas lentes.

\subsection{Reprocessing Anaglyph Images}

Assim como o processo de captura proposta por Bando, Chen e Nishita (2008), Dietz (2012) também propõe uma forma de modificar câmeras convencionais para captura de anáglifos com baixo custo. Ao invés de criar três divisões na lente, Dietz (2012) utiliza apenas duas divisões, separadas horizontalmente, assim como ilustrado pela Figura 21.

Segundo Dietz (2012), uma imagem em que o efeito de blur foi aplicado é muito similar a uma imagem em anáglifo, e assim como na imagem com blur, é possível reverter o processo por meio da aplicação de funções de deconvolução. Assim, Dietz (2012) aplica uma deconvolução para recuperar uma aproximação do par estéreo original. Apesar de ser um dos primeiros trabalhos a tratar a reversão anaglífica, obtendo resultados visualmente interessantes, a metodologia de como o processo foi realizado não está clara no trabalho apresentado na literatura. Além disso, resultados apresentados não incluem medidas de qualidade, nem objetivas e nem subjetivas, e as imagens mostradas apresentam mudanças perceptíveis na tonalidade de cor da cena, em relação ao par estéreo original. 
Figura 21 - Captura de anáglifos, utilizando dois filtros de cor em câmeras convencionais, proposta por Dietz (2012).

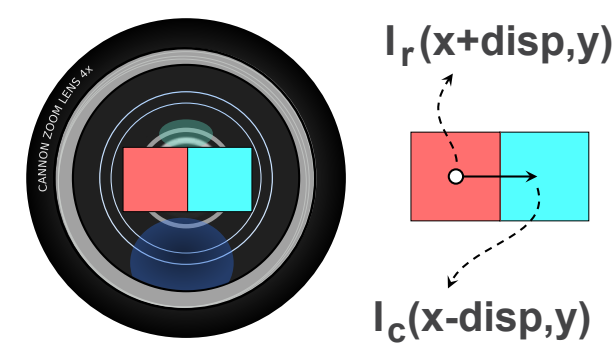

Fonte: Adaptada de Dietz (2012).

\subsection{Recovering Stereo Pair from Anaglyphs}

Joulin e Kang (2013) propõem o algoritmo Anaglyph SIFT (ASIFT), que é baseado no algoritmo SIFT-Flow, de Liu, Yuen e Torralba (2011), voltado para o alinhamento de cenas. O ASIFT, assim como o SIFT-Flow, utiliza adaptações do algoritmo SIFT (LOWE, 1999). O SIFT realiza a extração de descritores para uma imagem, sendo um algoritmo classificado como invariante à escala, translação, rotação e parcialmente invariante à luminosidade, ou seja, objetos similares na imagem tendem a serem detectados mesmo quando ocorrem estas variações. Os descritores representam um determinado pixel da imagem, portanto é possível realizar o matching entre descritores, utilizando técnicas como nearest-neighbour, para encontrar as correspondências entre pixels.

Como no anáglifo não há rotação, translação ou escala para objetos correspondentes, havendo apenas o deslocamento horizontal entre as cenas, para o algoritmo ASIFT (assim como o SIFT-Flow), foi adotada apenas a representação do descritor SIFT. Cada um dos pixels é descrito por uma janela fixa de $16 \times 16$ (Figura 22a) em ambos os trabalhos. O gradiente, com relação a cada um dos pixels desta grade, é computado (Figura 22b). Então uma divisão em blocos $4 \times 4$ é executada para a janela $16 \times 16$, gerando sub-blocos que são processados individualmente. Um histograma de 8 bins é criado a partir do sub-bloco, em que cada posição indica um ângulo, representando a magnitude do gradiente computado (Figura 22c) para o bloco $4 \times 4$. Todos os conjuntos de bins gerados para os sub-blocos são concatenados, gerando um vetor de 128 dimensões (Figura 22d).

O principal problema na recuperação do par estéreo a partir do anáglifo é a diferença de tonalidade entre os canais de cores (DIETZ, 2012). O ASIFT-flow é capaz de identificar estas diferenças por ser um algoritmo derivado do SIFT, que é invariante a luminosidade. Diferente do algoritmo SIFT-Flow, que mapeiam toda a imagem, o ASIFT trabalha apenas em uma região retangular $w / 12 \times w$, com $w$ igual a largura da imagem, considerando a predominância do deslocamento vertical. Após extrair as características SIFT para os pixels, o alinhamento é realizado por meio da minimização da função apresentada pela Equação 3.4. 
Figura 22 - Descritor de característica utilizando algoritmo SIFT, com bloco quadrado de lado 16.

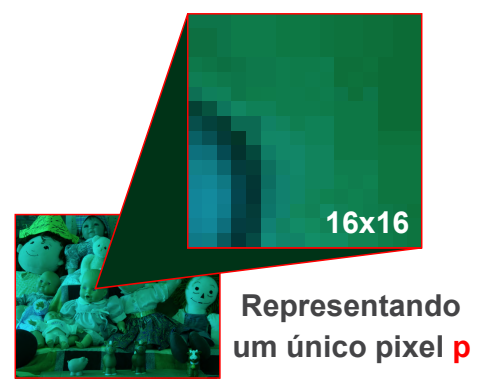

(a) Região de 16x16 utilizada para descrever o pixel $p$.

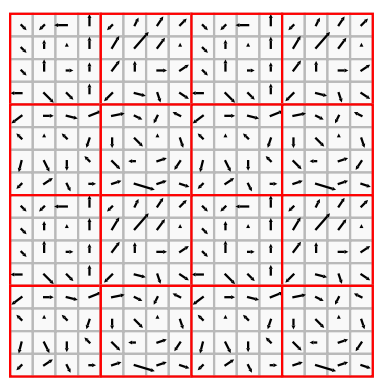

(b) Extração dos gradientes.

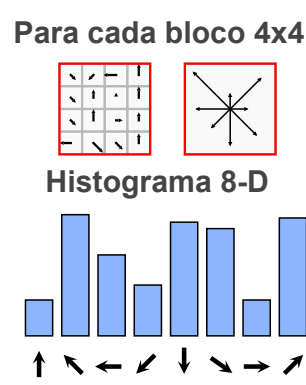

(c) Histograma das magnitudes dos gradientes.

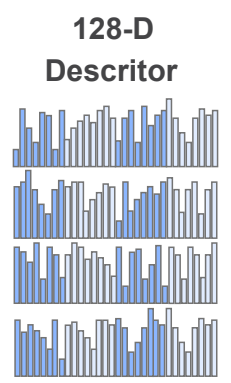

(d) Descritor do pixel $p$.

Fonte: Elaborada pelo autor.

$$
\begin{aligned}
E_{S F}= & \sum_{p \in E}\left\|S_{E}(p)-S_{D}(p+\operatorname{disp}(p))\right\|_{1}+\frac{1}{\sigma^{2}} \sum_{p}\|\operatorname{disp}(p)\|_{2}+ \\
& \sum_{p} \sum_{q \in N_{p}} \min \left(\alpha\left|\operatorname{disp}_{x}(p)-\operatorname{disp}_{x}(q)\right|, t_{x}\right)+\min \left(\alpha\left|\operatorname{disp}_{y}(p)-\operatorname{disp}_{y}(q)\right|, t_{y}\right)
\end{aligned}
$$

As funções de minimização de energia podem ser divididas em duas partes, a primeira é com relação ao custo do dado, que leva em consideração apenas o alinhamento do pixel $p$ em questão, ignorando os resultados de alinhamento dos pixels vizinhos. Já a segunda parte da função diz respeito ao termo de suavização, em que os resultados apresentados pelos alinhamentos dos pixels vizinhos são levados em consideração. O primeiro somatório da Equação 3.4 diz respeito ao custo do dado, indicando o quão apropriado é a disparidade $\operatorname{dis} p(p)$ para o pixel $p$, comparando as características SIFT do pixel $p$ do lado esquerdo $\left(S_{E}(p)\right)$ com a característica SIFT do pixel $p+\operatorname{dis} p(p)$ do lado direito $\left(S_{D}(p)\right)$. O segundo somatório, ainda relativo ao custo de dado, diz respeito ao termo de deslocamento dos pixels, para o qual deslocamentos grandes são penalizados. Por fim é apresentado o termo de suavização, em que $N_{p}$ é a vizinhança do pixel $p$, onde $\operatorname{dis} p(p)=\left(\operatorname{dis}_{x}(p), \operatorname{dis} p_{y}(p)\right)$, relativo ao deslocamento para o eixo $x$ e para o eixo $y$. Os valores de $\sigma, \alpha, t_{x}$ e $t_{y}$ são constantes do algoritmo proposto. O principal objetivo é minimizar o valor da equação, encontrando os deslocamentos mais adequados, levando em consideração todos os pixels e as relações entre si. Observe que a complexidade para encontrar o mínimo global é de $\mathscr{L}^{w * h}$, com $w$ e $h$ indicando, respectivamente, a largura e altura da imagem, e $\mathscr{L}$ a quantidade de disparidades possíveis. Assim, de modo a encontrar uma solução em tempo polinomial, existem algoritmos de otimização que encontram um mínimo local. Para minimização de energia da Equação 3.4, foi utilizado o algoritmo de Loopy Belief Propagation (LBP) (MURPHY; WEISS; JORDAN, 1999), que reduz a complexidade para $\mathscr{O}\left(I * w * h * \mathscr{L}^{2}\right)$. Internamente ao algoritmo LBP existe a passagem de mensagem, que ocorre de um pixel para seu vizinho imediato. Cada passagem de mensagem do algoritmo possui complexidade $\mathscr{O}\left(\mathscr{L}^{2}\right)$ (LIU; YUEN; TORRALBA, 2011), sendo executado para cada um dos pixels da imagem, $I$ 
vezes.

Após executar o alinhamento inicial por meio da minimização de energia, é realizado o refinamento por meio da consistência estéreo, em que as disparidades apresentadas em um lado da imagem devem ser aproximadamente as opostas das encontradas no lado complementar. Portanto, espera-se que $M_{R}(\operatorname{dis} p(p))=M_{L}(d(p+\operatorname{dis} p(p)))$, com $M_{R}$ e $M_{L}$ sendo as matrizes que armazenam as disparidades para o lado direito e esquerdo, respectivamente. Como imprecisões podem ocorrer, é adotado um threshold de $5 \times 2$ (5 para o eixo $x$ e 2 para o eixo $y$ ). Por exemplo, uma correspondência para o pixel na coordenada $x, y$ da imagem da direita é encontrada na imagem da esquerda com distância $8 \times 2$ (pixel $x+8, y+2$ ), e a da esquerda, para o pixel $x+8, y+2$ encontrou uma correspondência na imagem da direita com distância $-6 \mathrm{x},-1 \mathrm{y}$. Isso significa que o alinhamento é válido, pois $8+(-6) \leq 5$ e $2+(-1) \leq 2$.

Também é realizada a verificação das características geradas, em que são utilizados os descritores SIFT como base das comparações. Para que a correspondência seja considerada adequada, a distância entre as características SIFT deve ser menor que um limiar $t_{s}$. Ao final é realizada uma verificação com relação a textura, sendo necessário que as duas características SIFT sejam de baixa textura, ou ambas altas, também sendo adotado um limiar para definir o que é uma região de baixa/alta textura.

Todos os pixels que não atendem ao menos uma das três verificações de consistência, são eliminados. As cores que restaram no processo (cores corretas) são chamadas de cores âncoras, e são utilizadas para realizar o processo de colorização dos pixels eliminados. $\mathrm{O}$ algoritmo utilizado para recolorir os pixels remanescentes é o de Levin, Lischinski e Weiss (2004), que será discutido na Seção 3.6. Por fim, é realizado um processamento para evitar que cores incompatíveis apareçam na imagem, tendo como base o princípio de que regiões oclusas não gerarão cores diferentes das existentes em regiões não oclusas.

Após aplicar o ASIFT-Flow, resultados intermediários estão disponíveis, com ambas as imagens recuperadas e os canais alinhados. Então é aplicado um processo de refinamento por meio do algoritmo de fluxo óptico de Lucas-Kanade (LUCAS; KANADE, 1981) entre as duas imagens recuperadas. Observe que os erros resultantes da etapa em que o ASIFT-Flow foi aplicado também são enviados para o algoritmo de fluxo óptico. $\mathrm{O}$ algoritmo de fluxo óptico é comumente executado para vídeos, criando vetores de movimentos para os objetos da cena, por meio da comparação entre os quadros do vídeo. O mesmo ocorre no algoritmo ASIFT-Flow, porém ao invés de quadros de vídeo, são utilizados os pares recuperados (resultado intermediário), refinando o alinhamento realizado com os descritores SIFT. Observe que o algoritmo de fluxo óptico tem complexidade $\mathscr{O}\left(n^{2} * N+n^{3}\right)$ (LUCAS; KANADE, 1981), com $n$ representando o número de dimensões e $N$ representando o número de pixels da imagem. Após executar o algoritmo de fluxo óptico, as três verificações de integridade dos pixels são re-executadas, e ao fim o pixel é novamente colorizado, gerando o resultado final.

Apesar de ser um método que apresenta resultados visuais razoáveis, a técnica de Joulin 
e Kang (2013) mostrou-se lenta não somente devido a utilização do algoritmo ASIFT-Flow, mas também do algoritmo de fluxo óptico, convertendo imagens de baixa resolução (640x480) em tempos relativamente altos ( $4 \sim 10$ minutos), segundo os autores.

Roo e Richardt (2014) propõem um método para a recuperação de vídeos anáglifos, de maneira muito similar ao processo utilizado por Joulin e Kang (2013), também baseando-se no algoritmo SIFT-Flow para encontrar as correspondências entre as cenas. Porém, o método faz uso de uma técnica de transformação do domínio, criada por Gastal e Oliveira (2011), que é um algoritmo de suavização de imagem que mantém as bordas da imagem, sendo possível recolorir regiões oclusas, além de ser utilizado para os quadros subsequentes. Além disso, também é feito uso da coerência temporal, que leva em conta a relação existente entre os quadros do vídeo. $\mathrm{O}$ trabalho consegue obter tempos de conversão baixos em relação aos apresentados por Joulin e Kang (2013), porém só é aplicável a vídeos, já que a utilização da coerência temporal exige maior quantidade de dados, impedindo a sua aplicabilidade a imagens.

\subsection{Depth Map Estimation and Colorization of Anaglyph Images Using Local Color Prior and Reverse Intensity Distribution}

Seguindo a mesma linha de minimização de energia, Williem, Raskar e Park (2015) propõe um algoritmo baseado em minimização de energia no MAP-MRF framework (BOYKOV; VEKSLER; ZABIH, 2001), que consiste em utilizar grafos não direcionados para resolver problemas de minimização de energia, utilizado por exemplo por Boykov, Veksler e Zabih (2001), explicado brevemente adiante. A função que se deseja minimizar é dada pela Equação 3.5.

$$
E(f)=\sum_{p} D_{p}\left(f_{p}\right)+\sum_{p} \sum_{q \in N_{p}} V_{p q}\left(f_{p}, f_{q}\right)
$$

O primeiro termo da equação $\left(D_{p}\left(f_{p}\right)\right)$, é o custo do dado, descrito na Seção 3.4 , indicando o quão apropriada é a disparidade $f_{p}$ (correspndente a disp para as demais técnicas) para o pixel $p$. Já o segundo termo da equação $\left(V_{p q}\right)$ indica o quão consistente é o termo para o pixel $p$ em relação aos vizinhos. Para o algoritmo de Williem, Raskar e Park (2015), o custo de suavização adotado é baseado na fórmula $\alpha \min \left(\left|f_{p}-f_{q}\right|, V \max \right)$, em que $\alpha$ e Vmax são constantes. Observe que para iniciar o algoritmo de otimização é necessário enviar todos os custos de dado possíveis. Assim, para cada pixel da imagem, são realizados dMax cálculos de custo. O cálculo de custo é dado pela Equação 3.6.

$$
D_{p}\left(f_{p}\right)=D_{p}^{L C}\left(f_{p}\right)+D_{p}^{R I D}\left(f_{p}\right)+D_{p}^{S E G}\left(f_{p}\right)
$$


Cada termo do custo de dado é calculado utilizando uma janela quadrada, de tamanho $\beta$ ao redor do pixel. Para o termo $D_{p}^{L C}$ é criada uma pseudo-intensidade com base na média e desvio padrão para os blocos do lado alvo e o lado origem (móvel). Essa pseudo-intensidade é criada com base na distância do pixel central da janela em relação aos seus vizinhos, e também em relação à diferença de cor. Assim, quanto menor for a diferença entre as pseudo-intensidades do lado direito e esquerdo, menor o valor de $D_{p}^{L C}$. Já o termo $D_{p}^{R I D}\left(f_{p}\right)$, que intitula o trabalho, é calculado com base na relação de cor existente entre o pixel $p$ (central) e os seus vizinhos, gerando duas matrizes binárias, em que cada posição indica se o pixel é mais claro ou escuro que o central. A Figura 23 exemplifica o processo para uma disparidade igual a $20 \mathrm{em}$ um pixel $p$ qualquer.

Para a imagem pivô (em vermelho), originalmente com dimensões $19 \times 19$ (aumentado para melhor entendimento), é gerada uma máscara $\left(C_{r}\right)$ com base no pixel central. Supondo que o pixel central tenha intensidade de vermelho igual a 150, todos os pixels que possuem intensidade superior a 150 pertencem ao grupo mais claro (1), e os inferiores pertencem ao grupo mais escuro (0). Já para o lado complementar, tomando como exemplo a disparidade 20, são geradas duas máscaras $\left(C_{g}^{\prime}\right.$ e $\left.C_{b}^{\prime}\right)$, que são computadas individualmente, da mesma forma que o lado vermelho. Com base nestas três máscaras, é gerada uma máscara complementar para o lado vermelho $\left(\overline{C_{r}}\right)$, em que os valores 0 e 1 são negados em relação à máscara $C_{r}$. Então são computadas as distâncias $C_{r}-C_{g}^{\prime}, \overline{C_{r}}-C_{g}^{\prime}, C_{r}-C_{b}^{\prime}$ e $\overline{C_{r}}-C_{b}^{\prime}$. A menor distância (41 segundo o exemplo) é selecionada como resultado para $D_{p}^{R I D}(20)$.

Figura 23 - Funcionamento do cálculo de custo para $D_{p}^{R I D}\left(f_{p}\right)$. Originalmente os patches possuem tamanho $19 \times 19$, mas foram ampliados para melhor compreensão.

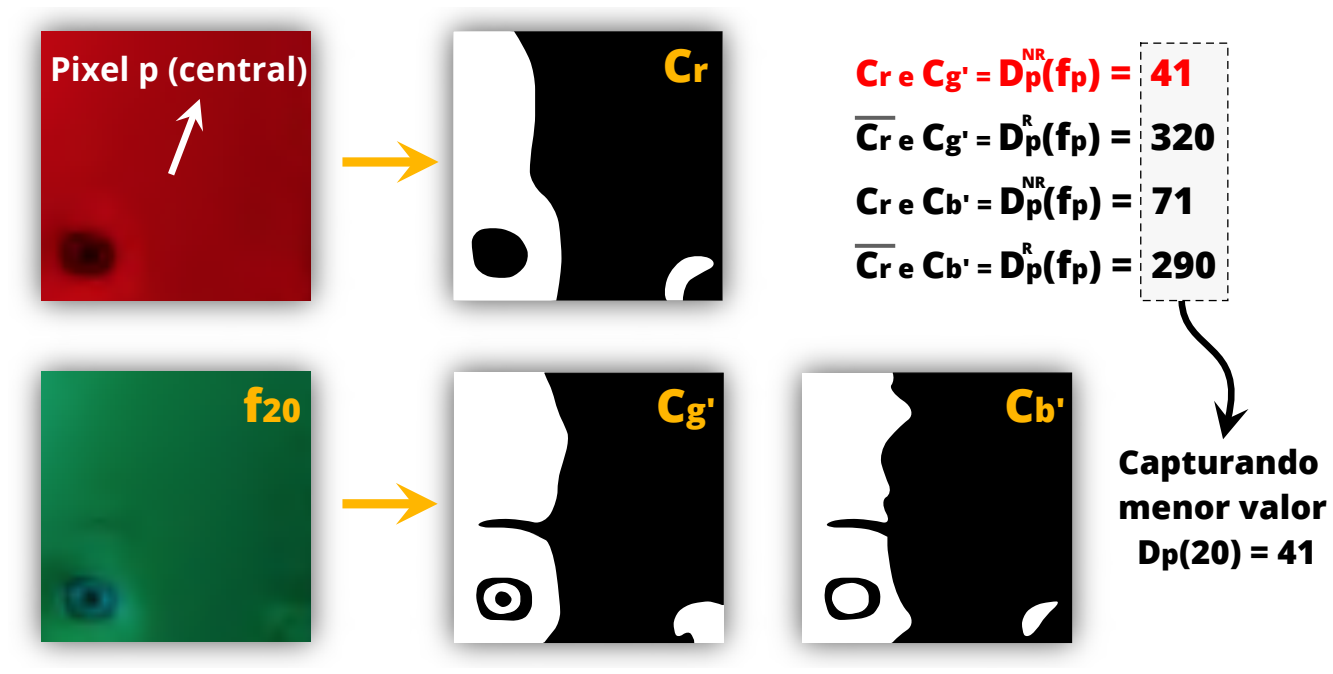

Fonte: Elaborada pelo autor.

Para o cálculo do último termo do custo de dado $\left(D_{p}^{S E G}\left(f_{p}\right)\right)$, é realizada a segmentação por meio do algoritmo mean-shift. Para cada um dos segmentos gerados, é extraída uma equação que descreve o plano 3D ao qual o objeto contido pertence. Note que a técnica de plane-fitting assume único plano para todo o segmento. Ao final, 3 coeficientes são gerados, e a Equação 3.7 
é aplicada. $D_{p}^{S E G}\left(f_{p}\right)=a_{s} x_{p}+b_{s} y_{p}+c_{s}$ representa o plano, que possui valor igual à disparidade encontrada. Portanto, é realizada a subtração da disparidade para o cálculo de custo da mesma, computando o erro para o plano encontrado.

$$
D_{p}^{S E G}\left(f_{p}\right)=\left|a_{s} x_{p}+b_{s} y_{p}+c_{s}-f_{p}\right|
$$

Após definir os custos de dado para todos os pixels, em todas as possíveis disparidades, tendo $w * h * \mathscr{L}$ cálculos de custo de dado ( $w$ e $h$ representam as dimensões da imagem e $\mathscr{L}$ o número de disparidades possíveis), os dados são inseridos como entrada para o algoritmo de minimização. Diferente do trabalho de Joulin e Kang (2013), que utilizou o algoritmo de Loopy Belief Propagation (MURPHY; WEISS; JORDAN, 1999), Williem, Raskar e Park (2015) optou pelo algoritmo de Boykov, Veksler e Zabih (2001). Ambos os algoritmos tem como objetivo encontrar um mínimo local para a função de minimização de entrada, capturando as disparidades mais adequadas para os pixels, segundo esta função.

Uma vez aplicados os dados ao algoritmo de minimização, é realizado uma verificação de reciprocidade entre as imagens, em que a consistência estéreo das disparidades da imagem do lado direito e esquerdo são verificadas, tal como ocorre para o algoritmo de Joulin e Kang (2013) (Seção 3.4). Este processo de verificação encontra pixels oclusos e também aqueles alinhados incorretamente. Por fim, estes pixels incorretos são colorizados por meio da adaptação do algoritmo de Levin, Lischinski e Weiss (2004), gerando as imagens finais.

Para determinar a complexidade do algoritmo proposto por Williem, Raskar e Park (2015), cada uma das etapas foi analisada de modo independente. Assim, para calcular $D_{p}^{L C}\left(f_{p}\right)$ e $D_{p}^{R I D}\left(f_{p}\right)$ é necessário apenas o tamanho do bloco $(19 \times 19)$. Tal processo é executado para todos os pixels da imagem, em todas as possíveis disparidades, assim a complexidade $\mathscr{O}\left(D^{L C}+\right.$ $\left.D^{R I D}\right)=O(\mathscr{L} \times N)$. Observe que foi desconsiderada a utilização de parâmetro variável para o tamanho do bloco (caso contrário, a complexidade deveria ser multiplicada por TamanhoBloco ${ }^{2}$ ). Para o cálculo do $D^{S E G}$ é necessário aplicar o algoritmo mean-shift, que possui complexidade $\mathscr{O}\left(I \times N^{2}\right)$ com $I$ igual ao número de iterações do algoritmo. Considerando $I$ como uma constante, a complexidade final para o custo de dado é igual a $\mathscr{O}\left(N^{2}+\mathscr{L} \times N\right)$.

Além da complexidade relacionada ao custos dos dados, o método proposto por Williem, Raskar e Park (2015) faz uso do algoritmo de minimização de energia de Boykov, Veksler e Zabih (2001). Para entender a complexidade do algoritmo de minimização é necessário entender alguns conceitos básicos relacionados à técnica. Dada uma imagem com altura $h$ e comprimento $w$, é criado um grafo em que cada pixel da imagem é representado por um nó, como ilustrado pela Figura 24a, em que os nós são representados pelas elipses em cinza. Os pixels (nós) adjacentes são conectados entre si (4-conectado) por meio de arestas, representadas em amarelo. Todas as $\mathscr{L}$ possíveis disparidades também são representadas por outros tipos de nó (coloridos em verde, azul e vermelho). Cada um dos nós de disparidade possui exatamente uma conexão para cada 
um dos pixels da imagem.

Figura 24 - Estrutura de grafos gerada pelo algoritmo de otimização de Boykov, Veksler e Zabih (2001)

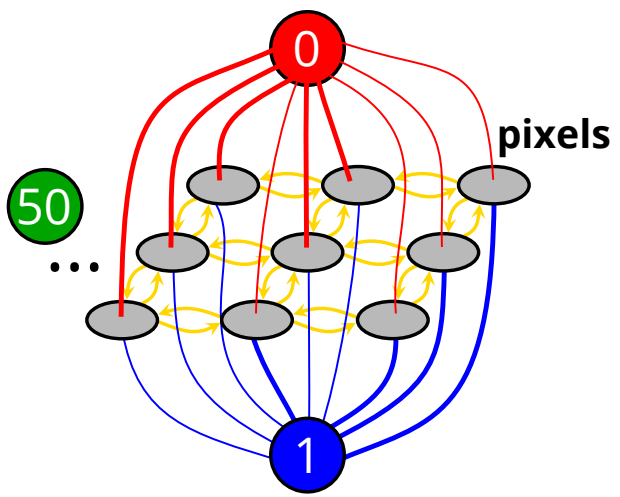

(a) Grafo gerado para execução do algoritmo de Boykov, Veksler e Zabih (2001).

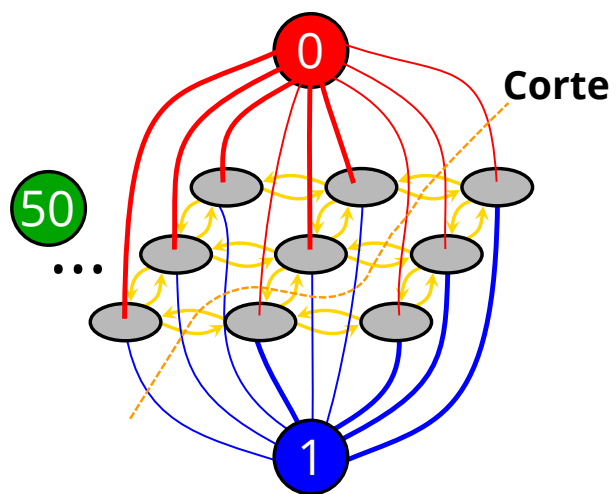

(b) Exemplo de corte para o grafo do algoritmo de Boykov, Veksler e Zabih (2001).

Fonte: Adaptada de Boykov e Kolmogorov (2004).

A Figura 24b apresenta um corte realizado no grafo, separando os pixels que pertencem à disparidade 0 daqueles que pertencem à disparidade 1 , e vice-versa. A complexidade para o algoritmo de Boykov e Kolmogorov (2004) é $\mathscr{O}(a \times n \times|C|)$, com $a$ igual ao número de arestas do grafo, $n$ igual ao número de nós, e $|C|$ a quantidade de cortes executados no grafo. Assim, a complexidade Big-O do método de Williem, Raskar e Park (2015) é igual a do algoritmo de Boykov, Veksler e Zabih (2001), uma vez que a complexidade do custo de dado é inferior.

\subsection{Comparação entre Métodos}

Considerando os métodos para a realização da reversão anaglífica apresentados neste capítulo, foi gerada uma tabela comparativa (Quadro 2), levando em consideração a utilização ou não de metadados, a possibilidade de reverter imagens e vídeos anaglíficos, e o custo para realizar a reversão, considerando o tempo de apenas um quadro. A coluna vídeo refere-se a utilização de informações contidas na sequência dos quadros de vídeo para a solução do problema, não somente a reversão de quadros avulsos.

Quadro 2 - Comparação entre métodos de reversão anaglífica.

\begin{tabular}{|c|c|c|c|c|c|}
\cline { 2 - 6 } \multicolumn{1}{c|}{} & Metadados & Imagens & Vídeos & Qualidade & Custo \\
\hline RevGlyph & $\operatorname{Sim} X$ & $\operatorname{Sim} \checkmark$ & Não $X$ & Boa $\checkmark$ & Muito Baixo $\checkmark$ \\
\hline HaarGlyph & $\operatorname{Sim} X$ & $\operatorname{Sim} \checkmark$ & Não $X$ & Boa $\checkmark$ & Muito Baixo $\checkmark$ \\
\hline ASIFT-Flow & Não $\checkmark$ & $\operatorname{Sim} \checkmark$ & Não $X$ & Média & Muito Alto $X$ \\
\hline Williem & Não $\checkmark$ & Sim $\checkmark$ & Não $X$ & Média & Muito Alto $X$ \\
\hline Roo e Richards & Não $\checkmark$ & Não $X$ & Sim $\checkmark$ & $?$ & Médio \\
\hline
\end{tabular}

Fonte: Dados da pesquisa.

Os símbolos apresentados indicam que a característica é, em relação à técnica: $(\checkmark)$ favorável; $(X)$ desfavorável; ( ) neutra. O símbolo (?) indica que o item não foi avaliado para a técnica. 
Como mencionado anteriormente, as técnicas RevGlyph (ZINGARELLI; ANDRADE; GOULARTE, 2011) e HaarGlyph (RODRIGUES; YUGOSHI; GOULARTE, 2016) fazem uso de metadados para recuperar uma aproximação do par estéreo, normalmente conseguindo obter resultados melhores de qualidade ${ }^{1}$. Além disso, quando estão sendo utilizados metadados, não há necessidade de processamentos custosos para a recuperação dos dados, portanto estes algoritmos são executados rapidamente. Técnicas que não utilizam metadados normalmente são mais lentas que as demais técnicas, tal como sumarizado na coluna de custo. Apesar disso, alguns autores apresentam soluções para reduzir o tempo de processamento, tal como Roo e Richardt (2014), que utilizam o algoritmo SIFT-Flow, mas aplicam coerência temporal entre quadros de vídeo para ganhar velocidade e, potencialmente, qualidade. Assim, a técnica de Roo e Richardt (2014) utiliza informações de outros quadros de vídeo, não utilizadas pelas demais técnicas analisadas.

\subsection{Colorização de imagens}

Como mencionado anteriormente, não é possível recuperar todo o conteúdo do par estereo a partir do anáglifo por meio do alinhamento, sendo necessário completar as regiões que estão oclusas, normalmente utilizando processos de colorização. Colorização é a arte de adicionar cor a uma imagem ou vídeo monocromático (YATZIV; SAPIRO, 2006), e surgiu em 1970 com Wilson Markle para adicionar cor a programas em preto e branco de televisão.

Uma das abordagem para colorização é o uso da técnica de transferência de cor (REINHARD et al., 2001; WELSH; ASHIKHMIN; MUELLER, 2002), em que duas imagens são dadas como entrada, e a segunda imagem é utilizada para recolorir a primeira.

Um dos métodos que utilizam essa abordagem é o de Welsh, Ashikhmin e Mueller (2002), que recebe como entrada uma imagem em escala de cinza e uma imagem colorida. $\mathrm{O}$ algoritmo é relativamente simples, sendo o primeiro passo do algoritmo subdividir a imagem colorida em blocos de 5x5, então cada um desses blocos gera um vetor de características composto da média da luminância do bloco, desvio padrão, e os valores dos canais de crominância. Um ponto a ser levado em consideração é a utilização do espaço de cores $L \alpha \beta$, em que as cores de crominância são independentes entre si, isto é, o $\alpha$ corresponde a uma aproximação do amarelo/azul, enquanto o $\beta$ corresponde a uma aproximação do vermelho/verde.

Após gerar os objetos para a imagem colorida, a imagem em escala de cinza também é subdividida em blocos de 5x5. Para cada um deles é encontrado o vizinho mais próximo utilizando a média da luminância do bloco e o desvio padrão, com cada um dos atributos contribuindo com 50\% no cálculo. Encontrado o vizinho mais próximo, as características de cores são então transferidas do bloco colorido para o bloco em escala de cinza, preenchendo o $\alpha$ e o $\beta$.

1 A qualidade das imagens geradas pela técnica de Roo e Richardt (2014) não foi verificada, uma vez que utiliza informações entre frames, o que não está disponível para as demais técnicas. 
Outros trabalhos utilizam como entrada apenas uma imagem e alguns pixels/regiões são fornecidos pelo usuário, e com base neles as demais regiões da imagem são recolorizadas (LEVIN; LISCHINSKI; WEISS, 2004; LUAN et al., 2007; HORIUCHI; HIRANO, 2003).

Um passo comum na maioria dos trabalhos de colorização é a conversão do espaço de cor, que normalmente ocorre do RGB para um espaço que contenha a luminância, tal como o YCrCb, ou então o YUV. O trabalho de Levin, Lischinski e Weiss (2004) faz uso do espaço YUV, e encontra um rótulo (cor) para o canal de crominância (U e V) do pixel em análise, com relação aos pixels vizinhos. A Equação 3.8 realiza o cálculo das intensidade para todos os pixels, minimizando o valor de $J(U)$, para a componente U. Lembrando que também é necessário o mesmo cálculo para a componente de crominância $\mathrm{V}$.

$$
J(U)=\sum_{r}\left(U(r)-\sum_{s \in N(r))} w e_{r s} U(s)\right)^{2}
$$

As variáveis $r$ e $s$ correspondem à tripla $(x, y, t)$, ou seja, coordenada $x, y$ da imagem em um dado tempo $t$ (quando utilizado para vídeo) e $w e_{r s}$ é o peso dado para a contribuição de um determinado pixel $s$. O valor de $w e_{r s}$ depende da proximidade da luminância entre os pontos $r$ e $s$, assim, se o valor de $Y(r)$ for próximo do valor de $Y(s)$, o valor de $w e_{r s}$ tende a ser grande; caso contrário, o valor é pequeno. Diversas funções de afinidade podem ser utilizadas para gerar $w_{r s}$. Levin, Lischinski e Weiss (2004) utilizam duas fórmulas, apresentadas em Equação 3.9 e Equação 3.10, com $\mu$ representando a média, e $\sigma$ a variância com relação aos elementos que são considerados vizinhos do pixel $p$.

$$
\begin{gathered}
w e_{r s} \propto e^{-(Y(r)-Y(s))^{2} / \sigma_{r}^{2}} \\
w e_{r s} \propto 1+\frac{1}{\sigma_{r}^{2}}\left(Y(r)-\mu_{r}\right)\left(Y(s)-\mu_{r}\right)
\end{gathered}
$$

A fórmula utilizada para o cálculo da componente $U$ também é utilizada para o cálculo da componente de cor $V$, sendo necessário apenas alterar as variáveis que fazem uso do $U$. A Figura 25 apresenta o resultado após a de colorização de Levin, Lischinski e Weiss (2004).

Figura 25 - Colorização de imagem por meio do algoritmo proposto por Levin, Lischinski e Weiss (2004).

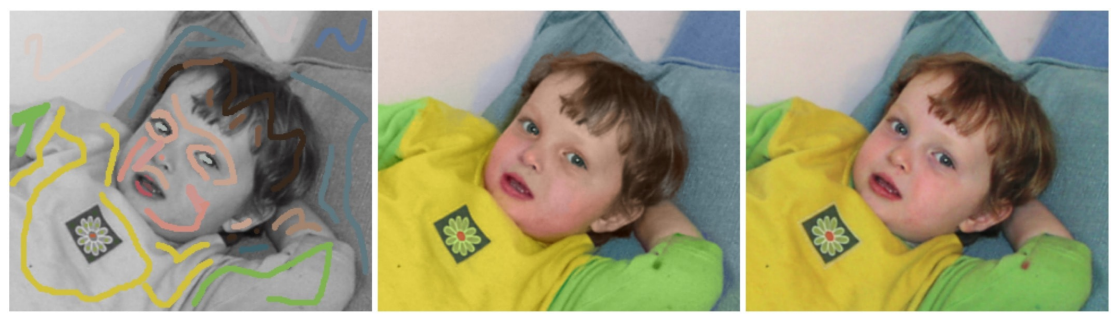

Fonte: Adaptada de Levin, Lischinski e Weiss (2004). 
Um ponto interessante em relação aos métodos de colorização é que, que geral, a proposta indica ser para colorização de imagens monocromáticas, porém normalmente é mais específica, necessitando que a imagem esteja em escala de cinza, sendo possível a extração da luminância, que muitas vezes é essencial para o método. Contudo, em um anáglifo, não é possível extrair a luminância dos canais, pois apesar de a imagem conter os três canais de cor, há o deslocamento, que afeta diretamente a luminância. No anáglifo ilustrado na Figura 26, a luminância 205 é encontrada em alguns pixels, apesar da imagem original não conter valores acima de 175 . Como não é possível utilizar a luminância, os métodos são adaptados (JOULIN; KANG, 2013; WILLIEM; RASKAR; PARK, 2015) para que possam suportar colorização diretamente no espaço de cor RGB.

Figura 26 - Extração da luminância diretamente do anáglifo.

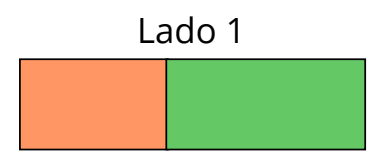

Luminâncias

175 e 158

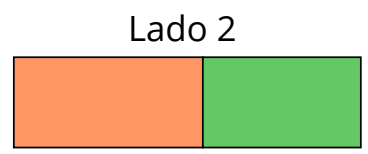

Luminâncias

175 e 158

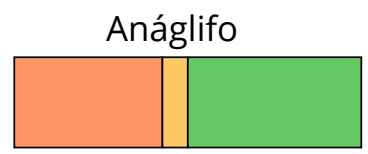

Luminâncias

175,205 e 158

Fonte: Elaborada pelo autor.

\subsection{Considerações Finais}

Este capítulo apresentou os principais trabalhos relacionados a reversão anaglífica e alguns métodos de recolorização. Dietz (2012) propõe uma técnica de reversão baseada em deconvolução, porém não apresenta o método de maneira clara e não fornece métricas objetivas/subjetivas de avaliação. Os trabalhos de Zingarelli, Andrade e Goularte (2011) e Rodrigues, Yugoshi e Goularte (2016) apresentam técnicas baseadas em metadados, sendo necessário o par estéreo que gera o anáglifo com metadados para a sua posterior reversão. Joulin e Kang (2013) propõe uma técnica de reversão baseada em minimização de energia utilizando utilizando os descritores geradas pelo algoritmo algoritmo SIFT-Flow (LIU; YUEN; TORRALBA, 2011), com resultados visivelmente interessantes, porém com alto custo computacional, mesmo para imagens de baixa resolução. $\mathrm{O}$ mesmo problema de desempenho recai sobre a técnica proposta por Williem, Raskar e Park (2015), também baseado em minimização de energia (BOYKOV; VEKSLER; ZABIH, 2001) e utilizando o algoritmo de (LEVIN; LISCHINSKI; WEISS, 2004).

Diante desse cenário, este trabalho de mestrado propõe uma nova técnica de reversão anaglífica, com custo computacionalmente inferior ao dos métodos correlatos (conforme discutido no presente Capítulo) e boa qualidade visual (de acordo com os resultados apresentados no Capítulo 6). Numa abordagem diferente das encontradas na literatura, a técnica proposta, denominada SIRA, utiliza técnicas de análise de séries temporais para encontrar a disparidade entre os pixels do anáglifo. O embasamento conceitual relacionado a séries temporais, relevante para este trabalho, é apresentado no Capítulo 4. A técnica SIRA é discutida em detalhes no Capítulo 5. 


\section{SÉRIES TEMPORAIS}

Uma série temporal é uma sequência de $n$ observações, representadas por valores reais, medidos em intervalos regulares de tempo (BOX; JENKINS; REINSEL, 1994; MORETTIN; TOLOI, 2006; MITSA, 2010). Bases de séries temporais vêm sendo utilizadas em diversas áreas do conhecimento, como na medicina, em eletrocardiogramas e encefalogramas; na economia, com o acompanhamento de taxas de juros e ações na bolsa de valores em um determinado período de tempo; em processamento de sinais, para reconhecimento de fala; agricultura, por meio do acompanhamento das safras ao longo do ano; metereologia, com o acompanhamento da temperatura ao longo das décadas, dentre outras aplicações. Exemplos de séries temporais são apresentados na Figura 27. O gráfico à esquerda mostra uma série da quantidade de produtos farmacêuticos vendidos ao longo das semanas e o gráfico à direita apresenta uma série das anomalias de temperatura que ocorrem ao longo dos anos.

As séries temporais podem ser multivariadas ou univariadas. Os exemplos apresentados na Figura 27 são de séries univariadas, uma vez que existe apenas uma variável em análise. Quando não é possível representar um problema real com apenas uma variável, são utilizadas as séries temporais multivariadas, que possuem ao menos duas variáveis em análise. Um exemplo de série temporal multivariada pode ser o lucro e quantidade de vendas de uma empresa analisados ao longo dos meses.

Formalmente, uma série temporal $S=s_{1}, s_{2}, \ldots, s_{n}$, para um $T=t_{1}, t_{2}, \ldots, t_{n}$ é uma função discreta com valor $s_{1}$ para o tempo $t_{1}$, valor $s_{2}$ para um tempo $t_{2}$, e assim por diante (MITSA, 2010). Já para uma série multivariada, cada valor $s_{i}, \operatorname{com} 1 \leq i \leq n$ representa um conjunto de $m$ observações, ao invés de somente uma.

Uma outra diferenciação existente para as séries temporais é relacionada a sua estacionariedade. Uma série estacionária tem valores variando em relação a uma média constante (BOX; JENKINS; REINSEL, 1994; MONTGOMERY; JENNINGS; KULAHCI, 2015). Já em uma série não estacionária, não há uma média ao qual a série varia, assim há um movimento com 
tendência ascendente ou descendente das observações. Por meio dessa definição, a Figura 27a representa uma série e a Figura 27b uma série não estacionária.

Figura 27 - Exemplos de séries temporais.

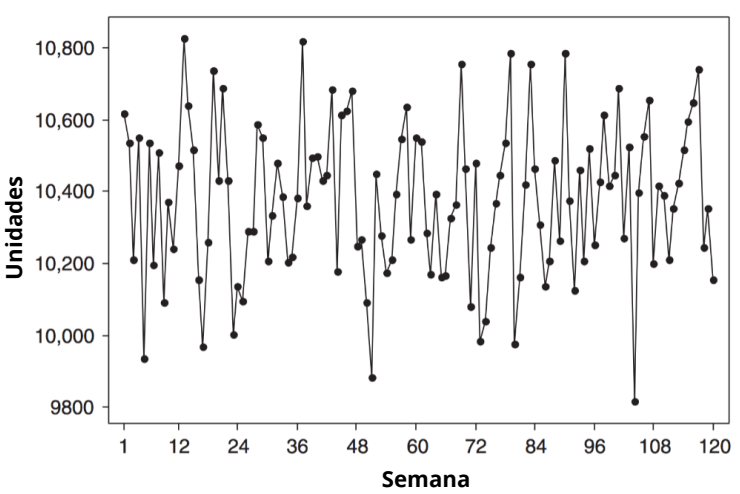

(a) Quantidade de produtos farmacêuticos vendidos (em unidades) ao longo das semanas.

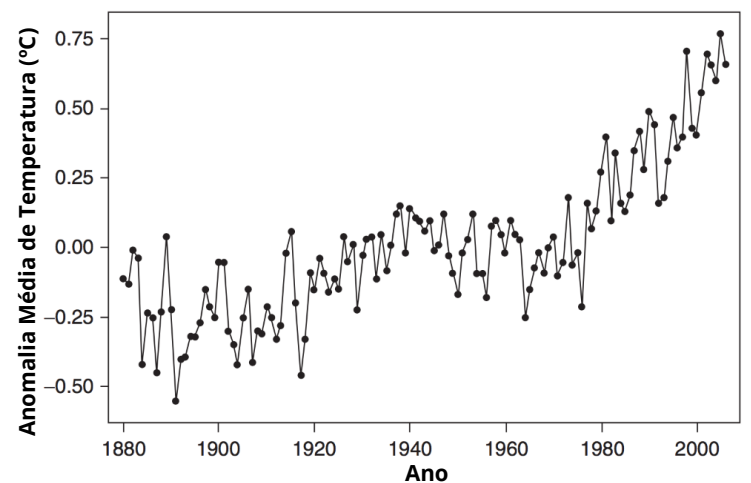

(b) Anomalia de temperatura registrada (em celcius) ao longo dos anos.

Fonte: Montgomery, Jennings e Kulahci (2015).

É importante notar que todas as observações de uma série são ordenadas em relação ao tempo $t$, portanto, ao analisar/comparar as séries temporais, é importante levar esta informação em consideração, não fazendo sentido capturar os elementos de modo desordenado.

\subsection{Decomposição de Séries Temporais}

Uma série temporal pode ser decomposta em componentes, assim como apresentado na Equação 4.1. Na equação, $s(t)$ representa a observação da série $S, T e(t)$ é a tendência, $S a(t)$ é a sazonalidade e $\varepsilon(t)$ é a componente estocástica, todas para o tempo $t$.

$$
s(t)=T e(t)+S a(t)+\varepsilon(t)
$$

A Figura 28 apresenta um exemplo de separação das componentes, para uma série de pedidos de equipamentos elétricos (computadores, eletrônicos e produtos ópticos) na região da Europa (16 países) ao longo do tempo. O primeiro gráfico (Figura 28a), apresenta a série temporal original S e os demais gráficos (Figura 28b-d) representam as decomposições da série $S$ em suas respectivas componentes.

A componente de tendência apresenta comportamento evolucionário, uma vez que as médias dos valores observados tendem a crescer (ou decrescer) quando novos valores ao longo do tempo são considerados. É interessante observar que esta componente influi diretamente na estacionariedade da série, assim uma série não estacionária apresenta a componente de tendência não nula (ISHII; RIOS; MELLO, 2011). A componente de sazonalidade é aquela que se repete a cada intervalo fixo, ou seja, cíclica (MORETTIN; TOLOI, 2006), e pode apresentar pequenas 
Figura 28 - Decomposição da série temporal S nas componentes de tendência $(T e)$, sazonal $(\mathrm{Sa} a)$ e estocástica $(\varepsilon)$.

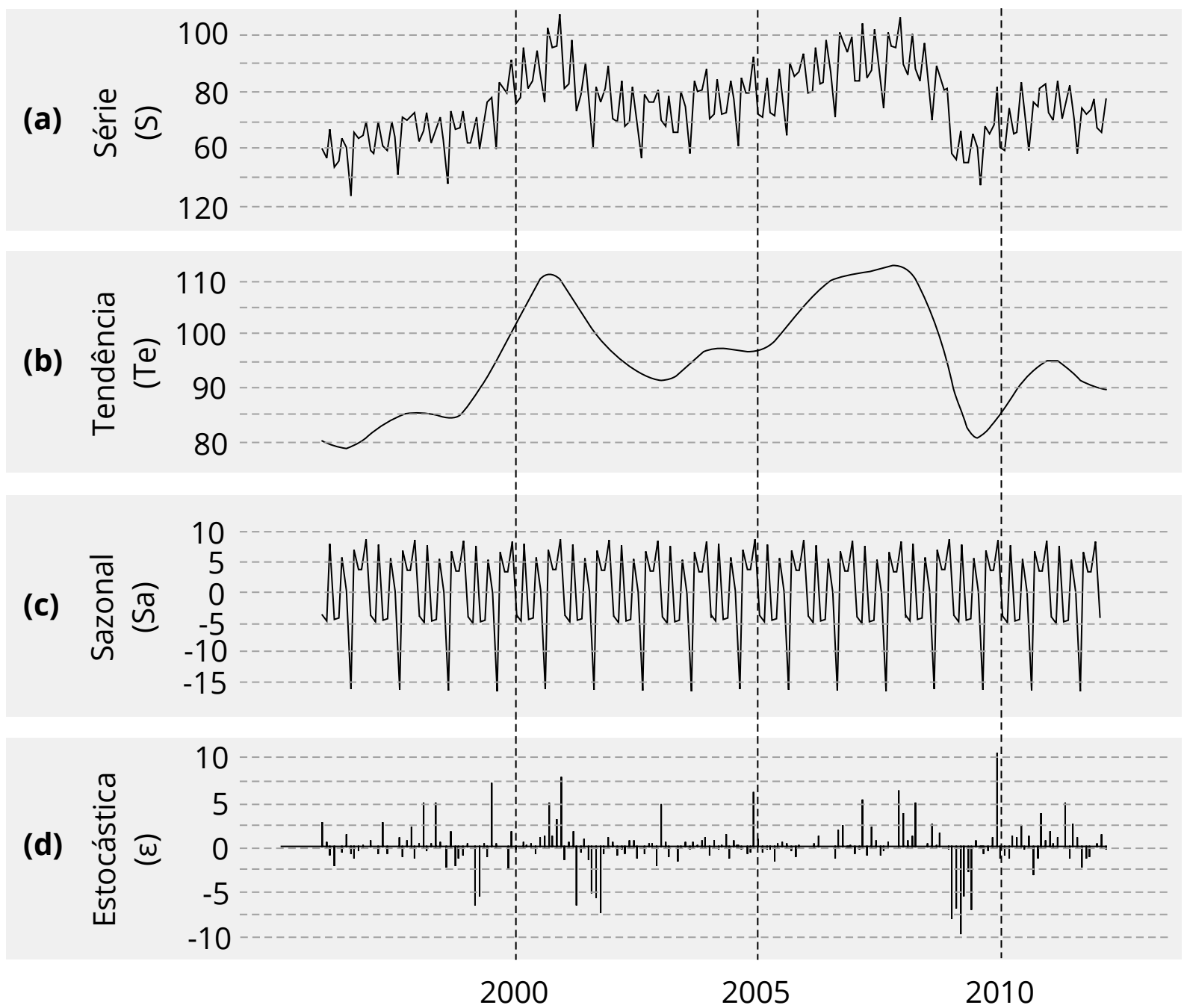

Fonte: Adaptada de Hyndman e Athanasopoulos (2018).

variações entre cada um desses ciclos. Desta forma, ciclos adjacentes são parecidos, porém a longo prazo podem apresentar grandes diferenças (HYNDMAN; ATHANASOPOULOS, 2018). Por fim, a componente estocástica é composta por observações aleatórias, que não se encaixam em tendência ou sazonalidade.

Dependendo do problema a ser resolvido, é interessante destacar alguma das componentes para melhor análise. Suponha uma série que indique o número de desempregos mensais ao longo dos anos, e deseja-se verificar possíveis recessões econômicas. Neste cenário não é interessante que dados de pessoas que abandonaram a escola para procurarem emprego sejam levados em consideração (sazonais), já que a recessão não é sazonal (HYNDMAN; ATHANASOPOULOS, 2018). Assim como ocorrem situações em que a sazonalidade é descartada, também podem ocorrer situações em que a componente de tendência ou a estocástica é descartada.

Uma das maneiras mais comuns de remover a tendência é utilizar a diferença entre 
elementos adjacentes (primeira diferença), sendo as novas observações $(\Delta s(t))$ representadas pela Equação 4.2 (MORETTIN; TOLOI, 2006).

$$
\Delta s(t)=s(t)-s(t-1)
$$

O conhecimento a respeito das características e comportamento da série pode, portanto, resultar em soluções mais precisas e adequadas ao problema abordado.

\subsection{Medidas de Dissimilaridade}

Em geral, comparar séries temporais por igualdade não tem sentido semântico, sendo necessário compará-las por meio de proximidade. Para isso são utilizadas medidas de similaridade ou dissimilaridade, que medem a distância entre pares de objetos. Na Subseção 4.2.1 são apresentadas as medidas de distâncias da família Minkowski, na Subseção 4.2.2 é apresentada a medida Dynamic Time Warping (DTW) e na Subseção 4.2.3 a medida Longest Common Subsequence (LCSS), que são medidas usuais para séries temporais.

\subsubsection{Distâncias Minkowski}

As distâncias da família Minkowski são também conhecidas por distâncias $L_{p}$, e podem ser expressas pela Equação 4.3.

$$
L_{p}(S, Q)=\left(\sum_{i=0}^{n}\left(\left|s_{i}-q_{i}\right|\right)^{p}\right)^{\frac{1}{p}}
$$

Em que $n$ é o número de observações presentes nas séries temporais $(S$ e $Q)$, que devem possuir a mesma quantidade de observações e $s_{i}$ e $q_{i}$ são as observações das séries $S$ e $Q$, respectivamente. $\mathrm{O}$ valor de $p$ indica a norma que está sendo utilizada. Para $p=0$ é gerada a distância de Hamming, $p=1$ tem-se a distância de Manhattan, também conhecida por City Block ou Taxicab, para $p=2$ é gerada a distância Euclidiana, que é a mais utilizada entre todas, dada pela Equação 4.4.

$$
L_{2}(S, Q)=\sqrt{\sum_{i=0}^{n}\left(s_{i}-q_{i}\right)^{2}}
$$

Quando $p$ tende ao infinito, tem-se a distância Chebyshev, que ressalta a magnitude máxima do vetor, já que os demais valores serão minimizados ao aplicar a raiz de $p$.

A Figura 29 exemplifica o funcionamento das distâncias da família Minkowski para um espaço bidimensional. Para um determinado $p$ é representado a distância entre o ponto na posição $(0,0)$ em verde, e um ponto em laranja, em uma posição $(x, y)$. Observe que qualquer ponto 
Figura 29 - Distâncias computadas entre ponto em verde e ponto em laranja para $p=1, p=2$ e $p=\infty$, respectivamente.
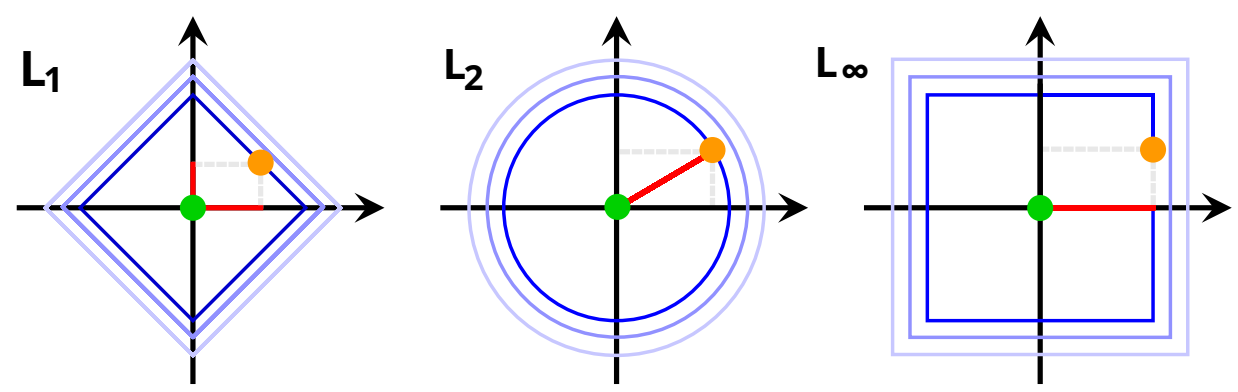

Fonte: Elaborada pelo autor.

sobre o contorno em uma mesma tonalidade de azul possui a mesma distância do ponto em verde, para um mesmo valor de $p$. Além disso, ao desenhar a mesma forma de maneira concêntrica ao centro em verde (linhas em diferentes tonalidades de azul), é possível definir que os pontos contidos nas linhas azuis mais escuras estão mais próximos ao ponto verde que as linhas mais claras.

Para a distância Manhattan, $\operatorname{com} p=1$, a distância entre o ponto em verde e em laranja é dado pela soma das projeções, em vermelho. Para a distância Euclidiana, com $p=2$, a distância entre o ponto verde e em laranja é dado pela hipotenusa em vermelho, formada pelo triângulo retângulo. Por fim, para a distância Chebyshev a distância entre o ponto verde e em laranja é dado pela maior magnitude, ou seja, é o maior valor entre os eixos que define a distância, em vermelho. Observe que quanto maior o $p$, maior é a influência de uma distância maior para um único eixo. Assim, quanto maior é o valor de $p$, vai ocorrendo o morphing, ou seja, se transforma lentamente, da figura gerada por $L_{2}$ até a figura gerada por $L_{\infty}$.

\subsubsection{Distância DTW}

A medida de distância Dynamic Time Warping (DTW) (KEOGH; PAZZANI, 2000) é uma medida de dissimilaridade com alinhamento não linear entre as séries temporais (GUPTA et $a l .$, 1996). Uma das primeiras aplicações desta medida de distância foi realizada para o problema de reconhecimento de fala, uma vez que uma pessoa pode falar trechos de maneira mais rápida e outros de maneira mais lenta, afetando o local do alinhamento e impossibilitando a utilização das medidas $L p$. Tal característica não era levada em conta de modo adequado até então. A medida DTW tem sido muito utilizada em diversos outros domínios de aplicação, dentre eles, processamento de sinais elétricos humanos (GUPTA et al., 1996), agricultura (AMARAL et al., 2014), reconhecimento de fala (SAKOE; CHIBA, 1978), dentre outros trabalhos que necessitam de distâncias com alinhamento não linear.

A Figura 30 ilustra a diferença entre o cálculo de distância Euclidiana e da DTW, para duas séries temporais. Diferentemente da distância da Euclidiana, em que a medida é realizada 
Figura 30 - Diferença entre distâncias da família Minkowsky e DTW.

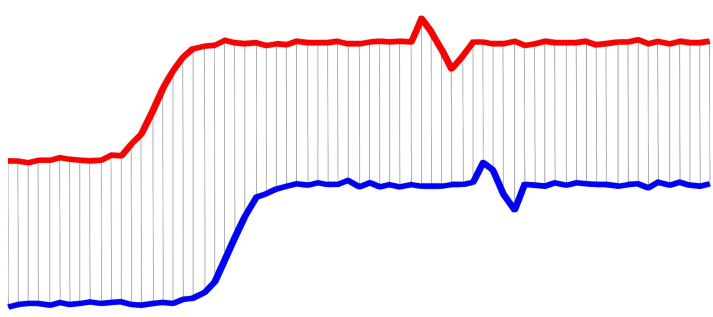

(a) Distância da família Minkowsky.

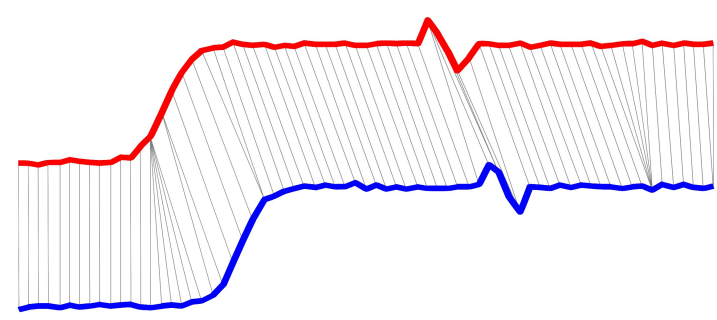

(b) Distância DTW.

Fonte: Ratanamahatana e Keogh (2004).

com base na diferença entre observações na mesma posição temporal, a distância DTW é capaz de associar o elemento no tempo $t$ de uma série com o elemento do tempo $t+$ wind da outra série. $\mathrm{O}$ valor wind determina quantas unidades de tempo (para a granularidade definida), foram utilizadas para associar os elementos de uma série com a outra. Supondo uma série com granularidade em meses, com a observação de janeiro (1) é associada com a observação de março (3), o wind assume valor $2(3-1)$. Observe que um mesmo elemento pode ser associado múltiplas vezes. Muitas vezes é definida uma janela máxima $N$ de deslocamento, tal que $-N \leq$ wind $\leq N$, com $N$ podendo ser inclusive infinito. Voltando ao exemplo dos meses, existem casos que não faz sentido associar diferenças muito grandes entre meses, então esse $N$ é definido. Supondo $\mathrm{N}$ igual 3 , a associação entre mês de janeiro (1) e maio (5) nunca irá ocorrer, uma vez que $5-1>3$. Uma outra característica da DTW é a de permitir que as séries temporais comparadas tenham tamanhos distintos, porém nenhuma observação é excluída do cálculo de distância, sempre havendo uma observação da outra série associada.

Dadas duas séries temporais $Q$ e $S$, de comprimentos $m$ e $n$ respectivamente, é gerada uma matriz de $m \times n$ dimensões, em que cada posição corresponde à distância Euclidiana entre os elementos da série. Assim, para cada elemento $(i, j)$ da matriz, com $1 \leq i \leq m$ e $1 \leq j \leq n$, é realizado o cálculo unidimensional $L_{2}\left(s_{i}, q_{j}\right)$.

A Figura 31 mostra duas séries temporais que representam as médias de temperaturas da cidade de São Carlos-Brasil $^{1}$ na horizontal e Sydney-Austrália ${ }^{2}$ na vertical para cada um dos meses do ano, computadas por meio das médias entre os anos de 1982 e 2012, e a matriz de custo da DTW.

A DTW mapeia todos os pontos de uma série em relação à outra e para isso é utilizada uma matriz de custo (Figura 31a), criada a partir da matriz $m \times n$. A matriz de custo gerada apresenta o custo para alcançar uma determinada posição da matriz por meio de valores cumulativos, partindo do canto superior esquerdo. As cores mais escuras representam custos baixos, enquanto cores claras representam custos altos. Para tanto é utilizado programação dinâmica, a fim de 
Figura 31 - Cálculo da matriz de custo da DTW.

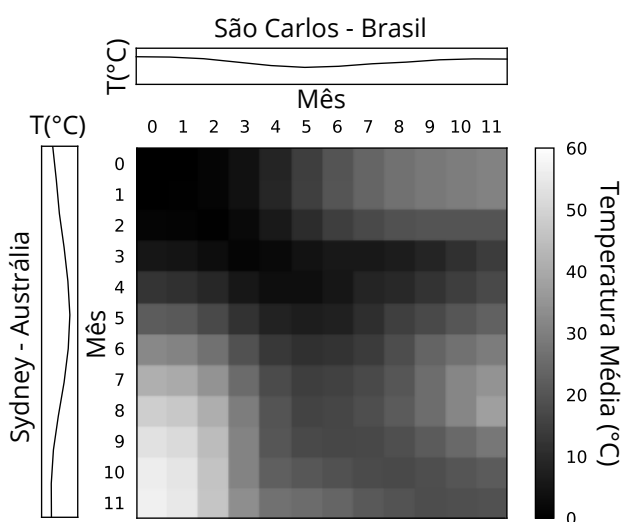

(a) Matriz de custo, e séries temporais $\mathrm{S}$ e $\mathrm{Q}$ apresentadas em cada um dos eixos.

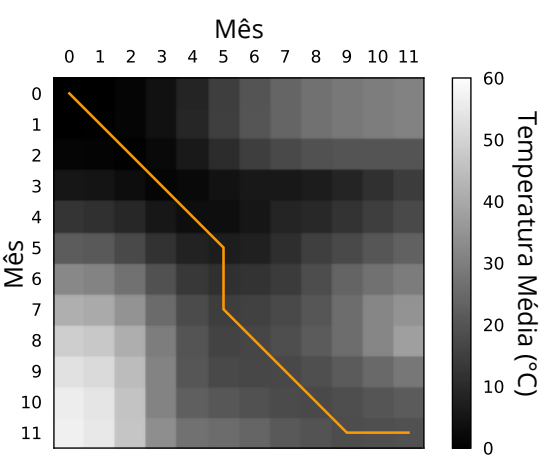

(b) Warping path gerado sobre a matriz de custo.

Fonte: Elaborada pelo autor.

resolver a recorrência indicada pela Equação 4.5, em que $\gamma$ representa o custo acumulado e $L_{2\left(q_{i}, s_{i}\right)}$ é a distância Euclidiana entre os elementos $q_{i}$ e $s_{i}$ correntes computados pela recorrência das séries $Q$ e $S$, respectivamente.

$$
\gamma(i, j)=L_{2\left(q_{i}, s_{i}\right)}+\min \{\gamma(i-1, j-1), \gamma(i-1, j), \gamma(i, j-1)\}
$$

O objetivo da DTW é traçar um caminho (Warping Path) $(W)$ com base na matriz de custo criada, em que o primeiro elemento seja a célula $(1,1)$ da matriz de custo e o último $(m, n)$, sendo esse caminho representado em laranja na Figura 31b, em que cada elemento representa uma linha traçada entre as séries $Q$ e $S$. O conjunto de elementos que compõem o Warping Path é dado pela Equação 4.6, com $w_{1}$ representando o custo dado pela célula $(1,1)$ e $w_{K}$ o custo dado pela célula $(m, n)$ da matriz de custo.

$$
W=w_{1}, w_{2}, \ldots, w_{k}, w_{K}
$$

Uma restrição é imposta para a geração do Warping Path, em que só é possível adicionar elementos adjacentes que avancem na matriz de custo, ou seja, se $w_{k-1}$ é representado pelo custo da célula $(i, j), w_{k}$ será obrigatoriamente representado pelo custo da célula $(i+1, j),(i, j+1)$ ou $(i+1, j+1)$, caso $w_{k-1}$ não seja o custo da célula $(m, n)$. A quantidade de linhas traçadas $(K)$ entre as séries $Q$ e $S$ que farão parte do resultado pode variar, tal que $\max (m, n) \leq K \leq m+n-1$. É interessante observar que com $K$ mínimo e séries $Q$ e $S$ de mesmo tamanho, o Warping Path gerado é somente na diagonal principal, e a distância encontrada é a mesma que a Euclidiana.

Apesar de ser especificada a maneira de construção do Warping Path, diversos caminhos podem ser gerados. Porém é desejado aquele que tenha menor custo, seguindo a Equação 4.7, 
gerando o resultado apresentado por Figura $31 \mathrm{~b}$.

$$
\operatorname{DTW}(S, Q)=\min \left\{\sqrt{\sum_{k=1}^{K} w_{k} / K}\right\}
$$

\subsubsection{Distância LCSS}

A Longest Common Subsequence (LCSS) (DAS; GUNOPULOS; MANNILA, 1997) é uma medida de similaridade (quanto maior o valor, mais similar são as séries) que considera a possível presença de outliers, em que erros de medição podem ser omitidos durante a comparação das séries. Assim, o LCSS apresenta vantagens em relação a DTW e a Euclidiana, que consideram os ruídos (VLACHOS et al., 2003). Além disso, o algoritmo LCSS é computacionalmente mais leve que o algoritmo DTW, por não comparar todos os elementos, e não apresenta overfitting como a DTW, que obriga todos as observações de uma série $Q$ a estarem associados a outra observação da série $S$, e vice-versa.

Figura 32 - Diferença entre as distâncias DTW e LCSS.
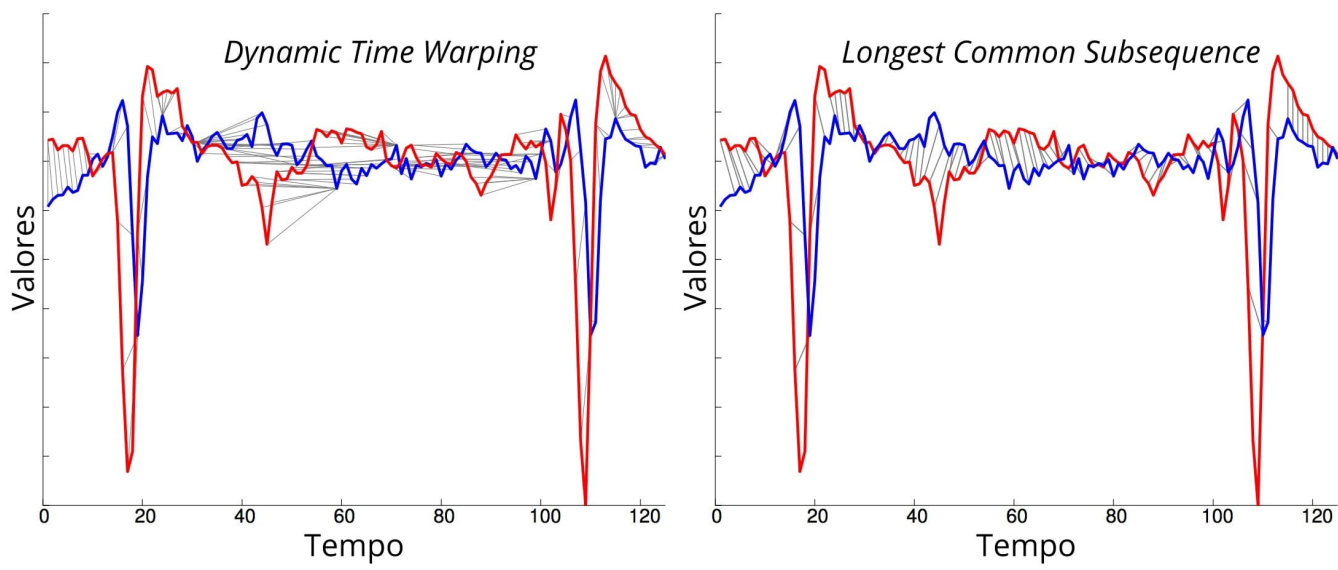

Fonte: Vlachos et al. (2003).

Considerando, por exemplo, as séries temporais $Q=\{0,1,3,5,7,9\}$ e $S=\{5,0,1,7,9\}$, a LCSS captura a maior subsequência comum entre as séries $Q$ e $S$, sendo a subsequência $\{0,1,7,9\}$ de tamanho 4 . Observe que dentre todas as possibilidades de combinações, seguindo a ordem das sequências, de diversos tamanhos ( $\{0\},\{1\},\{5\},\{7\},\{9\},\{0,1\},\{0,7\}, \ldots,\{5,7,9\}$, $\{0,7,9\},\{1,7,9\},\{0,1,7,9\})$, é selecionada aquela que possui maior tamanho. Devido ao fato de as séries apresentarem valores em ponto flutuante, ou uma faixa de valores muito ampla, algumas implementações permitem que valores diferentes, porém muito próximos sejam associados, por meio da utilização de um limiar para definir o que pode ou não ser associado. A Figura 32 ilustra a diferença entre a distância DTW à esquerda, em que todas as observações da série vermelha estão associadas a observações da série azul, e vice-versa, e o LCSS à direita, com algumas observações associadas. Note que as associações são ilustradas pelos segmentos de reta 
conectando observações das séries. Assim, a LCSS utilizada faz uso de limiar. Caso não utilizasse linear, os segmentos das associações seriam apenas traços horizontais, já que associariam apenas valores idênticos para o eixo vertical.

\subsection{Representação de Séries Temporais}

Em diversas aplicações, as séries temporais de interesse são muito extensas, ou então as bases de dados possuem muitas séries temporais, tornando computacionalmente custoso manipular essa grande quantidade de informação, comprometendo tarefas, por exemplo, de análise e mineração de séries. Um outro problema comum é que utilizar dados brutos de uma série temporal pode não ser eficaz para tarefas de análise. Nesses casos, é necessário transformar e/ou reduzir a dimensionalidade dos dados, mantendo as informações necessárias para a aplicação desejada (MITSA, 2010).

Existem diversas técnicas para representar uma série temporal, muitas delas com o objetivo de discretizar os dados, já que diversos algoritmos para análise e mineração de séries temporais consideram a série discretizada. Na literatura, há três principais abordagens para representar séries temporais, ilustradas pela Figura 33, sendo elas: 1) representações não adaptativas aos dados; 2) representações adaptativas aos dados; 3 ) representações baseadas em modelo (LIN et al., 2003; WANG et al., 2013).

Figura 33 - Modos de representação das séries temporais.

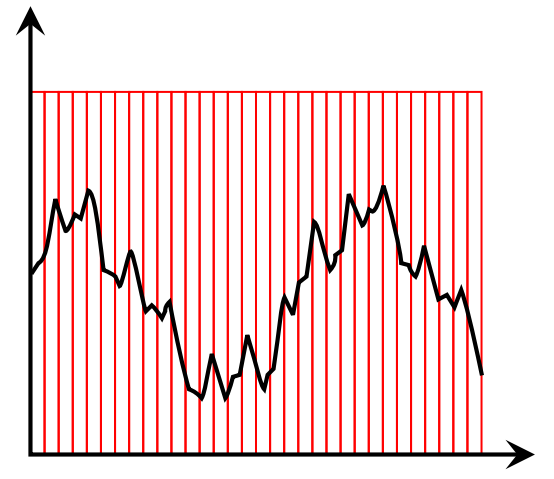

TEMPO

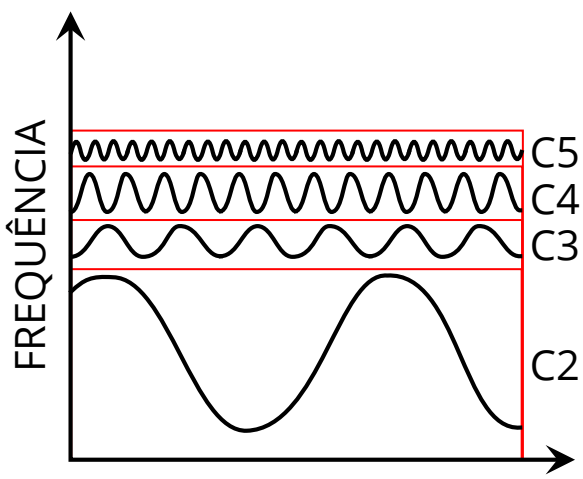

TEMPO

Fonte: Adaptada de Lin et al. (2003).

Os métodos não adaptativos utilizam parâmetros locais para gerar a nova série. Dentre os mais comuns estão a Discrete Fourier Transform (COOLEY; LEWIS; WELCH, 1969), a Discrete Wavelet Transform e o Piecewise Aggregate Approximation (KEOGH et al., 2001), sumarizados nas seções seguintes.

Métodos adaptativos utilizam parâmetros globais, ou seja, é necessário conhecer os dados para que o modelo possa ser aplicado. Dentre os mais comuns estão o Piecewise Linear 
Approximation (LAST; KANDEL; BUNKE, 2004) e o Symbolic Aggregate Approximation (LIN et al., 2003), descritos brevemente nas Seções 4.3.4 e 4.3.3.

\subsubsection{Transformada Discreta de Fourier}

Uma das maneiras de representar as séries temporais é por meio da frequência, na qual a questão temporal é perdida, parcialmente ou totalmente. A Discrete Fourier Transform (DFT) é uma das primeiras técnicas para redução da dimensionalidade, e possui o objetivo de quebrar uma série temporal em finitas ondas de seno ou cosseno, em que cada uma das ondas é representada como um número complexo chamado de coeficiente de Fourier (MITSA, 2010). Uma série temporal de tamanho $n$ pode ser decomposta em $n$ ondas de seno e cosseno. Após aplicar a transformada de Fourier, trabalha-se no domínio da frequência, sendo possível realizar o processo inverso, obtendo a série original a partir da transformada inversa, sem perdas significativas nos dados. Neste processo, normalmente ocorre uma perda mínima uma vez que parte dos dados da transformada é eliminada, devido a sua pequena contribuição para a representação da série original.

A Figura 34 ilustra como as séries temporais são representadas no domínio do tempo (à esquerda), com a série original, e no domínio da frequência (à direita), as funções seno e cosseno mais representativos aos coeficientes gerados no cálculo da FFT, que ao serem somadas, geram a série original. Observe que não há divisões no tempo, apenas na frequência (indicado pelas divisões em vermelho), assim todos os elementos possuem o "mesmo tempo". Os elementos $C 1, C 2, \ldots, C n$ representam os coeficientes que compõem a representação.

Figura 34 - Representação da série temporal por meio da DFT.

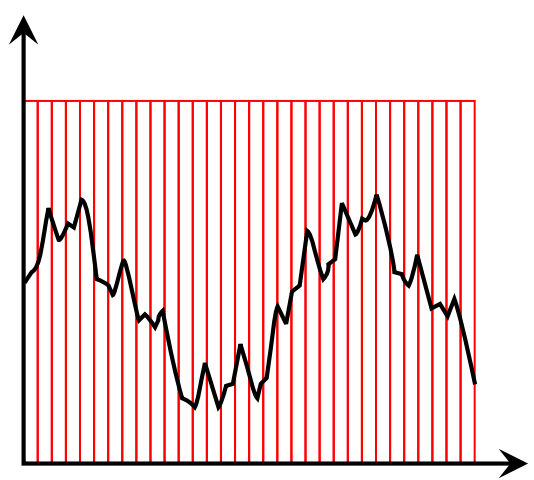

TEMPO

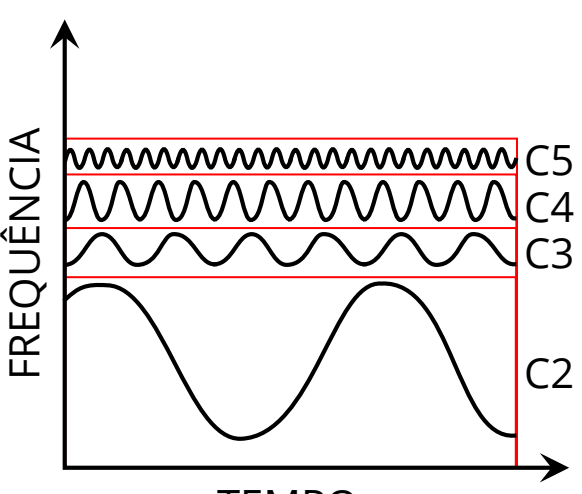

TEMPO

Fonte: Adaptada de Gonzalez e Woods (2008).

Os coeficientes $C_{k}$ da DFT, para uma série temporal $S=s_{0}, s_{1}, s_{2}, \ldots, s_{n-1}$, são números complexos dados pela Equação 4.8, em que $n$ representa a quantidade de elementos da série original, $j$ representa a unidade imaginária do número complexo, e $k=0,1, \ldots, n-1$. Para facilitar os cálculos dos coeficientes, normalmente é utilizada a fórmula de Euler para números complexos $e^{-j x}=\cos (-x)+j \sin (-x)$. O primeiro coeficiente $C 1$, que não foi representado na 
figura, é a simples média dos elementos, uma vez que o valor de $k$ é igual a 0 . É interessante mencionar que os coeficientes apresentados na Figura 34 não estão ordenados de acordo com a sua magnitude, portanto eliminar coeficientes que tem pouco impacto não significa eliminar os últimos coeficientes calculados.

$$
C_{k}=\sum_{i=0}^{n-1} s_{i} e^{-j 2 \pi i k / n}
$$

A complexidade da DFT é $O(n \log n)$, quando utilizado o algoritmo Fast Fourier Transform (FFT). Um fator interessante da transformada é que ao comparar um par de sinais por meio da distância euclidiana, seu resultado é o mesmo para o domínio do tempo, antes da transformada, e para o domínio da frequência. Devido ao fato de não trabalhar com a questão temporal, a DFT é normalmente utilizada para ondas estacionárias, que oscilam em relação a um determinado ponto. O processo inverso da DFT pode ser feito, reconstruindo a série de maneira aproximada, quando coefiecientes menos significativos são eliminados, ou exata.

\subsubsection{Transformada Discreta de Wavelet}

A Discrete Wavelet Transform (DWT) permite representar não só a frequência, como a DFT, mas também representar o tempo. Vale mencionar que variações da DFT são capazes de representar a questão temporal, como a Transformada de Fourier de tempo curto, porém esta solução não leva em conta o tipo de onda. Já a DWT permite que ondas com alta frequência sejam analisadas em alta resolução, enquanto as de baixa frequência, em baixa resolução. A DWT permite a visualização das séries temporais por meio de várias escalas, também conhecidas como resoluções (MITSA, 2010).

$$
\Psi(t)^{s, \tau}=\frac{1}{\sqrt{s}} \Psi\left(\frac{t-\tau}{s}\right)
$$

Enquanto na DFT são utilizadas as funções seno e cosseno, na DWT são geradas funções chamadas de wavelets, que vêm do termo onda pequena (LI; MA; OGIHARA, 2005). A partir de uma função wavelet mãe $\Psi$, outras funções filhas são criadas por meio da Equação 4.9, em que $s$ é a constante de escala, responsável pela contração e dilatação, e $\tau$ é a constante de translação. Por fim, $t$ é o valor no eixo temporal.

O modelo mais simples e comumente utilizado de Wavelets é a transformada de Haar. A Figura 35 ilustra a wavelet mãe $\left(\Psi(t)^{1,0}=\Psi\right)$ da transformada de Haar $(a)$, com escala igual a 1 e sem translação. Diversas combinações de Wavelets podem ser geradas a partir das variáveis de escala e translação, assim como apresentado em (b) e (c). O gráfico (b) apresenta uma Wavelet filha com escala igual a $1 / 2$ e translação 2 e o gráfico (c) apresenta uma Wavelet filha com escala igual a 8 e translação 0 . A Wavelet (b) representa uma resolução de tempo maior que a apresentada em (c), porém a resolução de frequência é menor. 
Figura 35 - Geração das Wavelets filhas a partir da Wavelet mãe.

(a)

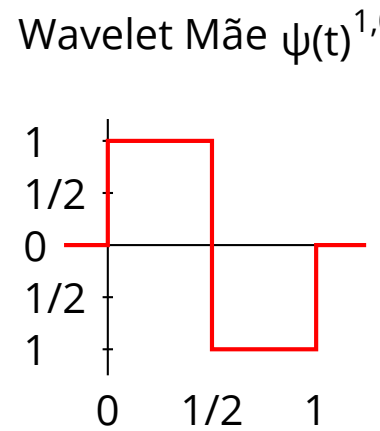

(b)

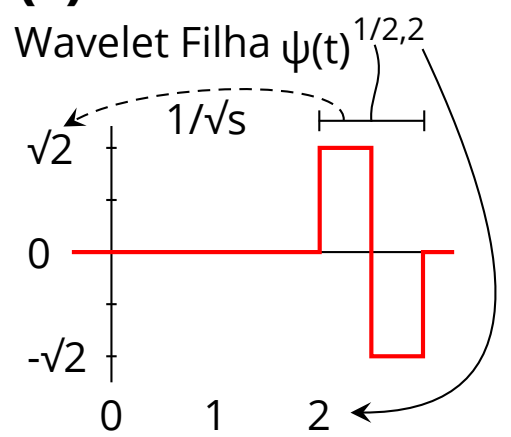

Fonte: Elaborada pelo autor. (c)

Wavelet Filha $\psi(\mathrm{t})^{8,0}$

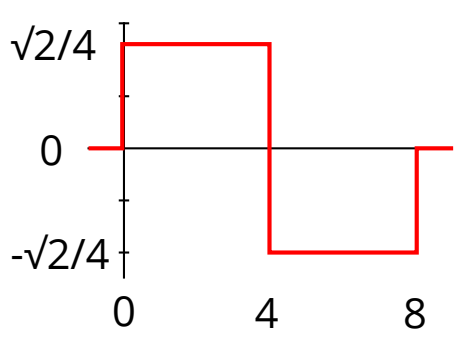

A Figura 36 apresenta a série temporal original à esquerda, em que há apenas a presença do tempo e as representações da série em diversas resoluções. As linhas vermelhas indicam a presença do tempo, assim, quanto mais traços vermelhos verticais, mais resolução de tempo e menor a de frequência. Observe que a FFT apresenta apenas o nível superior da DWT, para o qual só existe a presença da frequência.

Figura 36 - Representação da série temporal por meio da DWT.

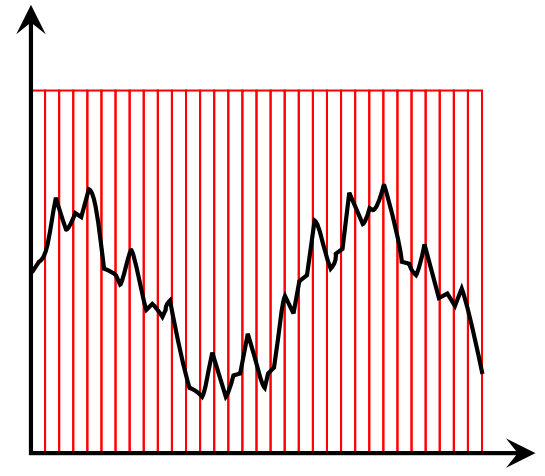

TEMPO

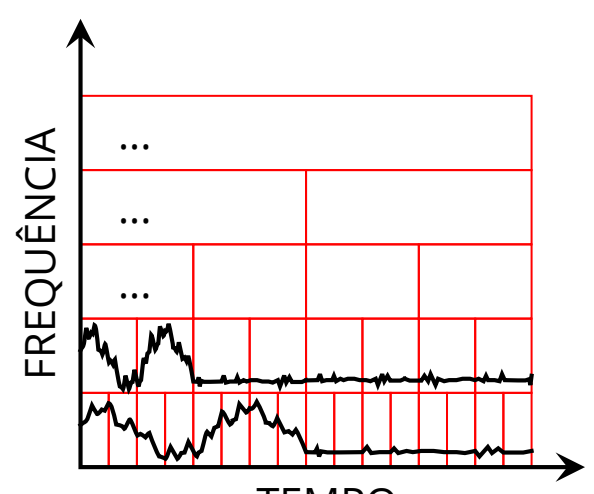

TEMPO

Fonte: Elaborada pelo autor.

\subsubsection{Piecewise Aggregate Approximation}

O Piecewise Aggregate Approximation (PAA) (KEOGH et al., 2001) tem por objetivo reduzir a dimensionalidade da série temporal fazendo uso da média dos elementos de janelas com tamanho previamente definido. A Equação 4.10 apresenta o seu funcionamento.

$$
\overline{s_{i}}=\frac{N}{n} \sum_{j=\frac{n}{N}(i-1)+1}^{\frac{n}{N} i} s_{j}
$$


$\mathrm{Na}$ equação $\overline{s_{i}}$ é o elemento $i$ da nova série, $n$ é a quantidade de pontos existentes anteriormente na série, $N$ é a nova quantidade de pontos, também chamada de cardinalidade, e o somatório é feito sempre para tamanho de "quadros" equidistantes de tamanho $N / n$. Por fim, $j$ é o iterador dos elementos da série original, que irá encontrar o novo valor para um "quadro", dado o valor de $i$. A Figura 37 exemplifica o processo do PAA, em que a série temporal é dividida em 6 partes, gerando a série temporal $\bar{S}=\{1.175,2.5,3.57,2.1,2.6,1.8\}$. A linha pontilhada (em azul) representa a série temporal original, e a representação PAA é indicada pela linha contínua (em vermelho).

Figura 37 - Representação do Piecewise Aggregate Approximation

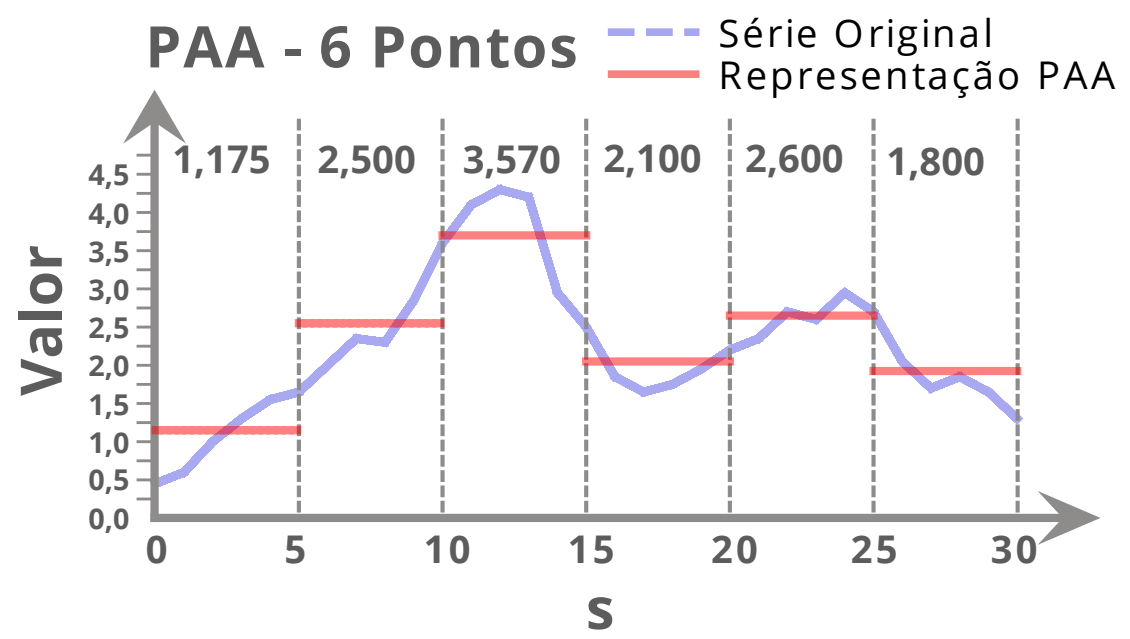

Fonte: Elaborada pelo autor.

\subsubsection{Piecewise Linear Approximation}

Como mencionado anteriormente, o Piecewise Linear Approximation (PLA) é um modelo de representação adaptativo, ou seja, adapta-se de acordo com os dados (LAST; KANDEL; BUNKE, 2004). Existem dois modelos para o PLA, sendo o primeiro deles por interpolação e o outro por regressão.

O algoritmo do PLA funciona a partir da criação de linhas que representam a série temporal, porém tais linhas podem ter comprimentos distintos em relação ao eixo $x$. Existem três modos para criar essa representação: por meio de Janela Deslizante, Top-down e Bottomup (MITSA, 2010). O algoritmo por Janela Deslizante recebe o primeiro ponto da série e vai incrementalmente adicionando pontos, até um certo limite de erro a partir do qual a reta para de crescer, e o algoritmo recomeça para o próximo ponto não pertencente à reta criada. No método Top-down a série é subdividida, até que um limite de erro aceitável seja alcançado. Por fim, o método Bottom-up começa da melhor subdivisão possível e vai unindo as partes, também fazendo uso dessa medida de qualidade, em que os erros são verificados a cada iteração (LAST; KANDEL; BUNKE, 2004). 
Diversas medidas podem ser utilizadas para mensurar a qualidade do potencial segmento, sendo a mais comum delas a soma dos quadrados, ou erro residual. Um exemplo é ilustrado pela Figura 38, em que um segmento de reta é considerado de qualidade se respeitar a Equação 4.11, em que $a$ e $b$ representam os pontos iniciais e finais para o eixo $x$ do segmento em análise (em azul), $O(i)$ representa o valor para o ponto $i$ da série original (pontos em verde), $N(i)$ o valor para o ponto $i$ do novo segmento (em laranja), e $T$ é o limiar definido pelo usuário, que representa o limite máximo de erro permitido. Observe que o erro total é dado pela soma dos quadrados das distâncias representadas em vermelho.

Figura 38 - Soma dos quadrados ou erro residual de um segmento do Piecewise Linear Approximation.

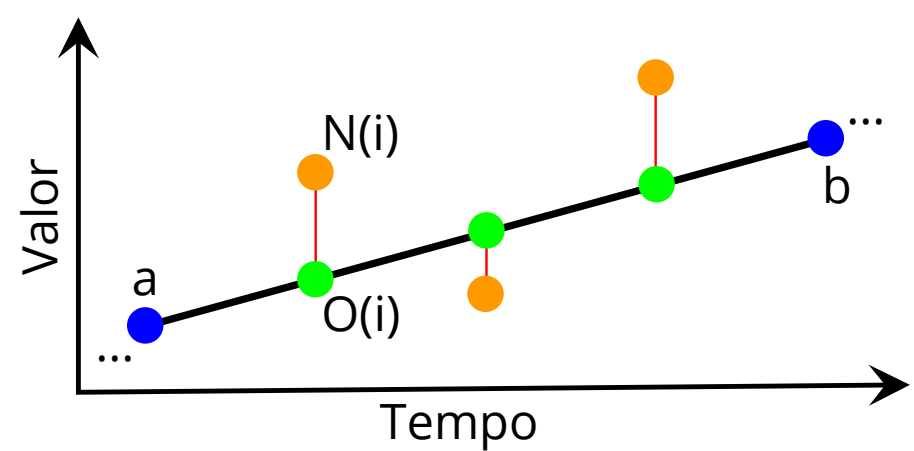

Fonte: Elaborada pelo autor.

$$
\sum_{i=a}^{b}(O(i)-N(i))^{2}<T
$$

As linhas podem ser criadas por meio de interpolação linear ou então regressão linear. Tal como no exemplo utilizando interpolação linear, os dois pontos que conectam a linha gerada são os mesmos do trecho da série em análise (complexidade $O(n)$ ); já na regressão linear utiliza-se a linha que melhor descreve os dados (o tempo necessário para essa construção é dependente da quantidade de pontos). A Figura 39 ilustra uma série original à esquerda, ao centro a série representada com interpolação linear, e à direita por regressão linear. Observe que a Equação 4.11 é utilizada tanto para interpolação, quanto para regressão, uma vez que o ponto inicial e final é considerado no cálculo.

Figura 39 - Representação do Piecewise Linear Approximation.

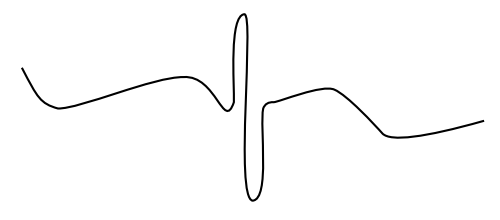

(a) Série temporal original.

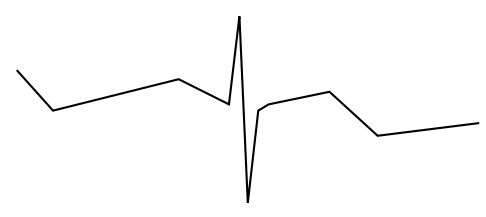

(b) Interpolação linear.

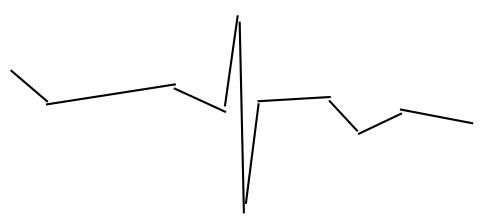

(c) Regressão linear.

Fonte: Adaptada de Last, Kandel e Bunke (2004). 


\subsubsection{Symbolic Aggregate Approximation}

Um outro modo de representação de séries temporais adaptativo é o Symbolic Aggregate Approximation (SAX) (LIN et al., 2007), que faz uso da representação Piecewise Aggregate Approximation. A partir do PAA, são extraidas informações que serão usadas para separar o eixo $y$ em partes, sendo que cada uma dessas partes recebe um valor simbólico.

Não existe nenhuma regra definida para a quantidade de símbolos a serem usados, necessitando apenas ser maior que dois. É desejável que a técnica de discretização gere símbolos de modo a respeitar a equiprobabilidade. Em um cenário onde os dados possuem distribuição Gaussiana, é possível definir os cortes de modo que as probabilidades sejam aproximadamente as mesmas. A Figura 40 exemplifica o funcionamento da representação, considerando os dados em uma distribuição Gaussiana, o que torna possível separar as regiões em espaços de mesma probabilidade. A curva no lado esquerdo da imagem ilustra essa distribuição, em que $68.2 \%$ dos dados encontram-se entre $-1 \sigma$ e $1 \sigma$. Assim, para dividir a região em 3 partes, é só encontrar os locais que separam os dados em $33 \%$ para cada uma das regiões, separando-as em $A, B$ e $C$. As divisões devem ocorrer aproximadamente em $-0.39 \sigma$ e $0.39 \sigma$. Os valores do PAA são então mapeados para as letras definidas para as regiões. Dessa forma a discretização dos dados da série indicada gera a sequência " $C B A C A B$ ".

Figura 40 - Representação do Symbolic Aggregate Approximation

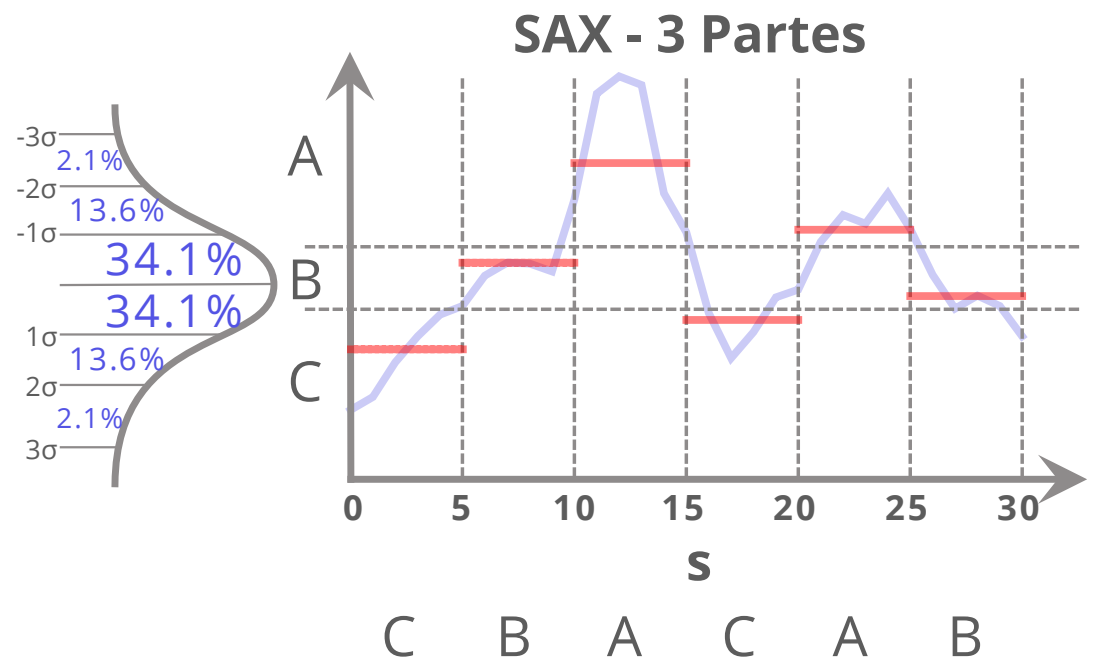

Fonte: Elaborada pelo autor.

Uma versão do SAX chamada de Indexable Symbolic Aggregate Approximation (iSAX) (SHIEH; KEOGH, 2008) foi criada para ser utilizada em larga escala, para que milhões de séries temporais possam ser indexadas de modo rápido. A $i S A X$ que utiliza a ideia por trás das multiresoluções dos Wavelets para permitir a indexação das séries temporais também em multiresoluções. A técnica permite representar uma mesma série temporal com diferentes cardinalidades e permite que séries com cardinalidades diferentes tenham sua distância calculada. 


\subsubsection{Representações Baseadas em Modelo}

As principais representações baseadas em modelos são os Hidden Markov Models (HMM) (RABINER; JUANG, 1986). Os HMM's representam uma série temporal de modo estocástico, isto é, um processo não determinístico, representando os elementos por meio da utilização dos parâmetros: número de estados, densidade das observações, a transição com a sua respectiva probabilidade e o estado inicial.

Dois modelos comumente utilizados para descrever as séries temporais são os modelos AutoRegressive Moving Average (ARMA) (BOX; JENKINS; REINSEL, 1994; MITSA, 2010) e AutoRegressive Integrated Moving Average (ARIMA) (BOX; JENKINS; REINSEL, 1994; MITSA, 2010), podendo modelar um grande número de séries temporais. O modelo pode ser dividido em duas partes: uma auto-regressiva, que se baseia nos elementos passados da série temporal, e outra chamada média móvel, que representa os erros das observações passadas (MITSA, 2010). Esse modelo serve tanto para entender melhor a série temporal ou para predizer os valores futuros com base nos passados. Os modelos ARMA e ARIMA são designados para séries temporais estacionárias, porém podem ser aplicados a séries não estacionárias após serem transformadas em estacionárias.

\subsection{Considerações Finais}

Este capítulo apresentou os principais conceitos relacionados a séries temporais, incluindo diferentes medidas de dissimilaridade e as principais técnicas de representação de séries temporais presentes na literatura. Neste trabalho, séries temporais são utilizadas na etapa de alinhamento dos canais do anáglifo, numa nova abordagem para reversão anaglífica. Foram exploradas diferentes medidas de dissimilaridade e técnicas de representação. Além disto, foi proposta uma representação mais adequada ao problema em questão.

O método desenvolvido (SIRA), é detalhado no próximo capítulo, incluindo a utilização de séries temporais, otimizações realizadas e análise de complexidade de cada uma das etapas do método. 
A geração e visualização de conteúdos estereoscópicos, como o anáglifo, tem crescido rapidamente nos últimos anos. Nesse contexto, trabalhos de pesquisa voltados à reversão anaglífica, com o intuito de recuperar o par estéreo, têm despertado interesse da comunidade científica. Entretanto, poucas técnicas para reconstruir uma aproximação do par estéreo original foram desenvolvidas.

Conforme discutido no Capítulo 3, grande parte das técnicas existentes utilizam metadados adicionais ou são aplicadas a cenários muito restritos, que não representam a realidade das imagens anaglíficas. Outra limitação é a alta complexidade computacional de tais técnicas, o que inviabiliza sua utilização em larga escala.

Com o intuito de superar as limitações mencionadas, neste trabalho de mestrado foi desenvolvida a técnica SIRA ${ }^{1}$, do inglês Stereo Images Retrieving from Anaglyphs, para reconstrução dos canais de cores do par estéreo a partir do anáglifo, com baixo custo computacional. Na Seção 5.1 são detalhadas as 6 etapas executadas pela técnica SIRA, para a realização da reversão anaglífica. Na Seção 5.2 são apresentadas as otimizações implementadas para a técnica proposta. Na Seção 5.3 são realizados os cálculos de complexidade para a SIRA. Por fim, na Seção 5.4 são apresentadas as considerações finais, incluindo as principais vantagens da técnica proposta em relação às correlatas.

\subsection{Etapas da técnica SIRA}

Conforme descrito na seção Capítulo 3, a reversão anaglífica é um processo interessante, pois permite a visualização de imagens por métodos bidimensionais ou outros métodos estereoscópicos. Para atingir este resultado, e superar as principais limitações existentes nos trabalhos

1 O código multiplataforma da técnica SIRA, códigos extras e anáglifos gerados estão disponíveis em: https://drive.google.com/sira_technique. 
correlatos encontrados na literatura, foi proposta a técnica SIRA, para reconstrução dos canais de cores do par estéreo perdidos a partir do anáglifo. A SIRA utiliza técnicas de análise de séries temporais e possui baixo custo computacional.

A técnica SIRA é composta por 6 etapas principais, ilustradas na Figura 41: (1) Separação dos Canais de Cores e Segmentação, (2) Extração de Características, (3) Alinhamento de Séries, (4) Validação da Reciprocidade entre Pixels, (5) Propagação do Alinhamento e (6) Colorização de Pixels Remanescentes. As seções seguintes apresentam detalhes sobre o funcionamento de cada etapa.

Figura 41 - Etapas do processo de recuperação anaglífica proposto.

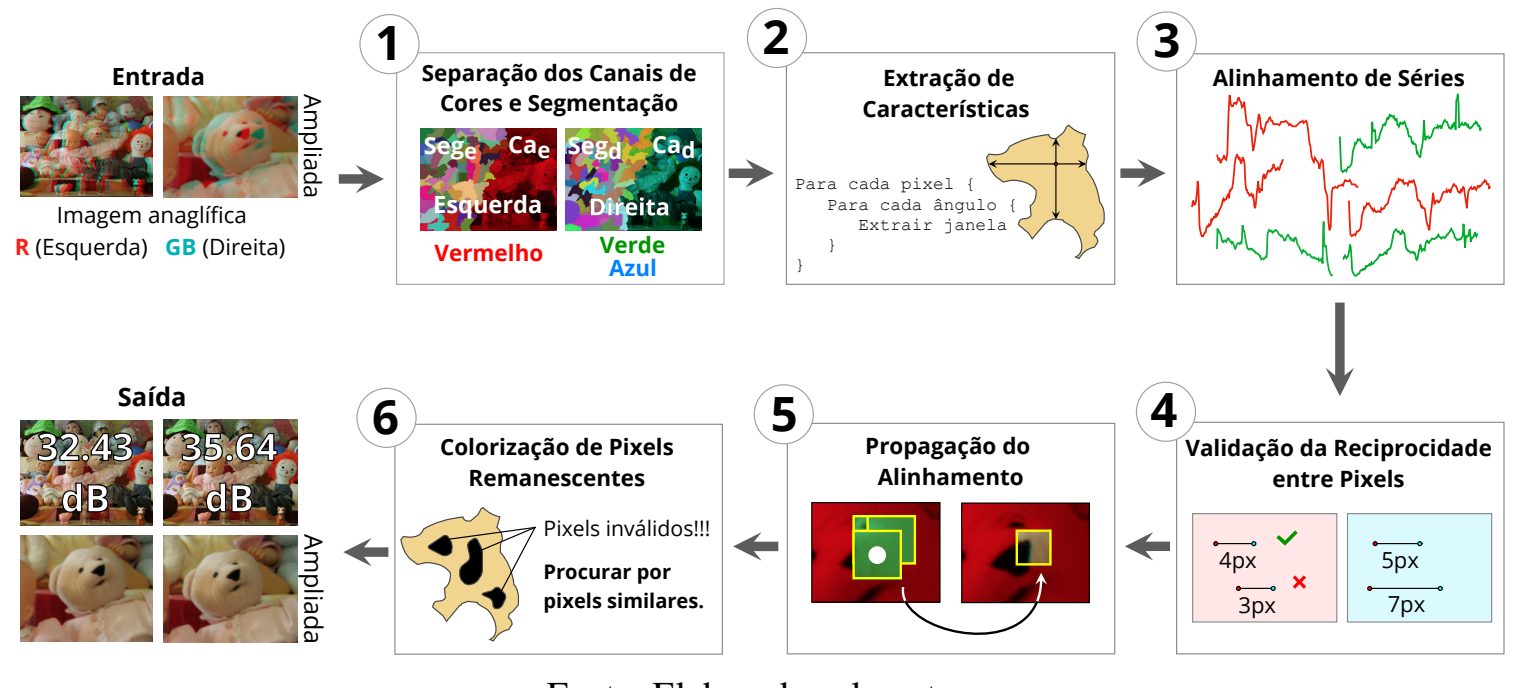

Fonte: Elaborada pelo autor.

As etapas de extração de características, alinhamento de séries, validação da reciprocidade entre pixels, propagação do alinhamento e colorização dos pixels remanescentes (2 à 6), apresentadas na Figura 41 são realizadas duas vezes, para gerar as aproximações das imagens esquerda e direita do par estéreo, respectivamente.

\subsubsection{Separação dos Canais e Segmentação}

A primeira etapa é o processo de Separação dos Canais de Cores e Segmentação (1), que tem como objetivo separar, a partir do anáglifo, cada uma das imagens a serem reconstruídas, permitindo processá-las individualmente e gerar segmentações para cada uma delas. Esta etapa recebe como entrada o anáglifo (no formato .bmp) e a sua composição.

A composição do anáglifo determina o lado (imagem esquerda ou imagem direita) em que estão dispostos cada um dos canais de cores, que pode ser vermelho-ciano, verdemagenta, azul-âmbar, dentre outras. Desse modo, é necessário informar a qual destas composições correspondente o anáglifo de entrada e o lado em que cada cor está presente. 
Por ser o modelo de anáglifo mais comum, a composição considerada como exemplo é a vermelho-ciano, em que o canal vermelho compõe o lado esquerdo e os canais verde e azul (imagem ciano) o lado direito. Sendo o lado esquerdo representado pelo valor 0 e o lado direito pelo valor 1 , a entrada da composição do anáglifo consiste na tripla $(0,1,1)$, que corresponde respectivamente aos lados dos canais vermelho, verde e azul (R,G,B), indicando que o vermelho está à esquerda (0), enquanto verde e azul estão à direita $(1,1)$.

O anáglifo de entrada é então separado em duas imagens, contendo os seus respectivos canais, de acordo com os valores da composição de entrada: uma imagem para o lado esquerdo $\left(C a_{e}\right)$ e outra para o lado direito $\left(C a_{d}\right)$. A do lado esquerdo $\left(C a_{e}\right)$ contém o canal vermelho não nulo e intensidade 0 para todos os pixels dos canais verde a azul, enquanto a imagem do lado direito $\left(C a_{d}\right)$, possui os canais verde e azul não nulos e canal vermelho com intensidade 0 para todos os pixels.

Um dos aspectos principais para realizar a tarefa de alinhamento é definir como os trechos das imagens esquerda e direita serão comparados, a fim de encontrar correspondências entre os lados. Observe que quando a imagem $\mathrm{Ca}_{e}$ está sendo processada, o lado complementar, onde busca-se o trecho correspondente, é a imagem $C a_{d}$, e quando a imagem $C a_{d}$ está sendo processada, o lado complementar é a imagem $C a_{e}$. Algumas técnicas, como a de Bando, Chen e Nishita (2008) e Lin et al. (2012), utilizam blocos quadrados para encontrar essas correspondências, tal como ilustrado pela Figura 42. Na parte superior é possível observar dois blocos correspondentes, um extraído do lado esquerdo (em vermelho) e outro extraído do lado direito (em ciano), em que, mesmo apesar das intensidades distintas, os olhos e as sobrancelhas da boneca estão alinhados.

Figura 42 - Problema no processo para encontrar blocos correspondentes entre as imagens.
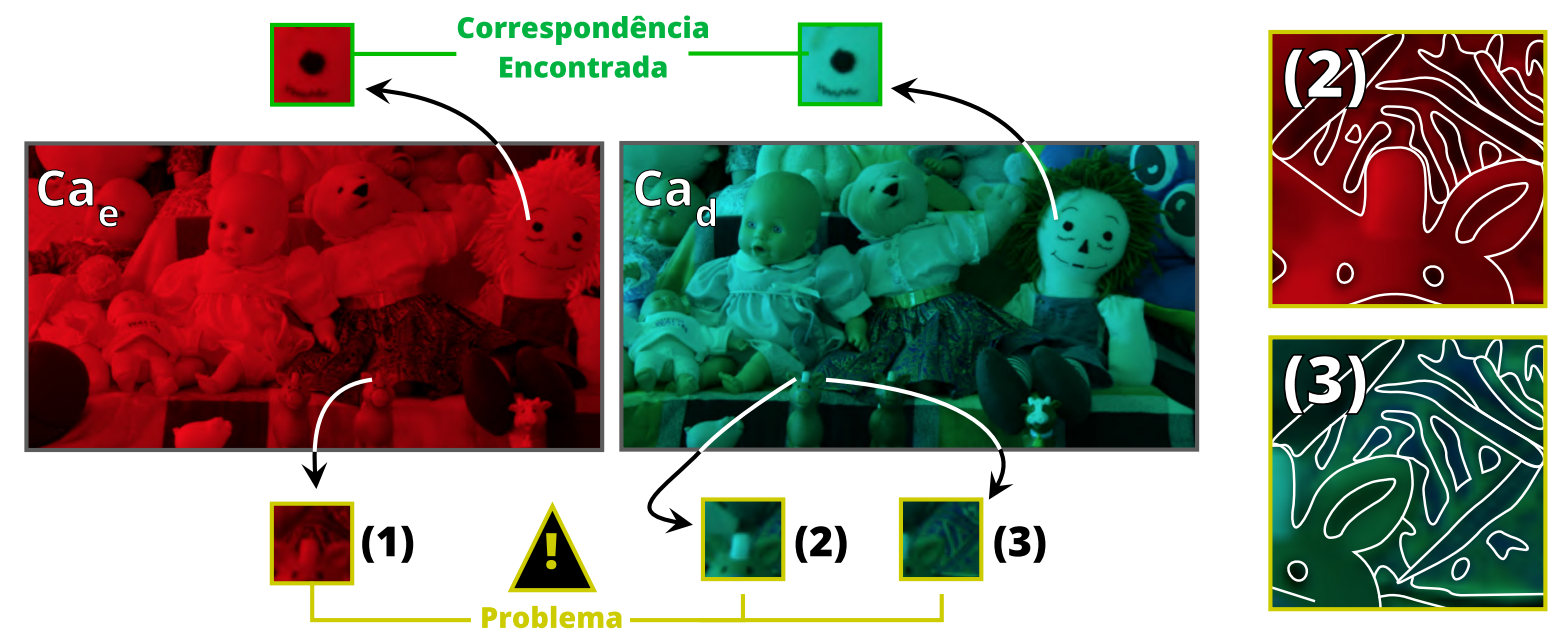

Fonte: Elaborada pelo autor.

Já na parte inferior, é apresentado um outro bloco como exemplo. Dentre todos os blocos comparados, dois blocos da imagem complementar apresentam maior similaridade com o bloco da imagem da esquerda (1). O primeiro (2) tem a parte da frente alinhado corretamente com 
o rosto do cavalo, e o segundo (3) tem o fundo alinhado corretamente no vestido da boneca. Portanto, dependendo do ponto central (que representa o bloco 1), a correspondência pode ou não ser realizada corretamente.

A fim de evitar os problemas apresentados com processamento em blocos, foi utilizada a segmentação de imagens. Efetuando a segmentação na Figura 42, o cavalo pertenceria a um segmento e o fundo, composto pelo vestido das bonecas, pertenceria a outro segmento, evitando assim os conflitos existentes quando comparado ao processamento em blocos. Assim, as imagens $C a_{e}$ e $C a_{d}$ são segmentadas de maneira independente, gerando, respectivamente, as imagens $\mathrm{Seg}_{e}$ e $\mathrm{Seg}_{d}$.

O processo de segmentação adotado é baseado em superpixels, pois normalmente geram segmentos menores que os objetos contidos na imagem. Este processo, conhecido como oversegmentation (WANG et al., 2017), é adequado para a etapa de alinhamento, pois a tendência é que um mesmo segmento (superpixel) tenha pixels com disparidades similares.

Dentre os algoritmos para geração de superpixels propostos na literatura, foi selecionado o SLICO Superpixels ${ }^{2}$, que corresponde ao algoritmo SLIC (ACHANTA et al., 2010) com parâmetro de compactação automático. O algoritmo SLIC é interessante no contexto deste trabalho por ser computacionalmente eficiente e gerar superpixels com boa qualidade (aderir bem às bordas) (STUTZ; HERMANS; LEIBE, 2018). Detalhes relacionados à implementação do algoritmo SLIC podem ser encontrados em seu trabalho original (ACHANTA et al., 2010). Além de oferecer melhor qualidade que o processamento de correspondências em blocos, o algoritmo de segmentação por superpixels permite podar diversas operações que seriam executadas para as técnicas que utilizam processamento de correspondências em blocos, otimizando a etapa de extração de características. Detalhes são apresentados nas próximas seções.

\subsubsection{Extração de Características}

Uma vez que as imagens de ambos os lados foram segmentadas, o processo de Extração de Características (2) pode ser executado. Este processo possui o objetivo de criar representações para os pixels, permitindo comparação e alinhamento individual de cada pixel.

A ideia principal proposta na técnica SIRA é tratar as intensidades dos pixels como séries temporais e realizar comparações por similaridade na etapa de alinhamento. É importante mencionar que os anáglifos de entrada possuem apenas o deslocamento horizontal, assim os pixels correspondentes para o alinhamento encontram-se na mesma linha. Mesmo não havendo presença de tempo no anáglifo, é possível traçar um paralelo entre séries temporais e imagens. Uma série temporal basicamente leva em consideração que a ordem das observações é importante, existindo portanto, um eixo para o tempo, e outro para a variável que está sendo analisada. $\mathrm{Na}$ abordagem proposta na SIRA, a ordem definida no eixo do tempo corresponde à sequência de

2 https://ivrl.epfl.ch/research-2/research-current/research-superpixels/. Acesso em 04/07/2019. 
pixels adjacentes, e as observações da variável analisada correspondem a variações de intensidade de pixels adjacentes. Observe que, tal como nos problemas relacionados com séries temporais, a ordem das observações também é levada em consideração.

A Figura 43a ilustra uma série multivariada, extraída de uma imagem estéreo comum (não anaglífica), que possui os três canais de cores (R,G,B) alinhados. Esta série foi extraída por meio das intensidades de cor dos pixels para uma mesma linha da imagem. Por meio desta série é possível verificar que existe uma forte correlação entre os três canais de cores, com as intensidades dos três canais oscilando em sincronia. Essa alta correlação entre as séries motivou a utilização de técnicas aplicadas a séries temporais para a tarefa de reversão anaglífica. Observe que as oscilações não necessariamente ocorrem com mesmas diferenças de intensidade ("amplitude") e não necessariamente na mesma direção. Por exemplo, o trecho destacado em amarelo mostra as três séries oscilando em sincronia, porém a série formada pela intensidade verde que estava em movimento ascendente, passou para descendente, enquanto a série formada pelas intensidades de azul que estava em movimento descendente, passou para ascendente.

Figura 43 - Representação de características por meio de séries. Ambas as séries são geradas para pixels adjacentes de uma mesma linha.

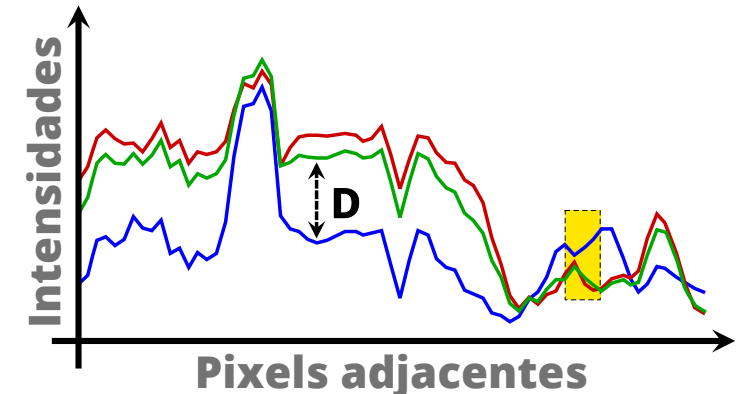

(a) Representação de série para imagem estéreo.

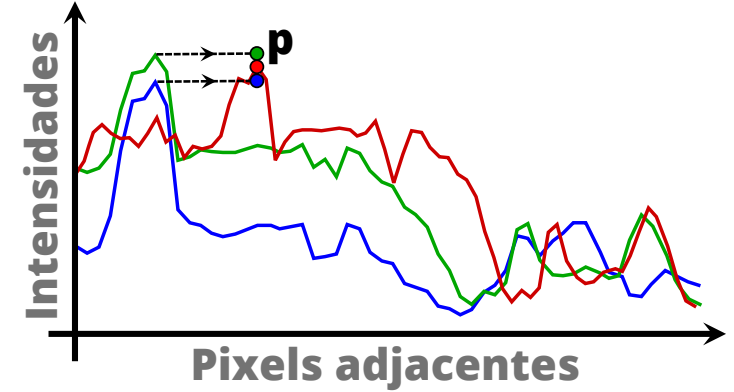

(b) Representação de série para imagem anaglífica

Fonte: Elaborada pelo autor.

Ao observar a série gerada na imagem anaglífica, ilustrada pela Figura 43b, é possível observar que apesar das séries em azul e verde estarem ligeiramente diferentes e deslocadas com relação as séries do par estéreo, as séries apresentam comportamentos ainda fortemente correlacionados com a série em vermelho. Deste modo, para encontrar a cor verde e azul aproximada de um determinado pixel $p$ (bolinha em vermelho), é necessário encontrar o deslocamento dessas duas séries e copiar as intensidades desta (única) posição encontrada para a posição do pixel $p$, tal como ilustrado pelas setas pontilhadas da Figura 43b, gerando como resultado as bolinhas em verde e azul. Portanto, ao executar este processo individualmente para todos os pixels, é obtido o alinhamento inicial, que pode ser representado como um mapa de profundidade (Seção 2.2). É importante mencionar que foi exemplificado o processo de recuperação dos canais verde e azul, mas tal processo também é executado para a reconstrução do canal vermelho.

Um dos grandes problemas em realizar a comparação direta entre as intensidades dos 
pixels é a diferença de amplitude dos canais, ilustrado na Figura 43a, observada pela distância $D$ entre os canais de cores (mesmo para imagem não anaglífica), além dos comportamentos ligeiramente distintos entre os canais de cores. Assim, para que canais diferentes possam ser comparados adequadamente, a solução proposta na técnica SIRA é representar as séries originais por meio da diferença entre intensidades adjacentes $\left(p_{\text {representado }}=a b s\left(p_{\text {posterior }}-p_{\text {anterior }}\right)\right)$. Suponha que uma série contem a sequência de valores $(100,110,112,115,120)$, então ela será representada por $(10,2,3,5)$. Essa representação por meio da diferença é ilustrada pela Figura 44a, em que a série vermelha contém as intensidades originais e a série em laranja é a representada. Esta solução, além de remover as diferenças nas direções (bloco amarelo pontilhado da Figura 43a), remove a tendência da série temporal (Seção 4.1), que é apresentada de maneira distinta para cada um dos canais de cores, dificultando as comparações entre as séries das diferentes cores. Assim é levada em consideração a componente sazonal e a componente estocástica, tratadas de maneira conjunta, e as grandes diferenças de intensidade são representadas por picos. Note que ao remover a tendência das séries, também deixa de ser necessário uma análise com relação a propriedade de estacionariedade das séries, já que séries sem tendência são estacionárias.

Figura 44 - Representação de séries por meio da diferença entre elementos adjacentes e extração do tamanho das janelas.

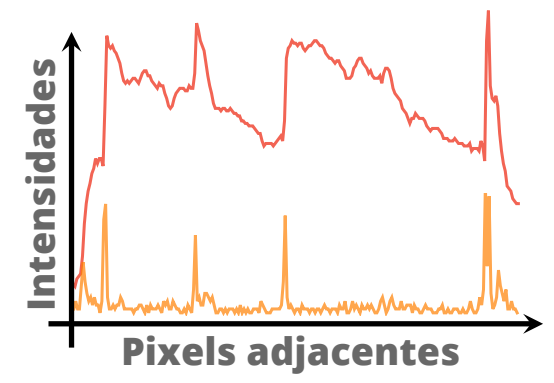

(a) Geração de série representada, em laranja, a (b) partir de série original, em vermelho.

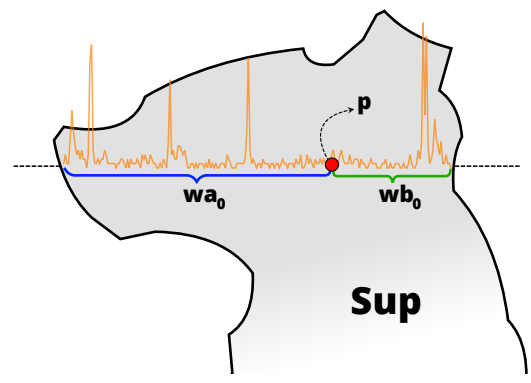

Tamanhos de janela da série definida com base no superpixel Sup.

Fonte: Elaborada pelo autor.

Para executar o alinhamento de um pixel, não faz sentido comparar o pixel do canal vermelho com um único pixel verde e/ou azul do lado complementar (ou vice-versa), uma vez que os canais tem cores distintas (caso oposto seria capturada a cor mais próxima, tendendo a uma imagem em escala de cinza). Porém também não faz sentido utilizar a série inteira (toda a linha) para realizar as comparações, uma vez que pixels de uma mesma linha geralmente possuem disparidades distintas. Portanto, a técnica SIRA utiliza os segmentos $\mathrm{Seg}_{e}$ e $\mathrm{Seg}_{d}$ gerados na etapa anterior para definir as janelas das séries a serem comparadas, assim como ilustrado na Figura 44b. Dado um pixel $p$, que se deseja alinhar, podem ser definidas duas medidas, $w a_{0} \mathrm{e}$ $w b_{0}$, correspondendo respectivamente a distância (chebyshev) da borda esquerda do superpixel (Sup) ao pixel $p$ e a distância do pixel $p$ até a borda direita do superpixel (Sup). Observe que Sup é um superpixel definido por $\mathrm{Seg}_{e}$ ou $\mathrm{Seg}_{d}$ (dependendo do lado que está sendo alinhado). 
Inicialmente, para encontrar um pixel correspondente na imagem complementar, foi utilizada apenas uma série ( 1 ângulo - horizontal - $0^{\circ}$ ), assim como exemplificado, mas estudos experimentais indicaram que a utilização de mais ângulos melhora a qualidade do alinhamento. Este resultado comprova que utilizar apenas um ângulo não fornece informações suficientes para executar um alinhamento satisfatório. Desta forma, ao utilizar mais ângulos, mais informações são apresentadas à técnica, permitindo distinguir melhor os alinhamentos corretos e incorretos. Vale mencionar que a utilização de informações de outras linhas é realizada para o alinhamento dos pixels na linha corrente, sendo assim, alinhamentos em linhas distintas não são considerados. Logo, foi definida a utilização de quatro ângulos, $\theta=4$, de maneira experimental (detalhes na Subseção 6.3.4), em que os $360^{\circ}$ ao redor do pixel $p$ são divididos igualmente em $2 \times \theta$ partes. Portanto, ao invés de utilizar somente $w a_{0}$ e $w b_{0}$, são utilizados mais ângulos para representar o pixel $p$, assim como ilustrado na Figura 45a, em que são extraidas os oito tamanhos de janela ( $w a_{c}$ e $w b_{c}$, com $c \in\left\{0^{\circ}, 45^{\circ}, 90^{\circ}, 135^{\circ}\right\}$ ) definidas com base na distância chebyshev, em pixels. Esse vetor de tamanhos para o pixel $p$ é formalizado pela Equação 5.1, é chamado de $F^{x, y, S e g_{e}}$, com $x, y$ correspondendo a posição do pixel $p$ na imagem $S_{e} g_{e}$, que contém todos os segmentos (ou superpixels) do lado esquerdo. Novamente, é relevante mencionar que todos os processos executados para a imagem do lado esquerdo, conforme explicado, também são executados para a imagem do lado direito. É importante mencionar que apesar de as séries estarem representadas, nenhuma série foi extraída até o momento. Até o momento foram extraídas informações relativas a tamanho de janelas.

$$
\begin{gathered}
F^{x, y, \operatorname{Seg}_{e}}=\left(\left(w a_{0}, w b_{0}\right),\left(w a_{45}, w b_{45}\right),\left(w a_{90}, w b_{90}\right),\left(w a_{135}, w b_{135}\right)\right) \\
P i v \hat{o}^{x, y, S e g_{e}}=S\left(F^{x, y, S e g_{e}}, C a_{e}, x, y\right)
\end{gathered}
$$

Por meio do vetor $F$, é possível realizar a extração das séries que representam o pixel $p$, por meio de uma função de extração $S$, formalizado pela Equação 5.2, que recebe o vetor $F$, a imagem que armazena as intensidades do canal vermelho $\left(C a_{e}\right)$ e a posição do pixel $p(x, y)$, gerando as séries representadas por meio da diferença entre elementos adjacentes, em laranja na Figura 45b. Portanto, para cada par de valores $\left(w a_{c}, w b_{c}\right)$ de $p$ (Figura 45a), de determinado ângulo $c$, é gerada uma série representada de tamanho $w a_{c}+w b_{c}+1$, com as intensidades que compõem o segmento gerado (Figura 45b). A estas quatro séries extraídas (Série 1 a Série 4) para o lado $C a_{e}$ (imagem sendo alinhada), daremos o nome de pivô do pixel $p$, uma vez que serão utilizadas para diversas comparações com o lado complementar.

Além de extrair característica para o pixel $p$, também é necessário extrair as características da imagem complementar, que serão utilizadas na comparação com o pixel $p$. A estes pixels que serão comparados com $p$ daremos o nome de candidatos. Entre estes $\mathscr{L}$ candidatos, um será selecionado como correspondente do pixel $p$. O valor de $\mathscr{L}$ é definido empiricamente, sendo necessariamente maior (ou igual) à maior disparidade encontrada na imagem. Cada uma dessas 
Figura 45 - (a) Extração dos tamanhos das janelas para cada um dos ângulos; (b) Extração das 4 séries representadas para um pixel $p$.

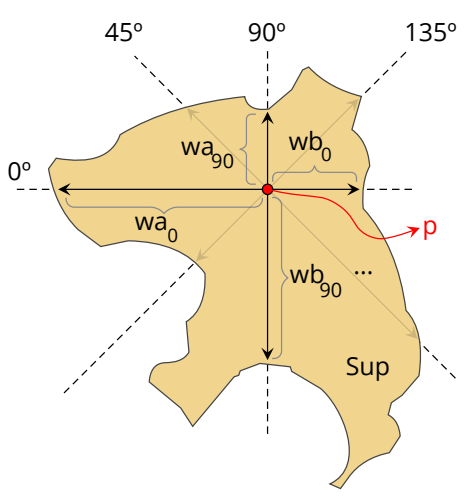

(a)

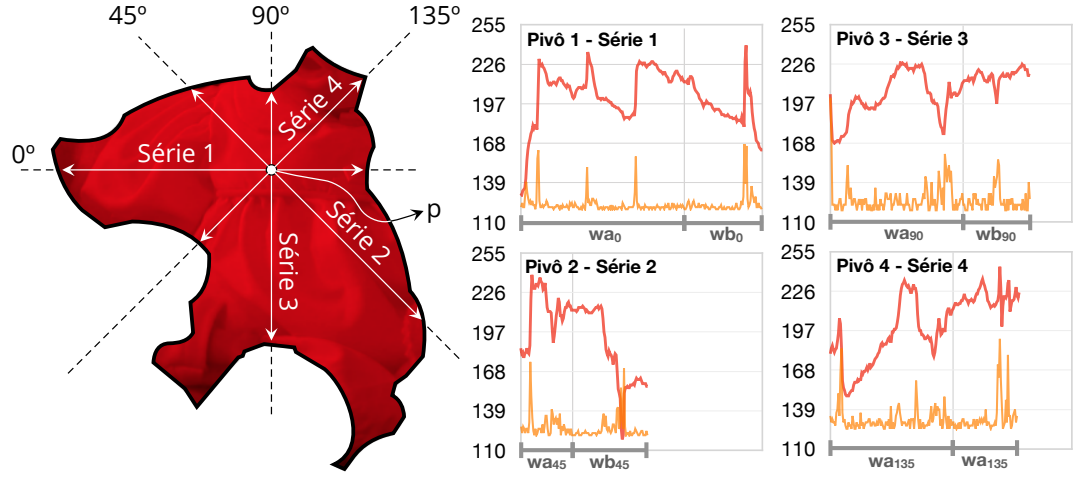

(b)

Fonte: Elaborada pelo autor.

possibilidades é dada pelo deslocamento horizontal de +1 pixel para a esquerda, ou seja, só ocorre deslocamento no eixo $x$ em relação à variável $p$. Quando o alinhamento é realizado para a imagem da direita, o deslocamento é para a direita. Lembrando que esses valores mudam quando está sendo utilizada outra composição de anáglifo, diferente de vermelho-ciano $(0,1,1)$.

$$
\operatorname{Comp}^{x, y, \operatorname{Seg}_{e}, \operatorname{disp}}=S\left(F^{x, y, S e g_{e}}, \operatorname{Ca}_{d}, x+\operatorname{disp}, y\right) \mid \operatorname{disp} \leq \mathscr{L}
$$

Portanto, para um pixel $p$ do lado esquerdo, são extraídas $\mathscr{L} \times 4$ características para o lado direito, pois cada pixel é representado por 4 séries. Essas características extraídas são formalizadas pela Equação 5.3, em que $S$ é a função que extrai uma série por meio dos oito tamanhos de janela do pixel $p$ (lado esquerdo), dado por $F^{x, y, S e g_{e}}$. Além disso, são enviadas as intensidades do canal direito, da qual serão extraídas as $\mathscr{L}$ séries $\left(C a_{d}\right)$ e a posição do pixel esquerdo, já acrescida da disparidade disp desejada $(x+$ disp $)$. A Figura 46 ilustra esse processo para um $\left(45^{\circ}\right)$ dos quatro ângulos extraídos. Observe que o tamanho da janela é sempre o mesmo

Figura 46 - Séries candidatas para alinhamento do pixel $p$.

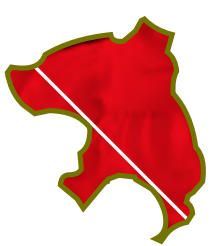

Série Representada

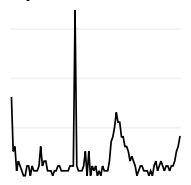

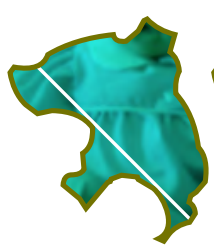

$\operatorname{disp}=0$

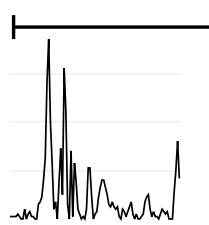

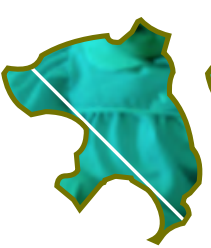

$\operatorname{disp}=1$

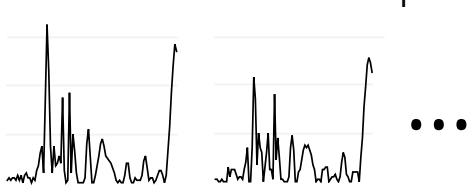

Fonte: Elaborada pelo autor.
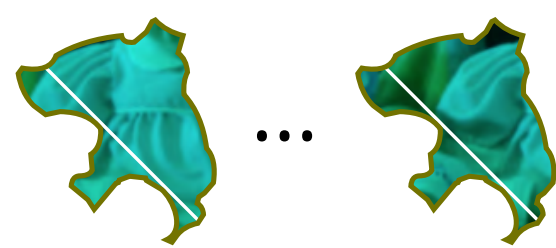

$\operatorname{disp}=60$

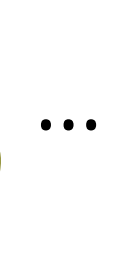

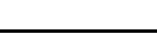
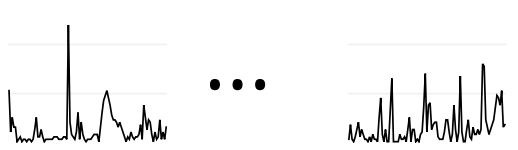
do extraído para o lado esquerdo (em vermelho), gerando assim as disparidades para o lado complementar, portanto é enviado $F^{x, y, S e g_{e}}$ para a função $S$ que captura a série representada, e não $F^{x+d i s p, y, S e g_{d}}$. Note também que $\mathscr{L}=60$ para o exemplo ilustrado.

Esta etapa apresentou a extração de características para um pixel $p$ qualquer, e também as características para seus respectivos $\mathscr{L}$ candidatos, ou seja, possíveis pixels correspondentes no lado complementar. O próximo passo é definir qual destes candidatos entre os $\mathscr{L}$ extraídos é o mais adequado para compor os canais $G$ e $B$ do pixel $p$.

\subsubsection{Alinhamento de Séries}

O principal objetivo da fase de Alinhamento de Séries (3) é encontrar os correspondentes entre os pixels do lado que está sendo alinhado e os pixels do lado complementar.

A função de distância utilizada no alinhamento é a $L_{2}$ (Equação 4.4 da Subseção 6.3.1). Por meio desta função de distância é possível realizar o cálculo das distâncias entre as séries (Equação 5.4), para cada disparidade disp, dado um ângulo $c$ e um ponto $p$. A disparidade varia de 0 até um valor maior ou igual à máxima disparidade encontrada nas imagens $(\mathscr{L})$.

$$
\operatorname{Dist}(c, \operatorname{disp})=L_{2}\left(\operatorname{Piv}_{c}^{x, y, \operatorname{Seg}_{e}}, \operatorname{Comp}_{c}^{x, y, \operatorname{Seg}_{e}, \operatorname{disp}}\right)
$$

Para cada ponto $p$ sendo alinhado, uma matriz Mat é gerada (Matriz M1). Nesta matriz, as colunas representam as disparidades e as linhas os ângulos. Por exemplo, $\operatorname{Dist}\left(45^{\circ}, 5\right)$ é a distância entre o pixel $p$ para o lado esquerdo, com o pixel $(p \cdot x+5, p \cdot y)$ do lado direito, lembrando que a configuração de janela é dada pelo lado que está sendo alinhado (no caso o esquerdo). Lembrando que para $\theta=4, c \in\left\{0^{\circ}, 45^{\circ}, 90^{\circ}, 135^{\circ}\right\}$. Observe que Dist $(c, \operatorname{disp})^{x, y, \text { Sege }_{e}}$ foi simplificado para $\operatorname{Dist}(c$, disp $)$ para melhor entendimento, uma vez que todo processamento desta etapa é executado para um único pixel $p$.

Exemplificando a matriz Mat, a Figura 46 apresenta a série pivô em vermelho e as $\mathscr{L}$ candidatas em verde, assim as distâncias computadas são: $\operatorname{Dist}\left(45^{\circ}, 0\right)$ é igual a comparação das séries geradas para dis $p=0$ e a pivô, por meio da distância $L_{2} ; \operatorname{Dist}\left(45^{\circ}, 1\right)$ é igual a comparação das séries geradas para $\operatorname{dis} p=1$ e a pivô, por meio da distância $L_{2}$; e assim por diante. Observe que após executar todas as comparações possíveis para a Figura 46 (ângulo 45º), a segunda linha da matriz Mat é completamente preenchida.

Na matriz Mat, são calculados $\theta$ medidas de distância para um mesmo valor de disparidade em um pixel $p$, não sendo possível afirmar, em princípio, qual é a melhor disparidade a ser considerada para alinhamento. A partir de testes experimentais, foram atribuídos pesos iguais para os ângulos, a fim de gerar um valor de distância único por disparidade.

A Equação 5.6 formaliza o processo de seleção do melhor alinhamento para o pixel $p$. Primeiramente a matriz $\mathrm{Mat}^{x, y, \mathrm{Seg}_{e}}$ (Matriz M1) é normalizada linha a linha (row-wise normali- 
zation) por meio da Equação 5.5, definindo valores entre 0 e 1 . Então é realizada a soma dos $\theta$ elementos da mesma coluna desta matriz normalizada, gerando um vetor de tamanho $\mathscr{L}$, em que cada posição contém a dissimilaridade entre o pixel $p$ em uma determinada disparidade. Uma vez que o principal objetivo é alinhar com pixel mais adequado, ou seja, com menor dissimilaridade, é executada a função argmin, capturando o valor disp do candidato que gerou menor dissimilaridade. $\mathrm{O}$ mesmo processo executado para este pixel $p$ é executado para todos os pixels da imagem direita e esquerda. Ao final do processo de alinhamento, todos os pixels são associados a uma disparidade, gerando as matrizes $r e s_{e}$ e $r e s_{d}$.

$$
\operatorname{Mat}^{x, y, \operatorname{Seg}_{e}}=\left[\begin{array}{ccccc}
\operatorname{Dist}\left(0^{\circ}, 0\right) & \operatorname{Dist}\left(0^{\circ}, 1\right) & \operatorname{Dist}\left(0^{\circ}, 2\right) & \ldots & \operatorname{Dist}\left(0^{\circ}, \mathscr{L}\right) \\
\operatorname{Dist}\left(45^{\circ}, 0\right) & \operatorname{Dist}\left(45^{\circ}, 1\right) & \operatorname{Dist}\left(45^{\circ}, 2\right) & \ldots & \operatorname{Dist}\left(45^{\circ}, \mathscr{L}\right) \\
\vdots & \vdots & \vdots & \ddots & \vdots \\
\operatorname{Dist}\left(135^{\circ}, 0\right) & \operatorname{Dist}\left(135^{\circ}, 1\right) & \operatorname{Dist}\left(135^{\circ}, 2\right) & \ldots & \operatorname{Dist}\left(135^{\circ}, \mathscr{L}\right)
\end{array}\right]
$$

$$
\begin{gathered}
\operatorname{NormMinMax}_{i, j}=\frac{\operatorname{Mat}_{i, j}-\min \left(\mathbf{M a t}_{\mathbf{i}}\right)}{\max \left(\mathbf{M a t}_{\mathbf{i}}\right)-\min \left(\mathbf{M a t}_{\mathbf{i}}\right)} \\
\operatorname{res}^{x, y, \text { Seg }_{e}}=\operatorname{argmin}\left(\sum_{m=0}^{m<\theta} \operatorname{NormMinMax}\left(\text { Mat }^{x, y, \text { Seg }_{e}}\right)_{m, d i s p}\right) * l_{\text {lado }}
\end{gathered}
$$

Figura 47 - Geração das matrizes de disparidade $r e s_{e}$ e $r e s_{d}$.

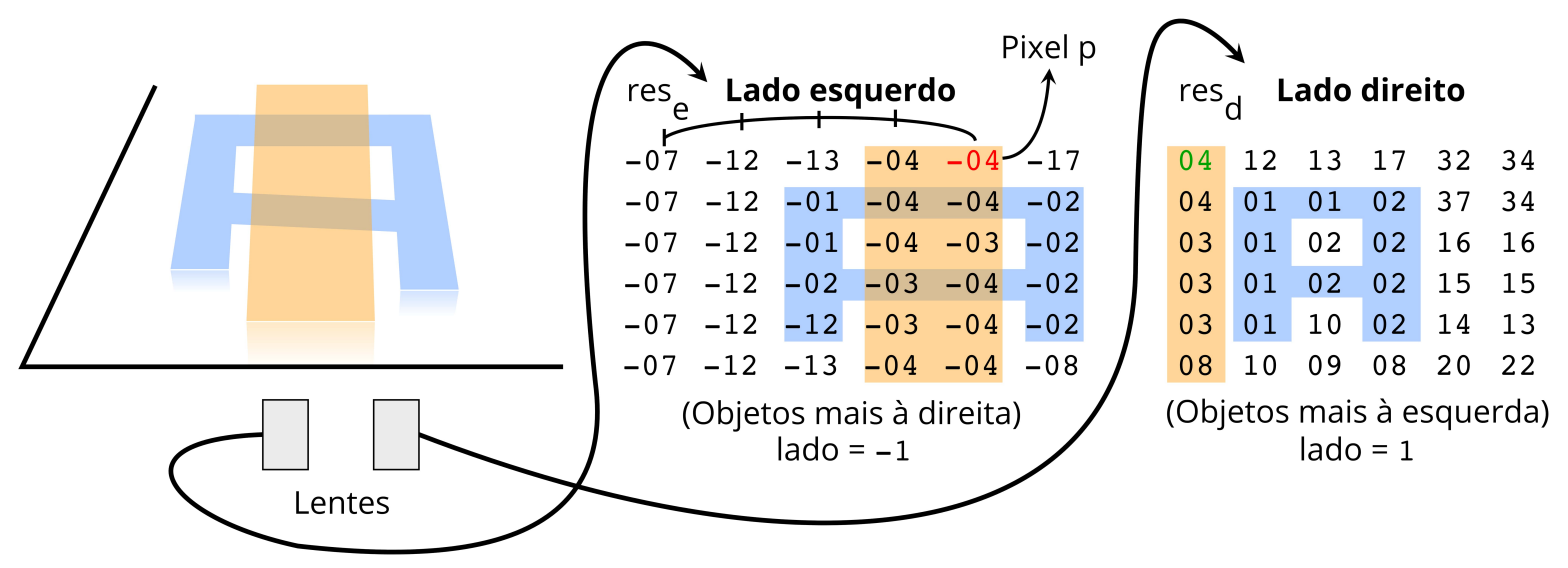

Fonte: Elaborada pelo autor.

A Figura 47 ilustra a geração das matrizes de disparidade $\left(r e s_{e}\right.$ e $\left.r e s_{d}\right)$, que possuem as mesmas dimensões da imagem anaglífica. Conforme explicado na Seção 2.2, o par estéreo é composto por duas imagens ligeiramente distintas devido a disposição das lentes, como apresentado à esquerda da Figura 47, com ambos os objetos capturados pelas duas lentes. Observe que a letra "I", em laranja, encontra-se mais à frente que a letra "A", em azul. Assim, 
as imagens capturadas por cada uma das lentes são ilustradas ao centro e à direita. Novamente é interessante observar que o lado esquerdo possui objetos deslocados à direta e o lado direito objetos deslocados à esquerda. Portanto, a matriz res r $_{e}$ indica o deslocamento necessário para capturar o pixel correspondente na imagem complementar. Por exemplo, ao constatar uma disparidade igual a -4 para o pixel $p$ (em vermelho) da imagem esquerda, significa que é necessário deslocar 4 pixels para a esquerda, encontrando o seu correspondente na imagem complementar (em verde).

Note que a variável lado indica se o algoritmo está reconstruindo a imagem da esquerda $($ lado $=-1)$ ou da direita $(l a d o=1)$. As próximas etapas têm o objetivo tratar os pontos inválidos gerados e refinar a imagem, encontrando também regiões que existem em uma imagem e não existem na sua complementar (regiões oclusas).

\subsubsection{Validação da Reciprocidade entre Pixels}

Após a etapa de alinhamento, todos os pixels de ambas as imagens possuem um valor associado, referente à quantidade de pixels que devem ser deslocados para encontrar o pixel correspondente na imagem complementar. Por meio de uma das propriedades existentes nas imagens estereoscópicas e em anáglifos, em que as disparidades de um mesmo ponto no espaço para duas imagens devem ser opostas, é possível realizar uma Validação da Reciprocidade entre Pixels (4), como ilustrado na Figura 48. Nela é possível observar o anáglifo à esquerda, o preenchimento do canal vermelho ao centro, em que com uma posição $\left(x_{1}, y_{1}\right)$ e uma disparidade igual a 20, é necessário deslocar 20 pixels para à direita, para encontrar o pixel $\left(x_{2}, y_{2}\right)$. Por fim é apresentado o preenchimento do canal verde e azul à direita, em que para o ponto $\left(x_{2}, y_{2}\right)$ é necessário deslocar 20 pixels para à esquerda, encontrando o pixel $\left(x_{1}, y_{1}\right)$. Para que o alinhamento esteja correto, é necessário que as disparidades apresentadas sejam opostas, como no caso ilustrado (20 e -20).

Figura 48 - Processo de validação para cada pixel, por meio da reciprocidade entre distâncias.

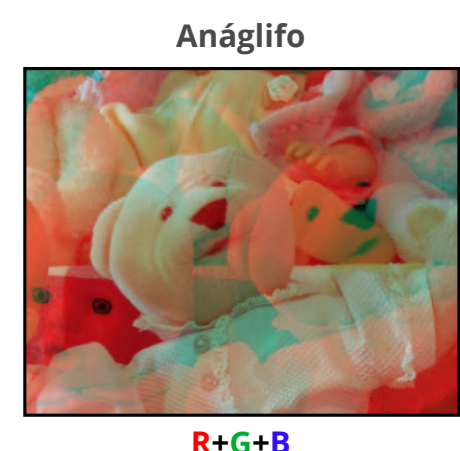

$\mathrm{R}+\mathrm{G}+\mathrm{B}$

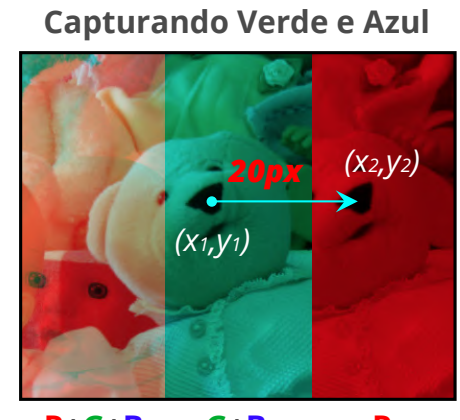

$R+G+B \quad G+B$
$\mathbf{R}$

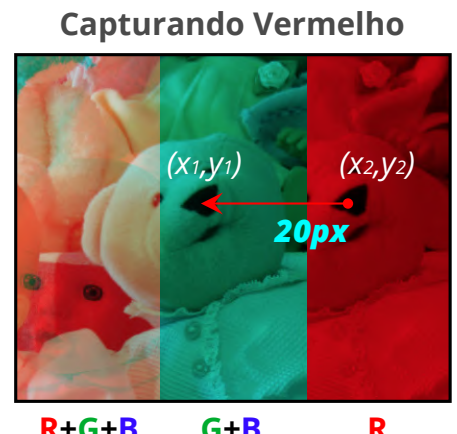

$R+G+B \quad G+B \quad R$

Fonte: Elaborada pelo autor.

Considerando as matrizes de alinhamento geradas para o lado direito $\left(\right.$ res $\left._{d}\right)$ e esquerdo $\left(r e s_{e}\right)$, que possuem as mesmas dimensões das imagens, o filtro apresentado da Equação 5.7 
é aplicado para cada um dos pixels. Considerando um alinhamento ideal, regiões não oclusas apresentam diferença igual a 0, porém, devido à existência de possíveis erros de alinhamento, é considerado um limiar $\gamma$. O valor, definido experimentalmente para $\gamma$ é igual a 4.

$$
\text { valido }_{e}(x, y)= \begin{cases}\text { valido, } & \text { se res } \\ \text { invalido, } & \text { caso oposto. }\end{cases}
$$

A mesma fórmula é aplicada para o lado direito da imagem, sendo necessário apenas trocar o $r e s_{e}$ por $r e s_{d}$ e vice-versa. Ao final são geradas as matrizes valido $e_{e}$ e $v^{2} l i d o_{d}$ que indicam se determinado pixel é valido (1) ou não (0).

\subsubsection{Propagação do Alinhamento}

Após verificar quais pixels foram alinhados com disparidades inconsistentes, muitas regiões ficam sem preenchimento. Neste caso, a aplicação de um algoritmo para colorização destes pontos comprometeria a qualidade final da imagem. Assim, para minimizar este problema, a imagem passa por um processamento intermediário, chamado de Propagação do Alinhamento (5), em que os alinhamentos corretos são propagados para os vizinhos. A principal ideia deste processo é que os vizinhos dos pixels que tiveram alinhamento correto na etapa 4 , também possuem disparidade similar, então os pixels são preenchidos por resultados de vários de seus vizinhos. É interessante mencionar que o processamento também é aplicado para pixels que foram considerados corretos, o que reduz o impacto visual dos erros, suavizando-os.

A partir desta etapa de refinamento os pixels deixam de ter uma disparidade associada, e possuem apenas as cores que os compõem, assim as matrizes de disparidades (res $s_{e}$ e res ${ }_{d}$ ) não são alteradas.

Figura 49 - Propagação do alinhamento para os pixels considerados incorretos nas etapas anteriores.
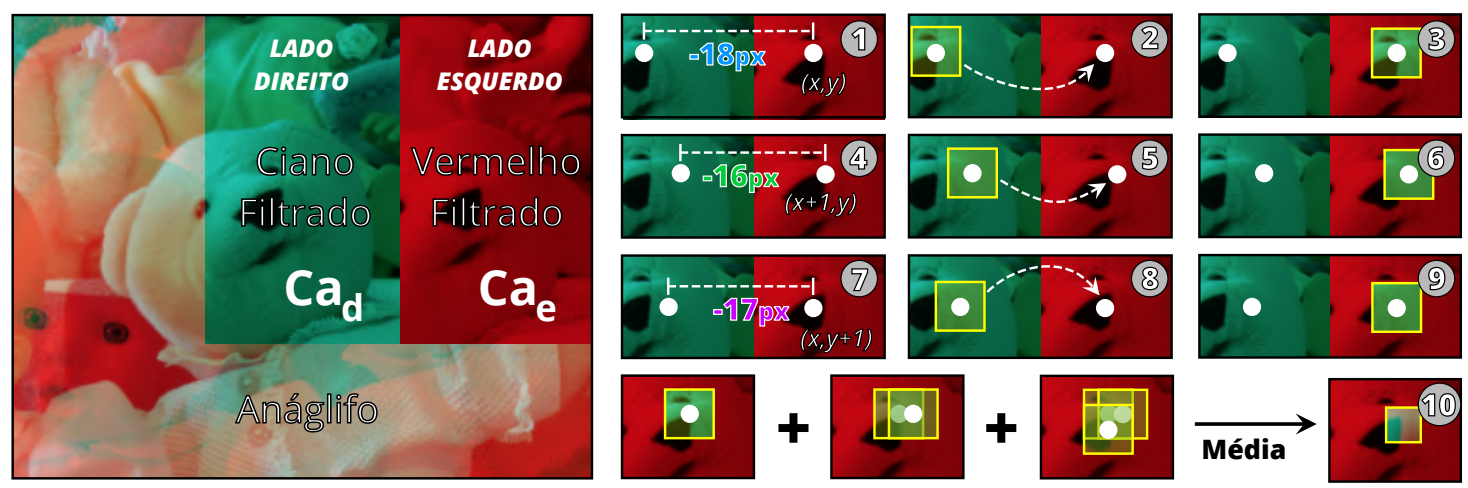

Fonte: Elaborada pelo autor.

A Figura 49 apresenta o processo de refinamento em blocos. À esquerda são apresentadas a imagem anaglífica e duas sub-imagens, uma mais à esquerda com filtro para os canais verde e 
azul $\left(C a_{d}\right)$ e outra para o canal vermelho $\left(C a_{e}\right)$. Ambas as subimagens fazem parte do mesmo anáglifo. Considerando o processamento em blocos para o lado esquerdo (objetos mais à direita), que será preenchido com os canais verde e azul, a matriz res $s_{e}$ é utilizada, contendo as disparidades para cada um dos pixels da imagem.

Para o pixel $p$, é capturado o deslocamento necessário para encontrar a cor correspondente nos canais complementares. Supondo que tal distância seja igual a -18, significa que é necessário deslocar 18 pixels para a esquerda ((9)). Nesta posição deslocada é criado um bloco quadrado com lado de tamanho igual a $2 \times \beta+1$, tendo o pixel deslocado como centro (2)). Por fim, o bloco gerado pelo processo (2) é copiado para a posição inicial $(x, y)$ (3) e o mesmo processo é realizado para o pixel $(x+1, y)$ (4) a (6)), com disparidade igual a 16 pixels e para $(x, y+1)$ ((2) a (2), com disparidade igual a 17 pixels. Esse processo é repetido sucessivamente para os demais pixels válidos (com valor 1 ) da matriz valido $_{e}$. O valor, adotado experimentalmente para $\beta$ é igual a 13.

Após o processamento de todos os pontos da matriz, os blocos copiados geram diversas colisões, que são tratadas ao computar a média das cores, independente para cada canal de cor (10). Suponha que durante as sobreposições um pixel tenha tido os valores $(120,130,140,134)$ para o canal verde e $(20,45,60,90)$ para o canal azul. O valor final para este pixel é dado por 131 para a intensidade de verde e 53 para o canal azul.

Neste momento, aqueles pixels que tiverem número de colisões inferior a $\delta$ serão considerados inválidos, pois considerando que cores inseridas incorretamente normalmente são amenizadas pelas demais colisões, um baixo número de colisões indica que, caso um erro ocorra, dificilmente será amenizado. O valor adotado experimentalmente para $\delta$ é igual a 5. Observe que para o exemplo dado no parágrafo anterior, o pixel seria inválido, uma vez que somente 4 pixels foram utilizados para compor a média, não atingindo o valor de $\delta$. Assim, todos os pixels que não atingiram o $\delta$, recebem 0 para a sua respectiva posição da matriz valido $o_{e}$ ou valido $o_{d}$, dependendo do lado que está sendo processado. Já os pixels que atingiram $\delta$ recebem valor 1 .

\subsubsection{Colorir Pixels Remanescentes}

A última etapa do método proposto é o de Recolorir Pixels Remanescentes (6), que tem por objetivo preencher os pixels remanescentes (com valor 0 nas matrizes valido $e_{e}$ e valido $o_{d}$ ), com intensidades de cor próximas às cores vizinhas. Considerando $q$ como um pixel inválido (valor 0 na matriz valido $_{e}$ ), pertencente ao superpixel Sup, é necessário encontrar a cor verde e azul que se adequa ao valor vermelho de $q$.

A ideia principal desta etapa é encontrar um pixel adequado para "pintar" aqueles pixels que foram considerados incorretos por etapas anteriores, sendo essencial para o processo de reversão, já que não executá-la significa manter as cores dos pixels que foram identificados como incorretos. Alguns testes foram realizados com abordagens convencionais de colorização, como a 
proposta por Levin, Lischinski e Weiss (2004), porém os resultados obtidos foram insatisfatórios, principalmente devido ao fato do algoritmo trabalhar com imagens em escala de cinza, geradas a partir de imagens coloridas. Observe que o processo de geração de uma imagem em escala de cinza é realizada por meio da média (ponderada ou não) dos três canais de cores RGB, portanto, não é possível simplesmente replicar os canais disponíveis a fim de preencher os demais canais. Desta forma seriam necessárias adaptações não triviais no algoritmo de Levin, Lischinski e Weiss (2004) para a aplicação em anáglifos.

Uma outra abordagem, mais simples, consiste encontrar o pixel válido com a cor mais próxima ao pixel inválido, com relação ao canal disponível, baseando-se nos métodos de nearestneighbors. Suponha que existam três pixels válidos, $p=(100,125,30), q=(200,150,0), r=$ $(30,30,200)$, com as suas respectivas cores RGB, e que é desejado encontrar uma cor adequada para o pixel $s=(120, ?, ?)$, que não possui os canais verde e azul. Assim, o único canal disponível (vermelho) é comparado, encontrando o pixel $p$ como mais próximo. Apesar de ser bem simples, podem ser destacados alguns problemas desta abordagem, como: definir os pixels utilizados para a comparação, podendo ser a imagem toda ou uma região dela, baseada na proximidade do pixel que está sendo colorizado; e a utilização de um único pixel para colorizar um outro, o que pode gerar muitos defeitos na imagem resultante.

Na técnica SIRA, a abordagem adotada é utilizar os superpixels gerados na etapa de segmentação (1). Por exemplo, se um pixel $q$ pertencente a um superpixel Sup é inválido, todos os demais pixels válidos de Sup são verificados para encontrar os que mais se adequam a $q$. Além disso, ao invés de utilizar os pixels mais próximos ( $k$ nearest-neighbors), foram utilizados os pixels que possuem um determinado nível de proximidade com o pixel $p$ (range nearest-neighbors).

Figura 50 - Processo para colorir pixel inválido.

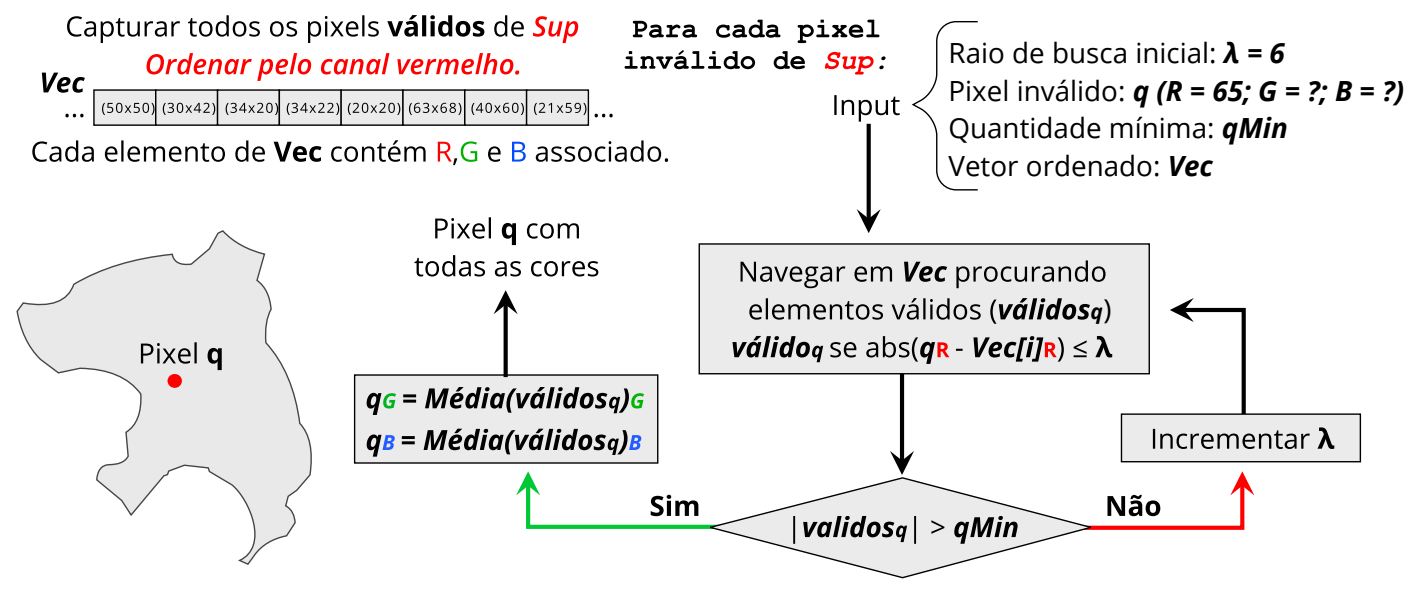

Fonte: Elaborada pelo autor.

A Figura 49 ilustra o processo para colorir o pixel $q$. O primeiro passo é capturar todos os pixels válidos $\left(\right.$ valido $\left._{e}=1\right)$ do superpixel Sup, e os ordenar de acordo com a cor vermelha, 
gerando o vetor $V e c$ que será utilizado para encontrar as cores verde e azul faltantes para todos os pixels inválidos internos ao Sup. Observe que a ordenação do canal vermelho $\left(\mathrm{Ca}_{e}\right)$, carrega também os valores verde e azul, ou seja, todos os elementos de $V e c$ possuem todos os três canais de cores preenchidos.

Uma vez ordenado, o vetor Vec pode ser utilizado para preencher todos os pixels inválidos de Sup, não sendo necessário reconstruí-lo. Assim, por meio de busca binária, o elemento mais próximo do pixel $q$ no canal vermelho é encontrado, e os elementos adjacentes a este elemento que possuem intensidade de cor vermelha próxima ao do pixel $q$ (dado um limiar $\lambda$ ) são selecionados. Para preencher os canais faltantes de $q$, são capturadas as médias de cor, de cada um dos canais, para os elementos selecionados. Suponha o seguinte vetor $V e c=\{(20,50,100),(45,60,90),(60,10,10),(65,12,15),(70,15,15),(71,50,50)\}$, em que cada posição representa um pixel RGB válido de Sup. Tendo um pixel $q$ inválido $(65, ?, ?)$ e um $\lambda$ igual a 6 (definido empiricamente), por busca binária o pixel $(65,12,15)$ é encontrado, e os adjacentes que possuem intensidade válida são selecionados $(60,10,10),(70,15,15)$ e $(71,50,50)$, uma vez que o valor de vermelho de todos estes pixels estão na faixa [59,71]. Assim, o pixel $q$ terá intensidade igual a $(65,25,25)$. Se a quantidade de elementos selecionados for menor que $q M i n$, o valor de $\lambda$ é incrementado e novos elementos são selecionados do vetor Vec. Quando a quantidade de elementos $q M i n$ for atingida, as cores correspondentes para os canais faltantes de $q$ são preenchidos.

O exemplo ilustrado em Figura 49 apresenta o processo para o preenchimento do lado esquerdo, em que há falta de informação nos canais verde e azul, porém o mesmo processo é executado para o lado direito. As principais diferenças estão na ordenação, que é feita na cor verde (selecionado aleatóriamente entre verde e azul) e o limiar $\lambda$ que é aplicado em ambos os canais de cor (valor igual).

O processo mencionado é executado para todos os superpixels de ambas as imagens. Para casos extremos em que não há pixels válidos para um determinado superpixel, a imagem inteira é considerada para o processo, ou seja, o superpixel Sup é substituido pelos limites da imagem. Ao final deste processo de colorização, todos os pixels das imagens estarão preenchidos com valores $\mathrm{R}, \mathrm{G}, \mathrm{B}$.

\subsection{Otimizações}

A partir da descrição da técnica SIRA, apresentada nas seções anteriores, é possível destacar a existência de pontos de otimização, que foram aplicados à técnica. O primeiro deles é a representação das séries por meio da diferença entre elementos (intensidades de cor) adjacentes, que não é executada durante as comparações das séries, mas sim em um processo anterior, sendo o resultado armazenado em memória a fim de evitar recálculos. A quantidade de memória despendida para evitar o recálculo corresponde a $W \times H \times 3 \times \theta$ bytes, com $W$ igual à largura 
do anáglifo e $H$ a altura, considerando as séries geradas para os 3 canais de cor em diferentes ângulos $(\theta)$.

Com o mesmo intuito de evitar recálculos, foi utilizada a técnica de memoization (FORD, 2014) para o cálculo das disparidades. A Figura 51 demonstra tal processo. Uma vez que o cálculo das disparidades é realizado para um pixel $p$ da imagem (em vermelho), todos os pixels contidos no mesmo segmento $r$ para aquele ângulo $c$ também recebem os mesmos valores de disparidade (curvas pontilhadas em azul). Ou seja, as linhas da matriz Mat ${ }^{x, y, \operatorname{Seg}_{e}}$ apresentadas na Equação M1 são compartilhadas por vários pixels (sempre na mesma posição da matriz).

Figura 51 - Utilizando memoization para evitar recálculos.

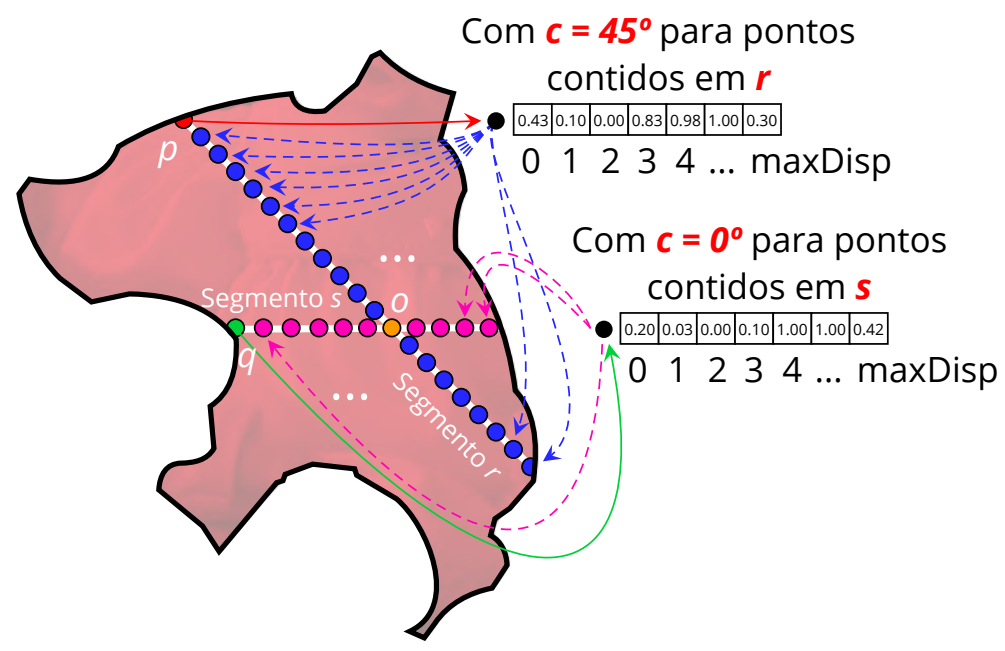

Fonte: Elaborada pelo autor.

Para que a disparidade adequada seja encontrada para um ponto $o$ (em laranja), é necessário que os valores para os seus $\theta$ ângulos tenham sido previamente cálculados: para o ângulo $45^{\circ}$, são os mesmos valores calculados para $p$ (em vermelho), propagado para todos os pixels pertencentes ao segmento $\mathrm{r}$ (em azul); para o ângulo $0^{\circ}$, são os mesmos valores calculados para o ponto $q$ (em verde), propagado para todos os pixels pertencentes ao segmento $s$ (em rosa). E assim sucessivamente, até que a matriz $\mathrm{Mat}^{x, y, \operatorname{Seg}_{e}}$ esteja preenchida e os valores possam ser somados para computar a disparidade final para o pixel $o$. Foi verificado que ao calcular as disparidades para os pixels 8-conectados com as bordas, é possível preencher todos os ângulos, de todos os pixels, do superpixel. A estes pixels de borda, que ao serem calculados fornecem os resultados necessários para gerar os valores dos demais pixels, daremos o nome de pontos chave.

Além das otimizações inerentes à técnica SIRA, implementada em $\mathrm{C}$, foi realizada a paralelização de todas as etapas apresentadas, exceto a separação dos canais. A etapa de segmentação, que é realizada por meio da biblioteca $\operatorname{OpenCV}(\mathrm{C}++)^{3}$, possui implementações nativas. Para a etapa de alinhamento inicial, cada thread lançada fica responsável por um

3 Detalhes de implementação e Setup utilizados são detalhados na Seção 6.4. 
superpixel. Para a propagação do alinhamento e colorização dos pixels remanescentes, a imagem é dividida em faixas horizontais, com a quantidade de partes igual ao número de threads lançadas. Observe que esta divisão permite equilíbrio de carga de processamento para as threads, fazendo com que elas terminem aproximadamente juntas, uma vez que a maior parte dos problemas se encontram nas bordas laterais da imagem, devido ao deslocamento horizontal entre as imagens estereoscópicas. Por exemplo, se fosse realizada a divisão por meio de faixas verticais, algumas threads quase não teriam pixels para colorizar, enquanto as divisões de borda ficariam sobrecarregadas.

Por fim, por ser o gargalo da técnica proposta, a etapa de colorização também foi otimizada. Para isso, nos casos extremos, em que toda a imagem é utilizada e a imagem ultrapassa 5 milhões de pixels, a imagem é subdividida em grids, em que o pixel que está sendo mapeado faz uso da grid ao qual pertence para encontrar a cor correspondente. A primeira grid divide a imagem tanto na vertical como na horizontal, gerando 4 células $(2 \times 2)$. Caso as células continuem a ultrapassar 5 milhões de pixels, a imagem original é redividida em 9 células (3x3), e assim sucessivamente, até que cada célula tenha menos que 5 milhões de pixels. É interessante mencionar que não há grandes impactos de qualidade, já que a busca em regiões muito distantes tem grande chance de encontrar pixels incorretos, ou seja, provavelmente um pixel incorreto já teria sido computado.

\subsection{Complexidade}

A principal diferença da técnica SIRA em relação à demais apresentados no estado da arte, é a maneira com que os custos de alinhamento são computados. Na grande parte dos trabalhos correlatos, o custo é computado por meio de blocos quadrados, formados ao redor do pixel que está sendo alinhado. Na técnica proposta neste trabalho, são utilizadas séries compostas pelas variações de intensidades dos pixels, utilizando apenas uma parte dos dados de um bloco.

A técnica SIRA é composta por seis etapas, processadas de maneira sequêncial. A primeira parte (1), de separação dos canais, é executada de modo linear, já que é necessário percorrer uma vez todos os $N$ pixels das imagens (lado direito e esquerdo). O processo de segmentação (2), que utiliza o algoritmo SLICO, também é linear em relação a $N$ e executado para ambas as imagens. Portanto, a complexidade de separar os canais e segmentar as imagens é igual a $C\left(s e p \_s e g\right)=2 \times N+2 \times N$. Em notação $B i g-O$ a complexidade é dada por $\mathscr{O}\left(s e p \_s e g\right)=$ $\mathscr{O}(N)$.

Para computar o alinhamento na etapa 3 é necessário calcular o alinhamento para cada um dos pixels chave, então o seu resultado é propagado para os demais pixels. Ao analisar o comportamento do algoritmo para um superpixel, é possivel notar que ao calcular o alinhamento para um ponto chave, todos os pixels utilizados para a geração das séries só serão utilizados novamente para computar outro ângulo. Tal processo é ilustrado pela Figura 52. Observe que 
o pixel $p$ apresentado em preto só é utilizado novamente quando outro ângulo é computado, e seu valor é gerado por um pixel chave, indicado em marrom para cada um dos ângulos. Além das séries geradas para a imagem que está sendo alinhada, são geradas $\mathscr{L}$ séries para a imagem complementar, seguindo o mesmo padrão. Assim, a complexidade do alinhamento é igual a $C($ alinhamento $)=(\mathscr{L}+1) \times N$, ou seja, $\mathscr{O}($ alinhamento $)=\mathscr{O}(N \times \mathscr{L})$.

Figura 52 - Complexidade para a etapa de alinhamento. Um único pixel $p$ é utilizado exatamente $\theta$ vezes para o alinhamento.

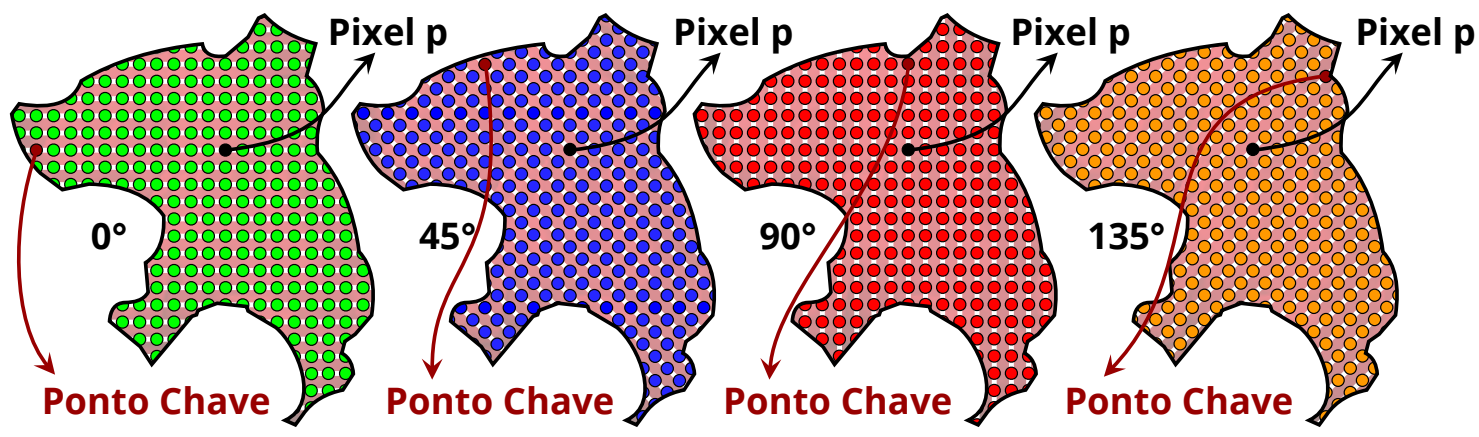

Fonte: Elaborada pelo autor.

Para a validação da reciprocidade entre pixels (4), é necessário percorrer ambas as imagens, verificando se o pixel é ou não válido. Esta operação é linear e executada duas vezes, uma para cada um dos lados do par de imagens, portanto $C$ (reciprocidade $)=2 \times N$, assim $\mathscr{O}($ reciprocidade $)=\mathscr{O}(N)$. Já a propagação de alinhamento (5) é executada para cada um dos pixels, de ambas as imagens, e possui complexidade $C$ (propaga_alinhamento $)=N \times(2 \times$ $\beta+1)^{2}$, pois o lado do quadrado é igual a $2 \beta+1$ e o processamento é executado utilizando blocos quadrados, portanto $\mathscr{O}($ propaga_alinhamento $)=\mathscr{O}\left(N \times \beta^{2}\right)$. Observe que, apesar de processado em blocos, esta técnica difere dos demais algoritmos de alinhamento da literatura, uma vez que a disparidade já está computada, não havendo medições de distância ou comparações neste processo.

O último passo da técnica SIRA é colorizar os pixels remanescentes. A complexidade da colorização é definida por ordenações (merge sort), que são realizadas para os pixels válidos de um determinado superpixel (Equação 5.8) e também por buscas binárias (Equação 5.9), com o objetivo de encontrar cores adequadas para pixels considerados inválidos. $C s_{i}^{\text {valido }}$ representa o número de pixels válidos de um superpixel $i$ qualquer.

$$
\begin{gathered}
C(\text { ordenação })=C s_{i}^{\text {valido }} \times \log C s_{i}^{\text {valido }} \\
C(\text { busca_binária })=\log C s_{i}^{\text {valido }}
\end{gathered}
$$

Para prosseguir com o cálculo é necessário verificar qual o tamanho máximo (em pixels) que um superpixel pode conter, possibilitando definir o valor máximo de $C s_{i}^{\text {valido }}$. O 
algoritmo SLICO utiliza como base o algoritmo SLIC (ACHANTA et al., 2010), tendo sua complexidade linear devido a uma de suas propriedades que limitam o espaço de busca de pixels pertencentes a um superpixel. Essa propriedade é ilustrada pela Figura 53, que apresenta um superpixel Sup (em preto), o seu centro correspondente $C_{S u p}$ (em verde), e a janela que delimita o seu tamanho máximo (quadrado maior com bordas vermelhas). Logo, o tamanho máximo do superpixel é igual a $2 S \times 2 S$, representado em preto, após a expansão do superpixel $S u p$. Portanto, $C s_{i}^{\text {valido }}+C s_{i}^{\text {invalido }} \leq 2 S \times 2 S$ para qualquer superpixel. Segundo os autores do algoritmo SLIC, o valor de $S$ é igual a $\sqrt{N / k}$, com $N$ igual ao número de pixels da imagem, e $k$ o número total de superpixels.

Figura 53 - Propriedade do algoritmo SLICO para tamanho do superpixel.

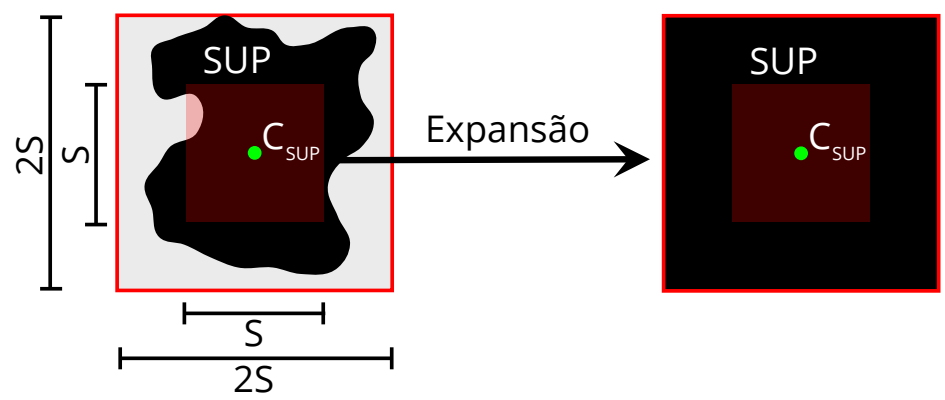

Fonte: Elaborada pelo autor.

A ordenação é realizada uma única vez por superpixel, já que o Vec da Figura 50 é único para todos os pixels inválidos do superpixel Sup. A busca binária é executada para cada um dos pixels inválidos de Sup. O primeiro passo da colorização é passar pelos $N$ pixels, determinando a qual superpixel o pixel pertence, determinando quais são os pixels válidos e inválidos. Após isso, a ordenação é realizada para cada um dos superpixels sendo realizadas $k$ ordenações.

Após a busca binária, para um pixel inválido de $C s_{i}^{\text {invalido }}$, todos os pixels válidos do superpixel considerando o pixel $C s_{i}^{\text {invalido }}$ são capturados. Tal captura pode ocasionar na navegação de todos os pixels válidos do superpixel, caso todos os pixels tenham abs $\left(q_{r}\right.$ $\left.V e c[i]_{r}\right) \leq \lambda$. Assim, $C s_{i}^{\text {invalido }} \times\left(C(\right.$ busca_binária $\left.)+C s_{i}^{\text {adjac }}\right)$, com $C s_{i}^{\text {adjac }}$ igual ao número de elementos percorridos após a busca binária, para compor o pixel inválido $\left(C s_{i}^{\text {invalido }}\right)$.

A Equação 5.10 sumariza a quantidade de operações realizadas para a colorização. Observe que $q M i n \leq C s_{i}^{a d j a c} \leq C s_{i}^{\text {valido }}$, uma vez que é necessário uma quantidade mínima $q M i n$ de elementos, conforme explicado na Subseção 5.1.6, porém todos os pixels adjacentes podem satisfazer a cor desejada. Todo o processo é executado para a imagem do lado esquerdo e do lado direito, por isso o resultado final de complexidade é multiplicado por dois.

$$
\begin{array}{r}
\text { Op }(\text { colorizar })=2 \times\left(N+\sum_{i=0}^{i<k} C(\text { ordenação })+\sum_{i=0}^{i<k} C s_{i}^{\text {invalido }} \times\right. \\
\left.\left(C(\text { busca_binária })+C s_{i}^{\text {adjac }}\right)\right)
\end{array}
$$


Para facilitar o cálculo da complexidade, em termos Big-O, adotamos que $\mathrm{Cs}_{i}^{\text {valido }}=$ $C s_{i}^{\text {invalido }}=(2 S)^{2}=(2 \sqrt{N / k})^{2}$, ao invés de $C s_{i}^{\text {valido }}+C s_{i}^{\text {invalido }}=(2 S)^{2}=(2 \sqrt{N / k})^{2}$. Esta alteração é irrelevante para a complexidade final Big- $O$ pois a relação entre os cálculos é dada por uma constante, suprimida para o cálculo do Big-O. Substituindo tais valores na Equação 5.10 e assumindo o pior caso, em que $C s_{i}^{\text {adjac }}=C s_{i}^{\text {valido }}$, é gerada a Equação 5.11 .

$$
\begin{aligned}
C(\text { colorizar })= & 2 \times(N+(k \times 4 \times N / k \times \log (4 \times N / k))+ \\
& (k \times 4 \times N / k \times(\log (4 \times N / k) \times 4 \times N / k)
\end{aligned}
$$

Em termos de $B i g-O$, que suprime a parte da ordenação e a parte linear $(N)$, a complexidade do alinhamento é dado por $\mathscr{O}($ colorizar $)=\mathscr{O}\left((4 N)^{2} / k\right)=\mathscr{O}\left(N^{2}\right)$. Observe que para pixels em casos extremos, a complexidade final, em termos Big-O também é $\mathscr{O}\left(N^{2}\right)$.

A complexidade final da técnica SIRA é dada pelo somatório da complexidade das partes. Portanto $\mathscr{O}(S I R A)=\mathscr{O}($ sep_seg $)+\mathscr{O}($ alinhamento $)+\mathscr{O}($ reciprocidade $)+\mathscr{O}($ propaga_alinhamento $)+\mathscr{O}($ colorizar $)$. Uma vez que a técnica proposta considera $\beta$ como constante, os maiores termos são dados pelo alinhamento e colorização. Assim a complexidade final para o algoritmo é igual a $\mathscr{O}(S I R A)=\mathscr{O}\left(N^{2}+N \times \mathscr{L}\right)$. Já no caso médio sua complexidade é bem inferior, uma vez que a quantidade de pixels que são colorizados é muito pequena.

\subsection{Considerações Finais}

Este capítulo apresentou a técnica SIRA e também as otimizações realizadas e a análise de complexidade para todo o processo de reversão anaglífica. Como é possível observar, o custo de processamento da SIRA é inferior ao dos demais métodos da literatura, ressaltando que Joulin (JOULIN; KANG, 2013) possui complexidade $\mathscr{O}\left(N^{3}\right)$ devido ao algoritmo de fluxo óptico, e Williem (WILLIEM; RASKAR; PARK, 2015) possui complexidade $\mathscr{O}(a \times n \times|C|)$, que é maior que $\mathscr{O}\left(N^{2}\right)$, uma vez que o número de nós $n$ é igual ao número de pixels $(N)$ acrescido do número de disparidades possíveis $(\mathscr{L})$, e $a$ representa as conexões com os pixels, que é, maior que o número de nós, para $N>2$.

Além da análise de complexidade, os resultados de experimentos apresentados na Seção 6.4 comprovam que a técnica proposta é muito mais rápida que técnicas correlatas da literatura, sem utilizar metadados para realizar a reversão anaglífica. O próximo capítulo apresenta uma análise das diversas etapas da técnica SIRA, além de comparações objetivas e subjetivas com demais métodos da literatura. 
6

\section{AVALIAÇÃO EXPERIMENTAL}

Neste capítulo são apresentados os experimentos realizados para avaliar a técnica proposta. Na Seção 6.1 são apresentados os conjuntos de dados utilizados nos experimentos. Na Seção 6.2 são apresentadas as medidas de avaliação objetiva e subjetiva a serem utilizadas.

Os experimentos discutidos na Seção 6.3 visam validar os principais pontos de decisão da técnica SIRA, incluindo comparações entre as diversas medidas de distância, métodos de representação, qualidade da segmentação das imagens e os impactos na utilização dos ângulos e do processamento em blocos. Na Seção 6.4 serão apresentadas comparações objetivas e subjetivas entre as técnicas do estado da arte, descritas no Capítulo 3, e a técnica proposta nesta dissertação.

\subsection{Bases de Imagens Estéreos}

Para os experimentos, foram utilizados três conjuntos de dados disponibilizados pela Middlebury ${ }^{1}$ (ilustrada pela Figura 54): Middlebury 2001 (SCHARSTEIN; SZELISKI; ZABIH, 2001); Middlebury 2003 (SCHARSTEIN; SZELISKI, 2003); Middlebury 2005 (SCHARSTEIN; PAL, 2007). Os três conjuntos de dados contém várias cenas, com diversos níveis de disparidade para cada uma delas, permitindo a construção de diversos pares estereoscópicos para uma mesma cena. As bases Middlebury foram utilizadas por serem muito conhecidas na área de correspondência estéreo e por possuirem ground-truth das disparidades, o que permite realizar uma análise mais adequada dos dados, permitindo ir além dos fatores apresentados apenas por meio das intensidades de cor dos pixels. Além disso, é interessante destacar que as bases Middlebury foram utilizadas por trabalhos correlatos, como o de Williem (WILLIEM; RASKAR; PARK, 2015), que utiliza parte das bases Middlebury 2001 (SCHARSTEIN; SZELISKI; ZABIH, 2001) e Middlebury 2003 (SCHARSTEIN; SZELISKI, 2003). Devido a baixa quantidade de cenas (9), foi adicionado a base Middlebury 2005 (SCHARSTEIN; PAL, 2007), compondo assim 
18 cenas.

Todas as imagens das bases Middlebury estão no formato PNG, com resolução entre $384 \times 288$ e $695 \times 555$, contendo os três canais de cores $R G B$. A composição de cada uma das bases é apresentada pelo Quadro 3, que apresenta as três bases de dados nas linhas. Nas colunas é apresentado o número total de cenas disponibilizadas pela base, os níveis de disparidade existentes, e os níveis utilizados para gerar os anáglifos a serem utilizados neste capítulo.

Quadro 3 - Composição das bases utilizadas para avaliação do método proposto.

\begin{tabular}{|c|c|c|c|}
\cline { 2 - 4 } \multicolumn{1}{c|}{} & $\begin{array}{c}\text { Número de } \\
\text { Cenas }\end{array}$ & $\begin{array}{c}\text { Níveis de } \\
\text { Disparidade }\end{array}$ & $\begin{array}{c}\text { Níveis Utilizados para } \\
\text { Gerar Anáglifos }\end{array}$ \\
\hline \multirow{2}{*}{ Middlebury 2001 } & Tsukuba & $6(1$ a 5) & 2 (esquerda) e 3 (direita) \\
\cline { 2 - 4 } & Demais Imagens (6) & $9(0$ a 8) & 2 (esquerda) e 6 (direita) \\
\hline Middlebury 2003 & 2 & $9(0$ a 8$)$ & 2 (esquerda) e 6 (direita) \\
\hline Middlebury 2005 & 9 & $7(0$ a 6) & 1 (esquerda) e 5 (direita) \\
\hline
\end{tabular}

Fonte: Dados da pesquisa.

Os níveis de disparidade indicam quantas imagens de uma mesma cena existem para uma determinada base de imagens, portanto, a base 2001 possui a imagem Tsukuba com 6 níveis de disparidade e as demais cenas com 9 disparidades, a base 2003 possui imagens com 9 disparidades e a base 2005 com 7 disparidades. A Figura 54 apresenta 4 imagens de diferentes níveis de disparidade para cada uma das cenas, em diferentes bases. Observe que apenas duas imagens são selecionadas para compor o par estéreo, assim, níveis mais distantes, por exemplo 0 e 8 são geralmente mais complexos do que 0 e 1, considerando uma mesma cena. Os níveis de disparidade utilizados neste capítulo foram selecionados com base nos mapas de profundidade fornecidos pela Middlebury e a partir deles foram gerados os anáglifos no formato vermelhociano, com vermelho para o lado esquerdo e ciano (verde + azul) para o lado direito.

$\mathrm{Na}$ Seção 6.3, que apresenta análises de diversas etapas da técnica SIRA, foi utilizada apenas a base Middlebury 2005 (SCHARSTEIN; PAL, 2007), inclusive para a realização do tunning dos parâmetros da técnica SIRA. Já na Seção 6.4, que apresenta comparações objetivas e subjetivas entre as técnicas, todas as bases foram utilizadas, com todos os algoritmos avaliados utilizando as configurações apresentadas no Quadro 3. É importante mencionar que os mapas de profundidade das cenas Computer, Drumsticks e Dwarves não foram disponibilizados pela Middlebury, portanto, para a etapa de análise foram utilizadas apenas 6 das 9 cenas da base Middlebury 2005 (SCHARSTEIN; PAL, 2007).

\subsection{Método de Avaliação}

A análise das imagens resultantes do processo de reversão anáglífica, por meio de métricas objetivas e subjetivas é fundamental para avaliar a qualidade dos resultados e comprovar a eficácia da técnica proposta. 
Figura 54 - Exemplo para as bases de imagens utilizadas.
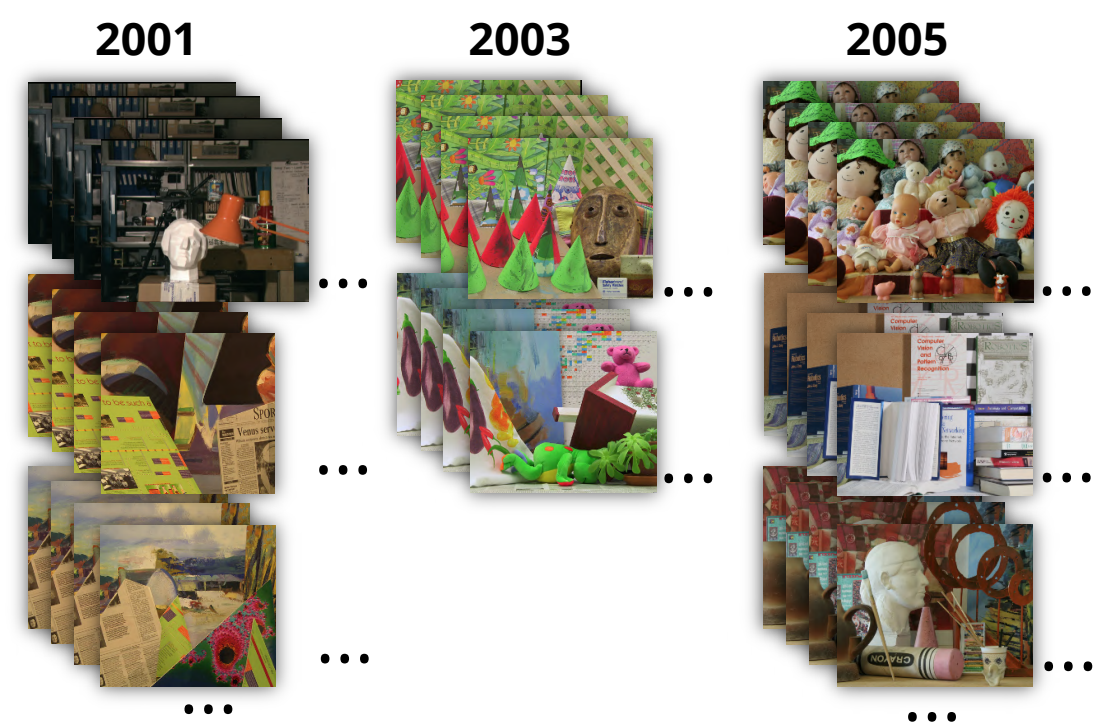

Fonte: Elaborada pelo autor.

Neste trabalho, a avaliação com relação à qualidade dos resultados será feita tanto por meio de medida objetiva, com o Peak Signal to Noise Ratio (PSNR) (JOULIN; KANG, 2013), quanto por medida subjetiva, com o Double Stimulous Continuous Quality Scale (DSCQS) (ITU, 2003). O PSNR foi escolhido por ser amplamente utilizado como método de avaliação na área de processamento de imagens e ser utilizado por trabalhos relacionados (JOULIN; KANG, 2013; WILLIEM; RASKAR; PARK, 2015). O PSNR pode ser dividido em duas partes, sendo a primeira delas o erro médio quadrado, MSE (Equação 6.1). O valor de $w$ é dado pelo comprimento da imagem, $h$ pela altura, $O(i, j)$ é a função que captura o pixel da imagem original na posição $i, j$, enquanto $N(i, j)$ captura o pixel na mesma posição da imagem nova (resultado de algum processamento).

$$
M S E=\frac{1}{w h} \sum_{i=0}^{w-1} \sum_{j=0}^{h-1}[O(i, j)-N(i, j)]^{2}
$$

Por meio da equação do MSE é possível concluir que poucos pixels muito errados acabam sendo mais prejudiciais do que muitos pixels ligeiramente diferentes dos pixels apresentados na imagem original. Isso ocorre pois a fórmula eleva as diferenças ao quadrado. É interessante observar que a equação trata todos os pixels da mesma forma, já que aplica uma média entre todos os quadrados das diferenças entre os pixels. Calculado o MSE, é possível realizar o cálculo do PSNR (Equação 6.2), cujos valores podem variar de 0 até 100 decibéis (dB), em que valores próximos de $100 \mathrm{~dB}$ indicam maior qualidade, e próximos de 0 menor. O valor de $M A X_{I}$ é representado pelo valor máximo possível por pixel, portanto, com 8 bits o valor a ser considerado é 255. Vale lembrar que como são utilizados 8 bits por canal de cor, e três canais, o erro médio 
quadrado é dividido por três.

$$
P S N R=20 \cdot \log _{10}\left(M A X_{I}\right)-10 \cdot \log _{10}(M S E)
$$

É interessante observar que, apesar de ser uma medida muito utilizada para avaliar a qualidade de imagens em processamento de imagens, o PSNR não leva em consideração a percepção visual. Assim, é possível que para imagens em que informações psicovisualmente redundantes são mantidas e aquelas perceptíveis ao ser humano são retiradas, o PSNR se mantenha alto, apesar de possuirem qualidade visual inferior à original. Esse caso é ilustrado na Figura 55, em que as bonecas com rosto desfigurado obtiveram PSNR maior que a imagem com brilho levemente aumentado.

Figura 55 - Valor PSNR para as diversas imagens.

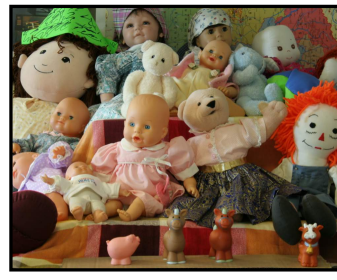

IMAGEM ORIGINAL PSNR: 100.0

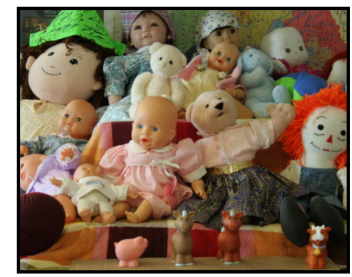

RUÍDO + BLUR PSNR: 31.67

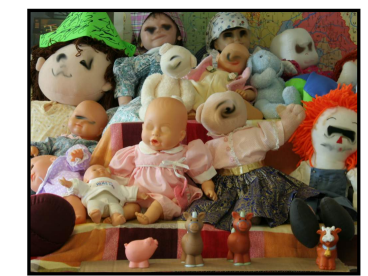

BORRÃO NO ROSTO DAS BONECAS PSNR: 28.23

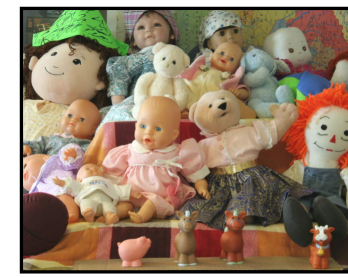

AUMENTO DE CLARIDADE PSNR: 20.15

Fonte: Elaborada pelo autor.

Por esse motivo, além do método de avaliação objetiva, foi utilizada a medida subjetiva Double Stimulous Continuous Quality Scale (DSCQS), a fim de verificar a qualidade perceptual das imagens. A DSCQS é a medida de qualidade indicada para testes subjetivos em imagens estereoscópicas pela ITU-R (ITU, 2003), e seu funcionamento, ilustrado pela Figura 56, consiste em apresentar diversos conjuntos de cenas (cena $s-1$ à 3 , cena $t-5$ à $7, \ldots$ ) intercalados por uma imagem de cor sólida cinza (4 e 8), sendo cada imagem de cor sólida cinza apresentada por um tempo pré-determinado (foi utilizado 10 segundos).

Para cada uma das cenas são apresentadas três imagens, sendo elas, respectivamente: imagem original ou gerada (1), uma imagem de cor sólida cinza (2) e imagem original ou gerada (3). A primeira e a terceira imagem são embaralhadas de maneira aleatória e são obrigatoriamente complementares, ou seja, se a primeira for a imagem original, a segunda é a gerada, e vice-versa. Este mesmo processo é executado para as demais cenas (cena $t, u, v$ e assim por diante). $\mathrm{O}$ tempo utilizado para as imagens de cor sólida cinza, entre as imagens de mesma cena, foi de 5 segundos. É importante mencionar que o método original da ITU indica que a mesma imagem pode ser apresentada diversas vezes, porém devido a quantidade de imagens e a fadiga gerada pela mesma, foi optado por mostrar o par apenas uma vez, por um período maior.

A qualidade das imagens é então avaliada em uma escala de 1 a 5, de péssimo a excelente, como mostrado na Figura 57. Essa avaliação normalmente ocorre durante as transições entre 
Figura 56 - Funcionamento do análise subjetiva DSCQS.

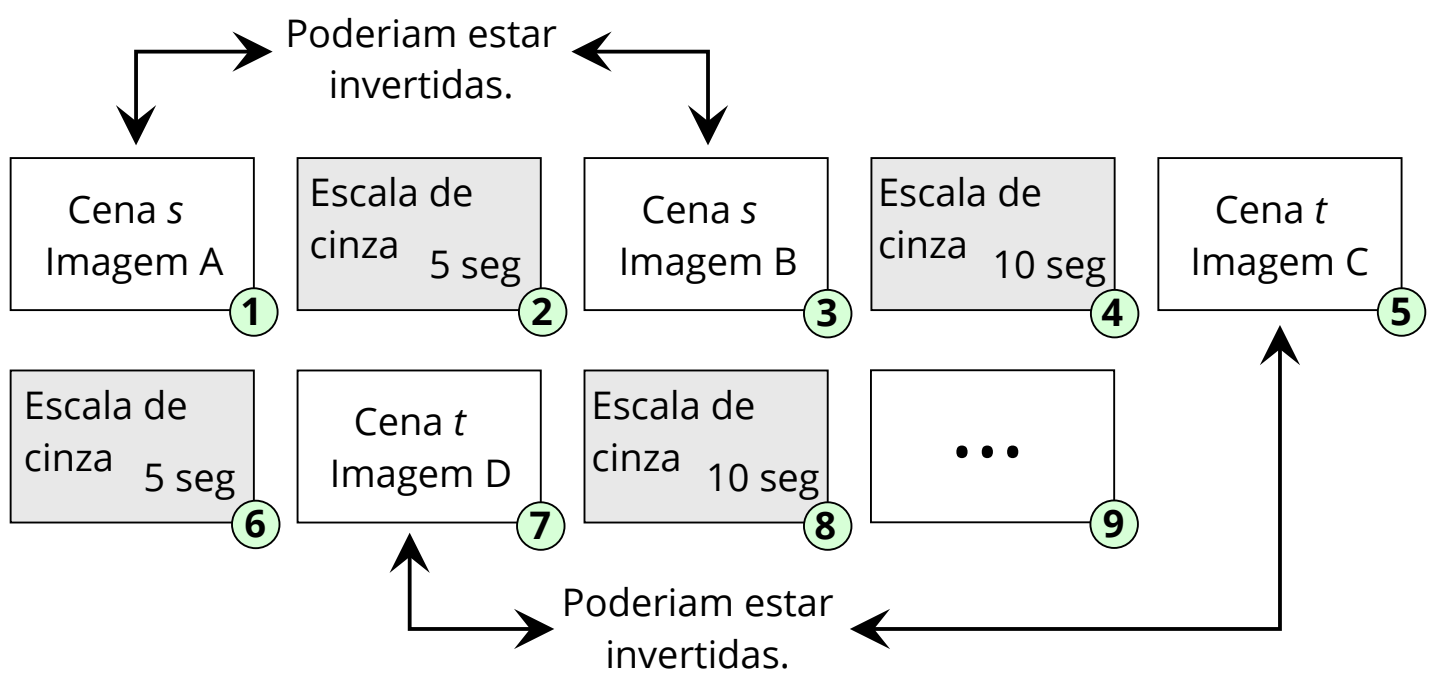

Fonte: Elaborada pelo autor.

as cenas (4 e 8 da Figura 56). Ao final do teste, a média dos votos de todos os participantes é computada, gerando o Mean Opinion Score (MOS). Vale lembrar que o tempo limite para o teste não deve ultrapassar 30 minutos devido ao possível cansaço gerado.

Figura 57 - Cartão de avaliação subjetiva das imagens, entregue ao usuário.

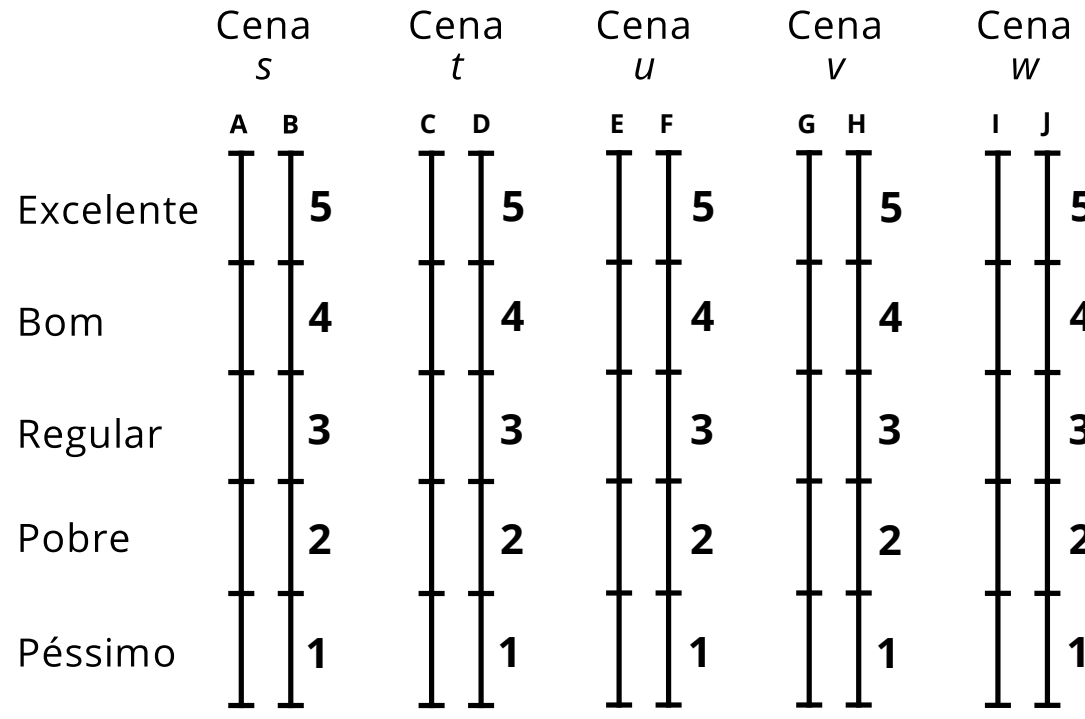

Fonte: Adaptada de ITU (2003).

\subsection{Análise da Técnica SIRA}

De modo a validar os principais pontos de decisão do algoritmo, são apresentados experimentos analisando diversas funções de distância (Subseção 6.3.1), métodos de representação 
Figura 58 - Parâmetros e etapas analisadas.

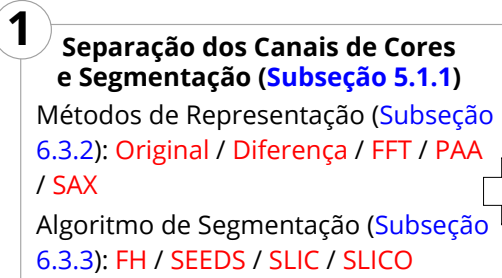

\section{6}

Colorização de Pixels Remanescentes (Subseção 5.1.6)

$\lambda$ - Raio de busca inicial. qMin - Quantidade mínima de elementos.
2 Extração de
Características (Subseção 5.1.2)

Ângulos para Extração de Características (Subseção 6.3.4) $\theta$ - Número de ângulos para representar o pixel.

\section{5}

\section{Propagação do
Alinhamento (Subseção 5.1.5)} Impacto da Propagação de Alinhamento (Subseção 6.3.5)

$\beta$ - Tamanho do bloco para propagação.

$\delta$ - Limiar para considerar pixel válido.
3

Alinhamento de Séries (Subseção 5.1.3)

Função de Distância (Subseção 6.3.1):

LCSS / DTW / Euclidiana / Manhattan

4

Validação da Reciprocidade entre Pixels (Subseção 5.1.4)

$y$ - Limiar para permitir pequenas diferenças no alinhamento.

Fonte: Elaborada pelo autor.

(Subseção 6.3.2), algoritmos de segmentação (Subseção 6.3.3), além de apresentar os impactos da utilização de múltiplos ângulos (Subseção 6.3.4) e do processamento em blocos (Subseção 6.3.5).

A Figura 58 sumariza as etapas da técnica SIRA (Capítulo 5), apresentando os principais pontos de decisão em vermelho, e os parâmetros utilizados em cada uma das etapas em verde. Alguns dos pontos de decisão definem alguns parâmetros utilizados na técnica, sendo eles a análise da utilização de mais ângulos, que define o parâmetro $\theta$ e a análise da propagação do alinhamento, que se mostra necessária como uma ponte entre o alinhamento inicial e a colorização e que define os parâmetros de tamanho de bloco $\beta$ e limiar $\delta$ para considerar ou não um pixel válido. Os demais parâmetros $(\gamma, \lambda, q$ Min $)$ foram definidos empiricamente.

É importante mencionar que a análise das funções de distância foi realizada antes das demais, já que é o único ponto de decisão que pode ser executado de forma independente. Além disso, a escolha de uma função de distância e representação incorreta pode inviabilizar a análise dos demais pontos de decisão.

\subsubsection{Funções de Distância}

Um dos pontos principais da técnica SIRA é a função de distância, utilizada para executar o alinhamento das séries, encontrando assim a disparidade mais adequada. A fim de definir a melhor opção, foi executado um experimento de análise comparativa entre as diversas funções de distância voltadas a séries temporais. Como o objetivo é apenas avaliar a função de distância, a segmentação não é considerada, ou seja, o tamanho da janela (em número de pixels adjacentes) é variado, porém a mesma configuração de janela é utilizada para toda a imagem. As principais medidas de distância apresentadas na Seção 4.2 foram testadas, sendo elas a LCSS, DTW, Euclidiana e Manhattan. Para a função LCSS, além da abordagem clássica que considera somente a igualdade das observações, também foram definidos limiares de associação (conforme explicado na Subseção 4.2.3), assim, para LCSS (10), uma intensidade 10 pode ser 
associada a uma intensidade igual a 15 , já que $|10-15|<10$. Para a DTW foram adotadas diversas configurações de banda ( $N$, conforme definido na Subseção 4.2.2). Os resultados comparando as distâncias, são apresentados pela Figura 59, com as funções de distância no eixo vertical, as janelas utilizadas para construir as séries no eixo horizontal, o tamanho das bolinhas representando o valor do PSNR e a cor o desvio padrão do PSNR para uma determinada configuração de janela e função de distância para o PSNR.

Figura 59 - Comparação das diversas funções de distância com base no PSNR das imagens.

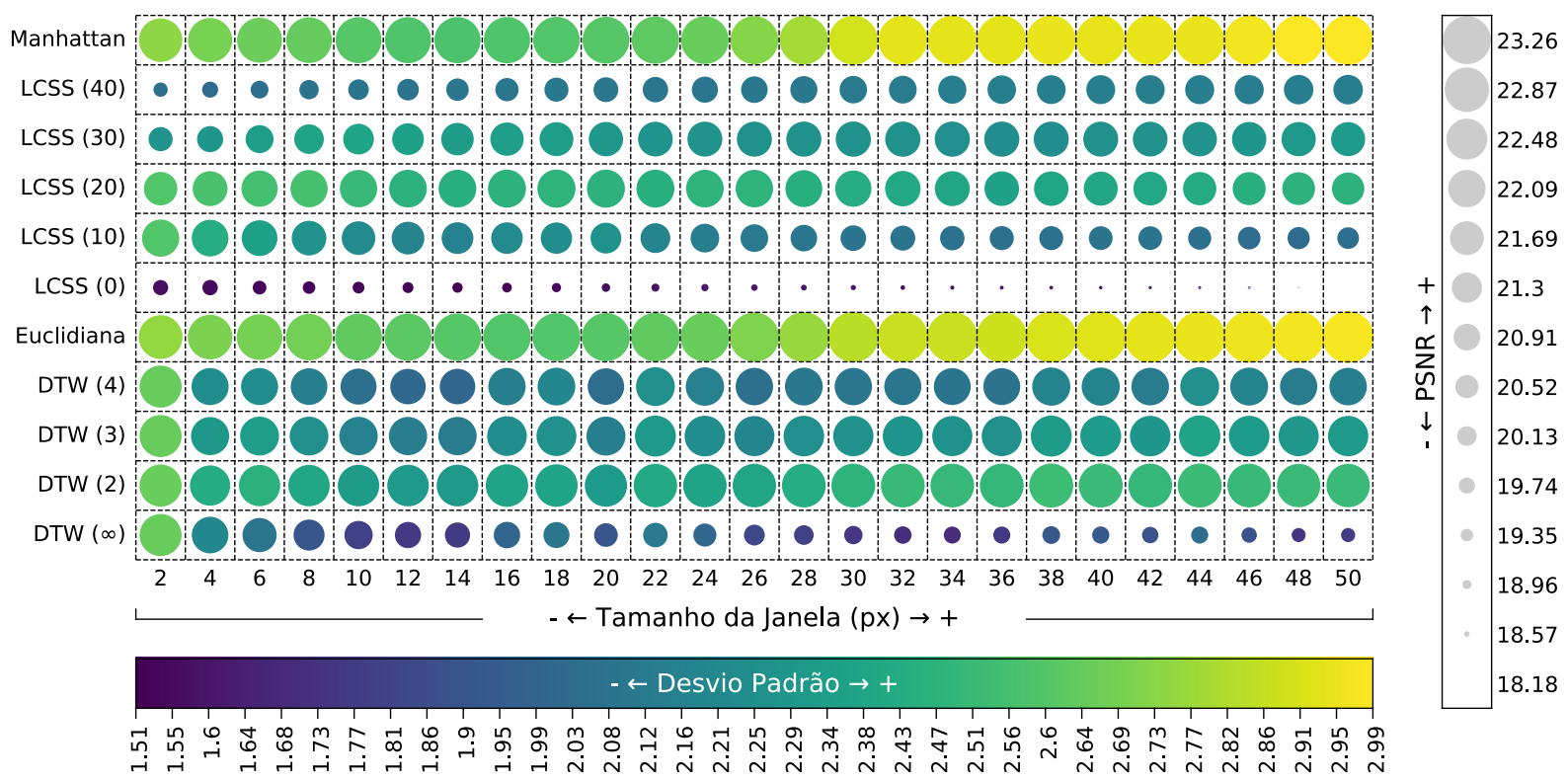

Fonte: Elaborada pelo autor.

Por meio do gráfico é possível identificar que a DTW (2), Euclidiana e Manhattan apresentam valores médios maiores que as demais funções de distância, porém ao analisarmos o desvio padrão, verificamos que há uma grande sobreposição com os valores apresentados pela DTW(3) e DTW(4), já que bolinhas mais amarelas indicam maior variação em relação aos valores médios. Assim, não é possível definir precisamente qual é a melhor função. Um outro ponto interessante a ser observado é o valor de PSNR para janela igual a 2, que é muito próximo aos melhores valores obtidos. Tal constatação é contraintuitiva, uma vez que janelas muito pequenas não têm informação suficiente para serem comparadas. Conclui-se, portanto, que o PSNR não é a melhor medida para avaliar a qualidade das etapas da técnica SIRA. Alternativamente, para avaliar de maneira mais adequada a função de distância, foi utilizada a quantidade de alinhamentos corretos, com base nos mapas de profundidade (Seção 2.2) fornecidos como ground truth pela Middlebury. Um alinhamento correto indica que o ponto correspondente foi encontrado na imagem complementar, permitindo que a cor correta possa ser capturada. Desta maneira, pode-se inferir que quanto mais alinhamentos corretos, mais próximo da imagem original está o lado recuperado, portanto, em termos gerais, quanto mais alinhamentos corretos, maior a qualidade da imagem. O resultado da comparação das diversas funções de distância em termos de alinhamentos corretos é apresentado pela Figura 60, com o tamanho das bolinhas 
representando a quantidade de alinhamentos corretos e as cores os valores de desvio padrão com relação a esta quantidade de alinhamentos corretos.

Figura 60 - Comparação das diversas funções de distância com base na quantidade de alinhamentos corretos das imagens.

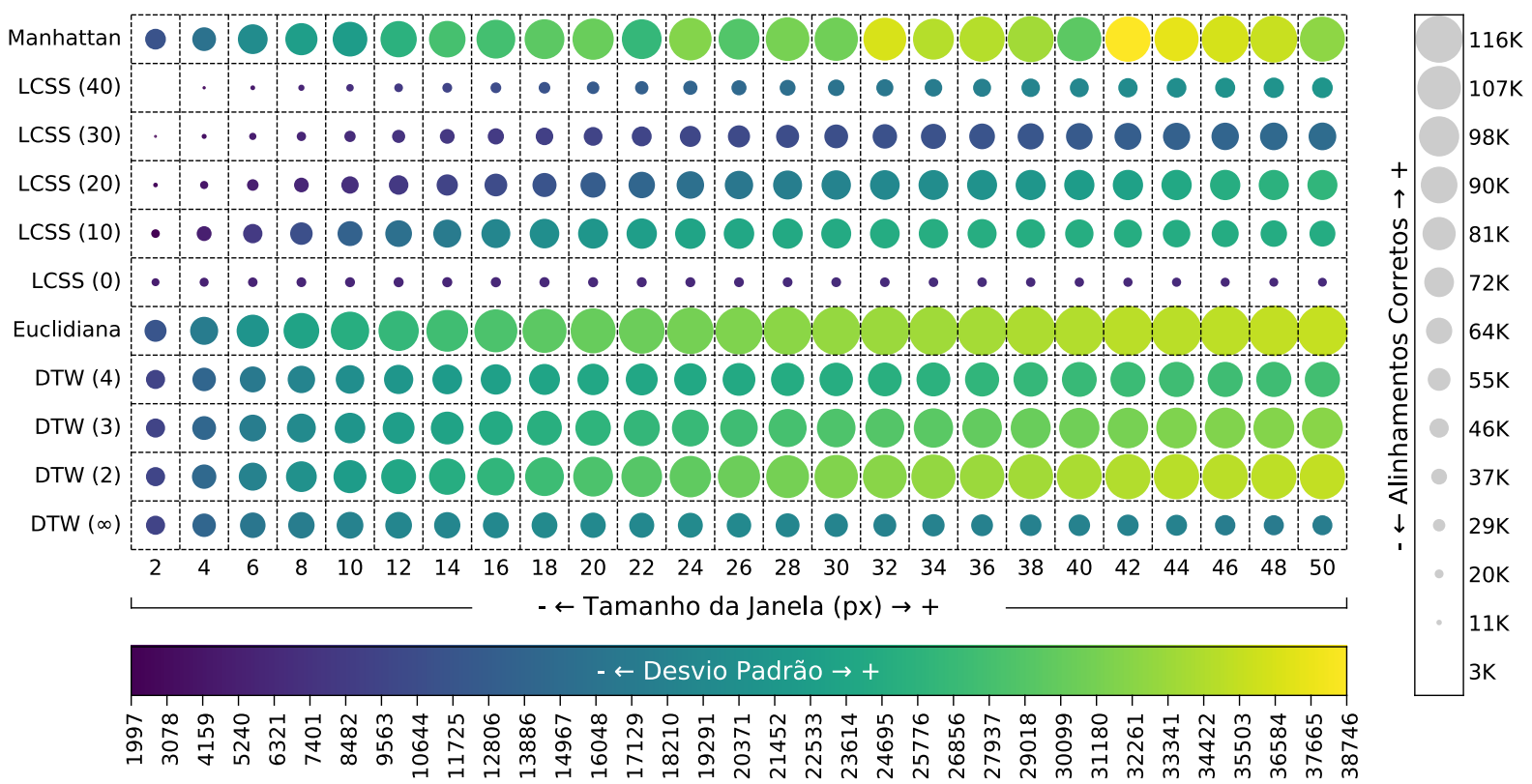

Fonte: Elaborada pelo autor.

Por meio do gráfico é possível verificar que as funções de distância Euclidiana, Manhattan e DTW (2) apresentam as maiores taxas de alinhamentos corretos, e diferente do que ocorreu para a análise do PSNR, o desvio padrão das demais funções não é relevante para incluí-las entre as melhores. Além disso, é possível verificar que a janela de tamanho 2 apresenta baixa taxa de alinhamentos corretos, assim como esperado, indicando que esta é uma medida mais adequada de qualidade para análise da função de distância. Dentre as três funções destacadas, a Euclidiana mostrou taxas de alinhamento melhores, pois a diferença entre os valores de desvio padrão não é significativa e a quantidade de alinhamentos é maior. Observe que os gráficos apresentados são sumarizações dos dados de diversas imagens (Art, Books, Dolls, Laundry, Moebius, Reindeer), porém tal constatação também pode ser feita para cada imagem individualmente.

É relevante notar que, intuitivamente, espera-se que funções de distância como a LCSS e DTW, que são mais flexíveis na comparação entre séries, reduzam a distância para alinhamentos corretos. Este resultado é de fato obtido, porém a flexibilização também ocorre para os alinhamentos incorretos, que acabam gerando distâncias menores que para o alinhamento correto. Assim, medidas mais rígidas, como é o caso da Euclidiana, apesar de gerarem distâncias maiores, encontram mais correspondências corretas. Com base nos resultados apresentados, a medida de distância Euclidiana foi adotada para a técnica SIRA e demais experimentos apresentados nas próximas seções. 


\subsubsection{Métodos de Representação}

Além das funções de distância, foi realizada uma análise com relação aos métodos de representação de séries temporais. A principal motivação desta análise está em encontrar a representação que melhor se adeque ao problema proposto, comparando as séries de canais de cores distintos de modo adequado.

Seguindo a abordagem executada na seção anterior, em que a quantidade de alinhamentos corretos é contabilizada, as representações Piecewise Aggregate Approximation (PAA), Symbolic Aggregate Approximation (SAX) e Fast Fourier Transform (FFT), explicadas na Seção 4.3 foram implementadas (exceto o $\mathrm{FFT}^{2}$ ) e aplicadas, não somente por serem as mais comumente utilizadas no domínio de séries temporais e processamento de sinais (no caso da FFT), mas também pois: a PAA permite que a granularidade seja reduzida, evitando que pequenos erros de alinhamentos tenham grande impacto negativo; o SAX permite que as 256 intensidades sejam divididas em faixas com aproximadamente a mesma quantidade de observações, com a ideia do PAA, porém para o eixo das intensidades; a FFT permite que o tempo seja removido, permitindo que deslocamentos no tempo deixem de afetar o resultado, evitando o que ocorre na série original. Além destas, foi avaliada a representação por meio da diferença entre elementos adjacentes, descrita na Subseção 5.1.2.

O tamanho da janela utilizada para as comparações foi variado de 2 até 50, executando diversas combinações possíveis para os algoritmos e suas variações (PAA e SAX). O parâmetro do PAA (Piecewise Aggregate Approximation) representa a quantidade de divisões que são executadas na série que está sendo comparada. Por exemplo, uma série com 18 valores e um PAA (6) gera uma série representada com 6 valores, em que cada valor foi gerado por meio da média de três valores da série original, conforme descrito na Subseção 4.3.3.

Já os parâmetros do algoritmo SAX (Symbolic Aggregate Approximation) indicam respectivamente a quantidade de divisões realizadas no eixo vertical e o parâmetro do PAA. As faixas SAX foram definidas independentemente para cada linha da imagem, levando em consideração a distribuição real da linha. Observe que ao extrair as faixas de modo independente, ocorre redução no impacto causado entre as diferenças de intensidades dos canais. Por exemplo, para um SAX $(12,15)$ é realizado o PAA(15) para ambos os canais de cores, e para a série das intensidades vermelhas são extraídas 12 faixas seguindo a distribuição do vermelho para a linha a qual está inserida, e 12 faixas para o verde seguindo a distribuição para sua respectiva linha (modelo vermelho-ciano). O valor de PAA(15) foi selecionado para os demais testes do SAX por obter melhores resultados em relação ao PAA(3), PAA(6) e PAA(9), e ligeiramente superior ao PAA(12). Já o PAA $(\infty)$, implícito em $\operatorname{SAX}(\ldots, \infty)$, foi selecionado pois a série original é mantida após a aplicação do PAA, sendo analisada apenas a divisão do eixo vertical.

Os resultados, são apresentados pela Figura 61, seguindo a mesma estrutura da seção

2 Código em C da representação FFT: https://rosettacode.org/wiki/Fast_Fourier_transform. Acesso em: 16/07/2019. 
Figura 61 - Comparação das diversas representações de séries, com base na quantidade de alinhamentos corretos das imagens.

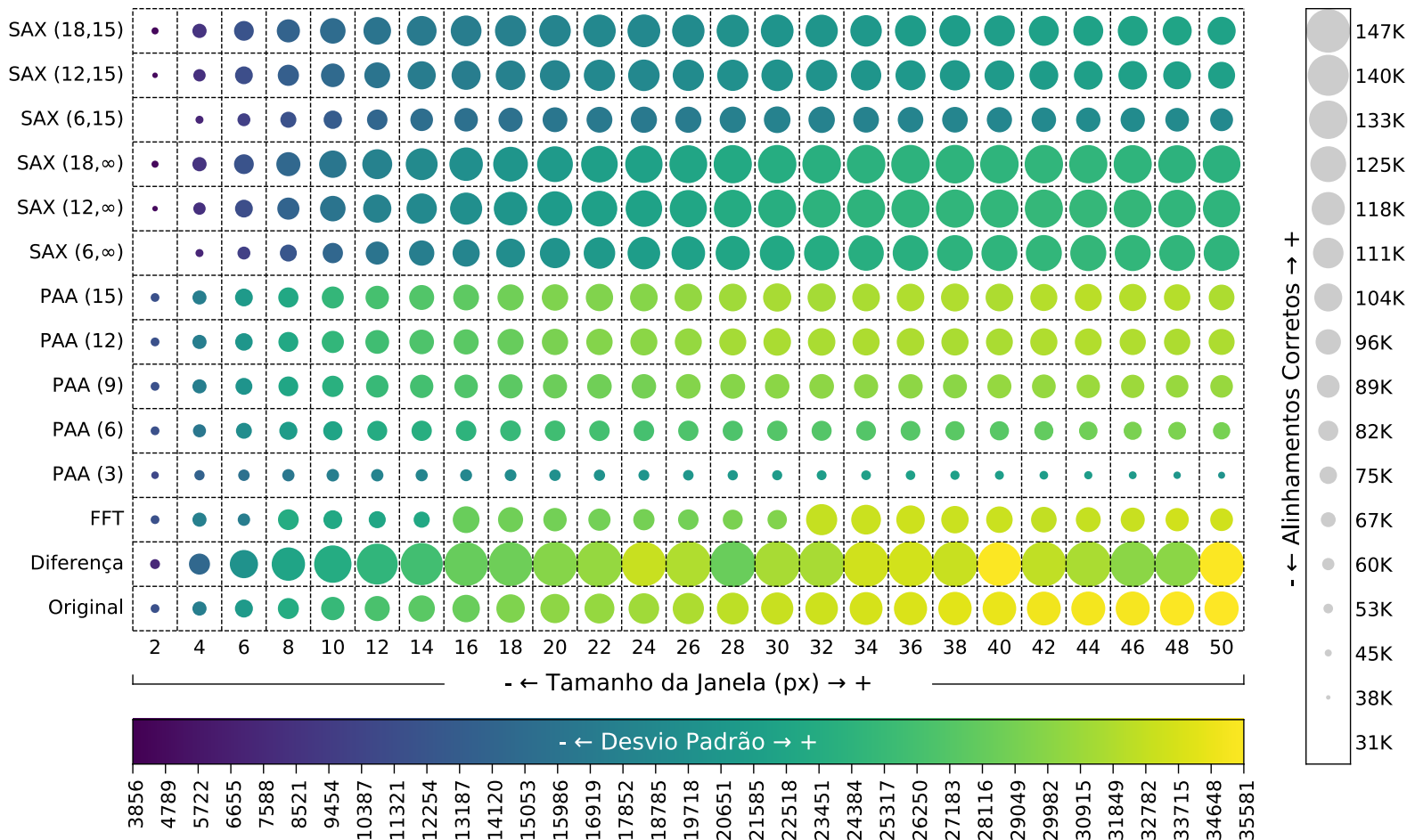

Fonte: Elaborada pelo autor.

anterior, em que são analisadas a quantidade de alinhamentos corretos (barra vertical) e desvio padrão (barra vertical em gradiente de cor) para cada uma das representações (linhas da coluna), variando o tamanho de janela (colunas), com o resultado de qualidade de cada combinação (método de representação $\times$ tamanho de janela) representado pelas bolinhas.

Por meio da Figura 61, é possível verificar que a FFT obteve resultados similares a série original para janelas em potência de 2, porém ligeiramente inferior. A aplicação do PAA obteve resultados inferiores à série original, para todas as divisões testadas. O principal motivo é que a granularidade aumenta, gerando menor detalhamento, influenciando negativamente no alinhamento das séries. Já a aplicação do SAX foi benéfica em relação à série original, já que obteve resultados superiores com desvio padrão menor. Apesar disso, a melhor representação é a baseada na diferença entre elementos adjacentes, que levou em consideração apenas as variações da cor em questão, e não sua intensidade propriamente dita. Observe que mesmo tendo desvio padrão maior que algumas representações, a quantidade de alinhamentos corretos é muito superior.

A Figura 62 apresenta maior detalhamento com relação aos dados apresentados na Figura 61, mostrando apenas os 3 melhores métodos de representação, comparados com a série original. Observe que o de desvio padrão possui faixa de 13.334 alinhamentos corretos, então mesmo considerando um cenário em que a série representada por meio da diferença possui 
Figura 62 - Comparação detalhada das melhores representações indicadas pelo experimento anterior.

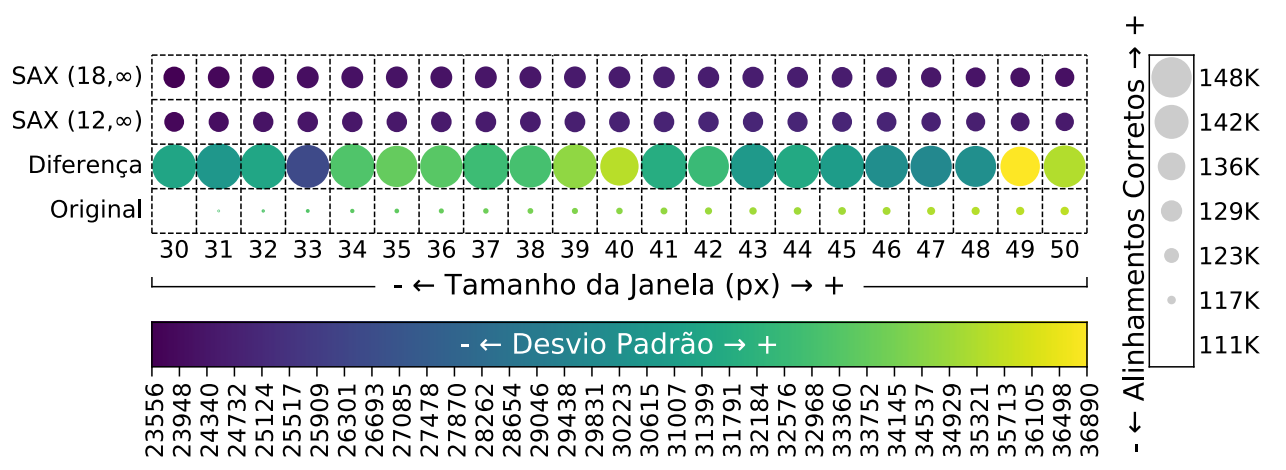

Fonte: Elaborada pelo autor.

maior desvio padrão, o valor para $-1 \sigma$ é de aproximadamente 135 mil alinhamentos, superior à quantidade média de alinhamentos do $\operatorname{SAX}(12, \infty)$ e $\operatorname{SAX}(18, \infty)$. Considerando os resultados apresentados, foi adotada a representação por meio da diferença entre elementos adjacentes como padrão para a técnica SIRA e demais experimentos realizados.

\subsubsection{Algoritmos de Segmentação}

O algoritmo de segmentação, mencionado na Subseção 5.1.1, permite delimitar as regiões para a extração de características e posterior alinhamento das imagens. Para que o resultado gerado tenha boa qualidade, é necessário que estas regiões sejam distintas para objetos diferentes. Assim, é preferível que uma região tenha mais segmentos do que o necessário, mas que não contenha trechos de outros objetos (oversegmentation). Uma das maneiras de obter segmentação com oversegmentation é por meio da utilização de algoritmos baseados em superpixels. Dentre os algoritmos para geração de superpixels, foram selecionados quatro algoritmos: SEEDS (BERGH et al., 2015) $)^{3}$, SLIC (ACHANTA et al., 2010) ${ }^{3}$, SLICO (ACHANTA et al., 2012) ${ }^{3} \mathrm{e}$ FH (FELZENSZWALB; HUTTENLOCHER, 2004) ${ }^{4}$. A escolha de tais algoritmos foi motivada pela alta aderência às bordas e baixo tempo de processamento propiciado pelos mesmos (STUTZ; HERMANS; LEIBE, 2018).

Seguindo os padrões de teste adotados nas subseções anteriores, em que são utilizados apenas dados de alinhamentos corretos, foram realizados experimentos variando parâmetros dos algoritmos de segmentação selecionados. O Quadro 4 mostra quais parâmetros foram variados e quais as faixas de valores assumidos por cada um deles, e o passo utilizado para realizar as combinações. Por exemplo, o algoritmo SLIC, que possui o parâmetro de tamanho médio em pixels dos superpixels (N/K) foi variado de 6 até 64 com incremento 4 a cada iteração e o fator de compactação (m) foi variado de 5 até 70 com incremento 5 a cada iteração, gerando todas as combinações possíveis (considerando as faixas pré-determinadas) entre os parâmetros.

3 https://docs.opencv.org/3.4/df/d6c/group_ximgproc_superpixel.html. Acesso em 16/07/2019.

4 http://cs.brown.edu/people/pfelzens/segment/index.html. Acesso em 16/07/2019. 
É interessante observar que apesar de alguns algoritmos possuirem parâmetros com nomes iguais, apresentam faixas de valores distintos de entrada. Tal fato ocorre devido à diferença nas implementações dos métodos. Os parâmetros foram estipulados com base nos artigos que descrevem cada uma das técnicas, e também com base nos manuais fornecidos pelo OpenCV ${ }^{5}$ para os algoritmos SEEDS, SLICO e SEEDS. Para o algoritmo SEEDS o número de iterações e número de níveis foram mantidos fixos, de maneira a priorizar a qualidade das imagens geradas, uma vez que quanto maiores, melhor a qualidade de saída da segmentação. Observe que o nome das variáveis é independente para cada algoritmo, assim o $K$ para o algoritmo FH é diferente do $\mathrm{K}$ apresentado para os algoritmos SLIC e SLICO. Para maiores informações relacionadas aos parâmetros, é necessário consultar os respectivos artigos originais.

Quadro 4 - Parâmetros utilizados para os algoritmos de segmentação.

\begin{tabular}{|c|c|c|c|}
\cline { 2 - 4 } \multicolumn{1}{c|}{} & Parâmetro & Variação & Incremento \\
\hline \multirow{4}{*}{ FH } & Termo de Suavização $(\sigma)$ & 0.0 até 1.0 & 0.2 \\
\cline { 2 - 4 } & Tamanho dos Superpixels/Componentes $(\mathrm{K})$ & 100 até 1900 & 200 \\
\cline { 2 - 4 } & Tamanho Mínimo da Componente (min_size) & 50 até 250 & 50 \\
\hline \multirow{4}{*}{ SEEDS } & Termo de Suavização & 0 até 4 & 1 \\
\cline { 2 - 4 } & Número de Superpixels & 80 até 280 & 20 \\
\cline { 2 - 4 } & Número de Níveis & Fixo: 12 & - \\
\cline { 2 - 4 } & Número de Bins de Histograma & Fixo: 13 & 2 \\
\cline { 2 - 4 } & Número de Iterações & 6 até 94 & - \\
\hline \multirow{2}{*}{ SLIC } & Tamanho Médio em Pixels dos Superpixels (N/K) & 4 \\
\cline { 2 - 4 } & Fator de Compactação $(m)$ & 5 até 70 & 5 \\
\hline SLICO & Tamanho Médio em Pixels dos Superpixels (N/K) & 6 até 94 & 4 \\
\hline
\end{tabular}

Fonte: Dados da pesquisa.

Com base nos mapas de profundidade fornecidos pela Middlebury, foi computada a quantidade de alinhamentos corretos para todas as combinações apresentadas no Quadro 4, de cada um dos algoritmos de segmentação para cada imagem da base Middlebury 2005 (SCHARSTEIN; PAL, 2007), com a quantidade de alinhamentos igual a soma dos alinhamentos corretos da imagem ciano e vermelha. Os resultados de qualidade para os quatro algoritmos de segmentação são apresentados no gráfico da Figura 63. Os grupos apresentados no eixo horizontal representam cada uma das imagens sendo analisadas. O eixo vertical apresenta o índice de qualidade das imagens, com relação à quantidade de acertos de alinhamento, considerando um limiar de 2 pixels de erro. Por exemplo, supondo o deslocamento correto como 40, deslocamentos para a faixa $[38,42]$ são considerados corretos. Os boxplots apresentados dentro de cada grupo representam os algoritmos de segmentação, sendo FH representado em vermelho, SEEDS em verde, SLIC em amarelo e SLICO em azul. Apesar de cada boxplot apresentar a soma dos resultados para o lado vermelho e ciano, foi verificado que os mesmos padrões ocorrem quando os canais são analisados de maneira independente. 
Figura 63 - Qualidade dos resultados obtidos para os diversos algoritmos de segmentação.

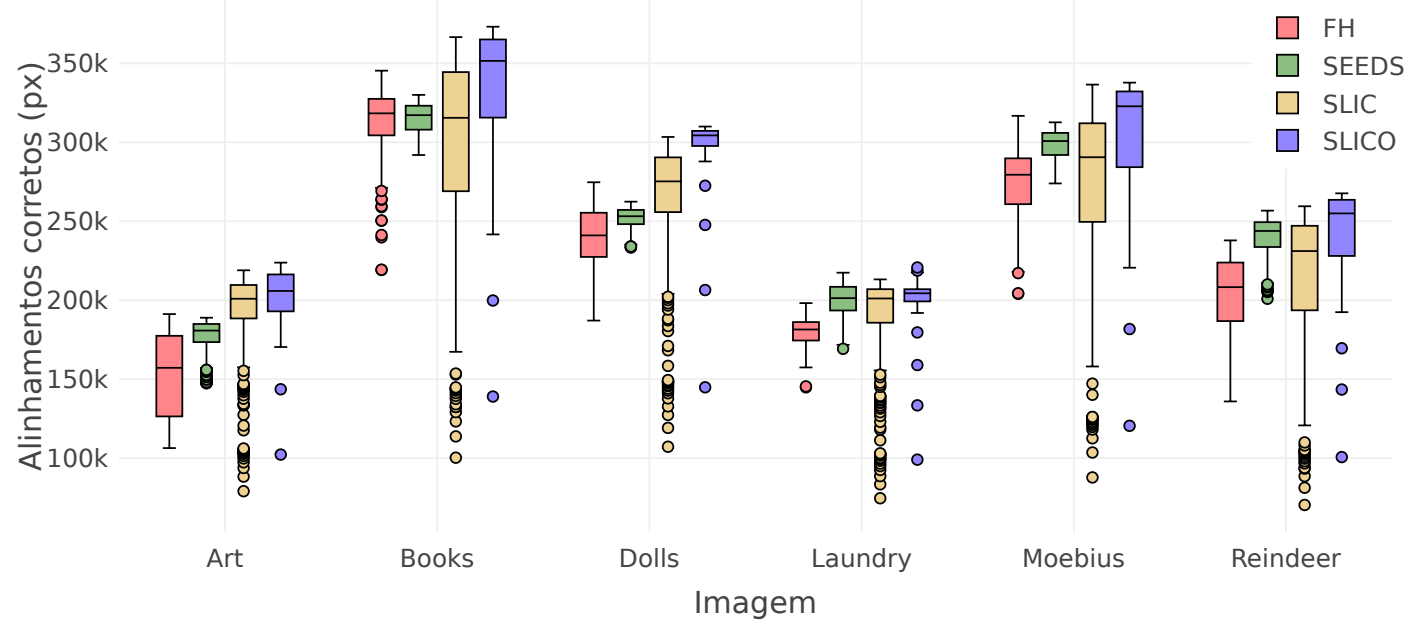

Fonte: Elaborada pelo autor.

O gráfico mostra que o algoritmo SEEDS apresenta comportamento mais estável em relação aos demais algoritmos analisados, uma vez que para todas as imagens, ocupa menor espaço vertical entre o primeiro e terceiro quartil. Além disso, é possível verificar que o algoritmo FH apresenta, para a maioria dos parâmetros avaliados, resultados inferiores que aos apresentados por SEEDS e SLICO para as imagens Art, Dolls, Laundry e Reindeer. Tal resultado é um indício de que o algoritmo FH pode não ser o melhor algoritmo para a tarefa de alinhamento. Apesar destas constatações, não é possível concluir qual é, objetivamente, o melhor algoritmo, pois grande parte da distribuição dos dados está sobreposta. Por exemplo, é possível que um algoritmo tenha uma configuração de parâmetros muito boa para uma imagem, tornando-o superior aos demais algoritmos, porém a mesma configuração é ruim para as outras imagens.

Como não houve um algoritmo de segmentação que obteve resultados comprovadamente superiores aos demais considerando diversos valores de parâmetros, foi realizada a análise quanto a melhor configuração de parâmetros apresentada para cada um dos algoritmos. A Figura 64 apresenta a maneira de execução dessa análise para o algoritmo SLIC, em que cada uma das configurações de parâmetros (tamanho médio dos superpixels e fator de compactação) é executada $(\{(6,5),(6,10),(6,15), \ldots,(66,70), \ldots\})$ de maneira independente para cada uma das imagens (Art, Books, Dolls, Laundry, Moebius, Reindeer), considerando a soma dos valores do lado esquerdo e direito. Os resultados computados são apresentados em cada uma das células do quadro à esquerda.

Para que cada imagem contribua da mesma maneira para a escolha da configuração de parâmetro mais adequada, os resultados de cada imagem foram normalizados ( 0 e 1 - min-max) de maneira independente, gerando o quadro à direita. Esses valores são somados a fim de gerar um único valor de qualidade por configuração parâmetros. $\mathrm{O}$ exemplo apresenta a configuração de parâmetros $(66,70)$ com valor mais alto no somatório (em azul), portanto esta é considerada 
a melhor configuração de parâmetros para o algoritmo SLIC, com a quantidade de alinhamentos corretos de cada imagem apresentados em verde.

Figura 64 - Computando melhor configuração de parâmetros para cada o algoritmo SLIC.

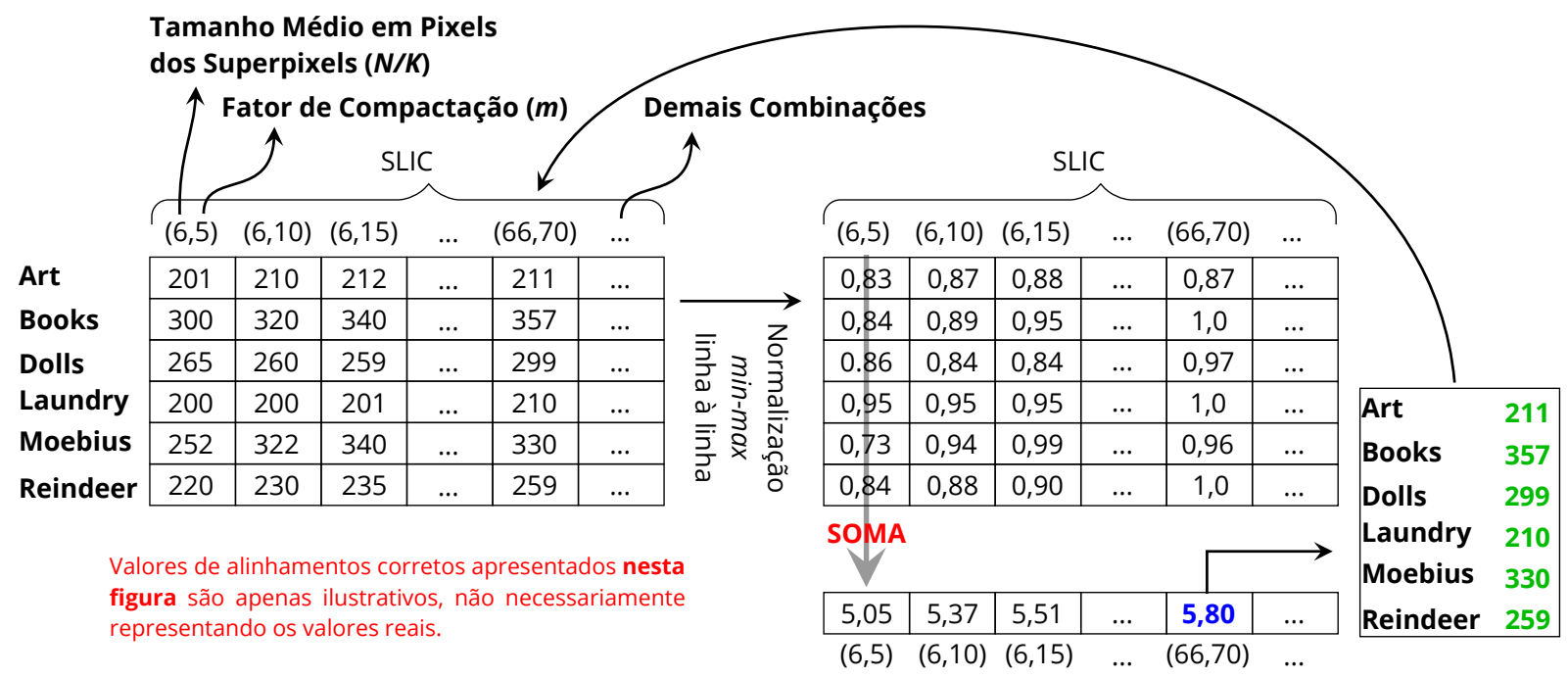

Fonte: Elaborada pelo autor.

O mesmo processo é executado para os algoritmos FH, SEEDS e SLICO, computando às melhores configurações de parâmetros para cada um dos algoritmos de segmentação. Por meio desta análise, as melhores configurações de parâmetros encontradas para os algoritmos são: FH $=(0.8,300$ e 50), indicando respectivamente o termo de suavização, o número de superpixels e o tamanho mínimo das componentes; SEEDS = (100, 3 e 11), indicando o número de superpixels, o número de bins, e o termo de suavização; $\operatorname{SLIC}=(66,70)$ indicando o tamanho médio dos superpixels e o fator de compactação; SLICO = (54) indicando o tamanho médio dos superpixels.

Considerando apenas a melhor configuração de parâmetros de cada algoritmo, são obtidos os resultados apresentados pela Figura 65. Os grupos de barras indicados pelo eixo horizontal representam as imagens, e cada uma das barras representa a quantidade de pontos alinhados corretamente, para a melhor configuração de parâmetro do algoritmo de segmentação em questão, em uma determinada imagem.

Por meio do gráfico é possível observar que todos os algoritmos apresentam resultados similares, porém no geral o SLIC e SLICO se destacam em relação ao FH e SEEDS. Observe que o SLICO obteve, na maioria das imagens, resultados melhores que o SLIC, seguindo o mesmo padrão encontrado no Figura 63. Comparando o FH com os demais algoritmos, é possível verificar que os resultados do FH foram inferiores para grande parte das imagens, comprovando os indícios apresentados na Figura 63.

A complexidade do algoritmo SLICO é $\mathscr{O}(N)$ com relação ao número de pixels, assim como o SLIC. O algoritmo FH tem complexidade $\mathscr{O}(N \log N)$ com relação ao número de pixels, e o algoritmo SEEDS tem complexidade dependente do parâmetro utilizado, porém é executado 
Figura 65 - Qualidade dos algoritmos de segmentação, considerando a melhor configuração de parâmetros para cada algoritmo.

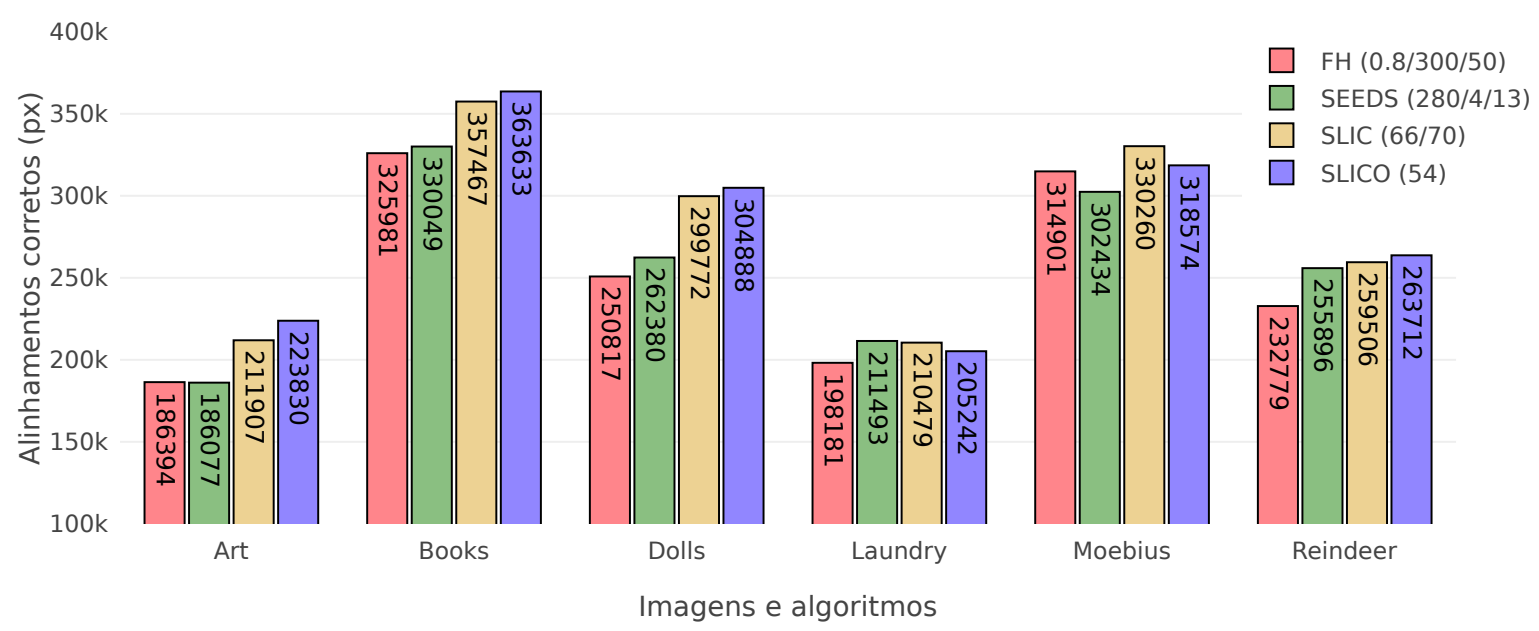

Fonte: Elaborada pelo autor.

em tempos muito baixos. Além da complexidade, todos os algoritmos apresentam baixo tempo de processamento.

De acordo com as informações apresentadas, foi selecionado para a técnica SIRA o algoritmo de segmentação SLICO, que possui complexidade linear (apesar de ser ligeiramente mais lento que o SLIC), e apresenta resultados melhores que os demais algoritmos, mesmo a diferença não sendo muito significativa. Uma outra vantagem reside na utilização de apenas um parâmetro. O SLICO também é utilizado nos experimentos discutidos nas próximas seções.

\subsection{4 Ângulos para Extração de Características}

A utilização de ângulos, na técnica SIRA, tal como explicado na Subseção 5.1.2, tem como objetivo elevar a quantidade de informação extraída, para posterior alinhamento das séries. Para isso, foi realizada uma análise objetivando determinar a quantidade mais adequada de ângulos a ser utilizada, isto é, o valor do parâmetro $\theta$, descrito na Subseção 5.1 .2 e recapitulado na Figura 58.

A Figura 66 apresenta, para cada imagem do conjunto, a quantidade de alinhamentos corretos considerando a utilização de apenas um único ângulo $(\theta=1)$. O principal objetivo deste teste é definir um baseline para determinar qual é o melhor ângulo, quando utilizado de modo independente. A partir deste baseline é possível verificar se a utilização de mais ângulos é relevante. O eixo horizontal do gráfico indica os ângulos utilizados de modo independente, e o eixo vertical apresenta a quantidade de pontos alinhados corretamente.

Por meio do gráfico é possível concluir que, de modo geral, o ângulo $0^{\circ}$ obtém melhores resultados. Um dos possíveis motivos para a baixa quantidade de alinhamentos corretos nos 
Figura 66 - Quantidade de alinhamentos corretos para cada ângulo.

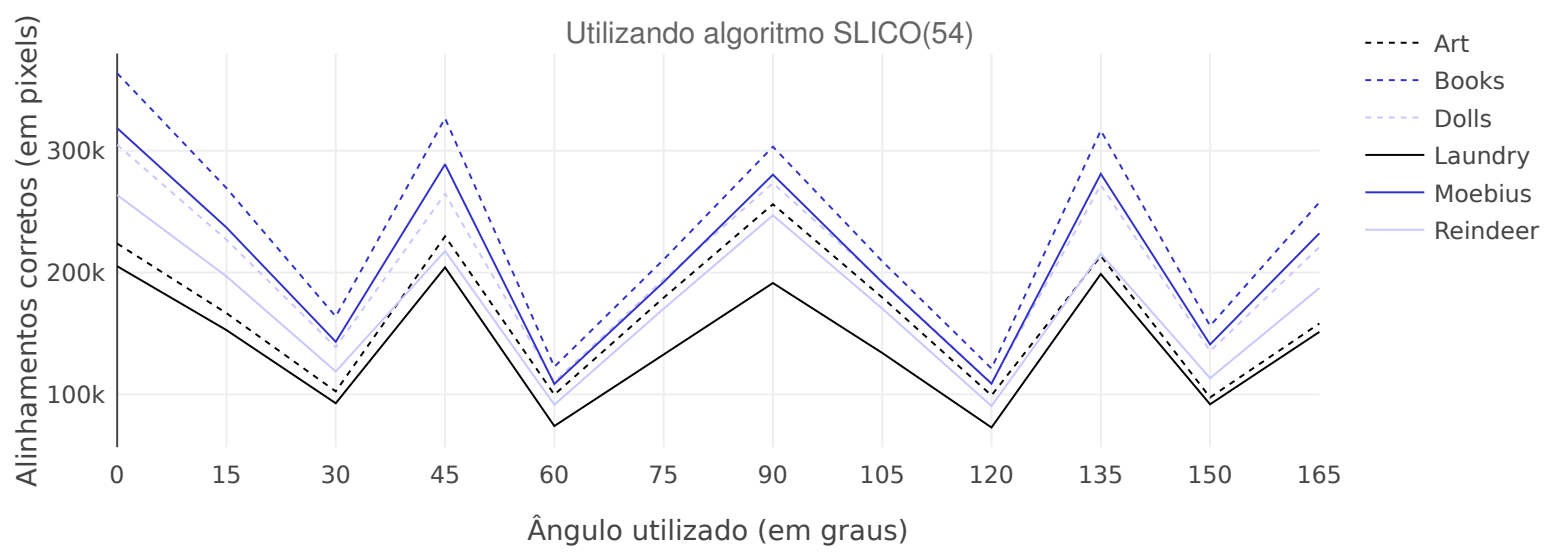

Fonte: Elaborada pelo autor.

demais ângulos é a discretização dos incrementos. Para o ângulo $0^{\circ}$ ocorre o incremento de 1 pixel para o eixo horizontal, e 0 pixels para o eixo vertical, já para um ângulo $15^{\circ} \mathrm{o}$ incremento é de 1 para o eixo horizontal, e 0.26 para o eixo vertical. Observe que devido ao fato de os pixels serem discretos, é necessário que ao menos um dos eixos tenha incremento igual a 1, sempre capturando pontos distintos para a série gerada.

Figura 67 - Exemplos de séries geradas para ângulos distintos.
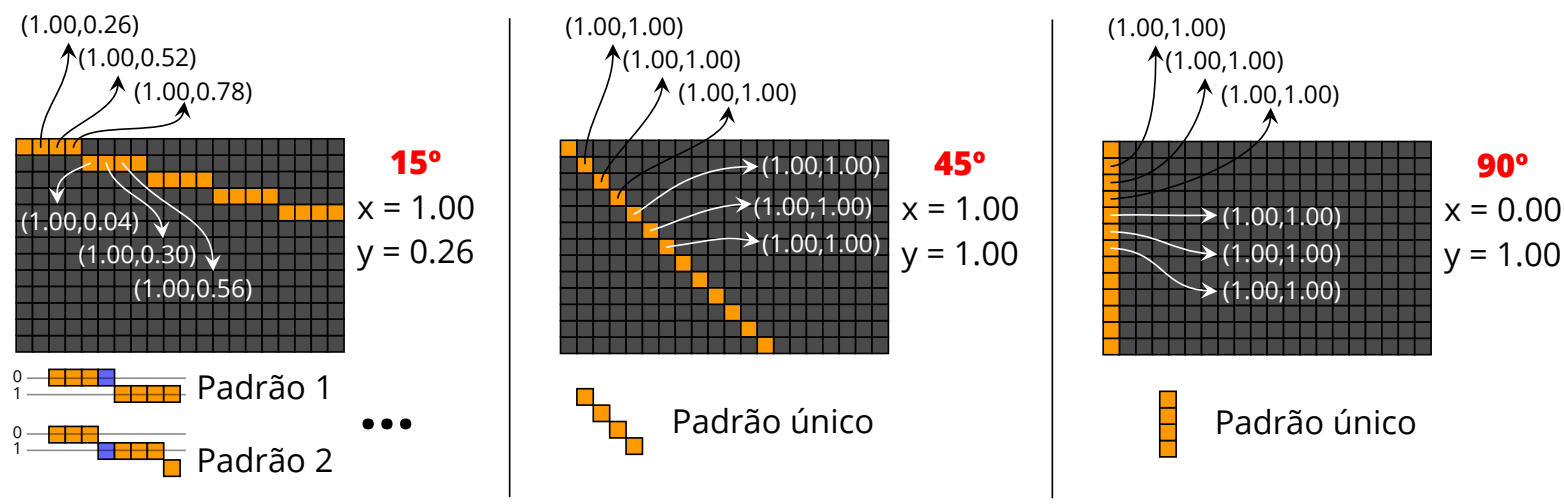

Padrão único

Fonte: Elaborada pelo autor.

A Figura 67 ilustra o problema para ângulos diferentes de $0^{\circ}, 45^{\circ}, 90^{\circ}$ ou $135^{\circ}$. Para um ângulo de $15^{\circ}$ existem diversos padrões possíveis para realizar a extração, permitindo ao algoritmo comparar elementos de linhas distintas. Por exemplo, a célula azul para o padrão 1 pertence à primeira linha, enquanto para o padrão 2 pertence à segunda linha. Já para os ângulos $0^{\circ}, 45^{\circ}, 90^{\circ}$, e $135^{\circ}$, a comparação é realizada sempre utilizando o mesmo padrão, o que evita tal problema. Por exemplo, para o ângulo $45^{\circ}$ é gerada uma série sempre relacionada com a linha inferior para o lado direito, e para o ângulo $90^{\circ}$ sempre para baixo.

Além de testar os ângulos de maneira individualizada, foi verificada a qualidade do resultado para diferentes combinações, incrementais, dos ângulos. A Figura 68 apresenta um 
conjunto de gráficos, com cada gráfico representando uma imagem. O eixo horizontal dos gráficos apresenta a quantidade de ângulos utilizados para compôr o conjunto de características de um determinado pixel, conforme explicado na Subseção 5.1.2. Assim, para o eixo horizontal igual a $1\left(\mathbf{0}^{\circ}\right)$, é utilizado apenas o ângulo $0^{\circ}$; Para a posição $\mathbf{2}\left(\mathbf{9 0}^{\circ}\right)$, são utilizados os ângulos $0^{\circ}$ e $90^{\circ}$; Para a posição $3\left(6^{\circ}\right)$ são utilizados os ângulos $0^{\circ}, 60^{\circ}$ e $120^{\circ}$. E assim sucessivamente, seguindo o padrão da quantidade de ângulos e incremento indicado entre parâmetros, sempre iniciando de $0^{\circ}$. Já no eixo vertical é apresentada a quantidade de alinhamentos corretos, considerando a soma dos valores das imagens do lado direito e esquerdo.

Figura 68 - Utilização de múltiplos ângulos para cada uma das imagens.
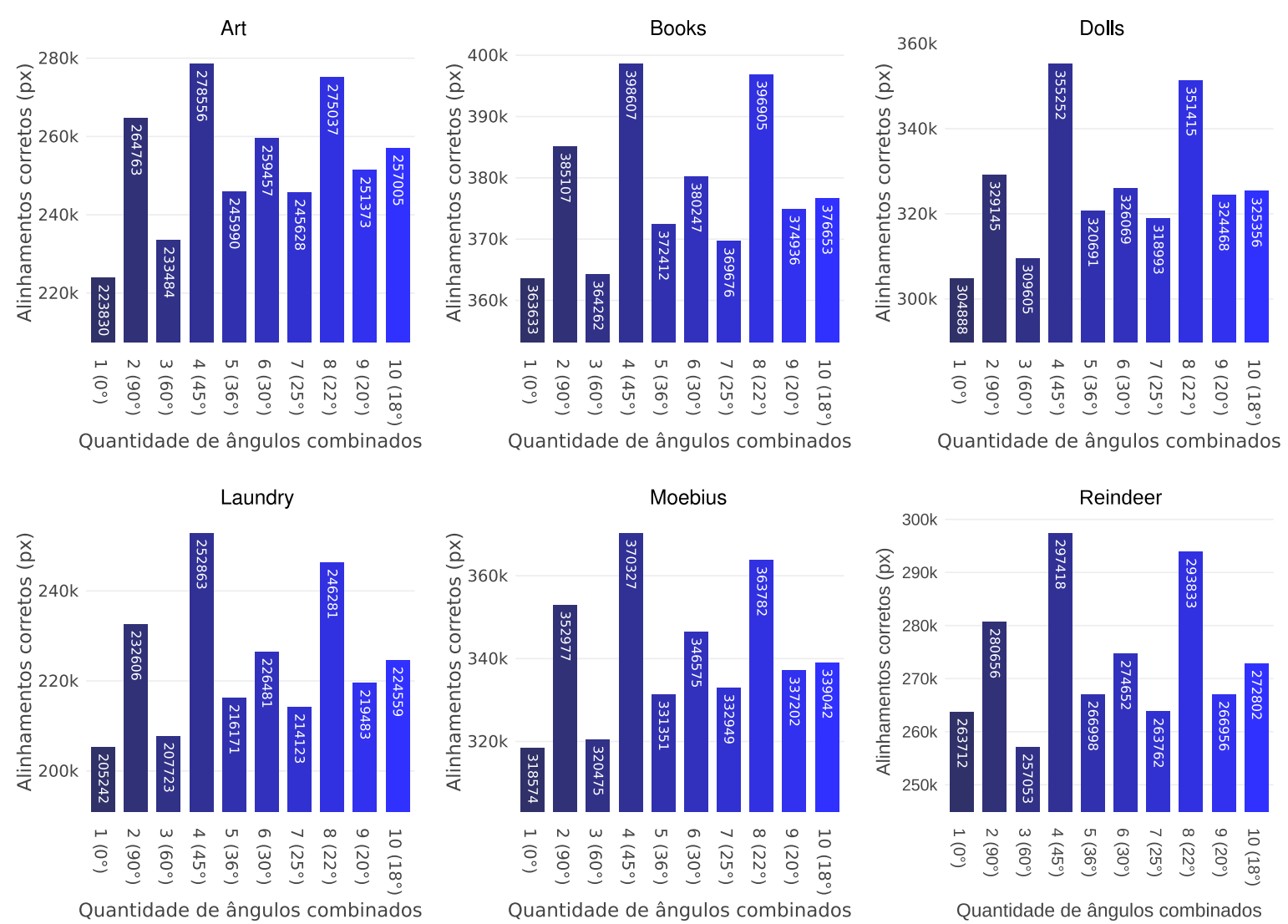

Fonte: Elaborada pelo autor.

A maior parte dos gráficos indicam que a utilização de mais de um ângulo é benéfica, seja qual for a quantidade de ângulos utilizada. Além disso, é possível observar que o melhor resultado é obtido com quatro ângulos, o que mostrou-se consistente em diversos outros testes realizados. Portanto, para a técnica proposta, foi adotado quatro ângulos como valor padrão para $\theta(\theta=4)$.

\subsubsection{Propagação do Alinhamento}

Conforme descrito na Subseção 5.1.5, a técnica SIRA inclui a etapa de propagação de alinhamento 5 que, além de reduzir os impactos visuais e qualitativos de alinhamentos indevidos, 
reduz a quantidade de pixels a serem colorizados na etapa seguinte. Para que a propagação do alinhamento seja eficaz, é necessário atribuir valores adequados ao parâmetro de tamanho de bloco $\beta$ e ao limiar de quantidade $\delta$, ambos descritos na Subseção 5.1 .5 e recapitulado na Figura 58.

Para encontrar a combinação adequada entre os parâmetros $\beta$ e $\delta$, o parâmetro $\beta$ foi variado de 0 à 20 e o parâmetro $\delta$ de 0 à 35, ambos com valor 1 de incremento. Diferente das etapas anteriores, em que a quantidade de alinhamentos corretos foi utilizada como medida de qualidade, esta etapa de propagação do alinhamento utiliza o PSNR, já que a informação de disparidade, utilizada para verificar a quantidade de alinhamentos corretos, não existe mais.

A Figura 69 apresenta mapas de cores para cada imagem do conjunto de dados utilizado, separadamente para cada um dos lados do par estéreo. O valor objetivo de qualidade é fornecido pela cor, em que cores mais escuras representam resultados inferiores, e cores mais claras (tendendo para o branco), representam resultados superiores. O eixo horizontal apresenta o tamanho $\beta$ do bloco utilizado e o eixo vertical apresenta o limiar $\delta$ utilizado. Observe que a utilização de bloco 0 e limiar 0 representa o PSNR sem a utilização da propagação do alinhamento, uma vez que o bloco representa o próprio pixel.

Por meio do gráfico é possível observar que a maior parte das imagens se beneficiam da etapa de propagação do alinhamento. A única exceção é a imagem Reindeer, que apresenta pequenos ganhos somente quando aplicadas janelas pequenas, um indício de que o alinhamento inicial obteve resultados pobres, já que propagar o alinhamento dos pixels supostamente corretos acabou piorando a qualidade das imagens geradas. De maneira a obter um par de parâmetros ( $\beta$ $\delta$ ) adequado para um conjunto de imagens, os resultados dos gráficos foram sumarizados. Assim, os valores de PSNR de cada um dos mapas de cor foram normalizados entre 0 e 1 (min-max normalization), e os resultados das células correspondentes foram somados, gerando valores entre 0 e 6 , já que são utilizadas 6 imagens.

A Figura 70 apresenta a sumarização dos dados para ambos os lados separadamente (Figura 70a), e o resultado final, gerado por meio soma dos lados (Figura 70b). Por meio deste, foi possível verificar que o parâmetro médio mais adequado para tamanho de bloco $\beta$ é igual a 13, e para limiar $\delta$ igual a 32. Observe que a escala está de 0 à 5 pois nenhuma célula obteve resultados superiores a 5, com relação ao máximo de 6 .

O Quadro 5 apresenta a diferença de resultados de PSNR obtidos com a aplicação da etapa de propagação de alinhamento e sem esta etapa. É possível observar que a propagação gera um ganho relevante para grande parte das imagens. O ganho total, quando somados os resultados das imagens é de $23.19 d B$, enquanto a perda é de apenas $2.65 d B$. É importante mencionar que ambos os resultados (com ou sem propagação do alinhamento) tem a etapa de colorização aplicada, representando o resultado final da técnica ${ }^{6}$.

6 Os resultados se diferem dos apresentados na Seção 6.4, já que as imagens são redimensionadas para permitir comparação com os algoritmos correlatos. 
Figura 69 - Relação entre tamanho da janela e threshold com medida de qualidade (PSNR) final.
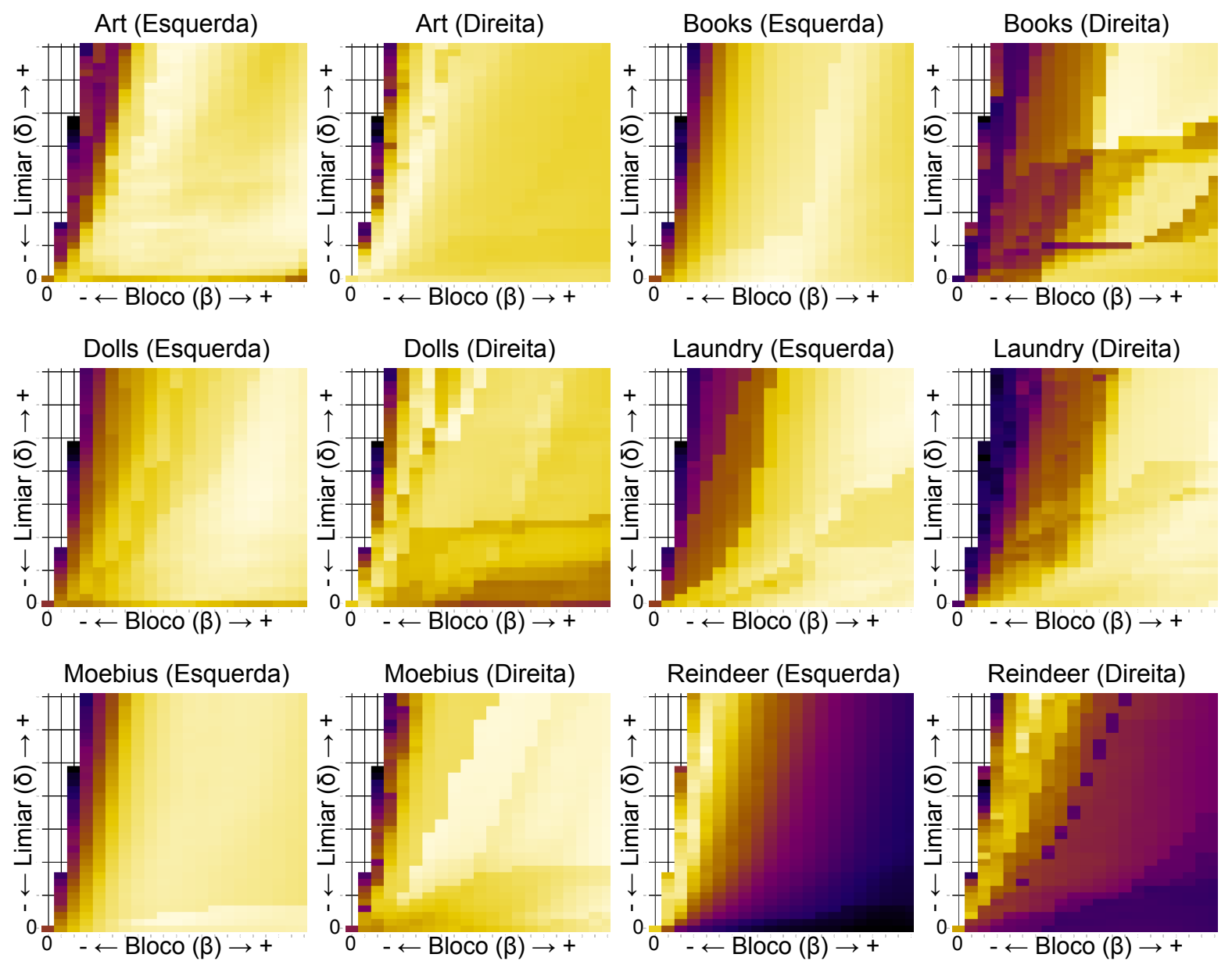

Pior

\section{PSNR}

Melhor

Fonte: Elaborada pelo autor.

\subsection{Comparação Objetiva}

As análises apresentadas na seção anterior mostram detalhes relacionados aos principais pontos de decisão que levaram à construção da técnica SIRA. Nesta seção, a técnica SIRA é comparada com os principais trabalhos do estado da arte que realizam o processo de recuperar

Quadro 5 - Comparação dos valores de PSNR com a utilização e não utilização de propagação de alinhamento.

\begin{tabular}{|c|c|c|c|c|c|c|c|c|c|c|c|c|}
\hline & \multicolumn{2}{|c|}{ Art } & \multicolumn{2}{|c|}{ Books } & \multicolumn{2}{|c|}{ Dolls } & \multicolumn{2}{|c|}{ Laundry } & \multicolumn{2}{|c|}{ Moebius } & \multicolumn{2}{|c|}{ Reindeer } \\
\hline & E. & D. & E. & D. & E. & D. & E. & D. & E. & D. & E. & D. \\
\hline $\begin{array}{l}\text { Sem Propagação } \\
\text { de Alinhamento }\end{array}$ & 21.9 & 26.8 & 24.86 & 23.24 & 22.54 & 27.06 & 20.19 & 22.69 & 23.93 & 24.98 & 25.61 & 26.16 \\
\hline $\begin{array}{c}\text { Com Propagação } \\
\text { de Alinhamento }\end{array}$ & 22.51 & 26.63 & 26.46 & 30.35 & 24.45 & 27.76 & 21.99 & 27.17 & 26.12 & 28.77 & 24.08 & 25.21 \\
\hline Diferença & +0.61 & -0.17 & +1.6 & +7.11 & +1.91 & +0.7 & +1.8 & +4.48 & +1.19 & +3.79 & -1.53 & -0.95 \\
\hline
\end{tabular}

Fonte: Dados da pesquisa. 
Figura 70 - Soma dos resultados normalizados para as diversas combinações $\beta$ - $\delta$.

(a) Soma dos resultados normalizados para o lado esquerdo e direito.
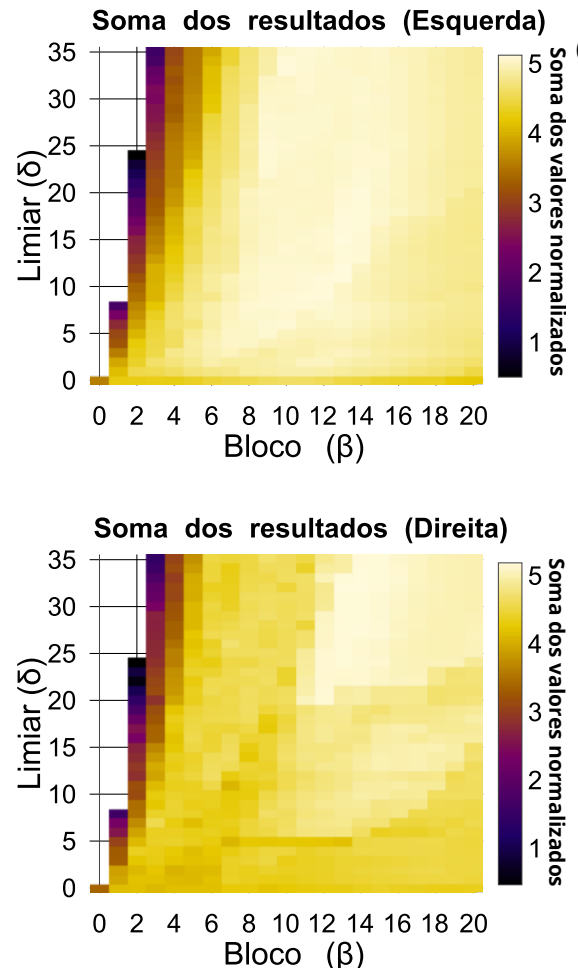

(b) Soma dos resultados dos gráficos apresentados na Figura 70a.

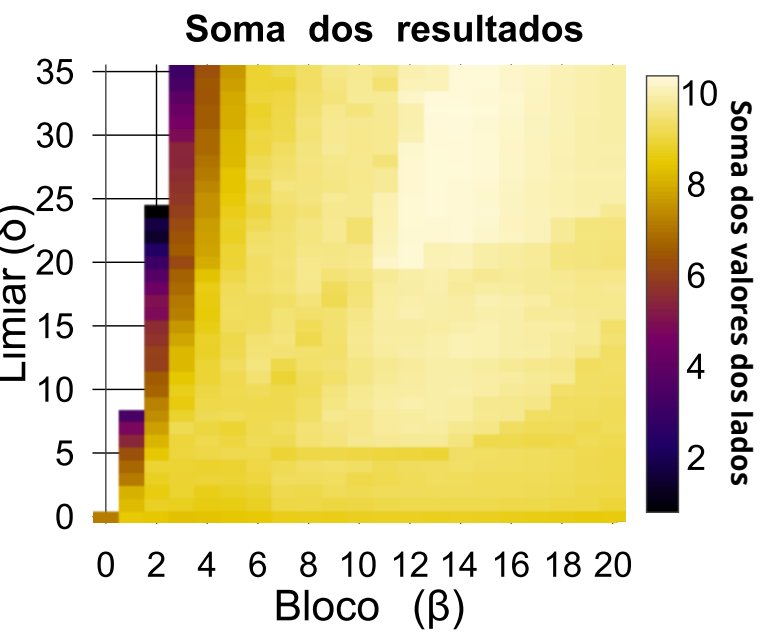

Fonte: Elaborada pelo autor.

uma aproximação do par estéreo, por meio da geração do anáglifo, sem a utilização de metadados adicionais. Para esta comparação, foram selecionados o algoritmo ASIFT (JOULIN; KANG, 2013) e o algoritmo proposto por Williem, Raskar e Park (2015). Para simplificar a apresentação dos resultados, a técnica ASIFT (JOULIN; KANG, 2013) será chamada somente de ASIFT e a técnica proposta por Williem, Raskar e Park (2015) será chamada apenas de Williem.

O código fonte do algoritmo ASIFT e o executável do algoritmo de Williem foram fornecidos pelos respectivos autores. As comparações realizadas têm por objetivo medir a qualidade objetiva (PSNR e tempo) e subjetiva (DSCQS) das imagens geradas pelos três algoritmos. Todos os experimentos comparativos foram executados utilizando Sistema Operacional Windows 10 Home (versão 1809), com processador 78700 @ 3.2GHz, placa de vídeo NVIDIA GeForceGTX 1070 e 16 GB de memória RAM. Os parâmetros fixos utilizados pela técnica SIRA são apresentados no Quadro 6, para todas as seis etapas (Capítulo 5).

Conforme descrito na Seção 6.1, foram utilizadas as bases 2001, 2003 e 2005 da Middlebury para comparações. As imagens com resolução maiores que 640 de largura foram redimensionadas para 640, mantendo as proporções da imagem. Este redimensionamento foi necessário para permitir comparações com o método ASIFT, que realiza este processo antes de iniciar o processamento das imagens. Com relação ao parâmetro de disparidade máxima 
Quadro 6 - Parâmetros fixos definidos para a técnica SIRA, utilizados na execução dos experimentos.

\begin{tabular}{|c|c|}
\hline Parâmetro & Valor \\
\hline Número de ângulos $(\theta)$ & 4 \\
\hline Limiar para erro de alinhamento $(\gamma)$ & 4 \\
\hline Tamanho do bloco $(\beta)$ & 13 \\
\hline Limiar de colisão para blocos $(\boldsymbol{\delta})$ & 32 \\
\hline Quantidade de pixels mínimos para colisão $($ qMin) & 10 \\
\hline Raio de busca inicial $(\lambda)$ & 10 \\
\hline Parâmetro SLICO $(N / K)$ & 54 \\
\hline
\end{tabular}

Fonte: Dados da pesquisa.

$(\mathscr{L})$, que é o único parâmetro da técnica SIRA, foi utilizado $\mathscr{L}=80$ para as bases 2001 e 2003 e $\mathscr{L}=110$ para a base 2005 , pois as imagens das bases 2001 e 2003 possuem disparidades máximas menores que as de 2005, e a utilização de parâmetros distintos evita cálculos desnecessários. Para a técnica de Williem, que também utiliza somente o parâmetro de controle de disparidade máxima $(\mathscr{L})$, as mesmas configurações foram aplicadas. Já a técnica ASIFT não exige parâmetros de entrada.

Os resultados da medida objetiva PSNR de cada um dos algoritmos é apresentado no Quadro 7. As três técnicas são agrupadas em três colunas (Williem, ASIFT e SIRA (Proposta)). Cada um dos grupos apresenta colunas para o PSNR da técnica em questão para as imagens do lado esquerdo (Esq.) e direito (Dir.). Já as linhas apresentam as diversas imagens das bases, com seus respectivos PSNR's comparadas com a imagem original fornecida pela Middlebury. Observe que as imagens estão agrupadas pelas bases (Mid. 2001, Mid. 2003, Mid. 2005). É importante mencionar que as imagens da esquerda normalmente apresentam resultados de qualidade inferiores às imagens da direita, já que o processo de reversão é mais difícil por ser necessário recuperar dois canais de cores $(\mathrm{G}, \mathrm{B})$ ao invés de um $(\mathrm{R})$.

Por meio dos resultados apresentados no Quadro 7, é possível observar que a técnica SIRA conseguiu atingir valores de PSNR maiores que as demais em 10 imagens, o ASIFT atingiu valores maiores em 11 imagens, e o algoritmo proposto por Williem em 15 imagens. Vale destacar que a SIRA obteve valor médio de PSNR superior para as imagens do lado esquerdo, que necessitam recuperar mais informações, e obteve resultados comparáveis para o lado direito. No geral, as três técnicas apresentaram valores objetivos muito similares, o que pode ser verificado pelas médias próximas, com diferença de PSNR entre a maior e menor média de 0,11 para o lado esquerdo e 1,46 para o lado direito. Associando aos valores das médias o desvio padrão, que está na faixa 3-4, é possível confirmar a estabilidade das técnicas.

A Figura 71 sumariza os dados apresentados no Quadro 7 por meio de boxplots para o lado esquerdo e direito. Analisando o gráfico esquerdo é possível verificar que todos os valores das medianas estão próximos para os três algoritmos, com pequena vantagem para o algoritmo de Williem. Apesar disso, a técnica SIRA possui os valores mínimos e máximos maiores que 
Quadro 7 - Comparação de PSNR entre as técnicas SIRA (proposta), ASIFT e Williem.

\begin{tabular}{|c|c|c|c|c|c|c|c|}
\hline & \multicolumn{2}{|c|}{ Williem } & \multicolumn{2}{|c|}{ ASIFT } & \multicolumn{2}{|c|}{ SIRA (Proposta) } \\
\hline & & \multicolumn{2}{|c|}{ PSNR } & \multicolumn{2}{|c|}{ PSNR } & \multicolumn{2}{|c|}{ PSNR } \\
\hline & & Esq. & Dir. & Esq. & Dir. & Esq. & Dir. \\
\hline \multirow{7}{*}{ i } & Sawtooth & 29,44 & $\mathbf{3 4 , 3 7}$ & 29,53 & 32,49 & 29,57 & 32,89 \\
\hline & Venus & 31,48 & 35,02 & 29,80 & 32,58 & 31,94 & 34,09 \\
\hline & Bull & 32,29 & 37,03 & 31,54 & 33,68 & 33,64 & 37,48 \\
\hline & Poster & 28,48 & 32,03 & 24,85 & 26,40 & 27,86 & 30,86 \\
\hline & BarnOne & 30,61 & 33,08 & 26,99 & 27,91 & 29,68 & 30,32 \\
\hline & BarnTwo & 30,87 & $\mathbf{3 5 , 5 0}$ & 30,33 & 32,33 & 31,36 & 33,34 \\
\hline & Tsukuba & $\mathbf{3 2 , 8 3}$ & 33,98 & 30,83 & 32,89 & 30,51 & 30,55 \\
\hline \multirow{2}{*}{ iْ } & Cones & 24,26 & 26,84 & 21,54 & 24,54 & 23,84 & 25,72 \\
\hline & Teddy & 23,35 & 30,71 & 21,27 & 24,70 & 24,65 & 29,81 \\
\hline \multirow{11}{*}{ 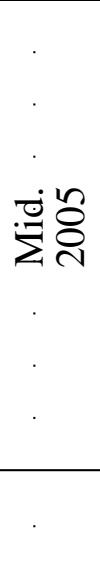 } & Art & 22,91 & 29,89 & 23,36 & 29,38 & 22,62 & 26,50 \\
\hline & Books & 22,14 & 30,49 & 25,91 & 32,83 & 27,42 & 29,28 \\
\hline & Dolls & 24,13 & 27,61 & 27,34 & 29,70 & 24,25 & 28,32 \\
\hline & Laundry & 20,40 & 28,67 & 20,89 & 27,09 & 22,59 & 28,07 \\
\hline & Moebius & 23,32 & 26,96 & 26,23 & 27,95 & 25,94 & 28,01 \\
\hline & Reindeer & 27,85 & 26,94 & 28,06 & 32,31 & 22,42 & 24,62 \\
\hline & Computer & 25,69 & 29,91 & 26,19 & 32,80 & 26,59 & 28.75 \\
\hline & Drumsticks & 23,05 & 26,03 & 26,28 & 28,70 & 22,66 & 24,38 \\
\hline & Dwarves & 26,03 & 30,25 & 29,23 & 30,10 & 23,53 & 26,10 \\
\hline & MÉDIA & 26,62 & 30,85 & 26,68 & 29,91 & 26,73 & 29,43 \\
\hline & DESV.PAD. & 3,92 & 3,37 & 3,31 & 2,98 & 3,66 & 3,58 \\
\hline
\end{tabular}

Fonte: Dados da pesquisa.

os apresentados por Williem e ASIFT. A analise do lado direito reforça que os três algoritmos apresentam resultados similares, devido à grande sobreposição do intervalo interquartil.

Figura 71 - Sumarização dos dados apresentados no Quadro 7 por Boxplots.
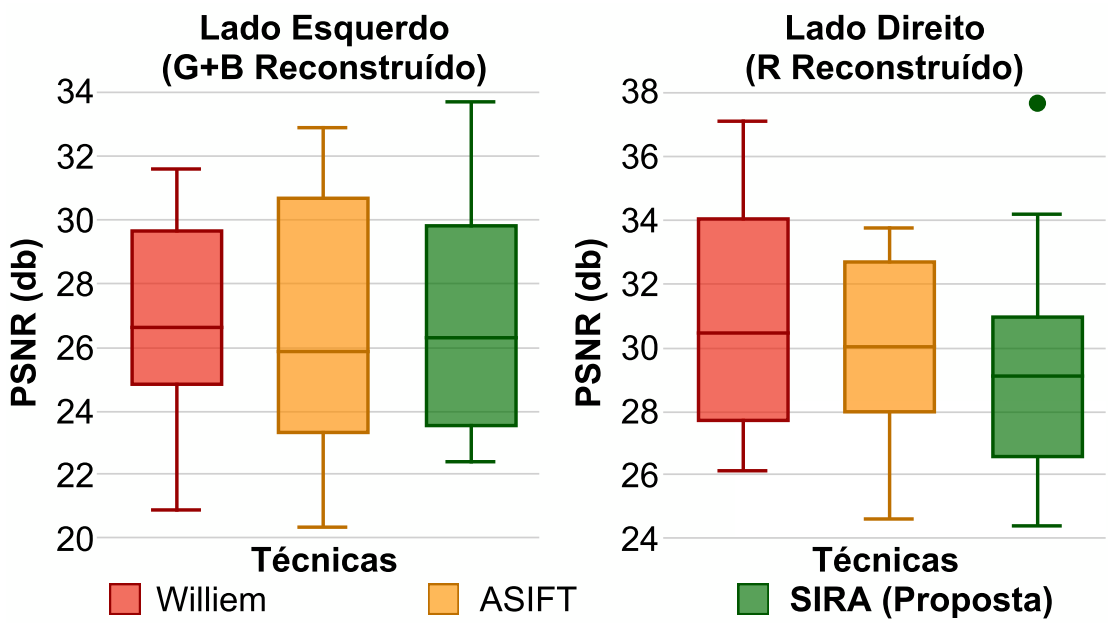

Fonte: Elaborada pelo autor. 
Além da comparação objetiva de qualidade, foi executada a comparação do tempo de processamento de cada uma das técnicas. Para isso, todas as imagens apresentadas no Quadro 7 foram processadas de forma independente, para cada um dos algoritmos. Este processo foi executado 10 vezes e a média dos tempos de execução foram computadas. Os resultados são apresentados na Figura 72, com as cenas das três bases Middlebury representadas no eixo horizontal, o tempo de processamento, em segundos, no eixo vertical e o tempo dispendido por cada um dos algoritmos representado pelas barras, para cada uma das imagens. É importante mencionar que o gráfico está em escala logarítmica, com cada valor representando a soma do tempo de processamento das imagens do lado direito e esquerdo, ou seja, de um par estéreo.

Figura 72 - Comparação de tempo de processamento entre as técnicas de Williem, ASIFT e SIRA (proposta).

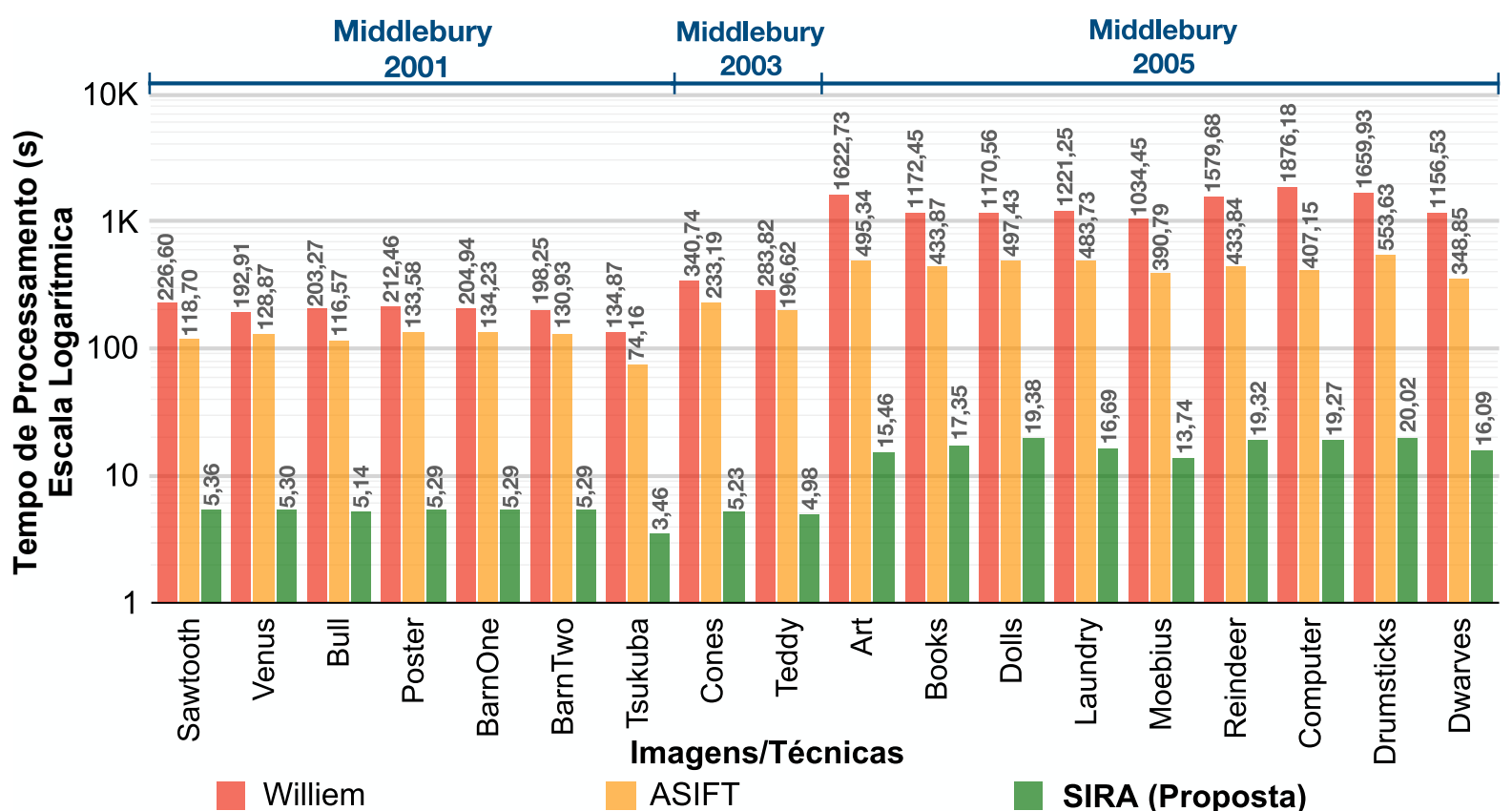

Fonte: Elaborada pelo autor.

De acordo com os resultados apresentados, a técnica SIRA é a mais rápida entre as três executadas. A média de tempo de processamento da técnica SIRA foi de 11,26 segundos, a técnica ASIFT foi de 295,08 segundos e a de Williem foi de 808,09 segundos. É importante mencionar que estas médias são relativas à reversão de um par estéreo (soma dos tempos dos dois lados). Por meio destes resultados foi verificado que a técnica SIRA é, em média, 26 vezes mais rápida que a técnica ASIFT e 71 vezes mais rápida que a técnica de Williem.

Para comparação, todas as técnicas foram executadas utilizando um único núcleo de CPU. Entretanto, a técnica SIRA, diferente das demais, possui implementação que permite paralelização, como discutido na Seção 5.2. Os tempos de processamento (em segundos) apresentados na Figura 73 mostram que a técnica é quase totalmente paralelizável. Os gráficos mostram o tempo de processamento de cada par estereoscópico, variando de 1 a 6 núcleos, além da configuração máxima do computador (6 núcleos físicos e 12 lógicos). Observe que com 2 núcleos o ganho de 
Figura 73 - Tempo de processamento das imagens ao utilizar mais núcleos de processamento para a técnica SIRA.

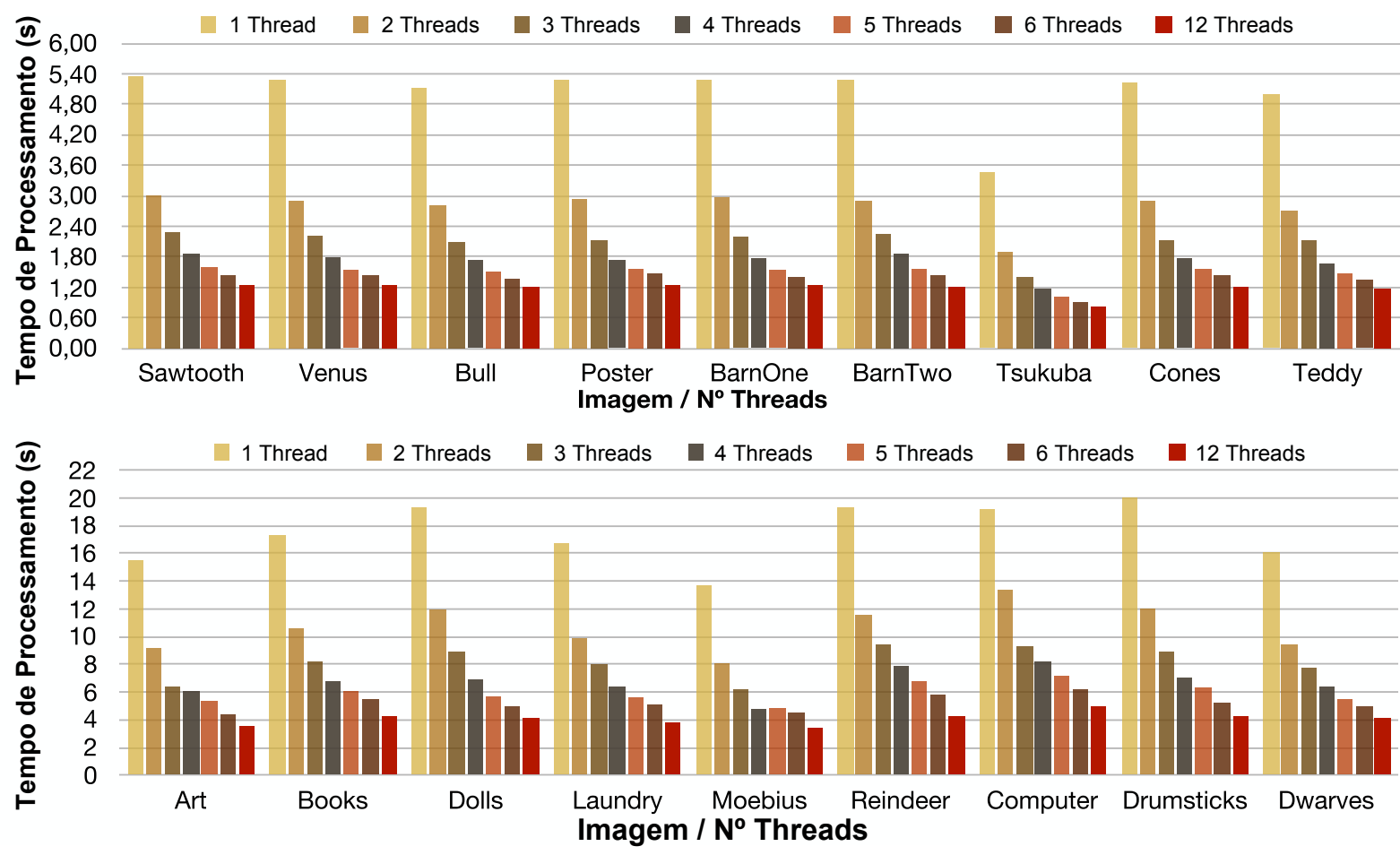

Fonte: Elaborada pelo autor.

tempo fica entre $30 \%$ e $45 \%$, e utilizando todos os núcleos, é possível atingir reversão anaglífica próxima ou abaixo de 1 segundo.

\subsection{Comparação Subjetiva}

Além da comparação objetiva, apresentada na Seção 6.4, foi realizada a análise subjetiva das imagens resultantes, analisando as três técnicas consideradas na seção anterior. A análise foi realizada utilizando as imagens $2 \mathrm{D}$ esquerda e direita do par estéreo resultante do processo de reversão anaglífica. A realização do teste subjetivo é interessante para avaliar a percepção que os usuários têm com relação às imagens, uma vez que, conforme discutido na Seção 6.2, é possível uma imagem possuir valores objetivos altos, porém com qualidade visual inferior.

Para ilustrar esse cenário, são apresentadas nas Figuras 74 e 75 imagens resultantes do processamento das três técnicas comparadas na Seção 6.4, com medidas objetivas de PSNR que não refletem a qualidade visual do resultado. Cada figura, apresenta a imagem anaglífica (a), o Ground Truth para o lado direito (b), o Ground Truth para o lado esquerdo (c), resultado para a técnica de Williem (d), resultado para a técnica ASIFT (e) e o resultado para a técnica SIRA (f). Para cada resultado é apresentado a imagem para o lado recuperado esquerdo, sua diferença com relação ao Ground Truth esquerdo (diferença esquerda), a imagem para o lado recuperado direito e a sua diferença com relação ao Ground Truth direito (diferença direita). Por meio dos mapas 
Figura 74 - Comparações para a imagem Cones (Middlebury 2003).

(a) Anáglifo

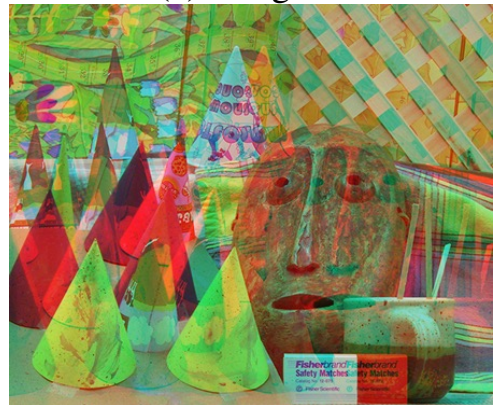

(d) Williem
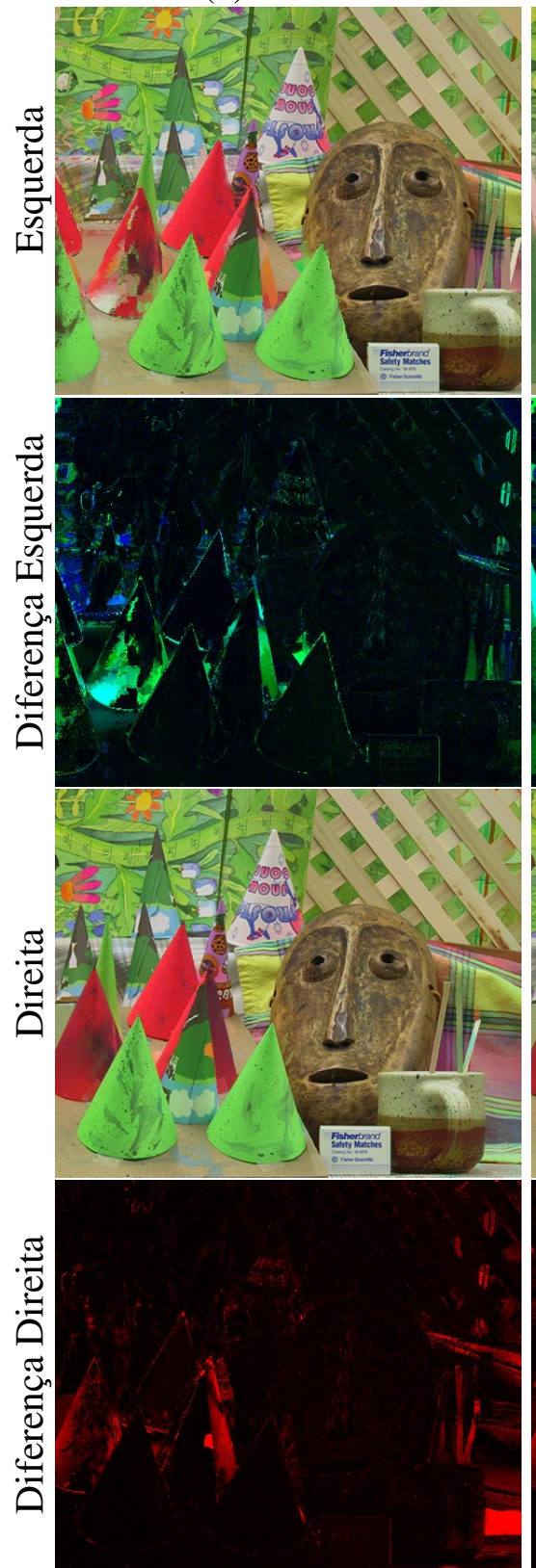

(b) Ground Truth Direita

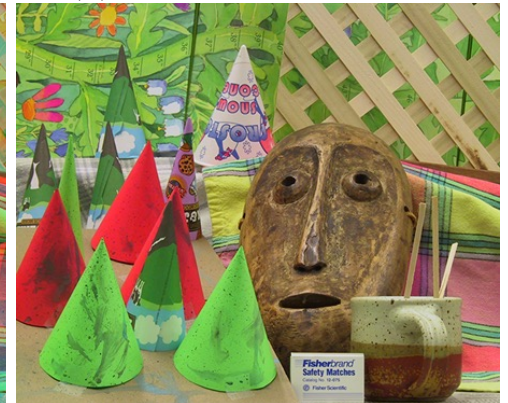

(e) ASIFT
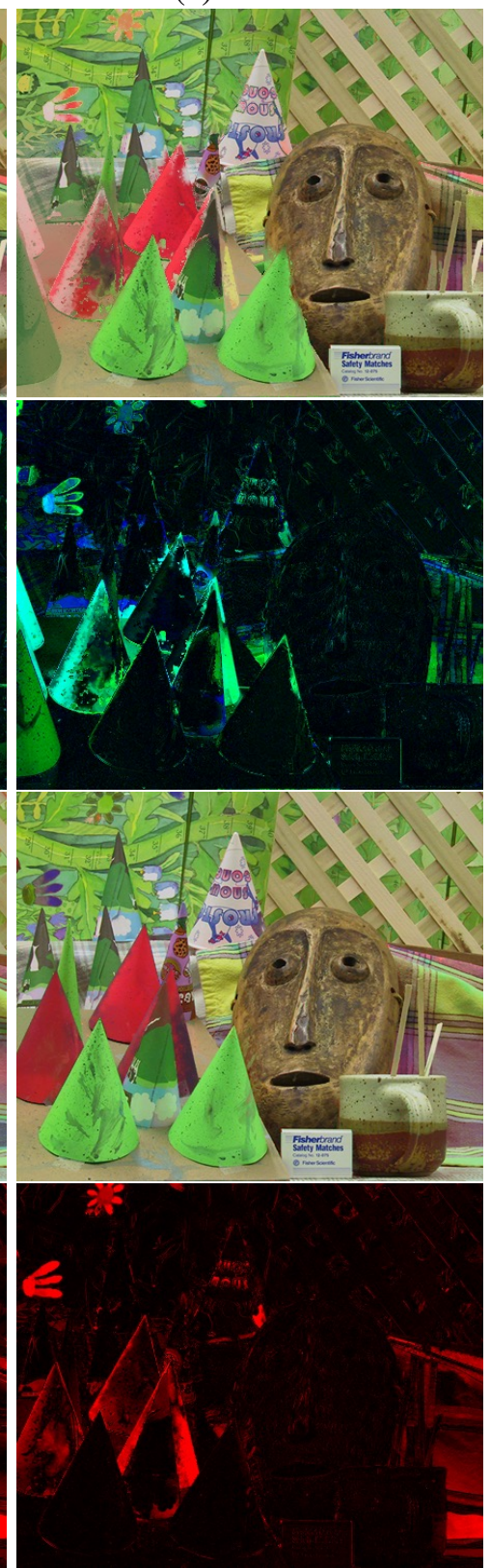

Fonte: Elaborada pelo autor. (c) Ground Truth Esquerda

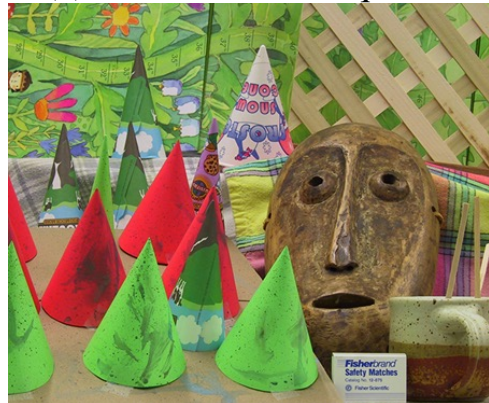

(f) SIRA (Proposta)
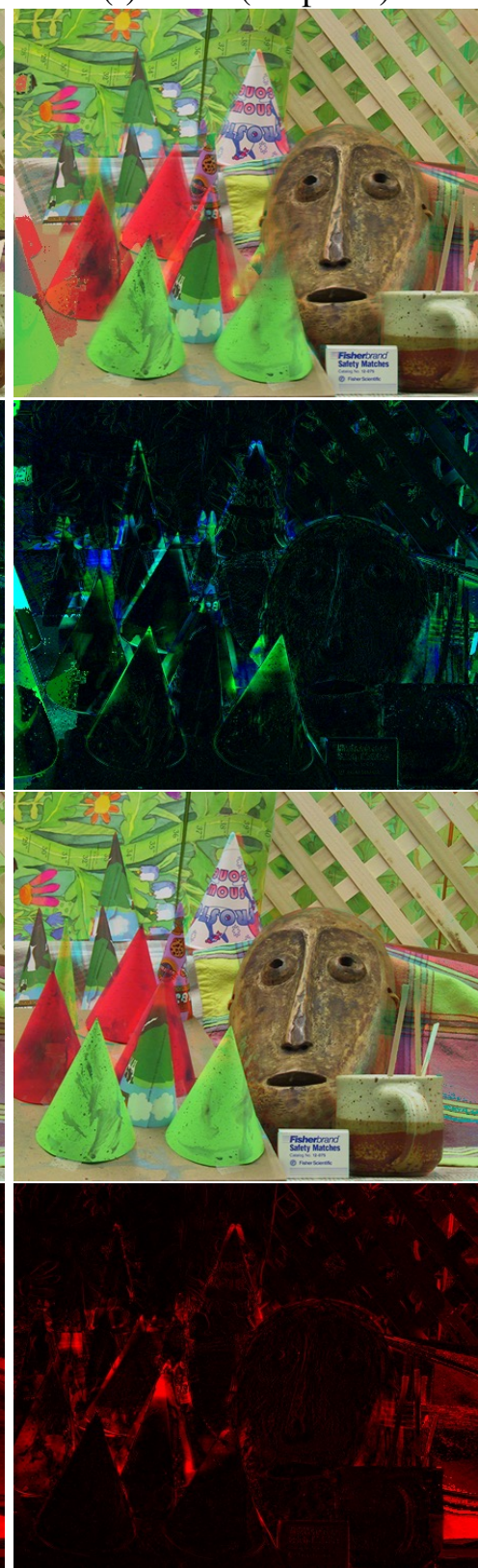
Figura 75 - Comparações para a imagem Computer (Middlebury 2005).

(a) Anáglifo

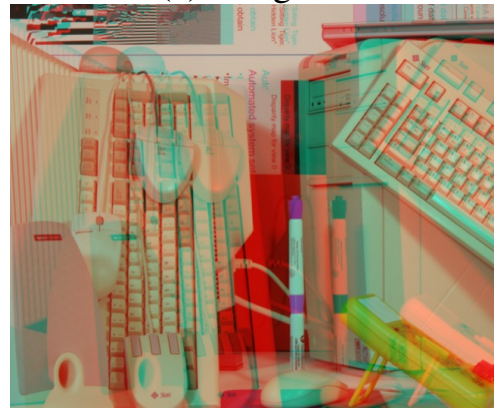

(d) Williem
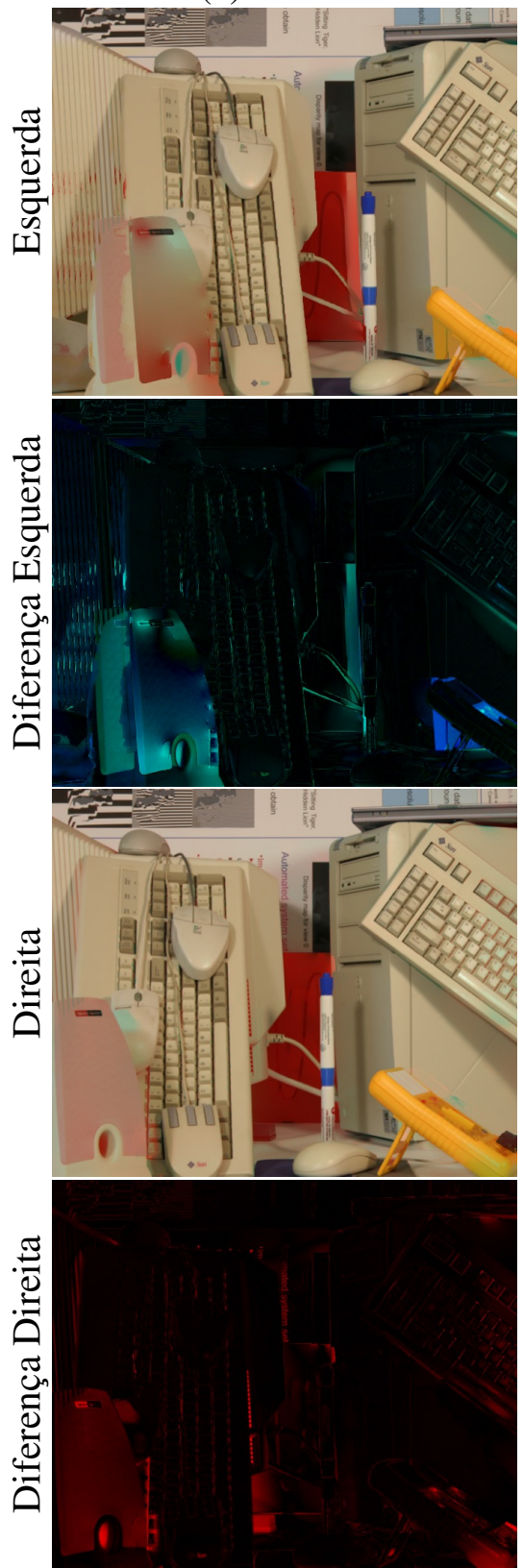

(b) Ground Truth Direita

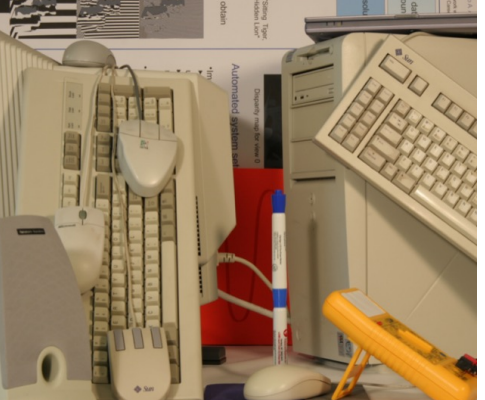

(e) ASIFT

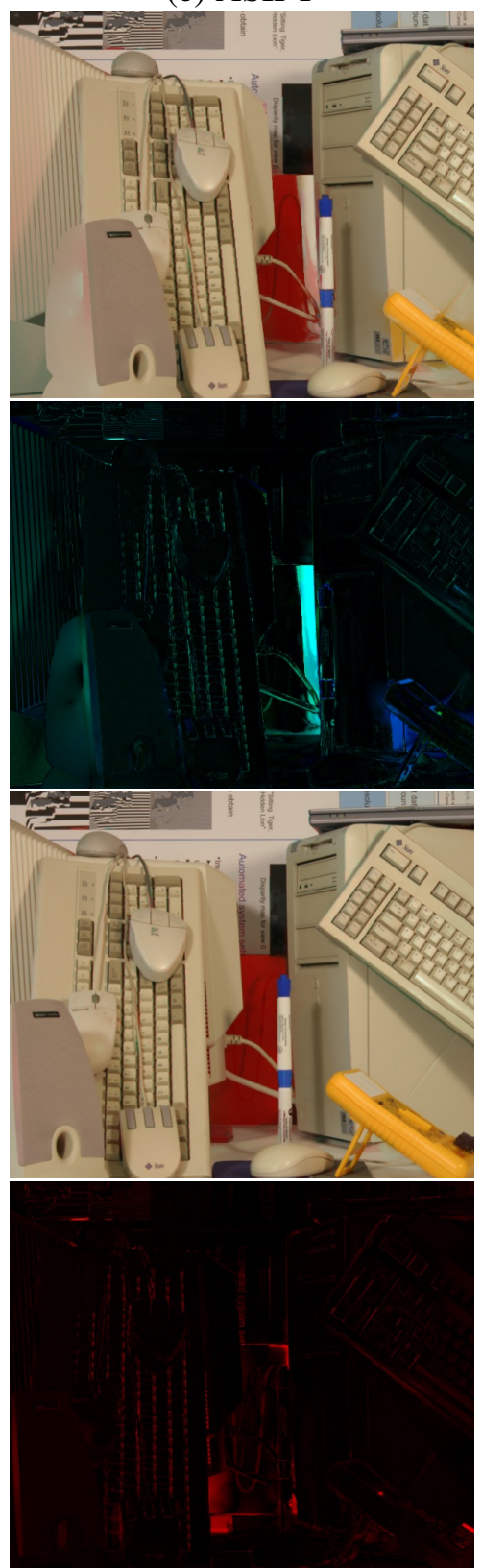

Fonte: Elaborada pelo autor. (c) Ground Truth Esquerda

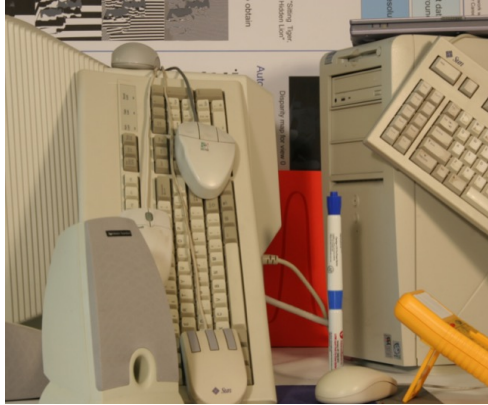

(f) SIRA (Proposta)

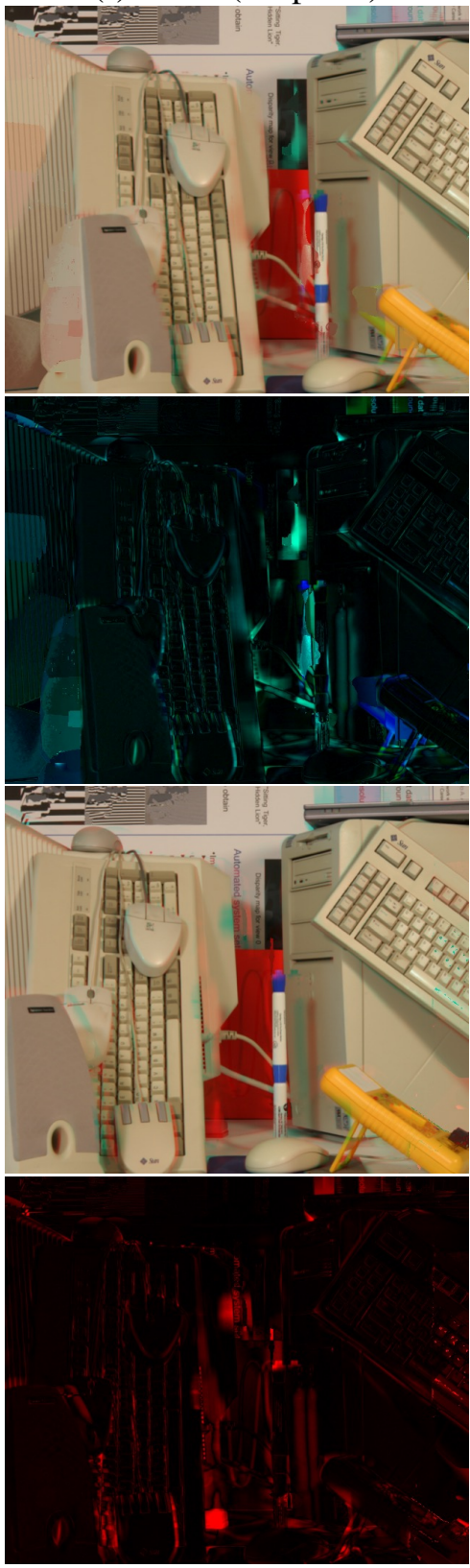


de diferença é possível observar as regiões da imagem que apresentam diferenças de cor quando comparadas com o seu Ground Truth. Locais com pixels coloridos no mapa indicam as regiões com cores incorretas na imagem, ou seja, idealmente os mapas deveriam ser totalmente pretos. Vale mencionar que para os mapas de diferença, as intensidades dos pixels foram multiplicadas por dois para melhor visualização dos erros.

A Figura 74 apresenta a imagem Cones, em que a técnica SIRA obteve PSNR de 25,72 para a imagem do lado direito, um valor baixo quando comparado com os demais do mesmo lado. Apesar disso, a imagem apresenta boa qualidade visual, com alguns pequenos defeitos visuais apresentados na lateral direita, próximo aos "palitos" e à "máscara". Já a Figura 75 apresenta a imagem Computer, em que a técnica SIRA obteve PSNR de 26,59 para a imagem do lado esquerdo, considerado um valor bom, principalmente por ser do lado esquerdo, porém apresenta muitos defeitos visuais, como borrões nas bordas dos objetos. Assim, é possível afirmar que as medidas de qualidade objetiva e subjetiva se complementam, apresentando uma avaliação mais confiável dos resultados.

Com o objetivo de avaliar a qualidade visual dos resultados, foi realizada uma análise subjetiva aplicando o método DSCQS, apresentado na Seção 6.2. O experimento foi realizado com um grupo de 45 participantes, de ambos os sexos, com idade variando entre 17 e 46 anos. As imagens utilizadas para este experimento são as mesmas utilizadas para comparação objetiva (Middlebury 2001, Middlebury 2003 e Middlebury 2005), porém ao invés de avaliar ambos os lados (esquerdo e direito), foram escolhidas 9 imagens para o lado direito e 9 para o lado esquerdo, de modo aleatório, ou seja, todas as cenas foram avaliadas, porém cada uma teve apenas um dos lados avaliados no teste subjetivo. Os mapas de diferenças não foram utilizados nesta análise.

Foram avaliadas a técnica de Williem, o ASIFT e a SIRA. Para isso, os 45 participantes foram divididos aleatoriamente em três grupos de 15 pessoas, sendo que cada um dos grupos avaliou uma das técnicas para todas as 18 imagens. A avaliação foi realizada segundo a metodologia descrita na Seção 6.2, e os resultados da avaliação, em termos de MOS são apresentados no Quadro 8. Cada linha representa uma imagem analisada e os resultados da avaliação para as três técnicas, indicando o MOS para a imagem original e a gerada pela técnica. A última coluna apresenta o lado que foi avaliado, com o lado esquerdo referente à reconstrução dos canais verde e azul, e o lado direito referente à reconstrução do canal vermelho.

Ao analisar somente as imagens do lado direito é possível observar que as três técnicas obtiveram resultados muito similares, em que a técnica SIRA atingiu 3,85 de MOS, enquanto os algoritmos de Williem e ASIFT atingiram, respectivamente, 4, 11 e 4, 18. A baixa diferença média de 0,33 entre a técnica proposta e o ASIFT é corroborada pelos dados objetivos apresentados na Seção 6.4.

Ao analisar as imagens do lado esquerdo, a SIRA e a técnica de Williem obtêm resultados similares, respectivamente 2, 69 e 2,90, enquanto o ASIFT apresenta resultados superiores $(3,69)$. 
Quadro 8 - Resultado MOS da imagem original e a gerada, para imagens utilizadas nas três técnicas de reversão analisadas.

\begin{tabular}{|c|c|c|c|c|c|c|l|}
\hline \multirow{2}{*}{ Imagem } & \multicolumn{2}{|c|}{ Williem } & \multicolumn{2}{c|}{ Anaglyph-SIFT } & \multicolumn{2}{c|}{ SIRA (Proposta) } & \multirow{2}{*}{ Lado } \\
\cline { 2 - 7 } & $\begin{array}{c}\text { MOS } \\
\text { Original }\end{array}$ & $\begin{array}{c}\text { MOS } \\
\text { Gerado }\end{array}$ & $\begin{array}{c}\text { MOS } \\
\text { Original }\end{array}$ & $\begin{array}{c}\text { MOS } \\
\text { Gerado }\end{array}$ & $\begin{array}{c}\text { MOS } \\
\text { Original }\end{array}$ & $\begin{array}{c}\text { MOS } \\
\text { Gerado }\end{array}$ & \\
\hline Sawtooth & 4,80 & 4,67 & 4,67 & 4,53 & 4,21 & 3,64 & Esquerdo \\
\hline Venus & 4,40 & 4,00 & 4,80 & 4,27 & 4,67 & 4,00 & Esquerdo \\
\hline Bull & 4,67 & 4,60 & 4,80 & 4,67 & 4,33 & 4,53 & Direito \\
\hline Poster & 4,80 & 3,67 & 4,67 & 3,87 & 4,87 & 3,33 & Esquerdo \\
\hline BarnOne & 4,80 & 4,53 & 4,33 & 4,40 & 4,53 & 4,33 & Direito \\
\hline BarnTwo & 4,60 & 4,27 & 4,47 & 4,13 & 4,00 & 3,87 & Direito \\
\hline Tsukuba & 4,87 & 3,67 & 4,87 & 3,87 & 4,67 & 3,07 & Esquerdo \\
\hline Cones & 4,80 & 4,60 & 4,93 & 4,33 & 4,87 & 4,33 & Direito \\
\hline Teddy & 4,80 & 4,80 & 4,80 & 4,27 & 4,87 & 4,13 & Direito \\
\hline Art & 4,87 & 3,60 & 4,47 & 4,07 & 4,80 & 3,53 & Direito \\
\hline Books & 4,80 & 2,47 & 4,53 & 4,00 & 4,20 & 3,00 & Esquerdo \\
\hline Dolls & 4,73 & 3,13 & 4,73 & 4,27 & 4,53 & 3,67 & Direito \\
\hline Laundry & 4,73 & 3,67 & 4,80 & 3,87 & 4,60 & 3,20 & Direito \\
\hline Moebius & 4,47 & 2,33 & 4,60 & 3,00 & 4,53 & 1,60 & Esquerdo \\
\hline Reindeer & 4,47 & 1,80 & 4,67 & 3,47 & 4,79 & 2,00 & Esquerdo \\
\hline Computer & 4,47 & 1,73 & 4,47 & 3,13 & 4,47 & 2,07 & Esquerdo \\
\hline Drumsticks & 4,60 & 1,73 & 4,73 & 3,07 & 4,67 & 1,47 & Esquerdo \\
\hline Dwarves & 4,80 & 3,80 & 4,67 & 3,67 & 4,80 & 3,07 & Direito \\
\hline Média Esquerdo & $\mathbf{4 , 6 3}$ & $\mathbf{2 , 9 0}$ & $\mathbf{4 , 6 7}$ & $\mathbf{3 , 6 9}$ & $\mathbf{4 , 5 6}$ & $\mathbf{2 , 6 9}$ & \\
\hline Média Direito & $\mathbf{4 , 7 5}$ & $\mathbf{4 , 1 1}$ & $\mathbf{4 , 6 6}$ & $\mathbf{4 , 1 8}$ & $\mathbf{4 , 5 9}$ & $\mathbf{3 , 8 5}$ & \\
\hline Média Total & $\mathbf{4 , 6 9}$ & $\mathbf{3 , 5 0}$ & $\mathbf{4 , 6 6}$ & $\mathbf{3 , 9 3}$ & $\mathbf{4 , 5 7}$ & $\mathbf{3 , 2 6}$ & \\
\hline
\end{tabular}

Fonte: Dados da pesquisa.

Observe que as imagens Moebius, Reindeer, Drumsticks e Dwarves geraram resultados subjetivos inferiores para a técnica proposta (e de Williem), o que também pode ser verificado de forma mais sutil nos valores objetivos. Ao compararmos os resultados para a imagem Computer é possível verificar que apesar de ter melhor índice objetivo, a técnica SIRA apresentou resultados inferiores no teste subjetivo. Um dos possíveis motivos para este resultado é que as cores na imagem gerada são mais fiéis às imagens originais, mas os danos causados pelos erros acabaram gerando impacto visual negativo maior que nas demais técnicas.

Por fim, ao avaliar as três técnicas de maneira geral (média total), é possível verificar que todas possuem resultados muito similares, em que as três obtêm MOS entre 3 e 4, indicando, de acordo com a Figura 57, que as imagens geradas possuem qualidade regular. Devido à proximidade dos valores do MOS Original (Ground Truth) para as três técnicas, suas diferenças foram ignoradas no processo de análise.

A Figura 76 apresenta o boxplot para os dados apresentados no Quadro 8. Novamente, é possível verificar que a técnica SIRA e de Williem obtêm resultados inferiores a técnica ASIFT 
Figura 76 - Sumarização dos dados subjetivos para o lado esquerdo, direito e ambos.

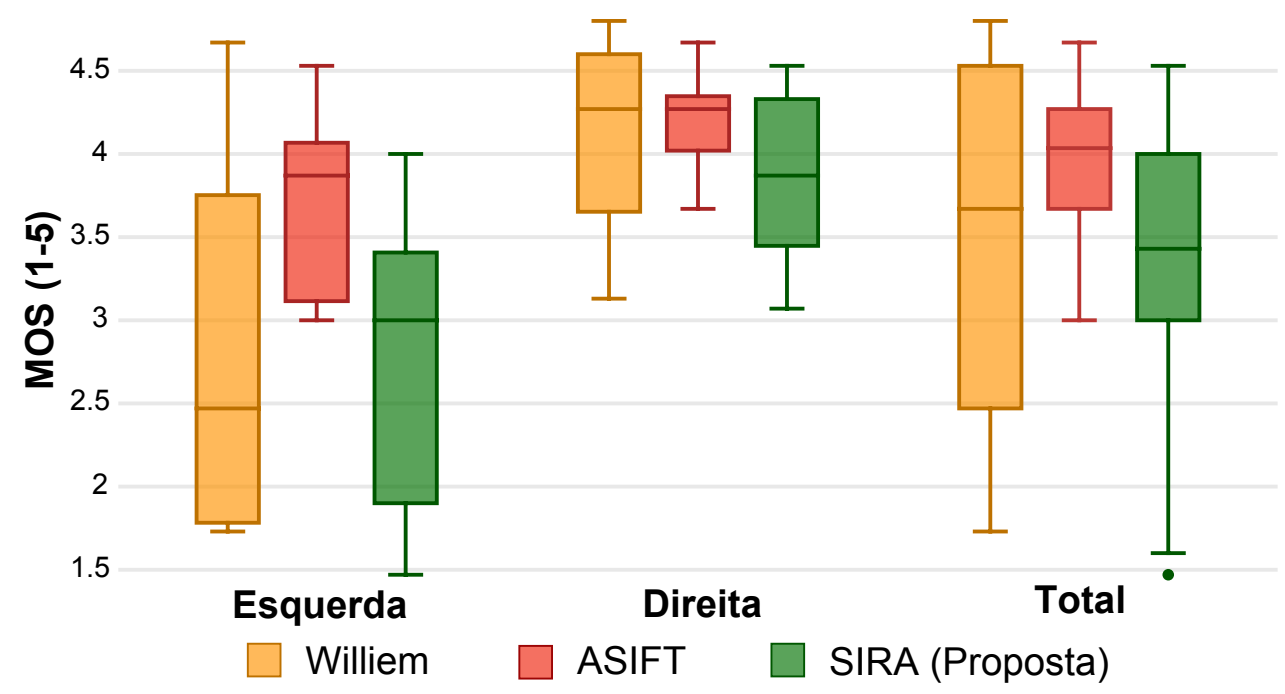

Fonte: Elaborada pelo autor.

para o lado esquerdo, porém ao analisarmos o desempenho geral (terceira coluna), é possível verificar que as três técnicas apresentam resultados similares. Um ponto interessante a ser observado são os Interquartile Range (IQR), em que a técnica SIRA apresenta valor 3,00 para o primeiro quartil e 4,00 para o terceiro quartil, enquanto a técnica ASIFT apresenta 3,67 para o primeiro quartil e 4,27 para o terceiro quartil, o que indica a proximidade das técnicas em termos de qualidade subjetiva.

\subsection{Considerações Finais}

Esta capítulo apresentou a análise dos principais pontos de decisão do algoritmo SIRA e a comparação objetiva (tempo e qualidade) e subjetiva da técnica para os algoritmos de Williem, Raskar e Park (2015), ASIFT (JOULIN; KANG, 2013) e SIRA (proposta), utilizando as bases da Middlebury (SCHARSTEIN; SZELISKI; ZABIH, 2001; SCHARSTEIN; SZELISKI, 2003; SCHARSTEIN; PAL, 2007). Por meio das comparações constatou-se que a técnica proposta é eficaz, obtendo resultados comparáveis às demais técnicas do estado da arte em termos de qualidade. Além disso, os resultados de tempo de processamento comprovaram que a técnica é muito mais eficiente que as demais analisadas, com tempo de processamento muito inferior às demais técnicas analisadas. Um dos principais fatores que levaram a este resultado foi a utilização de técnicas de análise de séries temporais para a comparação e alinhamento de pixels, tornando a técnica SIRA computacionalmente barata. 

CAPÍTULO

\section{CONCLUSÕES}

Neste trabalho de mestrado foram propostas uma metodologia de análise de imagens anaglíficas e uma técnica para realizar a reversão anaglífica de imagens, a fim de recuperar uma aproximação do par estéreo original. Considerando que um dos principais obstáculos nos métodos de reversão existentes é o alto tempo de processamento para realizar a reversão de uma única imagem anaglífica, este trabalho partiu do pressuposto que a utilização de técnicas de análise de séries temporais poderiam ser utilizadas para agilizar o processo de reversão, obtendo boa qualidade.

Experimentos realizados realizados com três conjuntos de imagens (Scharstein, Szeliski e Zabih (2001); Scharstein e Szeliski (2003); Scharstein e Pal (2007)) comprovam que a utilização de técnicas de análise de séries temporais, associadas a técnicas de segmentação e colorização gera um ganho relevante em relação ao tempo de processamento das técnicas de Joulin e Kang (2013) e de Williem, Raskar e Park (2015). Além disso, a qualidade objetiva (PSRN) das imagens resultantes da SIRA mostrou-se muito similar à dos demais métodos, inclusive apresentando qualidade superior, em média, para a recuperação dos canais do lado esquerdo (necessitava de mais informação). Tais índices de qualidade comprovam que a técnica é comparável em

termos de qualidade, porém muito superior em relação a tempo de processamento. É interessante observar que as técnicas foram testadas utilizando imagens com disparidades muito altas e com diferenças de disparidades muito altas entre objetos. Quando aplicadas a cenários menos agressivos, ou seja, a cenários com pequenas disparidades, com poucas oclusões, as três técnicas apresentam resultados mais semelhantes ainda.

\subsection{Contribuições Científicas}

Este trabalho apresenta as seguintes contribuições principais:

1. desenvolvimento de uma metodologia de análise dos anáglifos a partir de séries temporais. 
Tal processo é de grande utilidade para a área de correspondência estéreo e anaglífica, já que agrega conceitos de séries temporais, algo que mostrou-se promissor e que, de acordo com o melhor do conhecimento do autor deste trabalho, não havia sido explorado anteriormente. Além de abordar diversas funções de distância e representações de séries, este trabalho apresenta algumas outras vertentes que podem ser exploradas, como a extração de características utilizando diversos ângulos e o pós processamento em blocos.

2. técnica SIRA (Stereo Images Retrieving from Anaglyphs), para reversão anaglífica eficaz e eficiente. A técnica utiliza a modelagem de séries temporais para encontrar as correspondências entre os pixels, realiza a propagação do alinhamento como etapa de pós processamento, além do processo de colorização. A implementação em linguagem $\mathrm{C}$ da SIRA é suportada por diversos sistemas operacionais, uma vez que gera bibliotecas dinâmicas nos formatos .so (Linux), .dylib (MacOS) e .dll (Windows). Além disso, a técnica possui suporte a multiprocessamento, o que permite ao usuário utilizar todo recurso computacional disponível. Todos estes fatores auxiliam na disseminação e utilização da técnica, seja para fins acadêmicos ou para usuários finais, que desejam obter as aproximações do par estéreo para visualizá-los em outros formatos estereoscópicos.

3. trabalhos publicados e submetidos, resultantes das atividades de pesquisa realizadas:

- KUNZE, L.F.; AMARAL, T.; MORAES, L.M.; OLIVEIRA, J.J.; JUNIOR, A.G.; SOUSA, E.P.M.; CORDEIRO, R.L. .Classification Analysis of NDVI Time Series in Metric Spaces for Sugarcane Identification. In: Proceedings of the 20th International Conference on Enterprise Information Systems, Volume 1, Funchal, Madeira, Portugal ICEIS. 2018, 8p. Disponível em: <https://doi.org/10.5220/ 0006709401620169>

- KUNZE, L.F.; GOULARTE, R.; SOUSA, E.P.M. . SIRA - An Efficient Method for Retrieving Stereo Images from Anaglyphs. 13p. [Submetido para Signal Processing: Image Communication em 16/07/2019].

\subsection{Trabalhos Futuros}

Por meio deste trabalho de mestrado foi possível destacar algumas possíveis vertentes de trabalhos futuros, tanto para melhorar a qualidade (PSNR e tempo) da reversão anaglífica, quanto para novas aplicações. Algumas destas propostas são:

1. avaliar outras técnicas de colorização mais robustas, visando reduzir ainda mais o tempo de processamento, uma vez que trata-se de uma etapa custosa do processo de reversão anaglífica e, potencialmente, aumentar a qualidade das imagens resultantes. 
2. desenvolver métricas que utilizem informações de alinhamento para checar se um pixel está correto ou não (além de utilizar apenas a informação de reciprocidade), aumentando a quantidade de correspondências válidas e possivelmente reduzindo erros.

3. especializar o processo de reversão anaglífica para formatos de imagens que utilizam compressão com perdas, tal como o JPG, permitindo que peculiaridades destes formatos sejam levadas em consideração. Conforme descrito no Capítulo 3, imagens em que compressões com perdas foram aplicadas acabam gerando o efeito de crosstalk entre as componentes de cores, por exemplo, ao separar os canais de uma imagem anaglífica em vermelho-ciano, é possível verificar a interferência dos canais verde e azul na componente em vermelho e vice-versa.

4. aplicar a técnica SIRA à compressão de vídeos estereoscópicos, possivelmente fazendo uso das relações existentes entre os quadros adjacentes de vídeo, o que tem potencial para melhorar a qualidade dos quadros resultantes, além de permitir maior compressão, já que informações redundantes podem ser verificadas entre os quadros de um vídeo. Este processo deve ser avaliado por meio de métricas objetivas e subjetivas.

5. avaliar comparativamente por meio de testes subjetivos o uso da técnica SIRA em diferentes métodos de visualização, ou seja, a partir dos pares recuperados, gerar imagens estereoscópicas para visualização ativa, passiva e autoestereoscópica, permitindo validar a independência de visualização entre os dispositivos. 



\section{REFERÊNCIAS}

ACHANTA, R.; SHAJI, A.; SMITH, K.; LUCCHI, A.; FUA, P.; SÜSSTRUNK, S. Slic superpixels. Ecole Polytechnique Fédéral de Lausssanne (EPFL), Tech. Rep, Citeseer, v. 149300, p. 155-162, 2010. Disponível em: <https://infoscience.epfl.ch/record/149300>. Citado nas páginas 80,95 e 107.

. Slic superpixels compared to state-of-the-art superpixel methods. IEEE Transactions on Pattern Analysis and Machine Intelligence, v. 34, n. 11, p. 2274-2282, Nov 2012. ISSN 0162-8828. Disponível em: <https://doi.org/10.1109/TPAMI.2012.120>. Citado na página 107.

AMARAL, B. F.; CHINO, D. Y. T.; ROMANI, L. A. S.; GONÇALVES, R. R. V.; TRAINA, A. J. M.; SOUSA, E. P. M. The sitsmining framework - A data mining approach for satellite image time series. In: ICEIS 2014 - Proceedings of the 16th International Conference on Enterprise Information Systems, Volume 1, Lisbon, Portugal, 27-30 April, 2014. ICEIS, 2014. p. 225-232. ISBN 978-9-89-758027-7. Disponível em: <https://doi.org/10.5220/ $0004894002250232>$. Citado na página 65.

BANDO, Y.; CHEN, B.-Y.; NISHITA, T. Extracting depth and matte using a color-filtered aperture. ACM Transaction on Graphics, ACM, New York, NY, USA, v. 27, n. 5, p. 134:1134:9, Dec 2008. ISSN 0730-0301. Disponível em: <https://doi.org/10.1145/1409060.1409087>. Citado nas páginas 15, 48, 49, 50 e 79 .

BERGH, M. V. D.; BOIX, X.; ROIG, G.; GOOL, L. V. Seeds: Superpixels extracted via energydriven sampling. International Journal of Computer Vision, v. 111, n. 3, p. 298-314, Feb 2015. ISSN 1573-1405. Disponível em: <https://doi.org/10.1007/s11263-014-0744-2>. Citado na página 107.

BOX, G.; JENKINS, G.; REINSEL, G. Time Series Analysis: Forecasting and Control. Prentice Hall, 1994. (Forecasting and Control Series). ISBN 9780130607744. Disponível em: $<$ https://books.google.com.br/books?id=sRzvAAAAMAAJ>. Citado nas páginas 61 e 76.

BOYKOV, Y.; KOLMOGOROV, V. An experimental comparison of min-cut/max-flow algorithms for energy minimization in vision. IEEE Transactions on Pattern Analysis and Machine Intelligence, v. 26, n. 9, p. 1124-1137, Sep 2004. ISSN 0162-8828. Disponível em: <https: //doi.org/10.1109/TPAMI.2004.60>. Citado na página 57.

BOYKOV, Y.; VEKSLER, O.; ZABIH, R. Fast approximate energy minimization via graph cuts. IEEE Transactions on Pattern Analysis and Machine Intelligence, IEEE Computer Society, Washington, DC, USA, v. 23, n. 11, p. 1222-1239, Nov 2001. ISSN 0162-8828. Disponível em: $<$ https://doi.org/10.1109/34.969114>. Citado nas páginas 16, 54, 56, 57 e 60.

COOLEY, J.; LEWIS, P.; WELCH, P. The finite fourier transform. IEEE Transactions on Audio and Electroacoustics, v. 17, n. 2, p. 77-85, June 1969. ISSN 0018-9278. Disponível em: $<$ https://doi.org/10.1109/TAU.1969.1162036>. Citado na página 69. 
DAS, G.; GUNOPULOS, D.; MANNILA, H. Finding similar time series. In: Principles of Data Mining and Knowledge Discovery. Berlin, Heidelberg: Springer Berlin Heidelberg, 1997. p. 88100. ISBN 978-3-540-69236-2. Disponível em: <https://doi.org/10.1007/3-540-63223-9_109>. Citado na página 68.

DIETZ, H. G. Reprocessing anaglyph images. In: Three-Dimensional Image Processing (3DIP) and Applications II, Burlingame, California, USA, January 22, 2012. 3DIP, 2012. v. 8290, p. 0S:1-0S:10. Disponível em: <https://doi.org/10.1117/12.912212>. Citado nas páginas $15,25,47,50,51$ e 60 .

DODGSON, N. A. Autostereoscopic 3d displays. IEEE Computer Society, IEEE Computer Society, Los Alamitos, CA, USA, v. 38, n. 8, p. 31-36, Aug 2005. ISSN 1558-0814. Disponível em: <https://doi.org/10.1109/MC.2005.252>. Citado nas páginas 42 e 43.

FELZENSZWALB, P. F.; HUTTENLOCHER, D. P. Efficient graph-based image segmentation. International Journal of Computer Vision, v. 59, p. 167-181, Sept 2004. ISSN 1573-1405. Disponível em: <https://doi.org/10.1023/B:VISI.0000022288.19776.77>. Citado na página 107.

FORD, N. Functional Thinking. O’Reilly Media, 2014. ISBN 978-1-44-936550-9. Disponível em: <https://books.google.com.br/books?id=OysntAEACAAJ>. Citado na página 92.

GASTAL, E. S. L.; OLIVEIRA, M. M. Domain transform for edge-aware image and video processing. ACM Trans. Graph., v. 30, n. 4, p. 69:1-69:12, 2011. Disponível em: <https: //doi.org/10.1145/2010324.1964964>. Citado na página 54.

GOLDSTEIN, E. Sensation and Perception. Cengage Learning, 2009. ISBN 978-0-49-5601494. Disponível em: <https://books.google.com.br/books?id=2tW91BWeNq4C $>$. Citado nas páginas 25 e 31 .

GONZALEZ, R.; WOODS, R. Digital Image Processing. Pearson/Prentice Hall, 2008. ISBN 978-0-13-168728-8. Disponível em: <https://books.google.com.br/books?id=8uGOnjRGEzoC>. Citado na página 70 .

GUPTA, L.; MOLFESE, D. L.; TAMMANA, R.; SIMOS, P. G. Nonlinear alignment and averaging for estimating the evoked potential. IEEE Transactions on Biomedical Engineering, v. 43, n. 4, p. 348-356, Apr 1996. ISSN 0018-9294. Disponível em: <https:/doi.org/10.1109/10. 486255>. Citado na página 65.

HORIUCHI, T.; HIRANO, S. Colorization algorithm for grayscale image by propagating seed pixels. In: Proceedings of the 2003 International Conference on Image Processing, ICIP 2003, Barcelona, Catalonia, Spain, September 14-18, 2003. ICIP, 2003. p. 457-460. ISSN 1522-4880. Disponível em: <https://doi.org/10.1109/ICIP.2003.1246997>. Citado na página 59.

HYNDMAN, R. J.; ATHANASOPOULOS, G. Forecasting : principles and practice. 2nd. ed. OTexts.com [Heathmont, Victoria], 2018. ISBN 978-0987507112. Disponível em: <https: //books.google.com.br/books?id=_bBhDwAAQBAJ>. Citado na página 63.

ISHII, R.; RIOS, R.; MELLO, R. Classification of time series generation processes using experimental tools: A survey and proposal of an automatic and systematic approach. International Journal of Computational Science and Engineering, v. 6, p. 217-237, 2011. Disponível em: $<$ https:/doi.org/10.1504/IJCSE.2011.043919>. Citado na página 62. 
ITU, R. A. Methodology for the Subjective Assessment of the Quality of Television Pictures. Geneva 1211, Switzerland, 2003. Disponível em: <https://www.itu.int/dms_pubrec/itu-r/rec/bt/ R-REC-BT.500-11-200206-S!!PDF-E.pdf>. Citado nas páginas 99, 100 e 101.

JOULIN, A.; KANG, S. B. Recovering stereo pairs from anaglyphs. In: Proceedings of the 2013 IEEE Conference on Computer Vision and Pattern Recognition. Washington, DC, USA: IEEE Computer Society, 2013. (CVPR '13), p. 289-296. ISBN 978-0-76-954989-7. Disponível em: <https://doi.org/10.1109/CVPR.2013.44>. Citado nas páginas 26, 51, 54, 56, 60, 96, 99, 116, 125 e 127.

KEOGH, E.; CHAKRABARTI, K.; PAZZANI, M.; MEHROTRA, S. Dimensionality reduction for fast similarity search in large time series databases. Knowledge and Information Systems, v. 3, n. 3, p. 263-286, Aug 2001. ISSN 0219-1377. Disponível em: <https://doi.org/10.1007/ PL00011669>. Citado nas páginas 69 e 72.

KEOGH, E. J.; PAZZANI, M. J. Scaling up dynamic time warping for datamining applications. In: Proceedings of the Sixth ACM SIGKDD International Conference on Knowledge Discovery and Data Mining. New York, NY, USA: ACM, 2000. (KDD '00), p. 285-289. ISBN 1-58113-233-6. Disponível em: <http://doi.org/10.1145/347090.347153>. Citado na página 65.

LAST, M.; KANDEL, A.; BUNKE, H. Data Mining in Time Series Databases. World Scientific, 2004. (Series in machine perception and artificial intelligence). ISBN 978-9-81-238290-0. Disponível em: <https://books.google.com.br/books?id=f38wqKjyBm4C $>$. Citado nas páginas 70,73 e 74.

LEVIN, A.; LISCHINSKI, D.; WEISS, Y. Colorization using optimization. ACM Transaction Graphics, ACM, New York, NY, USA, v. 23, n. 3, p. 689-694, Aug 2004. ISSN 0730-0301. Disponível em: <https://doi.org/10.1145/1015706.1015780>. Citado nas páginas 16, 53, 56, 59, 60 e 90.

LI, T.; MA, S.; OGIHARA, M. Wavelet methods in data mining. In: Data Mining and Knowledge Discovery Handbook. Boston, MA, USA: Springer US, 2005. p. 603-626. ISBN 978-0-38-725465-4. Disponível em: <https://doi.org/10.1007/0-387-25465-X_27>. Citado na página 71.

LIN, H.-S.; ZHENG, C.-L.; LIN, Y.-H.; OUHYOUNG, M. Optimized anaglyph colorization. In: SIGGRAPH Asia 2012 Technical Briefs. New York, NY, USA: ACM, 2012. (SA '12), p. 9:1-9:4. ISBN 978-1-45-031915-7. Disponível em: <http://doi.org/10.1145/2407746.2407755>. Citado na página 79.

LIN, J.; KEOGH, E.; LONARDI, S.; CHIU, B. A symbolic representation of time series, with implications for streaming algorithms. In: Proceedings of the 8th ACM SIGMOD Workshop on Research Issues in Data Mining and Knowledge Discovery. New York, NY, USA: ACM, 2003. (DMKD '03), p. 2-11. Disponível em: <http://doi.org/10.1145/882082.882086>. Citado nas páginas 69 e 70 .

LIN, J.; KEOGH, E. J.; WEI, L.; LONARDI, S. Experiencing SAX: a novel symbolic representation of time series. Data Mining Knowledge Discovery, v. 15, n. 2, p. 107-144, 2007. Disponível em: <https://doi.org/10.1007/s10618-007-0064-z>. Citado na página 75.

LIPTON, L. Foundations of the Stereoscopic Cinema: A Study in Depth. Van Nostrand Reinhold, 1982. ISBN 978-0-44-224724-9. Disponível em: <https://books.google.com.br/books? id=1UViQgAACAAJ $>$. Citado nas páginas 25, 31, 33 e 34. 
LIU, C.; YUEN, J.; TORRALBA, A. SIFT flow: Dense correspondence across scenes and its applications. IEEE Transactions on Pattern Analysis and Machine Intelligence, v. 33, n. 5, p. 978-994, 2011. Disponível em: <https://doi.org/10.1109/TPAMI.2010.147>. Citado nas páginas 51,52 e 60 .

LOWE, D. G. Object recognition from local scale-invariant features. In: Proceedings of the Seventh IEEE International Conference on Computer Vision. Washington, DC, USA: IEEE Computer Society, 1999. v. 2, p. 1150-1157. Disponível em: <https://doi.org/10.1109/ICCV. 1999.790410>. Citado na página 51.

LUAN, Q.; WEN, F.; COHEN-OR, D.; LIANG, L.; XU, Y.-Q.; SHUM, H.-Y. Natural image colorization. In: Proceedings of the 18th Eurographics Conference on Rendering Techniques. Aire-la-Ville, Switzerland, Switzerland: Eurographics Association, 2007. (EGSR'07), p. 309320. ISBN 978-3-90-567352-4. Disponível em: <http://doi.org/10.2312/egwr/egsr07/309-320>. Citado na página 59.

LUCAS, B. D.; KANADE, T. An iterative image registration technique with an application to stereo vision. In: Proceedings of the 7th International Joint Conference on Artificial Intelligence - Volume 2. San Francisco, CA, USA: Morgan Kaufmann Publishers Inc., 1981. (IJCAI'81), p. 674-679. Disponível em: <http://dl.acm.org/citation.cfm?id=1623264.1623280>. Citado na página 53.

MITSA, T. Temporal Data Mining. CRC Press, 2010. (Chapman \& Hall/CRC Data Mining and Knowledge Discovery Series). ISBN 978-1-42-008977-6. Disponível em: <https://books. google.com.br/books?id=4P\_7ydvW7cAC>. Citado nas páginas 61, 69, 70, 71, 73 e 76.

MONTGOMERY, D.; JENNINGS, C.; KULAHCI, M. Introduction to Time Series Analysis and Forecasting. Wiley, 2015. (Wiley Series in Probability and Statistics). ISBN 978-1-11874515-1. Disponível em: <https://books.google.com.br/books?id=Xeh8CAAAQBAJ>. Citado nas páginas 61 e 62 .

MORETTIN, P.; TOLOI, C. Análise de Séries Temporais. Edgard Blucher, 2006. (ABE Projeto Fisher). ISBN 978-8-52-120389-6. Disponível em: <https://books.google.com.br/books? id=Q7bJAAAACAAJ $>$. Citado nas páginas 61, 62 e 64 .

MPAA. MPAA Report - A comprehensive analysis and survey of the theatrical and home entertainment market environment (THEME) for 2018. 2019. Acesso em: 09-05-2019. Disponível em: <https://www.mpaa.org/wp-content/uploads/2019/03/MPAA-THEME-Report-2018. pdf $>$. Citado na página 25.

MURPHY, K. P.; WEISS, Y.; JORDAN, M. I. Loopy belief propagation for approximate inference: An empirical study. In: Proceedings of the Fifteenth Conference on Uncertainty in Artificial Intelligence. San Francisco, CA, USA: Morgan Kaufmann Publishers Inc., 1999. (UAI'99), p. 467-475. ISBN 1-55860-614-9. Disponível em: <http://dl.acm.org/citation.cfm?id= 2073796.2073849>. Citado nas páginas 52 e 56.

PAL, C. J.; WEINMAN, J. J.; TRAN, L. C.; SCHARSTEIN, D. On learning conditional random fields for stereo - exploring model structures and approximate inference. International Journal of Computer Vision, v. 99, n. 3, p. 319-337, 2007. Disponível em: <https://doi.org/10.1007/ s11263-010-0385-z>. Citado na página 46. 
RABINER, L.; JUANG, B. An introduction to hidden markov models. IEEE ASSP Magazine, v. 3, n. 1, p. 4-16, Jan 1986. ISSN 0740-7467. Disponível em: <https://doi.org/10.1109/MASSP. 1986.1165342>. Citado na página 76.

RATANAMAHATANA, C.; KEOGH, E. J. Making time-series classification more accurate using learned constraints. In: Proceedings of the Fourth SIAM International Conference on Data Mining. Florida, USA: SIAM, 2004. ISBN 978-0-89-871568-2. Disponível em: <https: //doi.org/10.1137/1.9781611972740.2>. Citado na página 66.

REINHARD, E.; ASHIKHMIN, M.; GOOCH, B.; SHIRLEY, P. Color transfer between images. IEEE Computer Graphics and Applications, v. 21, n. 5, p. 34-41, 2001. Disponível em: $<$ https://doi.org/10.1109/38.946629>. Citado na página 58.

RODRIGUES, F. M.; YUGOSHI, J. K.; GOULARTE, R. Haarglyph: A new method for anaglyphic reversion in stereoscopic videos. In: Proceedings of the 22Nd Brazilian Symposium on Multimedia and the Web. New York, NY, USA: ACM, 2016. (Webmedia '16), p. 151-158. ISBN 978-1-45-034512-5. Disponível em: <http://doi.org/10.1145/2976796.2976864>. Citado nas páginas 39, 42, 48, 58 e 60.

ROLLAND, J. P.; FUCHS, H. Optical versus video see-through head-mounted displays in medical visualization. Presence: Teleoper. Virtual Environ., MIT Press, Cambridge, MA, USA, v. 9, n. 3, p. 287-309, Jun 2000. ISSN 1054-7460. Disponível em: <http://doi.org/10.1162/ $105474600566808>$. Citado na página 25.

ROO, J. S.; RICHARDT, C. Temporally coherent video de-anaglyph. In: ACM SIGGRAPH 2014 Talks. New York, NY, USA: ACM, 2014. (SIGGRAPH '14), p. 75. ISBN 978-1-45032960-6. Disponível em: <https://doi.org/10.1145/2614106.2614125>. Citado nas páginas 54 e 58.

SAKOE, H.; CHIBA, S. Dynamic programming algorithm optimization for spoken word recognition. IEEE Transactions on Acoustics, Speech, and Signal Processing, v. 26, n. 1, p. 43-49, Feb 1978. ISSN 0096-3518. Disponível em: <https://doi.org/10.1109/TASSP.1978.1163055>. Citado na página 65.

SCHARSTEIN, D.; PAL, C. Learning conditional random fields for stereo. In: 2007 IEEE Conference on Computer Vision and Pattern Recognition. Minneapolis, MN, USA: IEEE Computer Society, 2007. p. 1-8. ISSN 1063-6919. Disponível em: <https://doi.org/10.1109/ CVPR.2007.383191>. Citado nas páginas 97, 98, 108, 125 e 127.

SCHARSTEIN, D.; SZELISKI, R. High-accuracy stereo depth maps using structured light. In: 2003 IEEE Computer Society Conference on Computer Vision and Pattern Recognition. Madison, WI, USA: IEEE Computer Society, 2003. v. 1. ISSN 1063-6919. Disponível em: <https://doi.org/10.1109/CVPR.2003.1211354>. Citado nas páginas 97, 125 e 127.

SCHARSTEIN, D.; SZELISKI, R.; ZABIH, R. A taxonomy and evaluation of dense twoframe stereo correspondence algorithms. In: Proceedings IEEE Workshop on Stereo and Multi-Baseline Vision. Los Alamitos, CA, USA: IEEE Computer Society, 2001. p. 131-140. Disponível em: <https://doi.org/10.1109/smbv.2001.988771>. Citado nas páginas 97, 125 e 127.

SHIEH, J.; KEOGH, E. isax: Indexing and mining terabyte sized time series. In: Proceedings of the 14th ACM SIGKDD International Conference on Knowledge Discovery and Data Mining. New York, NY, USA: ACM, 2008. (KDD ’08), p. 623-631. ISBN 978-1-60-558193-4. Disponível em: <http://doi.org/10.1145/1401890.1401966>. Citado na página 75. 
STEREOGRAPHICS. Stereographics Developer's Handbook: Background on Creating Images for CrystalEyes and SimulEyes. Stereographics Corporation, 1997. Acesso em: 19-072019. Disponível em: <http://www.cs.unc.edu/Research/stc/FAQs/Stereo/stereo-handbook.pdf>. Citado nas páginas 31, 35 e 36 .

STUTZ, D.; HERMANS, A.; LEIBE, B. Superpixels: An evaluation of the state-of-the-art. Computer Vision and Image Understanding, v. 166, p. 1-27, Dec 2018. ISSN 1077-3142. Disponível em: <https://doi.org/10.1016/j.cviu.2017.03.007>. Citado nas páginas 80 e 107.

UREY, H.; CHELLAPPAN, K. V.; ERDEN, E.; SURMAN, P. State of the art in stereoscopic and autostereoscopic displays. Proceedings of the IEEE, v. 99, n. 4, p. 540-555, April 2011. ISSN 1558-2256. Disponível em: <https://doi.org/10.1109/JPROC.2010.2098351>. Citado nas páginas 26, 37, 41 e 42 .

VLACHOS, M.; HADJIELEFTHERIOU, M.; GUNOPULOS, D.; KEOGH, E. Indexing multidimensional time-series with support for multiple distance measures. In: Proceedings of the Ninth ACM SIGKDD International Conference on Knowledge Discovery and Data Mining. New York, NY, USA: ACM, 2003. (KDD '03), p. 216-225. ISBN 1-58113-737-0. Disponível em: <http://doi.org/10.1145/956750.956777>. Citado na página 68.

WANG, M.; LIU, X.; GAO, Y.; MA, X.; SOOMRO, N. Q. Superpixel segmentation: A benchmark. Signal Processing: Image Communication, v. 56, p. 28-39, 2017. ISSN 0923-5965. Disponível em: <https://doi.org/10.1016/j.image.2017.04.007>. Citado na página 80.

WANG, X.; MUEEN, A.; DING, H.; TRAJCEVSKI, G.; SCHEUERMANN, P.; KEOGH, E. J. Experimental comparison of representation methods and distance measures for time series data. Data Mining and Knowledge Discovery, v. 26, n. 2, p. 275-309, 2013. Disponível em: $<$ https://doi.org/10.1007/s10618-012-0250-5>. Citado na página 69.

WELSH, T.; ASHIKHMIN, M.; MUELLER, K. Transferring color to greyscale images. In: Proceedings of the 29th Annual Conference on Computer Graphics and Interactive Techniques. New York, NY, USA: ACM, 2002. (SIGGRAPH '02), p. 277-280. ISBN 1-58113-521-1. Disponível em: <http://doi.org/10.1145/566570.566576>. Citado na página 58.

WILLIEM; RASKAR, R.; PARK, I. K. Depth map estimation and colorization of anaglyph images using local color prior and reverse intensity distribution. In: Proceedings of the International Conference on Computer Vision. Washington, DC, USA: IEEE Computer Society, 2015. p. 3460-3468. ISBN 978-1-46-738391-2. Disponível em: <http://doi.org/10.1109/iccv.2015.395>. Citado nas páginas 54, 56, 57, 60, 96, 97, 99, 116, 125 e 127.

WOODS, A. J. Crosstalk in stereoscopic displays: a review. Journal of Electronic Imaging, v. 21, p. 21-22, 2012. Disponível em: <https://doi.org/10.1117/1.JEI.21.4.040902>. Citado nas páginas $37,40,41$ e 42 .

YATZIV, L.; SAPIRO, G. Fast image and video colorization using chrominance blending. IEEE Trans. Image Processing, v. 15, n. 5, p. 1120-1129, 2006. Disponível em: <https: //doi.org/10.1109/TIP.2005.864231>. Citado na página 58.

ZINGARELLI, M. R. U.; ANDRADE, L. A.; GOULARTE, R. Reversing anaglyph videos into stereo pairs. In: Proceedings of the 17th Brazilian Symposium on Multimedia and the Web on Brazilian Symposium on Multimedia and the Web - Volume 1. Porto Alegre, RS, Brazil: Brazilian Computer Society, 2011. (WebMedia 2011), p. 27:205-27:212. Disponível em: $<$ http://dl.acm.org/citation.cfm?id=3021508.3021541>. Citado nas páginas 38, 47, 48, 58 e 60 . 


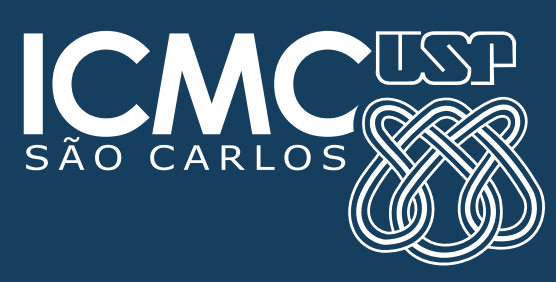

